\title{
I- 5182
}

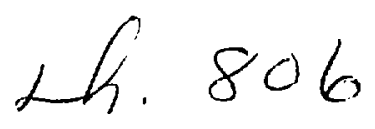

: Alamos Nationat Laboratory is operated by tho Unlversity of Califorra for the United States Department of Energy under Contract W-7405-ENG-36.
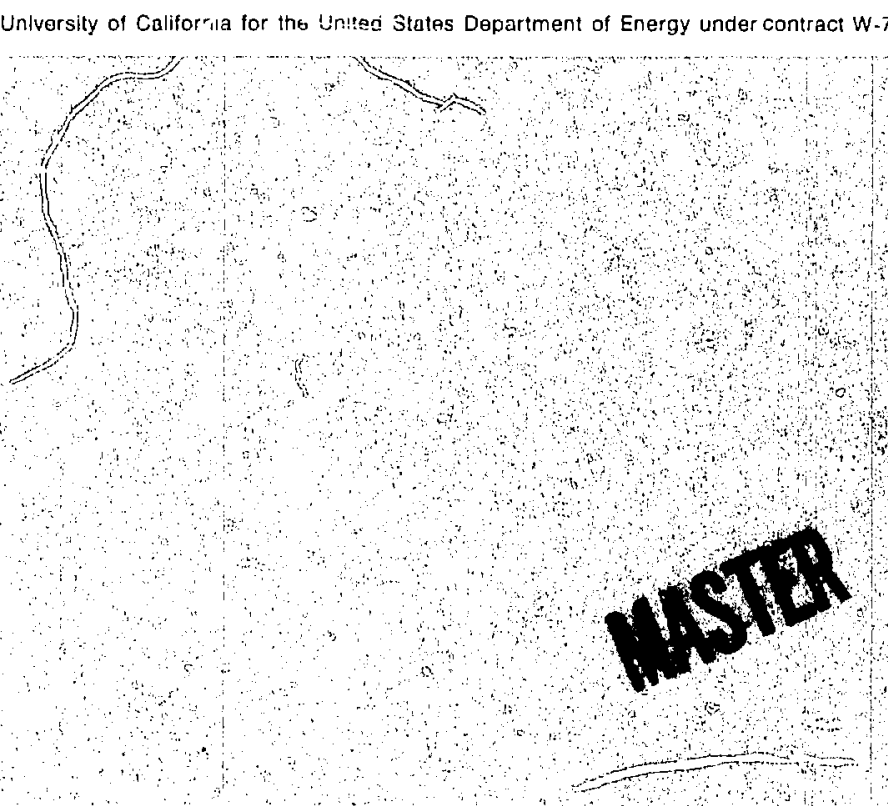

Materiats Accounting in a Fast Breeder Reactor Fuels Reprocessing Facility: Optinal Allocation of Measwrithent Uncertainties 
This work was supported by the US Department of Energy, Office of Safeguards and Security.

\section{Edited by Patricia Metropolis}

\section{DISCLAMER}

This report was prepared as an accuunt of work sponsored by an agency of the United States Governnent. Neither the United States Government nor any agency theteof, not any of their employees, makes any warranty, express or implied, or assumes any legal liability or responsibility for the accuracy, compleieness, or usefulness of any information, apparatus, product, or process disclosed, or represents that its use would not infringe privately owned rights, References herein to any specific commercial product, process, or service by trade name, trademark, manufacturer, or otherwise, does not necessarily constitute or imply its endorsement, recommendation, or favoring by the United States Government or any agency theteo\%. The views and opinions of authors expressed herein do not necessarily state or reflect those oi the Unitrd States Government or any agency thereof. 
UC-15

Issued: July 1982

LA --9265

DE82 021845

\title{
Materials Accounting in a Fast-Breeder-Reactor Fuels-Reprocessing Facility: Optimal Allocation of Measurement Uncertainties
}

\author{
H. A. Dayem \\ C. A. Ostenak \\ R. G. Gutmacher \\ E. A. Kern \\ J. T. Markin \\ D. P. Martinez
}

C. C. Thomas, Jr.

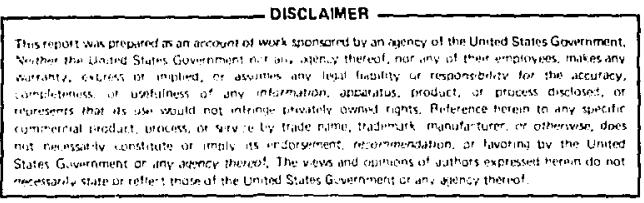




\section{EXECUTIVE SUMMARY}

This report describes the first in a series of studies in support of the US Department of Energy's (DOE) Consolidated Fuel Reprocessing Program. These studies develop and evaluate designs of advanced materials measurement and accounting systems (MMASs) for various nuclear spent-fuel reprocessing alternatives. This report examines safeguards design concepts for the feed preparation and chemical separations processes of the Hot Experimental Fasility (HEF), a conceptual fast breeder reactor spent-fuel reprocessing facility. We propose an MMAS and use optimization techniques to calculate instrument measurement uncertainties that meet four different accounting performance goals while minimizing the total development cost of instrument systems. We identify measurement uncertainty components that dominate the materials balance variance and instruments that require development to meet given performance goals.

Conceptual design efforts for MMASs are a major portion of an integrated safeguards systems study program that is implemented by the Safeguards Systems Group (Q-4) of the Los Alamos National Laboratory, at the direction of the US DOE/Office of Safeguards and Security. These designs invoke technology that has been demonstrated or can be projected within the construction schedules of future nuclear fuel-cycie facilities. The studies define systems concepts, develop methods for evaluating safeguards systems and the data they produce, and should stimulate further development of facilities, processes, systems, and instrumentation needed for improving nuclear materials accounting, thus providing more effective safeguards.

Previous Los Alamos National Laboratory studies in the safeguards coriceptual design series address the materials management requirements for mixed-oxide fuel refabrication facilities (LA-6536), domestic and foreign spent-fuel reprocessing plants (LA-688I and LA-8042), plutonium nitrate conversion (LA-70II) and coconversion facilities (LA-7521 and LA-7746-MS), spent-fuel storage ponds (LA-7730-MS), thorium-uranium fuel-cycle facilities (LA-7372 and LA-7411-MS), large fast-critical reactors (LA-7315), and nuclear waste repositories (LA-8049-MS). In general, these studies calculate the accounting systems performance by proposing a measurement system based on current technology or its reasonable extrapolations. The measurement uncertainties for each proposed instrument are then combined and propagated to obtain an overall materials loss-detection sensitivity. This study reverses the approach. We select specific accounting performance goals for the HEF and use optimization techniques to calculate measurement uncertainties required to meet these goals while minimizing the total development cost of the instrument system.

The design for Oak Ridge National Laboratory's HEF incorporates a modified Purex process that allows coprocessing uranium and plutonium. The flow sheet is based on reprocessing 0.5 tonne/day of breeder reactor fuel having (1) a maximum burnup of 150000 megawatt-days per tonne, (2) a minimum decay period of 60 days before shipment to the HEF, and (3) a minimum decay period of 90 days before reprocessing. The facility design also provides for nitrate-tooxide coconversion of mixed uranium-plutonium. In this study we consider only the feed preparation and chemical separations processes. The major process areas include (1) spent-fuel receiving and storage, (2) mechanical processing and feed preparation, (3) codecontamination/partitioning, (4) uranium purification, and (5) uranium-plutonium copurification. 
The HEF process has several design features that restrict the application of advanced materials measurement and accounting techniques. The dissolution and feed preparation area, in particular, has some novel features that require additional testing on a laboratory and pilot-plarit scale before incorporation into the HEF, such as the voloxidizer, the continuous dissolver, and the constantvolume accountability tank. Other areas of concern include the estimation of in-process inventories in solvent-extraction contactors and other process vessels, coprocessing, recycle streams, and the inaccessibility of nuclear materials for at-l ine analysis. We recommend revising the HEF design to permit penetration of the cell wa:l by sampling lines and to allow location of nondestructive analysis instrumentation in a coritrolled-access instrument gallery. Such a revision would provide more timely informacion for process control and materials accounting.

The HEF MMAS combines conventional materials accounting and near-real-time accounting (NRTA) and serves several functions including process monitoring, domestic safeguards, and international safeguards. It employs sampling and chemical analysis, weight and volume measurements, and nondestructive assay (NDA) instrumentation, supported by data base management and data analysis techniques. We describe a conventional accounting strategy that divides the facility into five materials balance areas (MBAs) and formulate two NRTA strategies that augment the MBA structure. In strategy 1, the feed preparation processes are treated as one unit process accounting area and the chemical separations processes are treated as another area. In strategy 2, the chemical separations area is further subdivided into codecontamination/partitioning processes and uranium-plutonium copurification processes.

Measurement points for the NRTA strategies are identified, and applicable measurement types and errors representative of current technology are chosen, based on materials and processes descriptions. Reference measurements are used for process control and materials accounting.

We use optimization techniques to calculate measurement uncertainties so that performance goals for detecting materials loss are achieved while the total development cost of the instruments is minimized. The cost of improving each measurement uncertainty component is determined by a hyperbolic cost function. Therefore, where the calculated measurement uncertainty is less than what is currently achievable, a development cost is imposed. Because the cost function is nonlinear, we use a nonlinear optimization technique for calculating measurement uncertainties to minimize instrument development cost.

We calculate measurement uncertainties that meet each of the four accountability performance goals for each unit process accounting area and for several cases of instrument recalibration. For each area, values for the measurement uncertainty components are restricted by specific ranges and by the materials balance standard deviation equations for abrupt (short-term) and protracted (long-term) losses.

We choose performance goals that represent a range of measurement capabilities and domestic and international safeguards goals. The four levels of NRTA performance goals are listed in Table S-I. The first two levels correspond to a likely range of measurement capabilities. The third and fourth levels correspond to desired international and domestic goals. The first performance goal is based on what should be possible using state-of-the-art instrumentation. The second represents reasonable extrapolations of current technology. The third goal is based on International Atomic Energy Agency criteria and the fourth on Nuclear Regulatory Commission goals that are being considered at present. 
TABLE S-I

PERFORMANCE GOALS

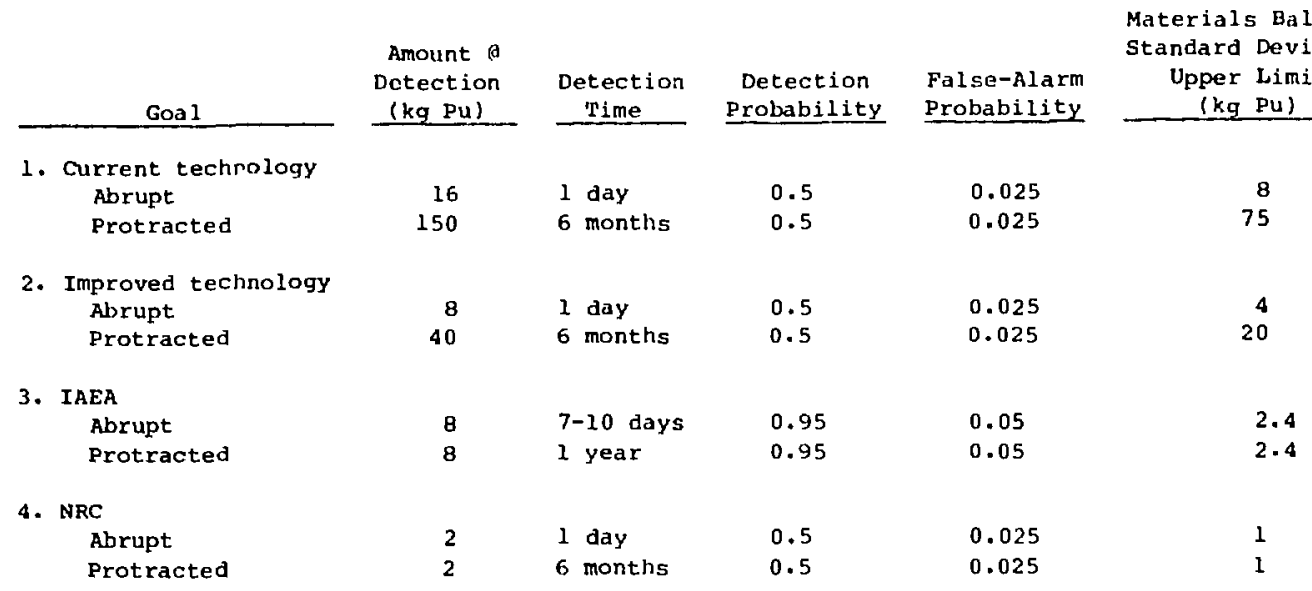

Each performance goal includes detection of an abrupt and of a protracted diversion with given detection and false-alarm probabilities. These quantities are used to calculate the maximum value of the materials balance standard deviation that will meet the performance goal.

It should be remembered that plant throughput is $2111 \mathrm{~kg}$ of plutonium per day and that the chemical separation and feed preparation portions of the process can have an inventory of $2750 \mathrm{~kg}$ of plutonium.

Table S-II lists materials balance standard deviations for each unit prociss accounting area for both one-day and six-month materials balances using current measurement technology. The feed preparation area has larger materials balance standard deviations than other areas because it has more in-process inventory, and the input transfer measurements (spent-fuel NDA) are not well characterized.

Table S-III lists relative costs for developing instrument systems that meet each of the performance goals. One cost unit is the "relative cost" of attaining a measurement uncertainty that is one-half that of current measurement technology. Each halving of measurement uncertainty costs twice what the previous halving did, plus 1 . Unit process accounting for the chemical separations processes meets the first goal with weekly recalibration of plutonium concentration measuring instruments for the accountability and product sample tanks. Hence, the total development cost of the system is zero. If periodic recalibration of key transfer measurements is performed, the relative cost of the system can be reduced by $30 \%$ or more. The relative cost of achieving goals 3 or 4 is between 20 and 50 times more than the cost of achieving goal 2.

We developed a dynamic computer model of the HEF headend and chemical separations processes. This simulation allows prediction of the dynamic behavior of materials flows, inventories, and measurements over many operating parameters and the rapid accumulation of data that represent relatively long operating periods. Our optimization calculations used nominal values for process variailes and did not include waste streams; we therefore applied a dynamic model of the measurement system to the simulated process data, using optimally calculated measurement uncertainties. Materials balance standard deviations obtained from these simulations agreed with optimization results. 


\section{MATERIALS BALANCE STANDARD DEVIATIONS WITH CURRENT MEASUREMENT TECHNOLOGY}

\begin{tabular}{|c|c|c|}
\hline & $\begin{array}{r}1 \text { Day } \\
(\mathrm{kg} \\
\end{array}$ & $\begin{array}{l}6 \text { Months } \\
(\mathrm{kg} \mathrm{Pu})\end{array}$ \\
\hline \multicolumn{3}{|l|}{ UPAA 1 (feed preparation) } \\
\hline No recalibration & 11.6 & 636 \\
\hline Weekly recalibration & $11 \cdot 6$ & 373 \\
\hline \multicolumn{3}{|l|}{ UPAA 23 (chemical separations) } \\
\hline No recalibration & $7 \cdot 6$ & 93 \\
\hline Weekly recalibration & 7.6 & 72 \\
\hline \multicolumn{3}{|l|}{ UPAA 2 (codecontamination/partitioning) } \\
\hline No recalibration & $5 \cdot 9$ & 289 \\
\hline Weekly recalibration & 5.9 & 109 \\
\hline \multicolumn{3}{|l|}{ UPAA 3 (copurification) } \\
\hline No recalibration & 5.5 & 284 \\
\hline Weekly recalibration & $5 \cdot 5$ & 114 \\
\hline
\end{tabular}

TABLE S-III

RELATIVE COST OF ACHIEVING THE PERFORMANCE GOALS

Goal 1 Goal 2 Goal 3 Goal 4

UPAA 1 (feed preparation)

No recalibration

Weekly recalibration

Daily recalibration

$\begin{array}{rrcc}20 & 111 & 1947 & 2546 \\ 9 & 64 & - & - \\ - & 53 & 942 & 1350\end{array}$

UPAA 23 (chemical separations)

No recalibration

$\begin{array}{llll}0.8 & 32 & 727 & 1544\end{array}$

weekly recalibration

022

Daily recalibration

$-$

19

495

-

UPAA 2 (codecontamination/partitioning)

No recalibration

$11 \quad 74 \quad 1404 \quad 2023$

Weekly recalibration

236

Daily recalibration

$-$

28

$-$

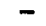

UPAA 3 (copurification)

No recalibration

weekly recalibration

$9 \quad 65 \quad 1263 \quad 1666$

Daily recalibration

$\begin{array}{cccc}1.7 & 29 & - & - \\ - & 21 & 518 & 735\end{array}$

viii 
For feed preparation processes, the performance goals cannot be met by current measurement technology. Materials accounting is complicated by inprocess inventories and spent-fuel assembly transfers that are difficult to measure. To alleviate these problems, inventories should be reduced wherever possible, spent-fuel NDA techniques should be refined and standards developed, and frequent flushouts of the feed preparation process should be considered.

For the chemical separations area, an abrupt loss-detection sensitivity of 15 $\mathrm{kg}$ of plutonium and a protracted loss-detection sensitivity of $150 \mathrm{~kg}$ of plutonium are attainable with current measurement technology. These loss-detection sensitivities have $50 \%$ detection probability and $2.5 \%$ false-alarm probability. If it is desirable to subdivide the chemical separations process and maintain lossdetection sensitivity, then a flow meter with measurement uncertainties comparable to those for the accountability tank must be developed, or buffer accountability tanks must be added at a designated feed tank location.

Achieving second-level performance $(8 \mathrm{~kg}$ of plutonium abrupt and $40 \mathrm{~kg}$ of plutonium protracted) is a reasonable goal for the chemical separations area of the HEF. This requires improving in-process inventory measurement uncertainty to $\sim 1 \%$ precision for process tank volume and concentration measurements. It also means improving accountability and plutonium sample tank transfer measurement uncertainties to $20.04 \%$ relative standard deviation (RSD) volume calibration, $\sim 0.04 \%$ RSD volume standards, $\sim 0.1 \%$ RSD concentration calibration, and $\imath 0.05 \%$ RSD concentration standards.

Attaining goals three and four requires inventory measurement or estimate errors $<0.2 \%$ RSD, transfer random errors $<0.03 \%$ RSD, and transfer correlated errors $<0.002 \%$ RSD. For comparison, today's primary standards have errors of about $0.04 \%$. Clearly, the proposed international and domestic safeguards goals cannot be achieved without major breakthroughs in measurement technology and standards preparation.

The optimization method developed for this study can identify measurement uncertainty components that dominate materials balance standard deviations and instruments that require development to meet specific performance goals. Further study is needed to determine the sensitivity of the results to costs and the constraints of measurement uncertainties. 


\section{CONTENTS}

GLOSSARY

$x v i$

ABSTRACT

I. INTRODUCTION
A. Objectives
B. NRTA Performance Goals
C. Study Ground Rules
D. The Reference Facility

II. MATERIALS MEASUREMENT AND ACCOUNTING SYSTEM
A. Introduction
1. Cleanout Physical Inventory Taking (CPIT)
2. Draindown Physical Inventory Taking
3. Rapid Physical Inventory Taking
4. Running Book Inventory Taking
B. MBA Structure
1. MBA-1: Fuel Receiving, Storage, Chop, and Leach
2. MBA 2: Chemical Separations
3. MBA 3: Uranium-Oxide Storage
4. MBA 4: Coconversion Process
5. MBA 5: Uranium-Plutonium-Oxide Storage
C. UPAA Structure
1. UPAA 1: Feed Preparation Processes
2. Chemical Separations Process Area
D. Measurements for NRTA
E. Performance Evaluation

III. OPTIMAL ALLOCATION OF MEASUREMENT UNCERTAINTIES

A. Application of Optimization Techniques 27

B. Cost Functions 28

C. Example 30

IV. RESULTS 37

A. UPAA 1: Feed Preparation Processes 39

B. UPAA 2 3: Chemical Separations Process 40

C. UPAA 2: Codecontamination/Partitioning 45

D. UPAA 3: Uranium-Plutonium Copurification

Process

V. IMPACT OF THE HEF PROCESS DESIGN ON MATERIALS ACCOUNTING 47

A. Introduction $\quad 47$

B. Some Requirements for Effective Materials Accounting 
C. HEF Process Design Features and Their Effect on Materials Accounting 48

1. Voloxidizer 48

2. Continuous Dissolver 49

3. Primary Centrifuge 50

4. Accountability Tank 50

5. In-Process Inventories 51

6. Coprocessing 52

7. Recycle Streams 52

8. Inaccessibility 52

VI. SUMMARY AND CONCLUSIONS 54
A. Summary

B. Conclusions

ACKNOWLEDGMENTS $\quad 60$

APPENDIX A. HEF PROCESS DESCRIPTION 61

I. FUEL RECEIVING AND STORAGE 62

II. DISSOLUTION AND FEED PREPARATION 62

III. URANIUM-PLUTONIUM CODECONTAMINATION A.ND PARTITIONING

IV. URANIUM PURIFICATION 72

V. URANIUM-PLUTONIUM COPURIFICATION

VI. NITRATE-TO-OXIDE COCONVERSION

VII. EXTRACTION BACKCYCLE 80

VIII. SOLVENT TREATMENT $\quad 80$

IX. LIQUID WASTES 80

X. OFF-GAS TREATMENT 81

APPENDIX B. DYNAMIC MODEL OF THE HEF CHEMICAL

I. INTRODUCTION 82 SEPARATIONS PROCESS 82

II. DYNAMIC MODEL 82

A. Introduction 82

B. HEF Model 83

I. Introduction 83

2. Brief Description 84

C. MODEL Computer Code 93

1. Introduction 93

2. Basic Structure 93

3 GASP IV Simulation Language 93

D. HEFMOD Computer Code 95

1. Introduction 95

2. Basic Structure 95

III. SAMPLE SIMULATION RESULTS 96

APPENDIX C. MATERIALS ACCOUNTING EQUATIONS 103

I. INTRODUCTION 103

II. MEASUREMENT MODELS 103

III. MATERIALS BALANCE 104

IV. MATERIALS BALANCE VARIANCE 105 
V. INDIVIDUAL INVENTORY VARIANCES 106

A. Inventory as One Measured Value (Type 1) 107

B. Inventory as the Product of Two Measured Values (Type 2)

VI. INDIVIDUAL TRANSFER VARIANCES

A. Transfer as One Measured Value (Type I) 110

B. Transfer as the Product of Two Measured Values (Type 2)

VII. MATERIALS BALANCE VARIANCES FOR HEF UPAA

APPENDIX D. OPTIMIZATION TECHNIQUES

I. INTRODUCTION

II. LINEAR OPTIMIZATION

III. NONLINEAR OPTIMIZATION

IV. PCON COMPUTER PROGRAM

APPENDIXE. OPTIMAL MEASUREMENT UNCERTAINTIES 


\section{TABLES}

\begin{tabular}{|c|c|c|}
\hline I. & Performance Goals & 4 \\
\hline II. & Bulk Measurements & 18 \\
\hline III. & NDA Measurements of Solutions & 19 \\
\hline IV. & NDA Measurements of Solids & 20 \\
\hline V. & Laboratory Analysis of Solutions & 21 \\
\hline VI. & HEF Measurement Points & 23 \\
\hline VII. & $\begin{array}{l}\text { Materials Accounting Loss-Detection Levels } \\
\text { Using Current Measurement Technology }\end{array}$ & 26 \\
\hline VIII. & Measurement Relative Standard Deviations & 33 \\
\hline $\mathrm{IX}$. & $\begin{array}{l}\text { Sample Process Measurement Uncertainty } \\
\text { Optimal Allocation Results }\end{array}$ & 35 \\
\hline X. & $\begin{array}{l}\text { UPAA } 1 \text { Dominant Measurement Uncertainties } \\
\text { (b RSD) }\end{array}$ & 41 \\
\hline XI. & $\begin{array}{l}\text { UPAA } 23 \text { Dominant Measurement Uncertainties } \\
\text { (10 RSD) }\end{array}$ & 43 \\
\hline XII. & $\begin{array}{l}\text { UPAA } 23 \text { Dominant Measurement Uncertainties } \\
\text { Relative Cost }\end{array}$ & 44 \\
\hline XIII. & $\begin{array}{l}\text { Materials Balance Standard Deviations with } \\
\text { Current Measurement Technology }\end{array}$ & 55 \\
\hline A-I. & $\begin{array}{l}\text { Mechanical Processing and Feed Preparation } \\
\text { Stream Characteristics }\end{array}$ & 63 \\
\hline A-II. & $\begin{array}{l}\text { Uranium-Plutonium Codecontamination and } \\
\text { Partitioning Stream Characteristics }\end{array}$ & 68 \\
\hline A-III. & Uranium Purification Stream Characteristics & 73 \\
\hline A-IV. & $\begin{array}{l}\text { Uranium-Plutonium Copurification Stream } \\
\text { Characteristics }\end{array}$ & 76 \\
\hline $\begin{array}{l}\mathrm{B}-\mathrm{I} . \\
\mathrm{C}-\mathrm{I} .\end{array}$ & $\begin{array}{l}\text { HEFMOD Independent Process Variables } \\
\text { Constants for the Materials Balance Variance }\end{array}$ & 85 \\
\hline & Equation & 115 \\
\hline E-I. & $\begin{array}{l}\text { Measurement Uncertainties: LPAA I, Goal I, } \\
\text { No Recalibration }\end{array}$ & 129 \\
\hline E-II. & $\begin{array}{l}\text { Measurement Uncertainties: UPAA 1, Goal 1, } \\
\text { Weekly Recalibration }\end{array}$ & 130 \\
\hline E-III. & $\begin{array}{l}\text { Measurement Uncertainties: UPAA 1, Goal 2, } \\
\text { No Recalibration }\end{array}$ & 131 \\
\hline E-IV. & $\begin{array}{l}\text { Measurement Uncertainties: UPAA 1, Goal 2, } \\
\text { Weekly Recalibration }\end{array}$ & 132 \\
\hline$E-V$. & $\begin{array}{l}\text { Measurement Uncertainties: UPAA 1, Goal 2, } \\
\text { Daily Recalibration }\end{array}$ & 133 \\
\hline E-VI. & $\begin{array}{l}\text { Measurement Uncertainties: UPAA 1, Goal 3, } \\
\text { No Recalibration }\end{array}$ & 134 \\
\hline E-VII. & $\begin{array}{l}\text { Measurement Uncertainties: UPAA 1, Goal 3, } \\
\text { Daily Recalibration }\end{array}$ & 135 \\
\hline E-VIII. & $\begin{array}{l}\text { Measurement Uncertainties: UPAA 1, Goal 4, } \\
\text { No Recalibration }\end{array}$ & 136 \\
\hline$E-I X$. & $\begin{array}{l}\text { Measurement Uncertainties: UPAA 1, Goal 4, } \\
\text { Daily Recalibration }\end{array}$ & 137 \\
\hline$E-X$ & $\begin{array}{l}\text { Measurement Uncertainties: UPAA } 23 \text {, Goal } 1 \text {, } \\
\text { No Recalibration }\end{array}$ & 138 \\
\hline
\end{tabular}




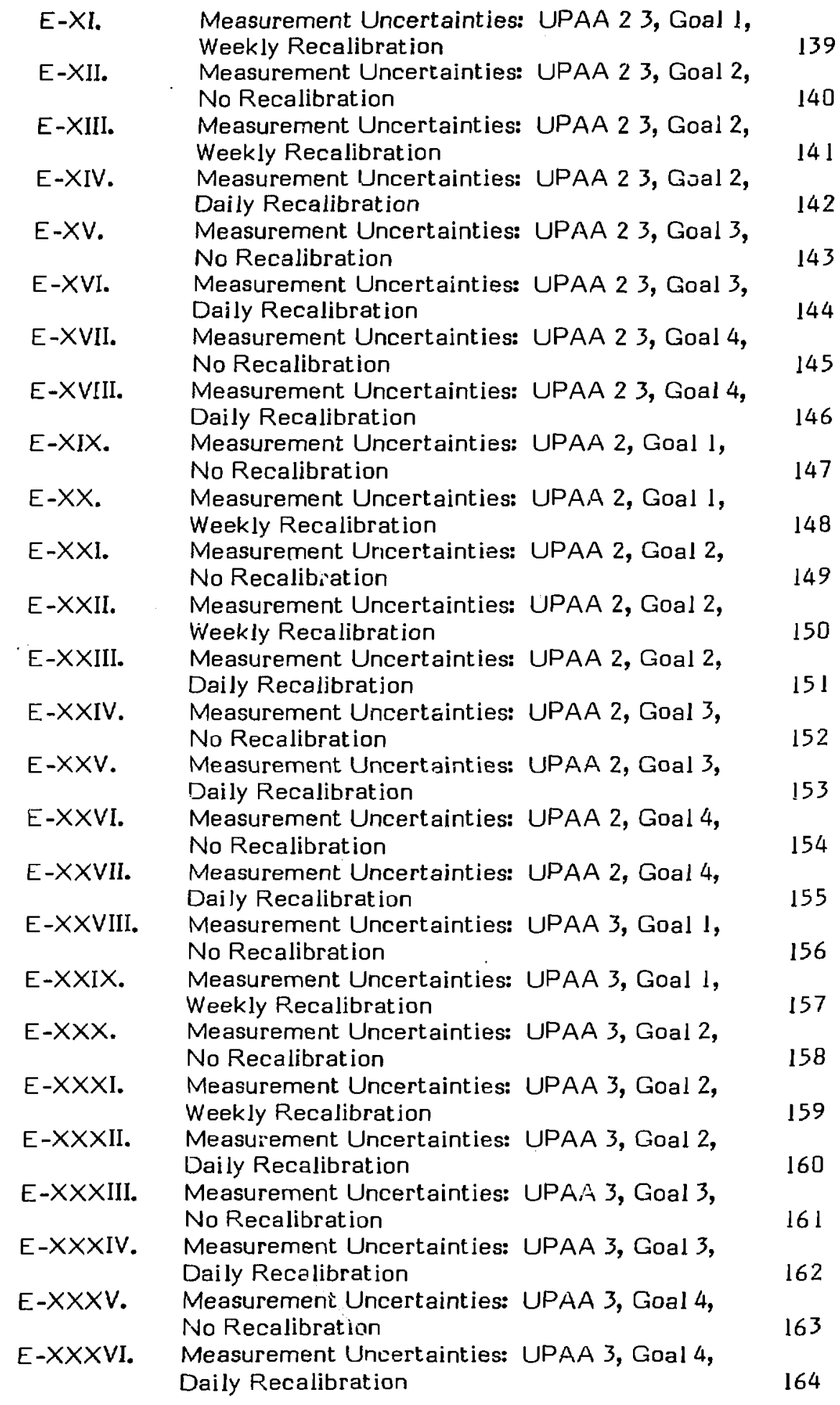


1. MBAs in the HEF. 12

2. UPAAs in the feed preparation and chemical separations process areas.

16

3. Cost functions for several values of $A$. 29

4. Simple process example. 31

5. Sample process cost functions. 34

A-1. Feed preparation. 65

A-2. Digester surge tank cycle. 66

A-3. Uranium-plutonium codecontamination and 71

A-4. Uranium purification. 75

A-5. Uranium-plutonium copurification. 79

B-1. Pulsed-column inventory linear estimator. 9!

B-2. "A" column measurement eq!rations. 91

B-3. Extraction/scrub pulsed column. 92

B-4. MODEL code structure. 94

B-5. Plutonium batch feed to the continuous dissolver. 97

B-6. Plutonium mass flow rate from the continuous dissolver. $\quad 97$

B-7. Plutonium in-process inventory of the continuous
dissolver.

B-8. Plutonium contert of leached hulls discharged from the continuous dissolver.

B-9. Plutonium inventory of the in-specification leached hulls.

B-10. Plutonium inventory of the off-specification leached hulls. $\quad 98$

B-11. Plutonium inventory of the solids sample tank. 98

B-12. Plutonium inventory of the feed solution surge tank. 98

B-13. Plutonium inventory of the accountability tank. 99

$B-14$. Plutonium mass flow rate into the HA centrifugal contactor.

$B-15$. Plutonium mass flow rate into the $3 A$ pulsed column.

B-16. Plutonium mass flow rate of the $3 \mathrm{~A}$ pulsed-column product stream.

B-17. Plutonium mass flow rate of the $3 \mathrm{~A}$ pulsed-column waste stream.

B-18. Plutonium in-process inventory of the $3 \mathrm{~A}$ pulsed column.

B-19. Plutonium inventory of the plutonium catch tank. 100

B-20. Plutonium inventory of the plutonium sample tank. $\quad 100$

D-1. Linear optimization example.

D-2. Nonlinear optimization example. 
CFRP Consolidạted Fuel Reprocessing Program

CPIT cleanout physical inventory taking

DOE Department of Energy

$H A$ high activity

HAW high-activity waste

HEF Hot Experimental Facility

HLW high-level waste

IAEA International Atomic Energy Agency

ICA item accounting area

IMP inventory, measurement point

LMFBR liquid-metal fast breeder reactor

MBA materials balance area

MMAS materials measurement and accounting system

MP measurement point

NDA nondestructive assay

NRC Nuclear Riggulatory Commission

NRTA near-real-time accounting

ORNL Oak Ridge National Laboratory

PIT

S/R

SST

TMP physical inyentory taking shipper/receiver solids sample tank

UPAA unit proces; accounting area

\section{Purex Process Identifiers}

Contactors

A extraction-scrub for $U-P u$ or $P u$ alone

B U-Pu partition or $P u$ strip

C U-Pu strip

$D$ extraction-scrub for $\mathrm{Pu}$ alone

$H$ preparation columns or streams

Stream

$A$ aqueous

$F$ feed

IS intermediate scrub

$O$ organic

$P$ product containing $\mathrm{Pu}$ or $\mathrm{Pu}+\mathrm{U}$

$R$ raffinate (no appreciable $\cup$ or $P u$ )

$S$ scrub

$\cup$ product containing only $U$

$W$ waste (no appreciable $U$ or $P u$ )

$X$ extractarit 
MATERIALS ACCOUNTING IN A FAST BREEDER REACTOR

FUELS REPROCESSING FACILITY: OPTIMAL ALLOCATION

OF MEASUREMENT UNCERTAINTIES

by

H. A. Dayem, C. A. Ostenak, R. G. Gutmacher, E. A. Kern: J. T. Markin, D. P. Martinez, and C. C. Thomas, Jr.

\begin{abstract}
This report describes the conceptual design of a materials accounting system for the feed preparation and chemical separations processes of a fast breeder reactor spent-fuel reprocessing facility. For the proposed accounting system, optimization techniques are used to calculate instrument measurement uncertainties that meet four different accounting performance goals while minimizing the total development cost of instrument systems. We identify instruments that require development to meet performance goals and measurement uncertainty components that dominate the materials balance variance. Materials accounting in the feed preparation process is complicated by large in-process inventories and spent-fuel assembly inputs that are difficult to measure. To meet $8 \mathrm{~kg}$ of plutonium abrupt and $40 \mathrm{~kg}$ of plutonium protracted loss-detection goals, materials accounting in the chemical separations process requires :

- process tank volume and concentration measurements having a precision $\leq 1 \%$;

- accountability and plutonium sample tank volume measurements having a precision $\leq 0.3 \%$, a shortterm correlated error $\leq 0.04 \%$, and a long-term correlated error $<0.04 \%$; and

- accountability and plutonium sample tank concentration measurements having a precision $\leq 0.4 \%$, a short-term correlated error $\leq 0.1 \%$, and a long-term correlated error $\leq 0.05 \%$.

The effects of process design on materials accounting are identified. Major areas of concern include the voloxidizer, the continuous dissolver, and the accountability tank.
\end{abstract}




\section{INTRODUCTION}

The United States Department of Energy (DOE) Consolidated Fuel Reprocessing Program (CFRP), centered at Oak Ridge National Laboratory (ORNL), comprises much of the DOE fuel reprocessing research and development. Its principal objective is the development of technology for reprocessing spent fuel from liquid-metal fast breeder reactors (LMFBRs). Los Alamos National Laboratory is tasked by the DOE/Office of Safeguards and Security to provide technical assistance in materials measurement and accountability technology to the CFRP. This reoort is the first in a series in support of the CFRP that develops and evaluates conceptual designs of advanced materials measurement and accountability systems for various reprocessing alternatives.

We give the study objectives, materials accounting performance goals, study ground rules, and a brief description of the Hot Experimental Facility (HEF) feed preparation and chemical separations processes in 5ec. I. Section II describes materials measurement and accounting strategies. We discuss optimization techniques and their application to the allocation of measurement uncertainties in Sec. III and present results of the optimal allocation calculations in Sec. IV. Section $V$ identifies HEF process design features that affect materials accounting, and Sec. VI gives the summary and conclusions of this study.

\section{A. Objectives}

The CFRP completed a conceptual design of the HEF, a pilot-scale plant designed to reprocess LMFBR fuels containing uranium and plutonium. This report describes a materials accounting system for the HEF feed preparation and chemical separations processes. For the proposed system, optimization techniques are used to calculate instrument measurement uncertainties that meet four different accounting performance goals while minimizing the total development cost of instrument systems. We identify measurement uncertainties that dominate the materials balance variance and instruments that require development to meet performance goals.

Previous materials accounting systems studies for various facilities in the nuclear fuel cycle calculated the near-real-time accounting (NRTA) systems performance by proposing a measurement system based on current technology or its reasonable extrapolations. ${ }^{1-5}$ The measurement uncertainties for each 
proposed instrument were combined and propagated to obtain an overall materials loss-detection sensitivity. This study reverses the approach. We use optimization techniques to calculate measurement uncertainties required to meet selected NRTA performance goals while minimizing the total development cost of the system. In this way we can answer the following questions.

(1) Given limited development resources, what measurement technology improvements provide maximum increase in accounting system performance?

(2) Which measurement uncertainties dominate materials balance variance?

(3) What values of measurement uncertainties are required to meet a given performance goal?

The overall study objective required that we

(1) formulate NRTA performance goals,

(2) define materials accounting strategies,

(3) identify measurement points,

(4) specify a reference materials measurement system that represents current technologv,

(5) deduce cost functions for improving each instrument measuremient uncertainty, and

(6) construct an optimal measurement allocation technique.

\section{B. NRTA Performance Goals}

Table 1 lists four levels of NRTA performance goals. The first two levels correspond to a likely range of measurement capabilities, the third and fourth levels to desired international and domestic goals. The first performance goal is based on state-of-the-art instrumentation. The second goal represents reasonable extrapolations of current technology. The third goal is based on International Atomic Energy Agency (IAEA) criteria and the fourth on Nuclear Regulatory Commission (NRC) goals that are now being considered.

Each performance goal includes detection of an abrupt (short-term) and a pratracted (long-term) diversion with given detection and false-alarm probabilities. These quantities are used to calculate the maximum value of the materials balance standard deviation that will meet the performance goal.

It should be remembered that the plant throughput is $2111 \mathrm{~kg}$ of plutonium per day and that the chemical separation and feed preparation portions of the process can have an inventory of $2750 \mathrm{~kg}$ of plutonium. 


Goal

1. Current technology Abrupt

Protracted

2. Improved technology Abrupt Protracted

3. IAEA

Abrupt

Protracted

4. NRC

Abrupt

Protracted

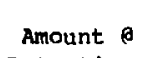

Detection (kg Pu)

Detection Time

Detection Probability

False-Mlarm Probability

Materials Balance standard Deviation Upper Limit ( $\mathrm{kg} \mathrm{Pu}$ )

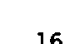

16
150

\section{1 day}

6 months

\section{5}

0.5

0.025

0.025

8
75

8
40

1 day

0.5

0.025

0.025

4
20

0.95

0.95

0.05

0.05

2.4

1 year

0.5

0.025

0.025

0.5

6 months

.

\section{Study Ground Rules}

We used the following ground rules for this study. The sensitivity of the results to the major assumptions will be considered in a subsequent report.

(1) Measurement points are identified and associated measurement uncertainties are calculated to allow us to achieve each performance objective. In most cases, the measurement points coincide with those required for process control. 6

(2) Materials balances are drawn once a day to coincide with feed and product batches.

(3) Each measurement is independent of all others. This assumption implies that there are no correlations between instruments; for example, each instrument is calibrated independently of any other instrument and with different standards. This, of course, is not the case in actual practice. There are two different assumptions that bracket the range of the materials balance standard deviation. If we assume that input and output instruments are calibrated with similar or identical standards, then the correlations between those instruments reduce the total materials balance staridard deviation. Alternatively, if we assume that all input measurements are calibrated using one standard and all output measurements are calibrated using another, then the correlations increase 
the materials balance standard deviation. Thus, the assumption of independence results in a materials balance standard deviation that is somewhere in the middle range of practical application.

(4) Each transfer or tank inventory measurement point has two measurement components, for example, volume and concentration. All other measurement points, for example, the inventory in the dissolver and the pulsed colurins, have one measurement component.

(5) Each measurement is specified by :

(a) a precision ( $\varepsilon$ ) with variance $\sigma_{\varepsilon}^{2}$,

(b) a short-term correlated error component $(n)$ with variance $\sigma_{n^{\prime}}^{2}$,

(c) a long-term correlated error component $(\theta)$ with variance $\sigma_{\theta}^{2}$,

(d) a calibration frequency.

The short-term correlated error represents those errors that are correlated only over each calibration period. Long-term correlated errors persist over all accounting periods and include errors in the primary and secondary standards and any inherent bias in sampling and measurement methods. All errors are assumed to be normally distributed with mean zero.

(6) A mixed measurement error model is used,

$$
m=\mu(1+\varepsilon+\eta)+\theta,
$$

where $\mu$ equals the actual value and $m$ equals the measured value.

(7) The "cost" of improving a measurement uncertainty $(\sigma)$ is described by an equilateral hyperbola,

$$
\cos t=A\left[\frac{\sigma_{u}-\sigma_{1}}{\sigma-\sigma_{1}}-1\right] \text {, }
$$


where $\sigma_{u}$ is an uncertainty achievable by current technology, $\sigma_{1}$ is an uricertainty not achievable at any cost, and $A$ is a relative improvement difficulty index.

(8) The materials balance standard deviation $\left(\sigma_{\mathrm{MB}}\right)$ is apportioned among the measurement uncertainties so that

$$
\sigma_{\mathrm{MB}}=\left[\sum_{i=1}^{\mathrm{N}_{\mathrm{m}}} \mathrm{B}_{\mathrm{ai}} \sigma_{\mathrm{i}}^{2}\right]^{1 / 2},
$$

where $N_{m}$ equals the number of measurement uncertainties and $B_{a i} \sigma_{i}^{2}$ equals total variance of the $i^{\text {th }}$ measurement uncertainty $\left(B_{a i}\right.$ is a function of the amount of material being measured and the number of measurements), such that the development cost

$$
\sum_{i=1}^{N_{m}} A_{i}\left[\frac{\sigma_{1 i}-\sigma_{1 i}}{\sigma_{i}-\sigma_{1 i}}-1\right]
$$

is minimized.

D. The Reference Facility

The HEF is a conceptual pilot-scale reprocessing facility that was conceived under the Advanced Fuel Recycle Program at ORNL. Its design, which was initiated in October 1976, was directed toward reprocessing uranium-plutonium fuels from LMFBRs. Consistent with changes since 1976 in US policy regarding fuel reprocessing and breeder reactor technology, the original HEF design has had several revisions, which emphasized proliferationresistant fuel cycles including thorium-based breeder reactor fuels. Because current emphasis is on the uranium-plutonium fuel cycle, this study addresses only the HEF uranium-plutonium flow sheet.

The current HEF design incorporates a modified Purex process that allows coprocessing uranium and plutonium. 7,8 The flow sheet is based on reprocessing 
one-half tonne per day of breeder reactor fuel having ( 1 ) a maximum burnup of 150000 megawatt-days per tonne, (2) a minimum decay period of 60 days before shipment to the HEF, and (3) a minimun decay period of 90 days before reprocessing. The design also provides for nitrate-to-oxide coconversion of mixed uranium-plutonium. In this study we consider only the feed preparation and chemical separations processes. Therefore, the following brief description highlights the major process systems, including (1) spent-fuel receiving and storage, (2) mechanical processing and feed preparation, (3) codecontamination/ partitioning, (4) uranium purification, and (5) uranium-plutonium copurification. A more complete description of the process is given in Appendix A.

In the fuel receiving and storage system, spent fuel is received in shipping casks, cleaned, assayed to determine its fissile content, and stored uritil it is scheduled for reprocessing. Operations include (1) cask unloading, (2) fuel cleaning and waste concentration, (3) fuel storage and water treatment, (4) nondestructive assay (NDA), and (5) sodium handling.

The mechanical processing and feed preparation system prepares a uranium-plutonium dissolved-fuel feed solution for subsequent processing by solvent extraction. Primary feed to this system is cleaned fuel assemblies. Secondary feed streams include fuel assembly fragments, storage-pool filter effluents, metal scrap, and high-activity (HA) centrifuge sludge. Major process steps are (1) mechanical disassembly and shearing, (2) voloxidation, (3) fuel dissolution, and (4) feed clarification.

The codecontamination/partitioning system includes a series of solventextraction contactors in which uranium and plutonium are selectively transferred between relatively immiscible, countercurrent aqueous and organic streams. In the first (codecontamination) cycle, fission products are separated from the uranium and plutonium. This cycle provides a fission-product codecontamination factor of $\sim 10^{3}$. The second cycle produces a partially purified uranium nitrate stream and a partially purified denatured plutonium nitrate stream having a uranium-to-plutonium ratio of 0.13:1.

The uranium purification system includes a solvent-extraction cycle (third cycle) that further purifies the uranium-nitrate product from the partitioning cycle. This purified uranium is concentrated and used to produce $\cup \mathrm{O}_{3}$ and to adjust the uranium-plutonium ratio in the copurification system. 
The uranium-plutonium copurification system includes two solvent-extraction cycles (fourth and fifth cycles) that further purify the uranium-plutonium nitrate product from the partitioning cycle. The copurification feed is denatured with uranium from the third cycle to increase the uranium-to-plutonium ratio from 0.13:1 to 2:1. Uranium also is added to the plutonium sample tank at the end of the fifth cycle to yield a final uranium-to-plutonium ratio of $3: 1$.

The liquid product storage system consists of eight plutonium storage tanks that can store up to 30 days of production. The storage tanks provide feed to the mixed-oxide conversion process. 


\section{MATERIALS MEASUREMENT AND ACCOUNTING SYSTEM}

A. Introduction

The primary objective of safeguards is to prevent the deliberate misuse of nuclear materials at both domestic and international levels. At the national level, facility operators' safeguards systems must address currently perceived threats that range from well-armed outsiders attempting forcible theft to well-informed insiders aiming at covert diversion of nuclear materials. These internal threats are addressed by several subsystems, including materials measurement a.J accounting, ${ }^{1-5,9,10}$ physical protection, ${ }^{11}$ and process monitoring and control. ${ }^{12}$ The goal of international safeguards is to deter diversion of nuclear materials by early detection. The IAEA uses materials accounting and containment/surveillance techniques with appropriate inspections. $^{13-19}$ Effective IAEA safeguards depend on the Agency's ability to verify data reported by the facility operator's materials measurement and accounting system (MMAS). The facility operator establishes and maintains MMAS to fulfill both domestic and international requirements. 20,21

The proposed MMAS combines conventional materials accounting with NRTA. The MMAS employs sampling and chemical analyses, weight and volume measurements, and NDA instrumentation, supported by automated data analysis and data base management technologies. Its three major tasks are

(1) data collection, including materials measurements;

(2) data analysis for assessment ; and

(3) data dissemination, including reporting.

Conventional accounting is based largely on physical inventory taking (PIT) and administrative controls. There are four common PIT methods.

1. Cleanout Physical Inventory Taking (CPIT). This is the best-known and most accurate method of PIT. The process line is drained and flushed into holding tanks for measurement, and residual holdup in the process equipment is measured directly or is estimated based on historical data. The CPIT method requires an extended shutdown period, and therefore it is costly and can be applied only infrequently. However, it provides essential information on the residual plant holdup, which is the zero base for more efficient PIT methods. 
2. Draindown Physical Inventory Taking. This method is similar to CPIT, except that there is minimal flushout of the process line after draindown. The draindown PIT method may be an economically attractive alternative to CPIT, if the plant is designed for its effective application.

3. Rapid Physical Inventory Taking. This method provides more efficient materials balances than CPIT by measuring the in-process inventory when the process is operated near steady state. If certain process run conditions are repeated periodically, then in-process inventory is essentially reproducible at those times. By measuring in-process inventory under identical run conditions, biases associated with inventory measurements will tend to cancel from the materials balances, and detection sensitivity will be improved. The process may be divided into accounting units smaller than the materials balance area (MBA), depending on the availability of flow and inventory measuiements. Sensitivity is better than might be expected, even though inventory measurement uncertainties are larger than for CPIT, because flow measurements are generally the dominant sources of uncertainty for a reprocessing plant.

4. Running Book Inventory Taking. In this method, not all in-process inventory components are measured. Instead, measurements are made on those process vessels that contain significant fractions of the in-process inventory and that are instrumented for rapid inventory determination. The unmeasured components of the in-process inventory are estimated by difference, and those estimates are compared with independent estimates of normal plant holdup based on historical data. Thus, running book inventory is applied only under normal operating conditions, similar to those required for rapid physical inventory. Also, the process line may be divided into smaller accounting units, and estimates by difference of the in-process output measurements become available. Depending on the variability of unmeasured inventory arid the quality of input-output measurements, this method may provide good sensitivity to abrupt diversion.

For conventional materials accounting the facility is divided into MBAs, of which there are two general types. 
(1) In an item control area (ICA), materials are maintained as discrete items. Materials accounting is largely vested in item counting and secure storage, with items identified by unique identifiers or seals. The contents of items may be measured if the seal is removed or if a shysical inventory is taken.

(2) Process MBAs are commonly areas in which material form and composition are changed. Materials balances are closed following a PIT by adding all receipts to the initial measured inventory and subtracting all shipments and final measured inventory.

In process MBAs, PIT lacks timeliness and sensitivity because (1) PITs are infrequent, so that losses may not be detected for extended periods; (2) MBAs often include the entire plant or a major portion of the process, so that localization of losses is difficult; and (3) the throughput in a facility such as the HEF is large; consequently, the absolute detection sensitivity is large even though relative measurement errors are very small. Materials balances for NRTA are drawn without shutting down the plant: in-process inventories are measured, or otherwise estimated, while the process is operating. A fiducial or reference point for NRTA is established by periodic conventional PITs.

To implement NRTA, a process MBA of the facility may be partitioned into unit process accounting areas (UPAAs), or an MBA may be treated as a single UPAA. The main difference between the MBA of PIT accounting and the UPAA of NRTA is that materials balances are drawn around UPAAs during plant operation. Each UPAA contains one or more chemical or physical processes and is chosen on the basis of process logic and the ability to draw a materials balance, rather than on geography, custodianship, or regulatory requirements. By dividing the facility into UPAAs, quantities of material much smaller than the total, plant inventory cari be accounted for on a timely basis, and any discrepancies can be localized to the portion of the process contained in the UPAA.

NRTA requires measurements of materials transfers between UPAAs and measurements or estimates of in-process inventories. Materials transfer measurements made for PITs are used by the NRTA system. Where transfers between UPAAs do not coincide with transfers between MBAs, then a transfer measurement must be added for NRTA. In some cases, process contol 
measurements of transfers can be used for NRTA. Measurements of in-process inventories can, in most cases, be based on process control instruments or improvements of those instruments.

The next section gives a brief description of the HEF MBA structure, followed by a description of the UPAA structure. It also discusses transfer and inventory measurement points and measurement methods that represent current technology. These measurements represent a reference case for the optimization calculations.

\section{B. MBA Structure}

For this study, the HEF is divided into five MBAs, as shown in Fig. 1. Also shown are PIT accounting measurement points (MPs) for the five areas. MPs are divided into transfer measurement points (TMPs) and inventory measurement points (IMPs). Each TMP can represent several types of measurements of various materials transfers between MBAs. IMPs are designated tanks in which flush

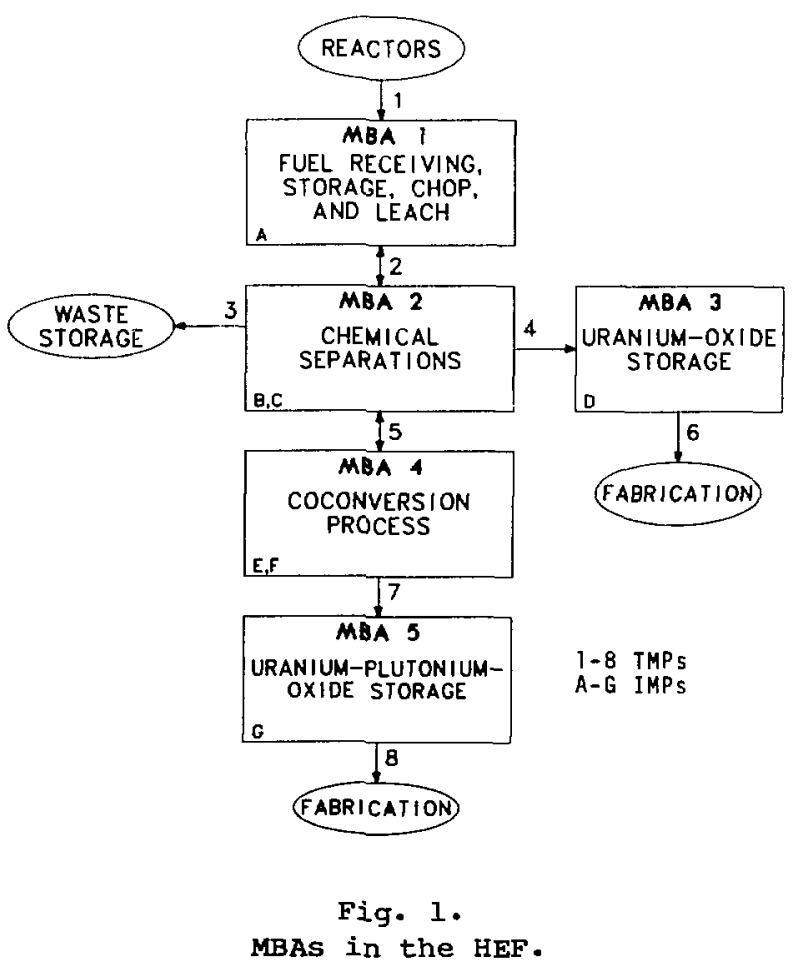


solutions are collected during a PIT. This MBA structure was chosen so that major materials storage areas are separated from process areas. Other HEF MBA structures were proposed ${ }^{22}$ and the final selection will depend on the facility operator's objectives and current regulatory requirements. Each MBA is described briefly below.

1. MBA 1: Fuel Receiving, Storage, Chop, and Leach. MBA 1 includes the spent-fuel receiving and cleaning area, the spent-fuel storage pool, and the disassembly, shearing, voloxidation, and dissolution operations to the accountability tank. MBA 1 comprises both item control areas (the fuel-storage pool and process operations before shearing) and process areas (chop and leach). Shipper/receiver (S/R) differences between the reactor and the HEF must be reconciled in MBA 1. The accountability tank is chosen as the product boundary of MBA I because the first accurate measurement can be made there. Accountability tank measurements are used for the receiver's values in settling $S / R$ differences and as input to the chemical separations processes. TMP $l$ is for the receipt of irradiated fuel, and TMP 2 is for transfers between MBA 1 and MBA 2. All irradiated fuel received passes through TMP I. Transfers that pass through TMP 2 include recycle solutions, off gas, leached hulls, fuel assembly scrap, unprocessed high-level waste (HLW), accountability batches, and laboratory samples. We assume that materials sent to waste storage are first processed in MBA 2.

IMP A comprises the spent-fuel storage pool and those process tanks for which reliable volume and concentration measurements can be made--probably digester tanks and the feed solution surge tank. During a PIT spent-fuel assemblies are counted and the process is flushed into designated tanks where the volume is measured and samples are taken for chemical analysis.

A materials balance can be closed about the chop and leach processes after each campaign (approximately every 30-40 days) when major process vessels and associated piping are drained and flushed into the accountability tank. If spent-fuel NDA methods become available, the MBA structure should be modified by making disassembly, shearing, voloxidation, and dissolution processes into a separate process MBA, instead of including those processes with spent-fuel storage. Also, the spent-fuel measurement would be used as the receiver's value to settle S/R differences, which is desirable because losses in the feed 
preparation process before the accountability tank would not cloud the S/R differences. Furthermore, the spent-fuel measurement could determine the amount of gadolinium required for criticality safety. NDA methods for verifying declared burnup and cooling time and for assaying fissile content of spent fuel are being developed. $23-27$

2. MBA 2: Chemical Separations. MBA 2 includes solvent-extraction and associated operations from the accountability tank to the uranium-plutoniumnitrate product sample tanks and the uranium-oxide packaging station; acid/ water and solvent recovery operations (extraction backcycle system, Nos. 1 and 2 solvent treatment systems, acid/water recycle system, and floor sump/rework operations); waste processing operations up to interim waste storage; and the analytical laboratory. TMP 2 is for transfers between MBA 1 and MBA 2 ; TMP 3 is for transfers from MBA. 2 to waste storage (processed intermediate- and high-level waste); TMP 4 is for transfers from MBA 2 to MBA 3 (uranium oxide canisters); and TMP 5 is for transfers between MBA 2 and MBA 4 (uraniumplutonium nitrate solution and laboratory samples). IMP B consists of those tanks in which solutions are collected when the process is drained and flushed and IMP C is the analytical laboratory.

A PIT in MBA 2 includes a shutdown and flushout of the separations process area, a cleanout of extraneous samples, and a piece-count verification of remaining materials in the laboratory. The process line is drained and flushed into designated tanks (IMP B) (for example, the plutonium catch, plutonium sample, uranium catch, and uranium sample tanks) that have been calibrated so that reliable volume measurements can be made and samples taken for analysis. A materials balance is drawn after each physical inventory by adding all measured receipts (TMPs 2 and 5) to the initial inventory (TMPs $B$ and $C$, initial) and subtracting all measured removals (TMPs 2, 3, 4, and 5) and the final inventory (TMPs $B$ and $C$, final).

3. MBA 3: Uranium-Oxide Storage. MBA 3 is the uranium-oxide storage vault and is an ICA. The content of each product canister is obtained from chemical analysis of a sample and weight measurement of the uranium oxide. $A$ physical inventory (IMP D) requires an item count and confirmation that tamper-indicating seals are intact and that prior measurements are still valid. 
4. MBA 4: Coconversion Process. MBA 4 includes the eight (seven operating and one spare) parallel 25\%-plutonium storage tanks and the entire uranium-plutonium nitrate-to-axide coconversion process from the mixed-oxide feed tanks to the mixed-oxide packaging. TMP 5 is for transfers between MBA 4 from MBA 2 (uranium-plutonium nitrate solution, recycle solution, and laboratory samples), and TMP 7 is for transfers from MBA 4 to MBA 5 (uranium-plutonium, oxide).

During a PIT the uranium-plutonium nitrate storage tanks (IMP E) are isolated, volume measurements are made, and samples are taken for chemical analysis. All process tanks are drained, the precipitators are flushed, and the flush solutions are collected in designated tanks (IMP F). The furnaces and dump-and-assay vessels are swept, and the powder is collected for measurement (IMP F). A materials balance is drawn after each PIT by adding all measured receipts (TMP 5) to the initial inventory (IMPs $E$ and $F$, initial) and subtracting all measured removals (TMP 7) and the final inventory (IMPs $E$ and $F$, final).

5. MBA 5: Uranium-Plutonium-Oxide Storage. MBA 5 is the mixed-oxide storage vault and is an ICA. Product canisters are assayed and sealed in MBA 4. A PIT (TMP G) requires item counting and confirmation that tamper-indicating seals are intact and that prior measurements are still valid. Measurements are made by assaying a random sample of the product canisters.

\section{UPAA Structure}

As noted earlier (Sec. II.A), PIT in process areas lacks timeliness and sensitivity. Clearly, a combination of conventional and NRTA methods is necessary in process areas. NRTA is implemented for timely detection of materials losses between conventional PITs. Under NRTA, a process area may be partitioned into UPAAs, which may include the entire area. Therefore, in many cases UPAA and MBA boundaries are identical. The distinguishing feature of a UPAA is that materials balances are closed frequently by measuring or estimating all significant materials flows and in-process inventories.

The three major process areas in the HEF are chop and leach, chemical separations, and coconversion. NRTA strategies for plutonium in the chop and leach and chemical separations process areas are discussed below. The UPAA structure is shown in Fig. 2. A subsequent report will address NRTA strategies for plutonium in MBA 4. 


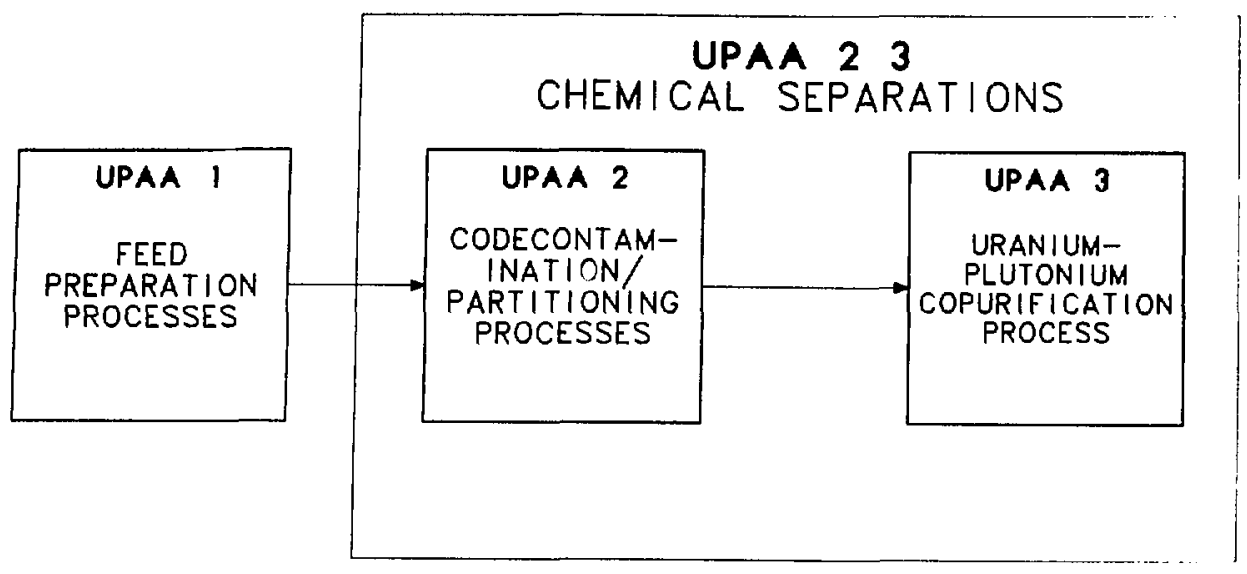

Fig. 2 .

UPAAs in the feed preparation and chemical separations process areas.

1. UPAA 1: Feed Preparation Processes. A UPAA can be formed around the feed preparation processes (Fig. A-1) by combining measurements of spent-fuel assembly plutonium content and accountahility tank contents with measurements or estimates of the in-process inventory. A near-real-time materials balance can be drawn once every day when an accountability batch is processed. Smaller batches, for example, waste batches sent to MBA 2, are included in materials balances when the measurements become available. Because at present we can only estimate in-process inventory in the shear, voloxidizer, and continuous dissolver, we must draw a materials balance following each flushout between campaigns. Increasing the frequency of flushouts may be desirable from both the materials-accounting and process-control points of view.

2. Chemical Separations Process Area. The chemical separations process area (Fig. 2) can be treated either as a single UPAA (UPAA 23) or as two UPAAs: a codecontamination/partitioning process UPAA (UPAA 2) and a uranium-plutonium copurification process UPAA (UPAA 3). A brief discussion of each follows.

a. UPAA 2 3: Chemical Separations Process. The chemical separations process MBA can be treated as a single UPAA if in-process inventory measurements are combined with TMPs 2, 3, 4, and 5 to form a near-real-time 
materials balance. Because most material is transferred through the feed and product TMPs, their frequencies govern the frequency of taking materials balances. Under normal operating conditions, one accountability batch and two product batches are processed every day. Therefore, process logic dictates that a materials balance can be taken every day to include an integral number of feed and product batches. Smaller batches, for example, waste batches sent to interim storage, are included in materials balances when the measurements become available.

b. UPAA 2: Codecontamination/Partitioning Processes. A separate UPAA can be formed around the codecontamination/partitioning processes ( $F$ ig. A-3) if flow and concentration measurements are added to the IWB, HAX, HAW, HCW, $I A X$, and IAPU streams. The HAX and IAX stream concentrations are determined at the 10 solvent surge tank in the No. 1 solvent treatment system. A near-real-time materials balance can be taken about UPAA 2 for each feed accountability batch (every $24 \mathrm{~h}$ ) by combining volume and concentration measurements of the feed batch, flow and concentration measurements of the IWB, HAX, HAW, HCW, IAX, and IAPU streams, and the initial and final in-process inventories in the process vessels.

c. UPAA 3: Uranium-Plutonium Copurification Process. Near-real-time materials balances can be taken about the uranium-plutonium copurification process ( $F$ ig. $A-5$ ) if flow and concentration measurements are added to the aqueous and organic recycle streams ( $2 A X, 2 A W, 2 B W, 3 A X, 3 A W$, and $3 B W$ ). The $2 A X$ makeup and $3 A X$ stream concentrations are determined th the 10 solvent surge tank in the No. 1 solvent treatment system. The balances can be taken about UPAA 3 for each product batch (every $12 \mathrm{~h}$ ) by combining volume and concentration measurements of the plutonium sample tank, flow and concentration measurements of the $2 A X, 2 A W, 2 B W, 3 A X, 3 A W$, and $3 B W$ streams, and initial and final in-process inventories in the process vessels.

Because UPAA 3 contains material in a relatively attractive form, it may be desirable to close materials balances more frequently. In this case, we can add a flow and concentration measurement at the plutonium concentrator product stream. With these added measurements, we can draw near-real-time materials balances for the copurification process perhaps every $30 \mathrm{~min}$. 


\section{Measurements for NRTA}

In consultation with ORNL, we developed tables of measurement types that can be used for NRTA in the HEF and measurement errors that are representative of current technology. ${ }^{28-63}$ Most of these measurements are also used for PITs ${ }^{22}$ and for process control. ${ }^{6}$ We identified measurement points for NRTA and chose applicable measurement types based on descriptions of materials in the process. This measurement system, which represents current technology, is a reasonable starting point for optimization calculations. Such a reference system provides a perspective on the improvements needed for meeting proposed performance goals and shows which goals can be met today. It includes flow and concentration measurements of the streams between the UPAAs as well as on-line or at-line concentration measurements for determining in-process inventories. Process equipment where in-process inventories cannot be directly measured (such as the solvent-extraction contactors) is based on models using measurements of observable process parameters. (See Appendix B for details on the application of process modeling and simulation.)

Tables II- $V$ show measurement types and errors that represent current technology. The tables list bulk measurements (Table II), NDA measurements of solutions (Table III), NDA measurements of solids (Table IV), and laboratory analysis of solutions (Table $V$ ). Volume measurements are listed separately for accountability and product tanks and waste and process tanks, because different accuracies and precisions are required as the optimization results will

TABLE II

BULK MEASUREMENTS

\begin{tabular}{|c|c|c|c|c|}
\hline \multirow[b]{2}{*}{$\begin{array}{c}\text { Measurement } \\
\text { Category }\end{array}$} & \multirow[b]{2}{*}{ Range/Limits } & \multicolumn{3}{|c|}{ Error $(8,1 \sigma)$} \\
\hline & & Precision & $\begin{array}{l}\text { Short-Term } \\
\text { Correlated } \\
\end{array}$ & $\begin{array}{l}\text { Long-Term } \\
\text { Correlated }\end{array}$ \\
\hline Volume (in-line) & $\begin{array}{l}\text { Accountability } \\
\text { and product tanks }\end{array}$ & 0.3 & 0.1 & 0.1 \\
\hline & $\begin{array}{l}\text { Waste and process } \\
\text { tanks }\end{array}$ & 3 & 3 & 1 \\
\hline Liquid flow & $>120 \mathrm{~L} / \mathrm{h}$ & $2 \cdot 5$ & 1.5 & 0.5 \\
\hline & $<120 \mathrm{~L} / \mathrm{h}$ & 5 & 3 & 1 \\
\hline
\end{tabular}


NDA MEASUREMENTS OF SOLUTIONS

(FISSION-PRODUCT CONCENTRATION $<10 \mathrm{Ci} / \mathrm{L}$ )

\begin{tabular}{|c|c|c|c|c|}
\hline \multirow[b]{2}{*}{$\begin{array}{c}\text { Plutonium } \\
\text { Concentration } \\
\end{array}$} & \multirow[b]{2}{*}{ Method } & \multicolumn{3}{|c|}{ Error $(8,10)$} \\
\hline & & Precision & $\begin{array}{l}\text { Short-Term } \\
\text { Correlated }\end{array}$ & $\begin{array}{l}\text { Long-Term } \\
\text { Correlated }\end{array}$ \\
\hline$<1 \mathrm{~g} / \mathrm{L}$ & $\begin{array}{l}\text { Alpha scintillation } \\
\text { counter }\end{array}$ & 5 & 2 & 2 \\
\hline \multirow[t]{5}{*}{$1-50 \mathrm{~g} / \mathrm{L}$} & $\begin{array}{l}\text { Alpha scintillation } \\
\text { counterb }\end{array}$ & 5 & 2 & 2 \\
\hline & Gamma spectroscopy & 1 & 0.5 & 0.2 \\
\hline & $\begin{array}{l}\text { Absorption-edge } \\
\text { densitometry }\end{array}$ & 1 & 1 & 1 \\
\hline & X-ray fluorescence & 1 & 1 & 1 \\
\hline & Spectrophotometry $\mathrm{C}$ & 5 & 2.5 & 1.5 \\
\hline \multirow[t]{4}{*}{$>50 \mathrm{~g} / \mathrm{L}$} & Gamma spectroscopy & 1 & 0.5 & 0.2 \\
\hline & $\begin{array}{l}\text { Absorption-edge } \\
\text { densitometry }\end{array}$ & 1 & 1 & 1 \\
\hline & $\mathrm{x}$-ray fluorescence & 1 & 1 & 1 \\
\hline & $\begin{array}{l}\text { Passive neutron } \\
\text { coincidence }\end{array}$ & - & - & - \\
\hline
\end{tabular}

a Hanford method.31 Applicable for concentrations of $10^{-4}$ to $1 \mathrm{~g} / \mathrm{L}$. To avoid excessive background, different scintillation cells should be used for these solutions and $>1 \mathrm{~g} / \mathrm{L}$ solutions.

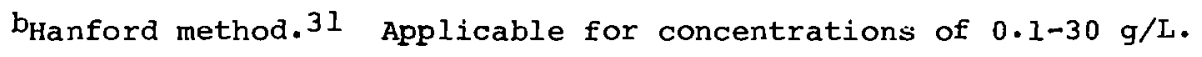

Coak Ridge method for uranium only.32 Concentration range 20-200 g/L.

$d_{\text {Passive neutron coincidence counter for solutions under development }}$ at Los Alamos. 
TABLE IV

NDA MEASUREMENTS OF SOLIDS

Material
Leached hulls
Mixed-oxide
product cans
Spent-fuel
assemblies
Waste containers
(packaged waste
for burial)
Process components

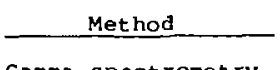

Gamma spectrometry Passive neutron

Passive neutron

Active neutron

weight and

chemistrya

ORNL active neutron

Gamma spectrometry

assive neutron

Active and passive

$$
\text { neut ron }
$$

Active neutron

Segmented gamma

scanner

Passive neutron

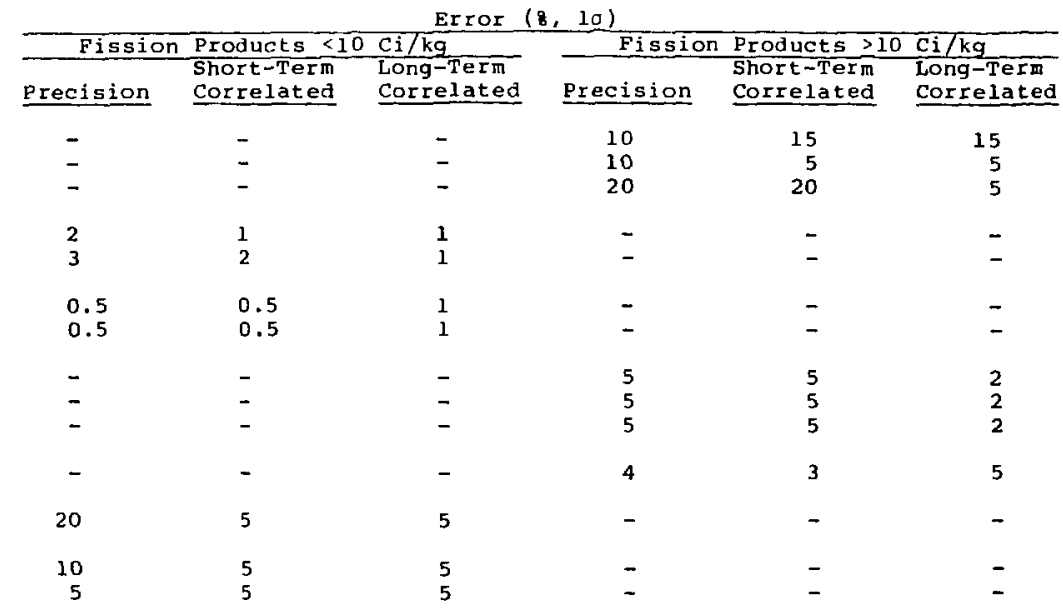

sludge from solids sample tank

and primary centrifuge

aplutonium concentration obtained by chemical analysis of samples.

bprincipal contribution to long-term correlated error is in specific heats of isotopes, because of uncertainty in half-1ives.

cplutonium in-process inventory of process components is estimat:d from modeling.

dsludge may be dried and then analyzed by one of the leached hulls techniques. If the material contains much plutonium, the errors will be lower than stated for leached hulls. 
TABLE V

LABORATORY ANALYSIS OF SOLUTIONS

Plutonium Concentration

$<1 \mathrm{~g} / \mathrm{L}$

$>50 \mathrm{~g} / \mathrm{L}$

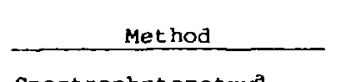

Spectrophotometrya

Extraction and alpha spectrometry or direct alpha spectrometry

Passive $x-$ ray

enissionb

I sotope- di l ut ion mass spectrometry

\section{Spectrophotometry ${ }^{\mathrm{a}}$}

Extraction and alpha

spectrometry or di rect alpha spectrometry

\section{$x$-ray fluorescence}

Isotope-dilution

mass spectrometry

Absorption-edge

densitometry

Gamma spectrometry

Electrometric

titration

$\mathrm{x}$-ray fluorescence

I sotope-dilution mass spectrometry

Absorption-edge

densi tometryc

Gamma spectrometryc

Electrometric

titration

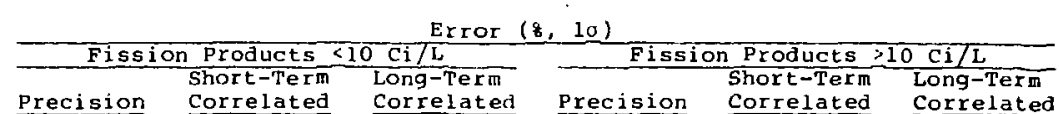

1

1.5

1

7

3

1

0.5

1

0.3

1

1

0.5

0.8

1.5

1

1.5

52

I

โิ

1

1

0.3

0.5

7

3

3

1

1

0.5

1

0.2

$0.3 \quad 0.2$

0.2

0.3

0.2

0.2

0.5

0.2

0.2

1

0.3

0.3

0.5

0.2

0.2

1

0.2

0.3

0.2

0.2

0.3

0.2

0.2

Method applicable if plutonium concentration is $>10 \mathrm{mg} / \mathrm{L} .34$

bethod developed by S-T. Hsue, F. Hsue, and D. Bowersox. 64

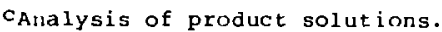


demonstrate. Because measurement errors are a function of the materials being measured, ranges are given for flow rates, plutonium concentrations, and fission-product concentrations. Flow rates are listed in two ranges, $>120 \mathrm{~L} / \mathrm{h}$ and $<120 \mathrm{~L} / \mathrm{h}$. Plutonium concentration ranges are $<1 \mathrm{~g} / \mathrm{L}, 1-50 \mathrm{~g} \mathrm{~L}$, and $>50 \mathrm{~g} / \mathrm{L}$. Fission-product concentrations are listed in two ranges, >10 Ci/L (or $>10 \mathrm{Ci} / \mathrm{kg}$ ) and $<10 \mathrm{Ci} / \mathrm{L}$ (or $<10 \mathrm{Ci} / \mathrm{kg}$ ).

The long-term correlated error includes more than the uncertainty in the standard reference material. $^{33}$ It also includes errors caused by sample-standard mismatch (how closely the standard approximates the samples to be analyzed), errors caused in the characterization of secondary standards, any bias in the method, and sampling errors for chemical and destructive methods. We have $t$ ried to include these factors in our estimates of long-term correlated errors.

The precision and short-term correlated errors also include sampling and weighing or volume measurement errors, if applicable, in addition to analytical errors. 33 Precision is the result of chance alone and indicates the reproducibility of a measurement method. Short-term correlated error is a combination of the errors made in the calibration of an instrument or method. The value of the short-term correlated error changes when a new calibration is performed.

Dissolver solutions and HLW solutions are slated for on-line concentration measurements in the HEF. NDA measurements for these solutions have not been successfully demonstrated. We have assumed that these solutions will be analyzed in the laboratory by isotope-dilution mass spectrometry.

We identified measurement points for NRTA (Sec. II.C) and used the measurements in Tables II-V to develop an NRTA materials measurement system that is representative of current technology. Table VI lists measurement points, measurement types, and measurement errors. This measurement system is the base case in the optimal measurement allocation procedure discussed in the next section. That is, the total system development cost of the base case measurement system is zero, but improvements on this system impose a development cost. The object is to minimize development cost while meeting performance objectives.

\section{E. Peformance Evaluation}

This section gives the NRTA systems materials loss-detection levels using the base case measurement system (Table VI). We employ the modeling, 


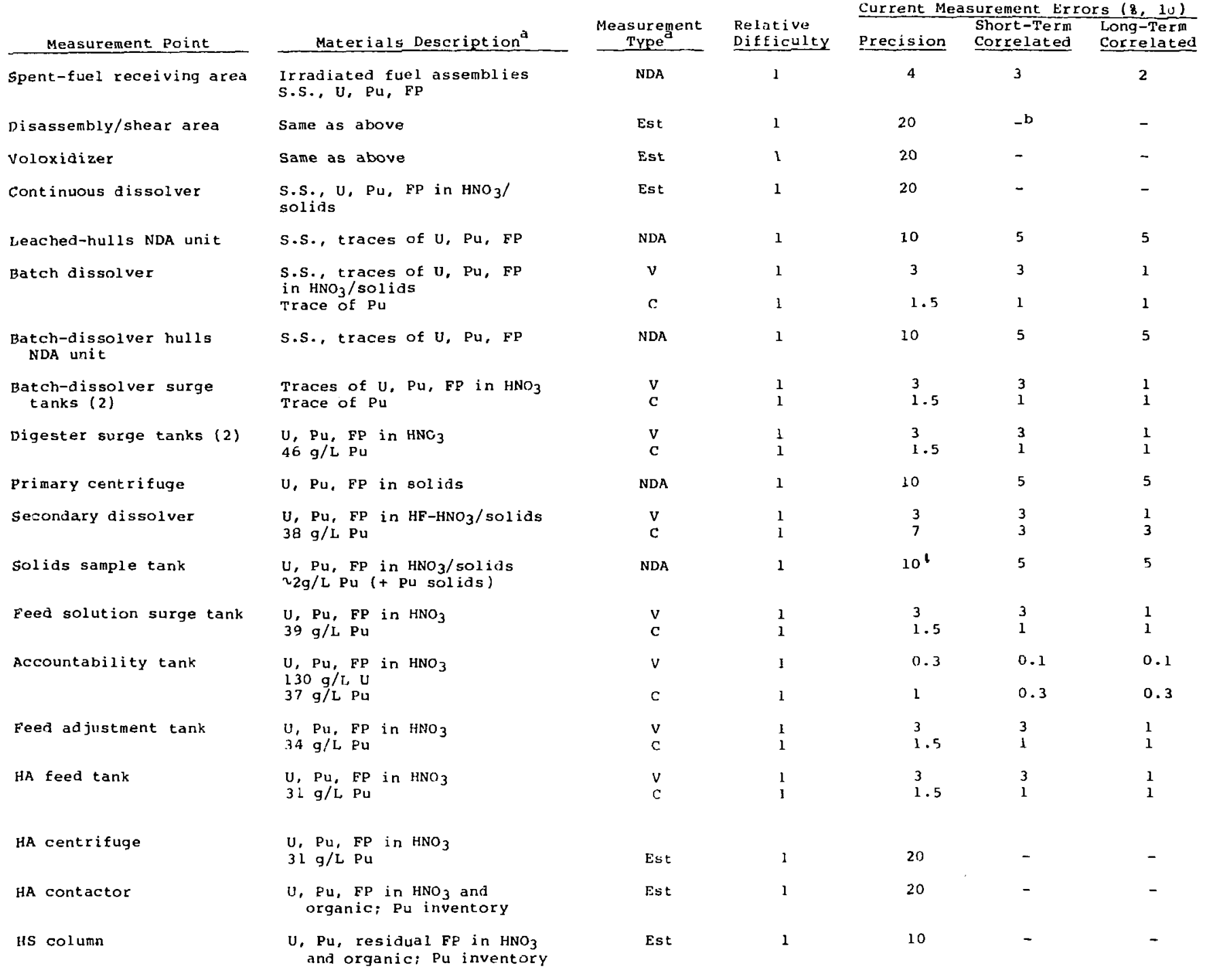




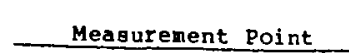

HC column

HCP reduction vessel

1 A feed tank

1A column

IAPU stream

2A feed tank

2A column

2 B column

$3 A$ feed tank

3A coluan

3B colunn

Pu stripper feed tank

Pu stripper

Pu concentrator

Pu catch tank

Pu sample tank

\section{Materials Description ${ }^{a}$}

$\mathrm{U}, \mathrm{Pu}$, regidual $\mathrm{FP}$ in $\mathrm{HNO}_{3}$ and organic; $\mathrm{Pu}$ inventory

$\mathrm{U}, \mathrm{Pu}$, residual $\mathrm{FP}$ in $\mathrm{HNO}_{3}$, $\mathrm{N}_{2} \mathrm{H}_{4}$, and HAN

$15 \mathrm{~g} / \mathrm{L} \mathrm{Pu}$

$\mathrm{U}, \mathrm{Pu}$, residual $\mathrm{FP}$ in $\mathrm{HNO}_{3}$, $\mathrm{N}_{2} \mathrm{H}_{4}$, and HAN

$13 \mathrm{~g} / \mathrm{L} \mathrm{Pu}$

U, Pu, residual FP in $\mathrm{HNO}_{3}$ and organic: $\mathrm{Pu}$ inventory

$\mathrm{U}, \mathrm{Pu}$, residual FP in $\mathrm{HNO}_{3}$, $\mathrm{N}_{2} \mathrm{H}_{4}$, and HAN

$422 \mathrm{~L} / \mathrm{h}$

$11 \mathrm{~g} / \mathrm{L} \mathrm{Pu}$

$\mathrm{U}, \mathrm{Pu}$, residual $\mathrm{FP}$ in $\mathrm{HNO}_{3}$

II $\mathrm{g} / \mathrm{L} \mathrm{Pu}$

U, Pu, residual $\mathrm{FP}$ in $\mathrm{HNO}_{3}$ and organic; $P u$ inventory U, Pu, residual FP in $\mathrm{HNO}_{3}$
and organic; Pu inventory

$\mathrm{U}, \mathrm{Pu}$, residual FP in $\mathrm{HNO}_{3}$

$14 \mathrm{~g} / \mathrm{L} \mathrm{Pu}$

v, Pu, resldual FP in $\mathrm{HNO}_{3}$ and organic; $\mathrm{Pu}$ inventory

U, Pu, residual FP in $\mathrm{HNO}_{3}$ and organic: $P u$ inventory

U, Pu, residual FP in $\mathrm{HNO}_{3}$, $17_{\mathrm{g} / \mathrm{L}}^{\mathrm{N}} \mathrm{Pu}$

U, Pu, reeidual FP in $\mathrm{HNO}_{3}$, $\mathrm{N}_{2} \mathrm{H}_{4}$
$17-32 \mathrm{~g} / \mathrm{L} \mathrm{Pu}$

\section{7-32 $\mathrm{g} / \mathrm{L} \quad \mathrm{Pu}$}

U, $\mathrm{Pu}$, residual FP in $\mathrm{HNO}_{3}$ 32-137 g/L Pu

U-Pu nitrate solution $137 \mathrm{~g} / \mathrm{L} \mathrm{Pu}$

U-Pu nitrate solution

$95 \mathrm{~g} / \mathrm{L} \mathrm{Pu}$

\begin{tabular}{c}
$\begin{array}{c}\text { Measurement } \\
\text { Type }\end{array}$ \\
\hline
\end{tabular}

Est

$$
\text { v }
$$

c

v

v

c

Est

Relative Difficulty

1

\begin{tabular}{l} 
Short-Term Long-Term \\
Preciaion Correlated \\
\hline
\end{tabular}

10

-

3

0.5

1

1
3

1

3

$$
0.5
$$$$
-
$$

$\begin{array}{cc}E & 1 \\ C & 1 \\ V & 1 \\ C & 1 \\ \text { Est } & 1 \\ \text { Eat } & 1\end{array}$

c

Est

Est

v

c

$\begin{array}{ll}\text { Est } & 1 \\ v & 1 \\ C & 1 \\ v & 1 \\ C & 1 \\ v & \\ C & \end{array}$

$\begin{array}{ll}0.5 & 0.2 \\ 0.5 & 0.2 \\ 3 & 1 \\ 0.5 & 0.2 \\ - & - \\ - & - \\ 3 & \\ 0.5 & 1 \\ - & 0.2 \\ & -\end{array}$

$$
-
$$

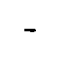

1

0.2

10

$\begin{array}{lll}3 & 3 & 1 \\ 1 & 0.5 & 0.2 \\ 3 & 3 & 1 \\ 1 & 0.5 & 0.2 \\ 0.3 & 0.1 & 0.1 \\ 0.3 & 0.2 & 0.2\end{array}$

dS.S. = stalnless steel, FP = flesion products, Est = estimation, $v=$ volume, $c=$ concentration, and $F=$ flow rate.

bcorrelated errors for inventory measurements and estimates are not 1 isted because these errors tend to cancel when materials balances are drawn. 
simulation, and analysis approach that has been used extensively in safeguards systems studies to evaluate the NRTA performance. ${ }^{1-5}$

This approach requires ( 1 ) a detailed dynamic model of the process based on actual design data and operator experience, (2) simuiation of the model process on a digital computer, (3) a dynamic model of each measurement system based on best estimates of instrument performance and behavior, (4) simulation of accountability measurements applied to nuclear materials flow and in-process inventory data generated by the model process simulation, and (5) evaluation of simulated materials balance data from various materials accounting strategies. Appendix $B$ describes the model process simulation, and Appendix $C$ gives the materials balance and materials balance variance equations.

Table VII presents loss-detection levels for each of the UPAAs. Results are given for 1 day (abrupt) and 6 months (protracted) for two pairs of detection and false-alarm probabilities that coincide with Table I performance goals. Two cases of recalibration frequency are given for each UPAA:

(1) no recalibration within the accounting period and

(2) recalibration of the feed and product concentration measuring inst ruments once every week.

Goal 1, abrupt and protracted loss-detection goals, can be met in the chemical separations area (UPAA 23 ). The protracted goal can be met only by weekly recalibration of feed and product concentrator measuring instruments. Abrupt loss-detection goals can be met in the codecontamination/partitioning area (UPAA 2) and the copurification area (UPAA 3). The loss-detection sensitivity for UPAA 1 will not meet goal 1 performance. Goals 2, 3, and 4 cannot be met by current measurement technology in any of the UPAAs.

The PIT loss-detection sensitivity is equivalent to that of the 6-months accounting period. Therefore, PIT will satisfy performance goal $I$ only in the shemical separations area and only if the feed and product concentration measuring instruments are recalibrated once every week. 
MATERIALS ACCOUNTING LOSS-DETECTION LEVELS

USING CURRENT MEASUREMENT TECHNOLOGY

\begin{tabular}{rlrl}
$\mathrm{DP}$ & $=0.5$ & $\mathrm{DP}$ & $=0.95$ \\
$\mathrm{FAP}$ & $=0.025^{\mathrm{a}}$ & $\mathrm{FAP}$ & $=0.05$ \\
\hline IDay & 6 Months & I Day & 6onths
\end{tabular}

UPAA 1 - Feed Preparation No recalibration Weekly recalibration

23.2

23.2

$$
1272
$$

746

$38 \cdot 3$

$38 \cdot 3$

2099

1230
UPAA 2 - Codecontamination/ Partitioning

No recalibration

Weekly recalibration

UPAA 3 - Copurification

No recalibration

weekly recalibration

UPAA 23 - Chemical Separations No recalibration

Weekly recalibration
15.2

15.2
11.1

$11 \cdot 1$

568

228

578

218

19.5

19.5

954

11.8

28

186

144

18.2

$18.2 \quad 376$

$\overline{a_{D P}}$ is detection probability and FAP is false-alarm probability. 


\section{OPTIMAL ALLOCATION OF MEASUREMENT UNCERTAINTIES}

In Sec. II we formulated materials accounting strategies and chose candidate base case instruments representing current technology. We used the base case measurement system to calculate materials loss-detection sensitivities. Current technology cannot meet performance goals 2, 3, and 4, and in some instances performance goal 1 . The primary objective of this study is to calculate the measurement uncertainties that meet each of the performance goals while minimizing the overall measurement system cost or development risk.

Optimization techniques can solve many problems, iñcluding the best allocation of resources (either maximum or minimum) to achieve a given goal. In this section, we formulate the allocation of measurement uncertainties as an optimization problem, explain the choice of cost functions, and illustrate the optimal measurement allocation with a simple example. Appendix $D$ discusses techniques and describes the computer program chosen for this study.

\section{A. Application of Optimization Techniques}

This section discusses a method for calculating measurement uncertanties so that performance goals for detecting materials loss are attained. These performance goals, defined in Sec. I and based in part on IAEA and NRC criteria, are stated as the amount of materials loss to be detected by accounting within a given time and with a specified probability. Performance goals are given for both abrupt and protracted diversions. Measurement system sensitivity to materials loss depends on the size of the materials balance standard deviation; a smaller deviation increases the probability of detecting materials loss. Calculation of uncertainties for each measurement error component requires that the materials balance standard deviation for both diversions be sufficiently small to meet the stated goals.

For this report we calculate measurement uncertainties that meet specified performance goals at minimum instrument development cost. That is, where the calculated uncertainty is below the current attainable value, a development cost is imposed. The optimal set of measurement uncertainties impose minimum measurement system development cost. 
The problem of calculating minimum development cost uncertainties to meet a given systems performance goal can be formulated as an optimization problem. To do so, we must write a set of constraint equations for measurement error components $\left(\sigma_{i}\right)$ and an objective function that relates them to instrument development cost. The materials balance standard deviation $\left(\sigma_{M B}\right)$ must be less than or equal to a specified abrupt systems performance goal $\left(\sigma_{a}\right)$ and a specified protracted systems performance goal $\left(\sigma_{p}\right)$.

In addition to the constraints imposed by materials balance uncertainties, upper and lower limits on allowable standard deviation for each measurement error component $\sigma_{i}$ are desirable to assure a reasonable uncertainty calculation. Clearly the upper limit $\left(\sigma_{\text {ui }}\right)$ should correspond to the current instrument performance, and the lower limit $\left(\sigma_{\mathrm{li}}\right)$ should be based on the judgment of instrument designers about reasonably attainable instrument uncertainties. Therefore, the constraints for our problem are given by

$$
\begin{aligned}
& {\left[\sum_{i=1}^{N_{m}} B_{a i} \sigma_{i}^{2}\right]^{1 / 2}=\sigma_{M B} \leq \sigma_{a} .} \\
& {\left[\sum_{i=1}^{N_{m}} B_{p i} \sigma_{i}^{2}\right]^{1 / 2}=\sigma_{M B} \leq \sigma_{p},} \\
& \sigma_{1 i}<\sigma_{i} \leq \sigma_{u i} \quad\left(i=1, \ldots, N_{m}\right) .
\end{aligned}
$$

The coefficients $\mathrm{B}_{\mathrm{ai}}$ and $\mathrm{B}_{\mathrm{pi}}$ are calculated from the amount of material being measured and the length of the accounting period (see Appendix $C$ ).

\section{B. Cost Functions}

To complete formulating uncertainty allocation as an optimization problem, the cost of uncertainty reduction must be incorporated in an objective function. For this study we chose an equilateral hyperbola to represent the relative cost of improving a measurement uncertainty. Any other convex cost function can be 
used for each measurement uncertainty component. The relative cost $\left(C_{i}\right)$ of improving the $\mathrm{i}^{\text {th }}$ measurement error component is given by

$$
c_{i}=A_{i}\left[\frac{\sigma_{u i}-\sigma_{1 i}}{\sigma_{i}-\sigma_{1 i}}-1\right] \text {. }
$$

where $A_{i} \equiv$ relative improvement difficulty factor for $\sigma_{i}, \sigma_{u i} \equiv$ upper limit of $\sigma_{i}$ (representative of current technology), and $\sigma_{j i} \equiv$ lower limit of $\sigma_{i}$ (probable limit of development).

Figure 3 shows a family of hyperbolas for $\sigma_{\mathrm{ui}}=0.01$ and $\sigma_{\mathrm{li}}=0.001$ for several values of $A$. Each curve gives the relative development cost for achieving a given measurement uncertainty. The hyperbolas cross the cost axis at $\sigma_{u i}$; that is, the development cost is zero for an uncertainty achievable by current

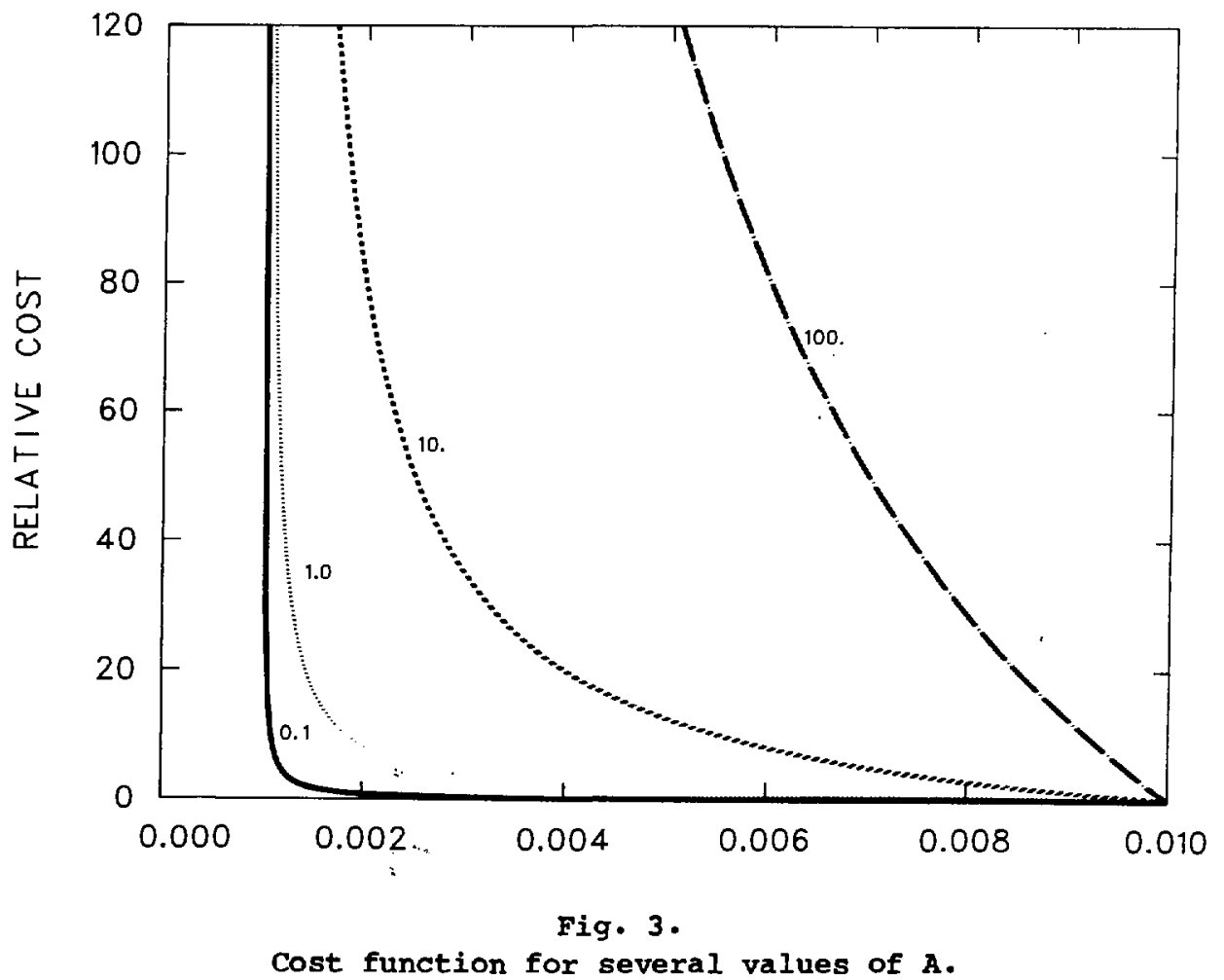


technology. On the other hand, $\sigma_{\text {li }}$ represents an uncertainty that is not achievable. Hence, the cost is infinite at $\sigma_{\mathrm{li}}$. The rate of increase in cost as $\sigma$ decreases within the range $\left(\sigma_{\mathrm{ui}}, \sigma_{\mathrm{li}}\right)$ is controlled by the factor $A$.

The objective function is given by

$$
\text { cost }=\sum_{i}^{\mathrm{N}_{\mathrm{m}}} c_{i}=\sum_{i}^{\mathrm{N}_{\mathrm{m}}} \mathrm{A}_{i}\left[\frac{\sigma_{\mathrm{u}}-\sigma_{1 i}}{\sigma_{i}-\sigma_{1 i}}-1\right] \text {. }
$$

Formulation now is complete. Next we must calculate $\sigma_{i}$ subject to the constraints in Eq. (1), while minimizing the total development cost, Eq. (3). Because the constraint and objective functions are convex, we are assured that the calculated minimum is a global minimum (see Appendix D).

\section{Example}

A simple example illustrates the application of optimization techniques in allocating measurement uncertainties to meet given performance goals. Figure 4 represents an ideal process having an in-process inventory of $10 \mathrm{~kg}$ and a daily throughput of $2 \mathrm{~kg}$ consisting of a single 2-kg feed batch and a single 2-kg product batch. The process is contained in a single UPAA.

Given this process, we must write the materials balance standard deviation $\sigma_{\mathrm{MB}}$ as a function of the measurement error components and specify (1) constraints on the range of each measurement uncertainty and (2) the cost of decreasing those uncertainties within their ranges. Finally, we must allocate the measurement uncertainties so that the total systems development cost is minimized.

For an accounting period of $N$ days, the materials balance $\left(M B_{N}\right)$ is given by

$$
M B_{N}=\Delta I_{N}+T_{N}
$$

where $\Delta I_{N}=I_{0}-I_{N}$, initial minus final inventory; and $T_{N}=N(f-p)$, feed minus product for $N$ net transfers. If there were no measurement uncertainties, $M B_{N}$ would be zero. Of course, that is not the case. 
$2 \mathrm{Kg} / \mathrm{BATCH}$

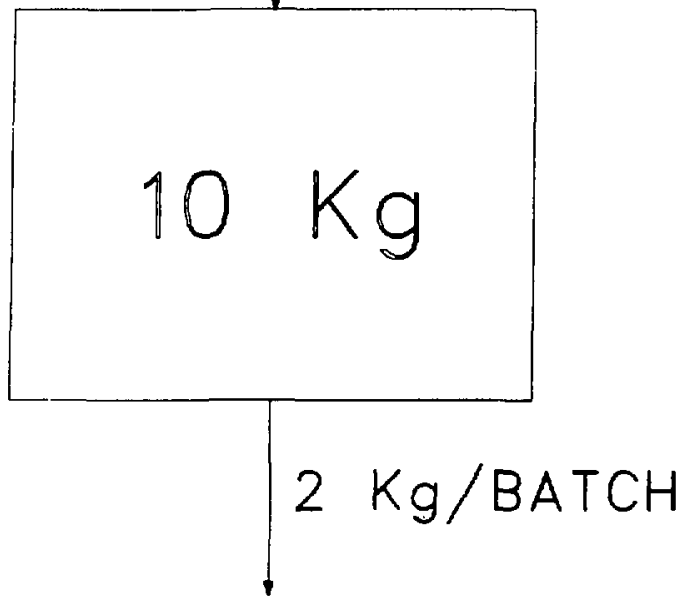

Fig. 4 .

Simple process example.

Let each instrument be represented by a multiplicative measurement error model. In this model the measured value $M$ of a true quantity $\mu$ is given by

$$
M=\mu(1+\varepsilon+\eta)
$$

where $E$ is the uncertainty caused by instrument imprecision and $\eta$ is the uncertainty caused by correlated effects such as calibration. The variance $\sigma_{M}^{2}$ of $M$ is given by

$$
\sigma_{M}^{2}=\mu^{2}\left(\sigma_{\varepsilon}^{2}+\sigma_{\eta}^{2}\right)
$$

Assuming $\eta$ does not change during a given period, then any two measurements $\left(M_{i}\right.$ and $M_{j}$ ) are correlated. The covariance $\sigma_{i j}$ between $M_{i}$ and $M_{j}$ is given by 


$$
\sigma_{i j}=\mu_{i} \mu_{j} \sigma_{n}^{2}
$$

These measurement errors produce an uncertainty in the materials balance having a variance $\sigma_{M B}^{2}$ given by

$$
\sigma_{\mathrm{MB}}^{2}=\sigma_{\Delta \mathrm{I}_{\mathrm{N}}}^{2}+\sigma_{\mathrm{T}_{\mathrm{N}}}^{2}
$$

The variance $\sigma{ }_{\Delta \mathrm{I}}^{2}$ of the net change in inventory is given by

$$
\sigma_{\Delta I_{N}}^{2}=\left(I_{0}^{2}+I_{N}^{2}\right) \sigma_{E_{I}}^{2}+\left(I_{0}-I_{N}\right)^{2} \sigma_{\eta_{I}}^{2}
$$

The initial and final inventories are the same; in most processes operating near steady state, $I_{0} \sim I_{N}$. Therefore, the variance of the net change in inventory is given by

$$
\sigma_{\Delta I_{N}}^{2}=2 I^{2} \sigma_{I}^{2}
$$

The variance $\sigma{ }_{\Delta T_{N}}^{2}$ of the net transfer is given by

$$
\sigma_{T_{N}}^{2}=N\left(f^{2} \sigma_{\varepsilon_{f}}^{2}+p^{2} \sigma_{\varepsilon_{p}}^{2}\right)+N^{2}\left(f^{2} \sigma_{\eta_{f}}^{2}+p^{2} \sigma_{\eta_{p}}^{2}\right)
$$


If we combine Eqs. (4) and (5) and substitute values for I ( $10 \mathrm{~kg}), f(2 \mathrm{~kg})$, and $p(2 \mathrm{~kg})$, the materials balance variance is given by

$$
\sigma_{\mathrm{MB}}^{2}=200 \sigma_{\varepsilon_{I}}^{2}+4 \mathrm{~N}\left(\sigma_{\varepsilon_{f}}^{2}+\sigma_{\varepsilon_{p}}^{2}\right)+4 \mathrm{~N}^{2}\left(\sigma_{\eta_{f}}^{2}+\sigma_{\eta_{p}}^{2}\right)
$$

This equation is the basis for the abrupt and protracted diversion constraints. In this example, let the abrupt constraint be for 1 day $(N=1)$ and the protracted constraint for 100 days $(N=100)$.

Each measurement standard deviation is constrained over a range $\left(\sigma_{\mathrm{ui}}, \sigma_{\mathrm{li}}\right)$. Table VIII is a list of the assumed relative standard deviations.

As shown in Fig. 5, the cost function for improving each measurement uncertainty is an equilateral hyperbola with $\sigma_{1 \mathrm{i}}$ vertical asymptote crossing the cost axis at $\sigma_{u i}$ [see $\left.E_{q .}(2)\right]$ where $A_{i}$ is equal to one.

TABLE VIII

MEASUREMENT RELATIVE STANDARD DEVIATIONS

$\begin{array}{lll} & \frac{\sigma_{1 i}}{1 . E-2} & \frac{\sigma_{u i}}{1 . E-1} \\ { }^{\sigma} \varepsilon_{I} & 6 \cdot E-3 & 6 . E-2 \\ { }^{\sigma} \varepsilon_{f} & 1 . E-3 & 1 . E-2 \\ { }^{\sigma} \eta_{f} & 5 \cdot E-3 & 5 . E-2 \\ { }^{\sigma} \varepsilon_{P} & 8 \cdot E-4 & 8 \cdot E-3 \\ { }^{\sigma} \eta_{p} & & \end{array}$




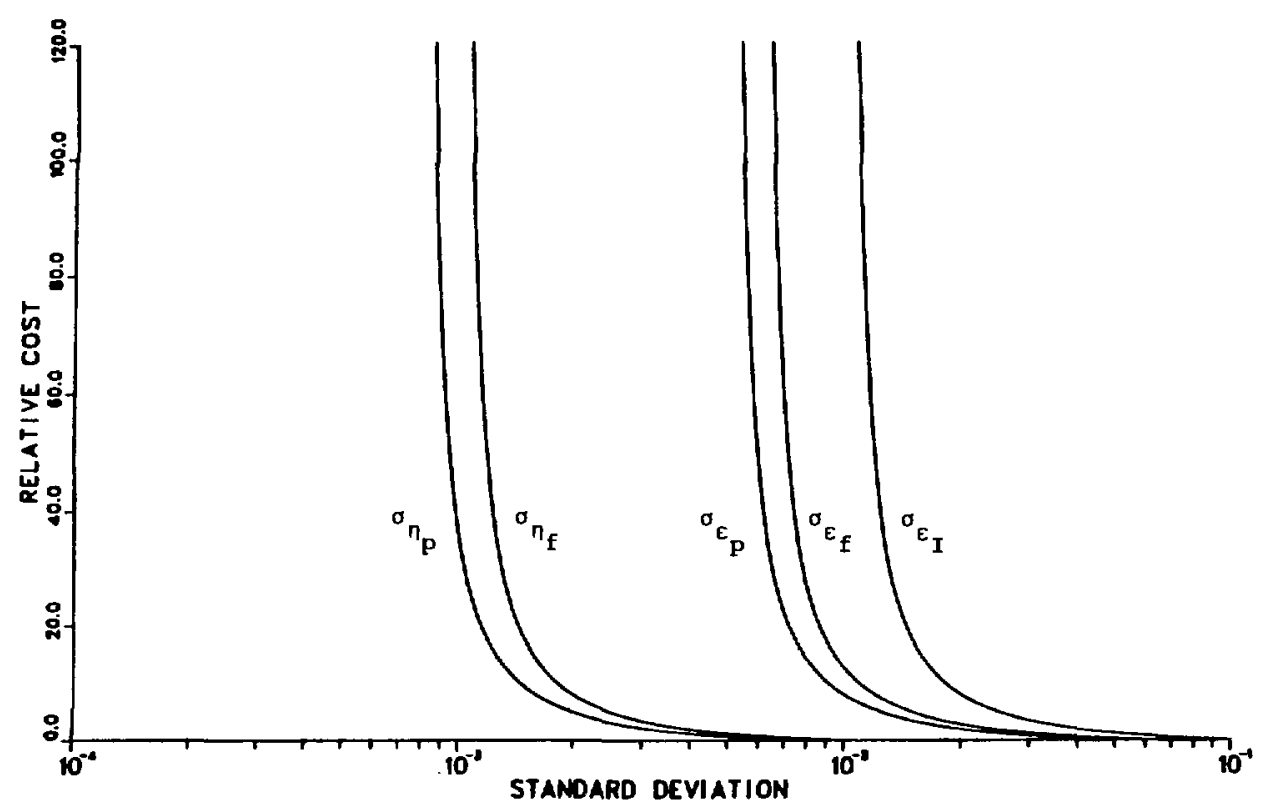

Fig. 5 .

Sample process cost functions.

We can now write the optimization problem for the example process.

Constraints :

$$
\begin{aligned}
& \sigma_{A} \geq\left[200 \sigma_{\varepsilon_{I}}^{2}+4\left(\sigma_{\varepsilon_{f}}^{2}+\sigma_{\eta_{f}}^{2}\right)+4\left(\sigma_{\varepsilon_{P}}^{2}+\sigma_{\eta_{P}}^{2}\right)\right]^{1 / 2} \\
& \sigma_{P} \geq\left[200 \sigma_{\varepsilon_{I}}+400\left(\sigma_{\varepsilon_{f}}^{2}+\sigma_{\varepsilon_{P}}^{2}\right)+40000\left(\sigma_{\eta_{f}}^{2}+\sigma_{\eta_{P}}^{2}\right)\right]^{1 / 2} \\
& 1 \cdot E-2 \leq \sigma_{\varepsilon_{I}} \leq 1 \cdot E-1 \\
& 6 \cdot E-3 \leq \sigma_{\varepsilon_{f}} \leq 6 \cdot E-2 \\
& 1 \cdot E-3 \leq \sigma_{\eta_{f}} \leq 1 \cdot E-2 \\
& 5 . E-3 \leq \sigma_{\varepsilon_{P}} \leq 5 \cdot E-2 \\
& 8 \cdot E-4 \leq \sigma_{n_{P}} \leq 8 \cdot E-3
\end{aligned}
$$


Minimize :

$$
\begin{aligned}
\text { Cost }= & {\left[\frac{9 \cdot E-2}{\sigma_{\varepsilon_{I}}-1 \cdot E-2}-1\right]+\left[\frac{5 \cdot 4 E-2}{\sigma_{\varepsilon_{f}}-6 \cdot E-3}-1\right] } \\
& +\left[\frac{9 \cdot E-3}{\sigma_{\eta_{f}}-1 \cdot E-3}-1\right]+\left[\frac{4 \cdot 5 E-2}{\sigma_{\varepsilon_{P}}-5 \cdot E-3}-1\right] \\
& +\left[\frac{7 \cdot 2 E-3}{\sigma_{n_{P}-8 \cdot E-4}}-1\right] .
\end{aligned}
$$

Cost minimization results for the $\sigma_{A}, \sigma_{p}$ constraint pairs are shown in Table IX. Substituting the $\sigma_{u}$ shown in Table VIII for each measurement uncertainty into the constraint equations results in $\bar{\sigma}_{A}=1.42$ and $\bar{\sigma}_{P}=3.32$. Therefore, in Case 1 , specifying abrupt and protracted constraints $\sigma_{A}>\bar{\sigma}_{A}$ and $\sigma_{p}>\bar{\sigma}_{p}$ results in measurement uncertainties equal to the $\sigma$ values and thus zero cost. In Case 2, $\sigma_{A}<\bar{\sigma}_{A}$ and $\sigma_{P}>\bar{\sigma}_{P}$ are specified. The calculated uncertainties result in much of the cost being assigned to the $\varepsilon$ error components, most of which are assigned to the inventory error $\sigma_{\varepsilon_{I}}$. This is expected because the abrupt diversion sensitivity is dominated by the precision components, which are dominated by the in-process inventory measurement uncertainty.

\begin{tabular}{|c|c|c|c|c|c|c|c|c|c|c|}
\hline \multirow{2}{*}{$\begin{array}{l}\text { Case } \\
\text { No. }\end{array}$} & \multicolumn{2}{|c|}{ Constraints } & \multicolumn{2}{|c|}{ Calculated } & \multirow{2}{*}{$\begin{array}{l}\text { Total } \\
\text { Cost }\end{array}$} & \multirow{2}{*}{$\begin{array}{l}\sigma_{E_{I}} \\
\operatorname{cost}{ }_{1}\end{array}$} & \multirow{2}{*}{$\begin{array}{l}\sigma_{\varepsilon_{f}} \\
\operatorname{cost}_{2} \\
\end{array}$} & \multirow{2}{*}{$\begin{array}{l}\mathrm{o}_{\text {rIf }} \\
\operatorname{Cost}_{3} \\
\end{array}$} & \multirow{2}{*}{$\begin{array}{l}\sigma_{E} p \\
\text { cost }\end{array}$} & \multirow{2}{*}{${ }_{n_{p}}{ }_{\cos t_{5}}$} \\
\hline & $\mathrm{U}_{\mathrm{A}}$ & ${ }^{0} \mathrm{P}$ & $O_{A}$ & $\sigma_{\mathrm{p}}$ & & & & & & \\
\hline 1 & 1.5 & 3.5 & 1.4 & 3.3 & 0 & $1.0-1$ & $\begin{array}{l}6.0-2 \\
0\end{array}$ & $1.0-2$ & $\begin{array}{l}5.0-2 \\
0\end{array}$ & $\begin{array}{l}8.0-3 \\
0\end{array}$ \\
\hline 2 & 0.5 & 3.5 & 0.50 & 3.0 & 2.9 & $\begin{array}{l}3.4-2 \\
2.8\end{array}$ & $\begin{array}{l}6.0-2 \\
5.1-3\end{array}$ & $\begin{array}{l}9.8-3 \\
2.4-2\end{array}$ & $\begin{array}{l}4.9-2 \\
3.0-2\end{array}$ & $\begin{array}{l}7 \cdot 9-3 \\
8 \cdot 9-3\end{array}$ \\
\hline 3 & 1.5 & 0.5 & 0.23 & 0.50 & 80 & $\begin{array}{l}1 \cdot 6-2 \\
14 \cdot 1\end{array}$ & $\begin{array}{l}9.7-3 \\
13.4\end{array}$ & $\begin{array}{l}1 \cdot 4-3 \\
20 \cdot 7\end{array}$ & $\begin{array}{l}8.5-3 \\
12.0\end{array}$ & $\begin{array}{l}1.1-3 \\
19.9\end{array}$ \\
\hline 4 & 0.15 & 0.35 & 0.15 & 0.35 & 771 & $\begin{array}{l}1.1-2 \\
169\end{array}$ & $\begin{array}{l}6.5-3 \\
115\end{array}$ & $\begin{array}{l}1.0-3 \\
216\end{array}$ & $\begin{array}{l}5.5-3 \\
98.8\end{array}$ & $\begin{array}{l}8.4-4 \\
172\end{array}$ \\
\hline 5 & 0.5 & 3.5 & 0.50 & 2.6 & 6.1 & $\begin{array}{l}3.5-2 \\
2.6\end{array}$ & $\begin{array}{l}2.7-2 \\
1.6\end{array}$ & $\begin{array}{l}9.7-3 \\
3.9-2\end{array}$ & $\begin{array}{l}2.1^{-2} \\
1.8\end{array}$ & $\begin{array}{l}7.8-3 \\
2.6-2\end{array}$ \\
\hline
\end{tabular}

TABLE IX

SAMPLE PROCESS MEASUREMENT UNCERTAINTY OPTIMAI, ALLOCATIOH RESULTS 
In Case 3, we specify the constraints $\sigma_{A}>\bar{\sigma}_{A}$ and $\sigma_{P}<\bar{\sigma}_{P^{*}}$. We calculate measurement uncertainties where most of the cost results from improving the correlated errors. This again is expected because these errors dominate the protracted diversion sensitivity.

In Case 4, constraints $\sigma_{A}<\bar{\sigma}_{A}$ and $\sigma_{P}<\bar{\sigma}_{P}$ are specified. The optimization program calculates measurement uncertainties such that both constraints are just satisfied.

In Case 5, we repeat Case 2 but multiply the cost of improving $\sigma_{E_{I}}$ (Cost 1 ) by 100 , for example, $A_{1}=100$. Comparison of Case 2 and Case 5 shows that the total systems cost is greater in Case 5, but the ratio of Cost 1 to Total Cost is less in Case 5. The inventory error was increased while the other precision components decreased. 


\section{RESULTS}

This section gives measurement uncertainties needed to achieve each of the four MMAS performance goals (Sec. I.B) for each UPAA (described in Sec. Il.C). We calculate measurement uncertainties as in the example in Sec. IIl.C. The materials balance equations, used as constraint equations, are developed in Appendix $C$. Each measurement uncertainty is constrained in the range $\left(0, \sigma_{u i}\right)$ where the $\sigma_{u i}$ represents current technology as shown in Table VI. For this study the lower bound for each measurement uncertainty $\left(\sigma_{1 i}\right)$ is zero, and the relative improvement difficulty index $\left(A_{i}\right)$ for each measurement uncertainty [see Eq. (2)] is one. In a subsequent study we will examine the effect of these parameters as well as the choice of cost functions on the calculated measurement uncertainties through a sensitivity analysis.

For each UPAA, the constraint equations are

$$
\begin{aligned}
& \sigma_{a} \geq\left[\begin{array}{cc}
\sum_{m} & B_{a i} \sigma_{i}^{2} \\
i=1
\end{array}\right]_{p}^{1 / 2}, \\
& \sigma_{p}\left[\begin{array}{c}
\sum_{m}^{N} B_{p i} \sigma_{i}^{2} \\
i=1
\end{array}\right]^{1 / 2}, \\
& 0 \leq \sigma_{i} \leq \bar{\sigma}_{u i}\left(i=1, \ldots, N_{m}\right)
\end{aligned}
$$

and the cost equation is

$$
\text { cost }=\sum_{i=1}^{N_{\mathrm{m}}}\left[\frac{\sigma_{\mathrm{u} i}}{\sigma_{i}}-1\right] \text {, }
$$


where $\mathrm{i}$ is the measurement error component index as given in the results table for each case; $N_{m}$ is the number of measurement error components for the UPAA; and the coefficients $B_{a i}$ and $B_{p i}$ for the abrupt and protracted goals, respectively, are functions of the nominal measured value, the number of measurements made, and the instrument calibration frequency (see Appendix $C$ ).

The calculated optimal measurement uncertainties were applied to the model process (see Appendix B) using the mixed measurement error model discussed in Sec. I.C and Appendix C. Use of this model is necessary because nominal values for transfers and inventories are used in the optimization calculations, whereas the process model allows variation in process parameters. The simulation results show that calculated measurement uncertainties meet the performance goals.

Appendix $E$ gives optimal measurement uncertainties for each UPAA that meet the four performance goals (Table I) while minimizing total systems development cost. Summary tables are given in this section. Tables E-I through E-XXXVI list the measurement error components $(\varepsilon, n$, and $\theta)$ for the UPAA and their calculated value, current technology value, uncertainty contribution to the abrupt and protracted goals, and relative cost.

One cost unit is the relative cost of achieving a measurement uncertainty that is one-half of that achievable by current technology $\left(\sigma_{i}=1 / 2 \sigma_{u_{i}}\right)$. Each halving of $\sigma_{i}$ costs twice what the previous halving did, plus 1 . For example, the cost of achieving $\sigma_{\mathrm{i}}=1 / 4 \sigma_{\mathrm{u}_{\mathrm{i}}}$ is 3 and of $\sigma_{\mathrm{i}}=1 / 8 \sigma_{\mathrm{u}_{\mathrm{i}}}$ is 7 .

In-process inventory uncertainties are entirely a function of precision ( $\varepsilon$ ) (see Sec. III.C and Appendix C). There are two types of inventory determinations : those determined by a single measurement or estimate (such as for the shear) and those calculated from the product of two measured values (such as for the HA feed tank volume and concentration).

Transfer uncertainties are a function of precision and short-term ( $n$ ) and long-term $(\theta)$ correlated instrument errors. There are two types of transfer determinations : those made by a single measurement (such as for the spent fuel) and those calculated from the product of two measurements (such as for the accountability tank volume and concentration).

In the tables, inventory uncertainties are given first, followed by transfer uncertainties. Results are given for cases where instruments are not recalibrated during the accounting period and for periodic recalibration of key transfer measurements (excluding volume measurements). Note that small differences in 
measurement uncertainties, and hence relative cost, are not significant, because these differences could result from numerical inaccuracies in the optimization computer program.

We discuss highlights of these results and identify dominant inventory and transfer measurement uncertainties in the following sections. Dominant terms are those measurement uncertainties that contribute most to the materials balance uncertainty and those identified by the optimization calculation as most improving materials balance uncertainty at least relative cost.

\section{A. UPAA 1: Feed Preparation Processes}

Materials balances are drawn once each day about the feed preparation processes by combining the following measurements :

(1) feed transfer : spent-fuel assembly plutonium content (7 each day);

(2) product transfer: accountability tank volume and concentration ( 1 each day);

(3) waste out : hulls plutonium content (48 each day) and centrifuge sludge plutonium content ( 1 each day);

(4) recycle input: HA centrifuge sludge plutonium content (1 each week); and

(5) inventories : tank volumes and concentrations, and disassembly/shear, voloxidizer, and continuous dissolver estimates ( 1 each day).

There are 41 measurement uncertainty components for UPAA 1 . Tables E-I through E-IX give the measurement uncertainties that satisfy each of the four performance goals for each recalibration case. In the periodic recalibration cases, only the spent-fuel NDA and the accountability tank concentration instruments are recalibrated.

The feed preparation headend processes comprise several process operations for which inventory measurement or estimation is difficult. Each of these process operations contains a large $(>14 \mathrm{~kg})$ plutonium inventory. The dominant inventory uncertainty terms for UPAA 1 result from in-process inventory estimates in the shear, voloxidizer, and continuous dissolver, and volume and concentration measurements in the digesters and the feed solution surge tank.

The dominant transfers are spent-fuel feed and accountability tank product. Of the two, spent-fuel NDA dominates transfer uncertainties and therefore requires greater development. 
As shown in Sec. II.E, goal 1 cannot be achieved in UPAA 1 with current measurement technology. With current measurements, $\sigma_{\mathrm{MB}}$ for 1 day is $11.6 \mathrm{~kg}$

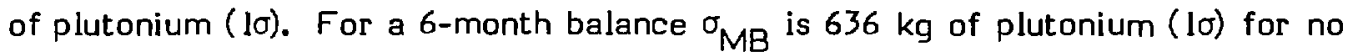
recalibration, and for weekly recalibration $\sigma_{\mathrm{MB}}$ is $373 \mathrm{~kg}$ of plutonium ( $\mathrm{l \sigma}$ ).

UPAA 1 optimal measurement uncertainties for dominant inventory and transfer terms that satisfy the four performance goals are summarized in Table $X$. To achieve goal 1 with weekly recalibration, errors in the estimates of the in-process inventory in the voloxidizer and continuous dissolver must be decreased from $20 \%$ each to $13 \%$ and $17 \%$, respectively. The spent-fuel NDA $\eta$ and $\theta$ measurement uncertainties must be reduced from $3 \%$ and $2 \%$ to $1 \%$ and $0.3 \%$, respectively, and minor reductions are necessary in a few other measurement uncertainty components.

Goal 2 attainment requires modest improvements in inventory estimate errors and large improvements in transfer measurement errors. Errors in the inventory estimates of the shear, voloxidizer, and continuous dissolver must be reduced from $20 \%$ to $13 \%, 6 \%$, and $7 \%$, respectively. We need spent-fuel transfer measurements having a precision $\leq 1 \%$ and correlated errors of $\leq 0.2 \%$ short-term and $\leq 0.07 \%$ long-term. For the accountability tank, we need volume measurements having a precison $\leq 0.02 \%$, a short-term correlated error $\leq 0.03 \%$, and a long-term correlated error $\leq 0.03 \%$; and we require concentration measurements having a precision $\leq 0.3 \%$, a short-term correlated error $\leq 0.1 \%$, and a long-term correlated error $\leq 0.04 \%$.

To achieve goals 3 or 4 requires measurement improvements of approximately an order of magnitude for the inventories and two to three orders of magnitude for the key transfers. For example, these goals need inventory estimates that are $<1 \%$ and transfer correlated errors that are $<0.002 \%$. Clearly, these goals will not be achieved without major breakthroughs in measurement technology and standards preparation.

\section{B. UPAA 2 3: Chemical Separations Process}

Materials balances are drawn once each day about the chemical separations process by combining the following measurements :

(1) feed transfer : accountability tank volume and concentration (one each day);

(2) product transfer : plutonium product sample tank volume and concentration (two each day); 
TABLE $X$

UPAA 1 DOMINANT MEASUREMENT UNCERTAINTIES

(10 RSD)

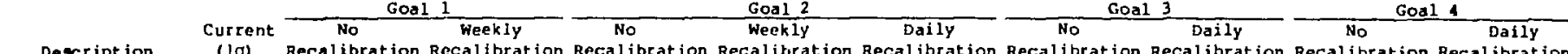
INVENTOALES

\begin{tabular}{|c|c|c|c|c|c|c|c|c|c|c|}
\hline Shear $(\varepsilon)$ & $2 \cdot 0-1$ & $2.0-1$ & $2.0-1$ & $1.1-1$ & $1,3-1$ & $1.3-1$ & $2.3 \div 2$ & $2.3-2$ & $1.0-2$ & $1.2-2$ \\
\hline Voloxidizer $(E)$ & $2.0-1$ & $1.4-1$ & $1.3-1$ & $5.7-2$ & $5.8-2$ & $5.5-2$ & 8.1-3 & $9.9-3$ & $4,4-3$ & $5.2-3$ \\
\hline $\begin{array}{l}\text { Continous dissolver } \\
\text { (E) }\end{array}$ & $2.0-1$ & $1.7-1$ & $1.7-1$ & $7.2-2$ & $7.1-2$ & $7.3-2$ & $1.2-3$ & $1.2-2$ & $4.6-3$ & $6.2-3$ \\
\hline \multicolumn{9}{|l|}{ Digester (2) } & $19-3$ & $27-3$ \\
\hline Concentration (E) & $1.5-2$ & $1.5-2$ & $1.5-2$ & $1.5-2$ & $1.5-2$ & $1.5-2$ & $3.5-3$ & $4.0-3$ & $2.1-3$ & $2.2-3$ \\
\hline \multicolumn{11}{|l|}{ Feed solution surqe } \\
\hline $\begin{array}{l}\text { Volume }(E) \\
\text { Concentration }(E)\end{array}$ & $\begin{array}{l}3.0-2 \\
1.5-2\end{array}$ & $\begin{array}{l}3.0-2 \\
1.5-2\end{array}$ & $\begin{array}{l}3.0-2 \\
1.5-2\end{array}$ & $\begin{array}{l}1.9-2 \\
1.3-2\end{array}$ & $\begin{array}{l}1.9-2 \\
1.3-2\end{array}$ & $\begin{array}{l}1.9-2 \\
1.3-2\end{array}$ & $\begin{array}{l}2.8-3 \\
2.2-3\end{array}$ & $\begin{array}{l}3.5-3 \\
2.7-3\end{array}$ & $\begin{array}{l}1.3-3 \\
1.2-3\end{array}$ & $\begin{array}{l}1.8-3 \\
1.4-3\end{array}$ \\
\hline \multicolumn{11}{|l|}{ TRANSFERS } \\
\hline Spent fuel (E) & $4,0-2$ & $3.3-2$ & $3.7-2$ & $8,8-3$ & $9.8-3$ & $1.0-2$ & $6.1-4$ & $7.8-4$ & $3.9-4$ & $4.9-4$ \\
\hline (n) & $3.0-2$ & $2.8-3$ & $1.0-2$ & $6.9-4$ & $2.3-3$ & $1.7-3$ & 4.1-5 & $3.5-4$ & $3.3-5$ & $2.1-4$ \\
\hline$(\theta)$ & $2 . n-2$ & $2.5-3$ & $3.1-3$ & $6.0-4$ & $7.1-1$ & $7.6-1$ & $3.6-5$ & $4,6-5$ & $2,8-5$ & $3.4-5$ \\
\hline \multicolumn{11}{|l|}{$\begin{array}{l}\text { Accountability tank } \\
\text { Volume }(\varepsilon)\end{array}$} \\
\hline Volume $(\varepsilon)$ & $3,0-3$ & $3.0-3$ & $3.0-3$ & $1.8-3$ & $2.1-3$ & $2,2-3$ & $1.1-4$ & $1.8-1$ & $9.2-5$ & $1.2-4$ \\
\hline (n) & $1.0-3$ & $9.2-4$ & $9.9-4$ & $2.3-4$ & $2.8-4$ & $2.9-4$ & $1,1-5$ & $1.8-5$ & $1.2-5$ & $1.5-5$ \\
\hline$(\theta)$ & $1.0-3$ & $9.2-4$ & $9.9-4$ & $2.3-4$ & $2.8-4$ & $2.9-4$ & $1.4-5$ & $1.8-5$ & $1.3-5$ & $1.1-5$ \\
\hline \multirow[t]{3}{*}{ Concentration (e) } & $1,0-2$ & $9.6-3$ & $9.9-3$ & $2.6-3$ & $3.1-3$ & $3.3-3$ & $2.0-4$ & $2,6-4$ & $1.6-4$ & $1.7-4$ \\
\hline & $3.0-3$ & $1.4-3$ & $3.0-3$ & $3.3-4$ & $1.1-3$ & $2.2-3$ & $2.0-5$ & $1.7-4$ & $1.7-5$ & $1.1-1$ \\
\hline & $3.0-3$ & $1.4-3$ & $1.6-3$ & $3,3-4$ & $4,0-4$ & 1.3-4 & $2.0-5$ & $2.5-5$ & $1.5-5$ & $2.0-5$ \\
\hline
\end{tabular}


(3) waste out : HA centrifuge sludge plutonium content (one each week); and

(4) inventories: tank volumes and concentrations and column estimates (one each day).

In the optimization calculations we did not include the aqueous and organic waste streams going from the UPAA to recovery. This reduced the number of variables describing the optimization space. These streams have a very low plutonium concentration and do not contribute significantly to materials balance uncertainty. Flow and concentration measurements are made on waste streams and are included in simulated balance calculations. Without waste streams there are 43 measurement uncertainty components for UPAA 23.

Tables E-X through E-XXVII list each measurement component, the measurement uncertainty to achieve each goal, and the relative cost of achieving each measurement uncertainty. For each goal, two cases were simulated:

(1) no recalibration during the accounting period, and

(2) periodic recalibration of the accountability tank and plutonium sample tank concentration measuring instruments, and the NDA instrument measuring the sludge.

We simulated weekly recalibrations for goal 1 , both weekly and daily recalibrations for goal 2, and daily recalibrations for goals 3 and 4.

Table $X I$ gives a summary of the dominant inventory and transfer measurements, and Table XII presents the relative cost for improving each measurement. The tables give measurement uncertainties and the relative cost of each for the four performance goals and the recalibration cases.

The dominant inventory uncertainties result from volume and concentration measurements of the HA feed tank and the 2A feed tank contents. For goal 1 with no recalibration, these two inventories have a combined standard deviation of $7.2 \mathrm{~kg}$ of plutonium, whereas the 1 -day $\sigma_{M B}$ is $8 \mathrm{~kg}$ of plutonium, with volume measurement making the larger contribution of the two components.

The dominant transfers are the accountability and plutonium sample tanks where volume and concentration measurements are made. Of the two measurement types, the concentration measuring instruments require more development.

Goal I can be achieved by current measurement technology if the transfer concentration measuring instruments are recalibrated weekly. To achieve goal 2 
TABLE XI

UPAA 23 DOMINANT MEASUREMENT UNCERTAINTIES

(10 RSD)

\begin{tabular}{|c|c|c|c|c|c|c|c|c|c|c|c|c|}
\hline \multirow[b]{2}{*}{ No. } & & & \multirow[b]{2}{*}{$\begin{array}{l}\text { Current } \\
(10) \\
\end{array}$} & \multicolumn{2}{|c|}{ Goal 1} & \multicolumn{3}{|c|}{ Goal 2} & \multicolumn{2}{|c|}{ Goal 3} & \multicolumn{2}{|c|}{ Goal 4} \\
\hline & \multicolumn{2}{|l|}{ Description } & & $\begin{array}{c}\text { No } \\
\text { Recalibration }\end{array}$ & $\begin{array}{c}\text { Weekly } \\
\text { Recalibration }\end{array}$ & $\begin{array}{c}\text { No } \\
\text { Recalibration }\end{array}$ & $\begin{array}{c}\text { Weekly } \\
\text { Recalibration }\end{array}$ & $\begin{array}{c}\text { Daily } \\
\text { Recalibration }\end{array}$ & $\begin{array}{c}\text { No } \\
\text { Recalibration }\end{array}$ & $\begin{array}{c}\text { Daily } \\
\text { Recalibration }\end{array}$ & $\begin{array}{c}\text { No } \\
\text { Recalibration }\end{array}$ & $\begin{array}{r}\text { Dally } \\
\text { Reraalibrati } \\
\end{array}$ \\
\hline \multicolumn{13}{|c|}{ INVENTORIES } \\
\hline & \multicolumn{12}{|l|}{ HA Eeed tank } \\
\hline 3 & Volume $(E)$ & & $3.0-2$ & $3.0-2$ & $3.0-2$ & $1 \cdot 3-2$ & $1.3-2$ & $1 \cdot 3-2$ & $1.9-3$ & $2.2-3$ & $1.8-3$ & $1.2-3$ \\
\hline 4 & Concentration & (E) & $1.5-2$ & $1.5-2$ & $1.5-2$ & $1.1-2$ & $1.1-2$ & $1.0-2$ & $1.8-3$ & $2 \cdot 1-3$ & $1.5-3$ & $9 \cdot 3-4$ \\
\hline & \multicolumn{12}{|l|}{ 2A feed tank } \\
\hline 14 & Volume (c) & & $3.0-2$ & $3.0-2$ & $3.0-2$ & $1.3-2$ & $1.3-2$ & $1.3-2$ & $2 \cdot 1-3$ & $2.4-3$ & $1.7-3$ & $1.2-3$ \\
\hline 15 & Concentration & (E) & $1.0-2$ & $1.0-2$ & $1.0-2$ & $8.8-3$ & $8 \cdot 3-3$ & $8.8-3$ & $1.4-3$ & $1.7-3$ & $1.1-3$ & $8.1-4$ \\
\hline & \multicolumn{12}{|l|}{ TRANSFERS } \\
\hline & \multicolumn{12}{|c|}{ Accountability tank } \\
\hline 29 & Volume (c) & & $3.0-3$ & $3.0-3$ & $3.0-3$ & $2.4-3$ & $2.7-3$ & $2.7-3$ & $1.8-4$ & $2.1-4$ & $1.6-4$ & $1.3-4$ \\
\hline 30 & (n) & & $1.0-3$ & $9.8-4$ & $1.0-3$ & $3 \cdot 3-4$ & $3.6-4$ & $3.7-4$ & $1.9-5$ & $2.2-5$ & $1.6-5$ & $1.7-5$ \\
\hline 31 & $\{\theta\}$ & & $1.0-3$ & $9.8-4$ & $1.0-3$ & $3.3-4$ & $3.6-4$ & $3.8-4$ & $1.9-5$ & $2.2-5$ & $1.3-5$ & $1.7-5$ \\
\hline 32 & \multirow[t]{3}{*}{ Concentration } & (घ) & $1.0-2$ & $9.8-3$ & $1.0-2$ & $3.7-3$ & $4.1-3$ & $4 \cdot 3-3$ & $2.8-4$ & $3.1-4$ & $1.7-4$ & $1.9-4$ \\
\hline 33 & & (n) & $3.0-3$ & $2.4-3$ & $3.0-3$ & $4.7-4$ & $1.5-3$ & $2 \cdot \theta-3$ & $2 \cdot 8-5$ & $2.1-4$ & $9.8-6$ & $1.3-4$ \\
\hline 34 & & ( $\theta)$ & $3.0-3$ & $2 \cdot 3-3$ & $3.0-3$ & $4.7-4$ & $5.2-4$ & $5.4-4$ & $2.7-5$ & $3.1-5$ & $9.7-6$ & $2.4-5$ \\
\hline & \multicolumn{12}{|l|}{ Pu sample tank } \\
\hline 35 & Volume $(E)$ & & $3.0-3$ & $3.0-3$ & $3 \cdot 0-3$ & $2.9-3$ & $2.8-3$ & $3.0-3$ & $2.3-4$ & $2.6-4$ & $1.8-4$ & $1.6-4$ \\
\hline 36 & $(n)$ & & $1.0-3$ & $9 \cdot 9-4$ & $1.0-3$ & $3.3-4$ & $3.6-4$ & $3.7-4$ & $1.9-5$ & $2 \cdot 2-5$ & $1.5-5$ & $1.7-5$ \\
\hline 37 & $(\theta)$ & & $1.0-3$ & $9.8-4$ & $1.0-3$ & $3 \cdot 3-4$ & $3.6-4$ & $3.8-4$ & $1.9-5$ & $2.2-5$ & $1.0-5$ & $1.7-5$ \\
\hline 38 & Concentration & (E) & $3.0-3$ & $3.0-3$ & $3.0-3$ & $2.9-3$ & $2.7-3$ & $3 \cdot 0-3$ & $2.3-4$ & $2.6-4$ & $6.7-5$ & $1.6-4$ \\
\hline 39 & & (n) & $2 \cdot 0-3$ & $1.9-3$ & $2 \cdot 0-3$ & $4.0-4$ & $1.3-3$ & $2.0-3$ & $2 \cdot 3-5$ & $1.8-4$ & $9.7-6$ & $1.1-4$ \\
\hline 40 & & $(\theta)$ & $2 \cdot 0-3$ & $1.8-3$ & $2.0-3$ & $4 \cdot 1-4$ & $4.6-4$ & $4.7-4$ & $2 \cdot 5-5$ & $2.7-5$ & $9.7-6$ & $2.1-5$ \\
\hline
\end{tabular}


TABLE XII

UPAA 23 DOMINANT MEASUREMENT UNCERTAINTIES RELATIVE COST

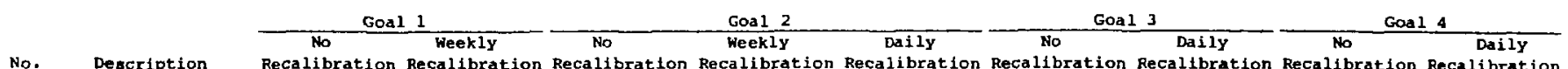
No. Description Recalibration Recalibration Recalibration Recalibration Recalibration Recalibration Recaltbration Recalibration Recalibration INVENTORIES

HA feed tark

3 Volune $(E)$

Concentration $(E)$

2A feed tan

14 Volume $(E)$

15 Concentration $(E)$

TRANSFERS

Accountability tank

$\begin{array}{lcll} & & \\ 29 & \text { volume (E) } & & 0.01 \\ 30 & (n) & & 0.02 \\ 31 & (\theta) & & 0.02 \\ 32 & \text { concentration (E) } & 0.02 \\ 33 & & (n) & 0.2 \\ 34 & & (\theta) & 0.3\end{array}$

0.01
0.02

0.02

0.02

Pu sample tank

$\begin{array}{lcll}35 & \text { Volume }(\varepsilon) & & 0 \\ 36 & (\eta) & & 0.01 \\ 37 & (\theta) & & 0.02 \\ 38 & \text { Concentration }(\varepsilon) & 0 \\ 39 & & (n) & 0.01 \\ 40 & & (\theta) & 0.09\end{array}$

0.8

1.4
0.4
1.3
0.1


0.3
2.1
2.1
1.7
5.4
5.4

1.2

0.4

1.3
0.2

1.3
0.5

1.3

0.1

0
0
0
0
0
0

0.1
1.8
1.8
1.4
1.2
4.8

0.1

1.7

1.7

0.08
4.5

0.3
2.1
2.1

2.1
0.05

0.05
4.0
4.0

32

0

1.7

0

0.01

0

22

20

14
7
13
6


15
52
51
35
106
110

1

15

727 
requires that $\imath 1 \%$ RSD volume and concentration measurements be made in process tanks; $20.3 \%$ RSD precision, $20.04 \%$ RSD calibration, and $20.04 \%$ RSD standards for volume measurements be made in primary transfer tanks; and ఒ0.3\% RSD precision, $20.2 \%$ RSD calibration, and $20.05 \%$ RSD standards for concentration measurements be made on samples from primary transfer tanks. To achieve goals 3 and 4 requires that measurement uncertainties be decreased by more than an order of magnitude.

Periodic recalibration of key instruments has a striking effect. For goal 2, as an example, compare the weekly, daily, and no recalibration cases for the $\eta$ concentration error components of the accountability tank. Compared to the no recalibration case, weekly and daily recalibrations permit increasing $\eta$ by a factor of 23 and $\sim 6$, respectively. Also note that the relative cost of achieving goal 2 is decreased by $\imath 30 \%$ for weekly recalibration.

\section{UPAA 2: Codecontamination/Partitioning Processes}

The chemical separations UPAA can be divided into two by adding a flow and concentration measurement to the IAPU stream (see Sec. II.C). Materials balances are drawn once each day about the codecontamination/partitioning processes by combining the following measurements :

(1) feed transfer : accountability tank volume and concentration (one each day);

(2) product transfer: IAPU stream flow and concentration (every half hour);

(3) waste out: HA centrifuge sludge plutonium content (one every week); and

(4) inventories: tank volumes and concentrations and column estimates (one each day).

There are 28 measurement uncertainty components for UPAA 2. Measurement uncertainties that meet each of the four performance goals for selected recalibration cases are shown in Tables E-XIX through E-XXVIII. We simulated periodic recalibration only for the accountability tank concentration and the IAPU stream flow and concentration instruments.

The dominant inventory term in UPAA 2 is the HA feed tank. If we compare UPAA 23 and UPAA 2 HA feed tank volume and concentration measurement uncertainties that are required to meet a specific goal, we find that 
UPAA 2 uncertainties can be larger, hence have a lower development cost. This is because the total inventory in UPAA 2 is less than that in UPAA 23. This illustrates control of smaller in-process inventories by UPAA partitioning.

The dominant transfers are the accountability tank and the IAPU stream. Accountability tank measurement requirements for UPAA 2 are tighter than for UPAA 23 , because the IAPU stream flow and concentration measurements are not as precise or accurate as those for the plutonium sample tank.

For UPAA 2, goal I abrupt is achievable by current technology. Achieving goal i protracted requires $230 \%$ decrease of the accountability tank $\theta$ concentration uncertainty and the $\eta$ flow rate uncertainty; $\imath 25 \%$ decrease of the IAPU $\theta$ concentration uncertainty; and $\imath 50 \%$ decrease of the IAPU $\theta$ flow uncertainty. Goal 2 is achievable by modest improvements in in-process inventory measurements and by about an order of magnitude improvement in transfer correlated errors. Goals 3 and 4 require about an order of magnitude decrease of in-process inventory measurement uncertainties and about two orders of magnitude decrease in transfer correlated uncertainties.

\section{UPAA 3: Uranium-Plutonium Copurification Process}

Materials balances are drawn once daily about the uranium-plutonium copurification process by combining the following measurements :

(1) feed transfers : IAPU stream flow and concentration (every half hour);

(2) product transfer: plutonium product sample tank volume and concentration (two each day);

(3) inventories: tank volumes and concentrations and column estimates (one each day).

There are 27 measurement uncertainty components in UPAA 3 . UPAA 3 optimization results are given in Tables $E-X X V 1 l l$ through $E-X X X I V$ and are similar to those of UPAA 2. For UPAA 3 the dominant inventory uncertainty is the $2 \mathrm{~A}$ feed tank, and the dominant transfer uncertainties are the IAPU stream and the plutonium sample tank. The relatively poorer quality transfer measurements for the IAPU stream require a greater decrease in plutonium sample tank measurement uncertainties than is required for UPAA 23. 


\section{IMPACT OF THE HEF PROCESS DESIGN ON MATERIALS ACCOUNTING}

\section{A. Introduction}

Features of process design and operation affect the application to a reprocessing facility of both conventional and NRTA methods. ${ }^{2,5,20}$ This section considers the impact of the Oak Ridge HEF process design on safeguards, with special emphasis on the ability to apply advanced materials measurement and accounting techniques. The safeguards system guards against the loss of source and special nuclear material and provides timely indication of possible loss or credible assurance that no loss has occurred. The safeguards systems designer strives to meet required performance goals with minimum process interference. The process designer should consider changes in design and operation that may enhance the effectiveness of materials accounting without sacrificing production capacity or operating convenience. The more frequent the upsets and interruptions, the more vulnerable the process becomes to loss of nuclear materials.

This section describes some requirements for effective materials accounting. We discuss design features of the HEF process that may hinder the application of effective materials accounting techniques and some possible changes that could facilitate their application.

\section{B. Some Requirements for Effective Materials Accounting}

Effective near-real-time materials accounting requires accurate and precise measurements of key materials transfers (feed and product) and measurements or estimates of sidestreams and in-process inventories of process vessels. Where there is high plutonium throughput, the relative accuracy between feed and product measurements limits long-term detection sensitivity. ${ }^{65,66}$ The process designer should control long-term relative errors between feed and product measurements by careful design of the sampling, measurement, and calibration hardware and procedures. ${ }^{33,67-69}$ He should design feed and product accountability vessels for accurate calibration and make possible frequent calibration checks and periodic recalibrations. The best applicable sampling and assay techniques should be used.

In near-real-time materials accounting, precision of in-process inventory measurements and variability of any unmeasured holdup are the limiting uncertainties in short-term detection. ${ }^{66}$ Most of the inventory should be in vessels 
that are instrumented for on-line measurements. Even if precise measurements are possible, large buffer-storage tanks may introduce large absolute errors that will seriously degrade the short-term detection sensitivity. Relatively minor holdups and sidestreams have little effect on detection sensitivity, and estimates based on historical data will serve until these components are measured, for example, during a physical inventory. The effect of in-process inventory on short-term detection sensitivity is minimized by operating the process near steady state. In case of a severe upset, the ability to drain in-process material into instrumented tanks and then to recover normal operation aids materials accounting and control.

Well-defined input and output batches also facilitate materials accounting. Continuous operation requires continuous measurements of process streams. If there are significant recycle streams, input-output correlations will be of limited value. Semicontinuous operation approximates continuous operation and maintains batch definition by feeding alternately from two or more tanks that are designed for accurate and precise volume and concentration measurements. The decrease in volume of solution in the tanks determines the quantity of material that has entered the process.

\section{HEF Process Design Features and Their Effect on Materials Accounting}

The HEF process has several design features that restrict application of advanced materials measurement and accounting techniques. The dissolution and feed preparation area, in particular, has some novel features that require additional testing on a laboratory and pilot-plant scale before incorporation into the HEF, such as the voloxidizer, the continuous dissolver, and the constantvolume accountability tank. The effect of elements in other areas of the process also requires assessment. In addition to these specific features, we discuss some general aspects of the HEF process.

1. Voloxidizer. The voloxidizer is designed to remove tritium from the chopped spent fuel before aqueous processing. 70 Voloxidation should remove 90-99\% of the tritium and convert it to tritiated water. However, some iodine, krypton, and volatile fission products are volatilized as well, and an additional process is required to separate these gases from each other and also to remove 
various aerosols. If only stainless-steel-clad fuel is to be reprocessed, voloxidation may not be necessary, because the tritium should diffuse readily through the stainless-steel cladding while the fuel is in the reactor.

The voloxidizer heats the chopped fuel to the range $450-650^{\circ} \mathrm{C}$ in an oxidizing atmosphere. The oxidation of $\mathrm{UO}_{2}$ to $\mathrm{U}_{3} \mathrm{O}_{8}$ may cause the fuel to crumble to a fine powder, and the accompanying increase in volume is expected to crack the cladding. Although it would be expected that $\cup_{3} \mathrm{O}_{8}$ powder with its larger surface area would dissolve more rapidly, there is evidence that clad $\cup_{2}$ and powdered $\mathrm{U}_{3} \mathrm{O}_{8}$ fuel dissolve at about the same rate. Voloxidation almost doubles the amount of insoluble material. 71 The insoluble residue from voloxidized fuel contains more plutonium than does the residue produced without voloxidation. 72 The conditions of fuel pellet fabrication and irradiation histories also influence dissolution characteristics, but subsequent voloxidation always markedly increases the insoluble plutonium. ${ }^{70-73}$. This larger quantity complicates subsequent processing and materials accounting.

The voloxidizer is to be operated continuously. A batch of sheared fuel will be transferred to the voloxidizer and a product batch will be discharged every $1.2 \mathrm{~min}$. These operating conditions make measurement or estimation of the in-process inventory complicated if not impossible. Residual holdup (material remaining after runout and cleanout) can only be measured during shutdown at the end of a campaign. The voloxidizer configuration complicates holdup measurement.

2. Continuous Dissolver. The HEF uses a continuous dissolver rather than the submerged-basket type to maintain a continuous off-gas flow and to keep undissolved solids in suspension. The continuous dissolution system consists of a rotating cylindrical dissolver followed by two digester surge tanks. The dissolver is divided into nine compartments: a feed compartment, seven dissolution stages, and a compartment where the hulls are rinsed before discharge from the dissolver. Chopped fuel proceeds though the dissolver in batches, with a residence time of $0.5 \mathrm{~h}$ per dissolution stage. There is a continuous counterflow of nitric acid from stage 7 to the feed compartment, and the continuous product stream of dissolved fuel flows from the feed compartment to the digester surge tanks. 
The continuous dissolver is an incubus for materials accounting. There is always an in-process inventory of plutonium and uranium, and this inventory is a cornbination of solution, suspended matter, and undissolved solids. A new batch of fuel enters the feed compartment every $0.5 \mathrm{~h}$ and product solution leaves continuously. Under these conditions, estimation of the in-process inventory is extremely complex if not impossible. Backmixing in the rotary dissolver could lead to a buildup in inventory and the possibility of a criticality incident. The configuration of the continuous dissolver makes cleanout and measurement of residual holdup difficult.

3. Primary Centrifuge. Product solution from the continuous dissolver and the digester surge tanks is clarified in the primary centrifuge before transfer to the feed solution surge tank. The undissolved solids contain primarily fission products, cladding fines, and corrosion products, as well as some plutonium. Enough insoluble residue remains, particularly if the spent fuel has undergone voloxidation, to disrupt the first solvent extraction cycle. Separation of these solids is challenging because they consist of 1 - to $15-\mu \mathrm{m}$ particles. There is evidence that centrifugation alone will not clarify the solution, but that a combination of centrifugation and filtration or centrifugation and an organic flocculent may be required. ${ }^{74-76}$ The centrifugal contactors used in the first solvent extraction cycle require relatively complete removal of solids.

The treatment given solids separated in the primary centrifuge depends on their nuclear materials content. Centrifuge solids that exceed fissile specification are to be transferred to the secondary dissolution cycle. We need methods for obtaining a representative sample of the solids and analyzing it for nuclear materials content, and for subsequently transferring the solids either to the secondary dissolution cycle or to high-level liquid waste storage.

4. Accountability Tank. The accountability tank is the first point in the HEF process at which we can make accurate and precise measurements of the quantity of nuclear materials and their isotopic composition. Quantity is determined from concentration and volume measurements. Isotope dilution mass spectrometry determines concentration. Volume measurement should equal or closely approach concentration measurement in accuracy and precision. 
The accountability tank in the HEF process receives feed from the feed solution surge tank. The volume of solution in the accountability tank is measured by first filling the tank above the overflow line in the necked-down section at its top. The solution is then air-sparged to assure homogeneity. An airlift returns excess solution to the feed solution surge tank by way of the overflow line, which runs uphill.

The above procedure is intended to ensure that the volume of solution in the accouritability tank is precisely known and is essentially identical from batch to batch. Additional laboratory and pilot-plant-scale experiments may be required to demonstrate these concepts. We must show that an airlift can precisely and reproducibly adjust the solution level in the neck of the accountability tank. We must also demonstrate that air sparging can homogenize all the solution in the tank, including the portion in its neck above and below the overflow line.

5. In-Process Inventories. Near-real-time materials accounting requires frequent closure of materials balances by measuring or estimating in-process inventories of the principal vessels and columns and all significant materials flows. Because high-quality techniques for direct measurement are not available, we infer in-process inventories of contactors from measurements of flow and concentration on inlet feed, extractant, scrub, out let product, and waste streams. ${ }^{77-80}$ We can obtain many of these measurements from process control instrumentation, but additional on-line instrumentation to nondestructively determine concentrations at important measurement points is desirable. Contactor models use measurement results for estimating in-process inventory. ${ }^{81,82}$

Mathematical models for simulating complex extraction processes are important for safeguards, as well as for process design and control. In reprocessing breeder reactor fuels, the Purex process must be adapted to the uranium-plutonium ratio, radioactivity, and heat generation encountered with these fuels. For example, because of high radioactivity, contact times during extractions are kept short. Whether pulsed columns or centrifugal contactors are more suitable is still undecided. ${ }^{76}$ From a safeguards standpoint, centrifugal contactors are preferable, because of their smaller in-process inventories.

The fourth and fifth solvent-extraction cycles are designed for uraniumplutonium copurification. Mathematical models must be developed and validated 
for the specific extraction processes of the HEF, which will require quantitative experimental data on mixed systems. On-line instruments for measurement of both plutonium and uranium concentrations will be required at some measurement points.

In-process inventory estimation for some process vessels, such as the plutonium stripper and the plutonium concentrator, would be very difficult by direct measurements. Instead, on-line concentration and flow measurements could be made on the streams that enter the plutonium stripper and leave the plutonium concentrator or on the solution in the plutonium stripper feed tank and the plutonium catch tank.

6. Coprocessing. The HEF process design allows coprocessing of uranium and plutonium from uranium-plutonium oxide fast breeder fuels. Uranium and plutonium in the dissolver solution are codecontaminated and partially separated in the first and second solvent extraction cycles. Uranium is added to the plutoniurn stream at the beginning of the fourth extraction cycle to increase the uranium-to-plutonium ratio of the feed solution from 0.13:1 to 2:1. Copurification is performed in the fourth and fifth extraction cycles.

Coprocessing has no safeguards advantage over partitioning. On the contrary, greater quantities of material must be handled in a coprocessing facility to achieve a given throughput of fissile material, and this will probably have a deleterious effect on materials accounting. In addition, concentration measurements and in-process inventory estimates of both plutonium and uranium will be required at various points in the fourth and fifth solvent extraction cycles.

7. Recycle Streams. The process design of the HEF incorporates all possible flexibility to allow economical plant operation and the reworking of off-specification materials. As a result, there are numerous recycle loops to facilitate intraplant transfers of material. The recycle routes significantly complicate partitioning the process into UPAAs and establishing correlations based on feed and product measurements. To alleviate these problems, we should make flow and concentration measurements on all recycle streams that cross UPAA boundaries.

8. Inaccessibility. Plant design philosophy is extremely important in a materials accounting system. It affects not only the accessibility of nuclear 
materials but also measurement strategy and access to instrumentation for calibration, repair, and replacement. If sample lines are allowed to penetrate the cell wall to transport nuclear materials to an instrument gallery, the choice of analytical instruments and techniques is greatly increased. At the same time, effects of the hostile environment on instrumentation and quality of measurements are decreased and instrument maintenance is simplified. In the case of in-line instrumentation, it is desirable that only the sensor be in the process cell and that other components be in an area shielded from radioactivity and process fumes. 


\section{SUMMARY AND CONCLUSIONS}

\section{A. Summary}

In this study, we calculated materials measurement uncertainties for instruments used by an NRTA system that meet four different performance goals. The first two goals were chosen to represent a range of measurement capabilities, from state-of-the-art measurements to those that may be attainable in the next decade if an aggressive instrument development program is undertaken. The third and fourth goals correspond to desired international and domestic goals. Each performance goal includes an abrupt and a protracted goal for given detection and false-alarm probabilities.

The facility MMAS combines conventional materials accounting and NRTA and serves several functions including process monitoring, domestic safeguards, and international safeguards. It employs sampling and chemical analysis, weight and volume measurements, and NDA instrumentation, supported by data base management and data analysis techniques. We described a conventional accounting strategy that divides the facility into five MBAs and formulated two NRTA accounting strategies that augment the MBA structure. In the first strategy, feed preparation processes were treated as one UPAA (UPAA 1) and chemical separations processes were treated as another (UPAA 23 ). In the second, the chemical separations UPAA was further subdivided into UPAA 2 (codeconlamination/partitioning processes) and UPAA 3 (uranium-plutonium copurification processes).

We identified measurement points for NRTA strategies and chose applicable measurement types and errors representative of current technology based on materials and process descriptions. The reference measurements are used for process control and materials accounting.

We used optimization techniques to calculate measurement uncertainties so that performance goals for detecting materials loss are achieved while total development cost of the instruments is minimized. The cost of improving each measurement uncertainty component is determined by a hyperbolic cost function. Therefore, where calculated measurement uncertainty is less than what is currently achievable, a development cost was imposed. Because the cost function is nonlinear, we used a nonlinear optimization technique to calculate measurement uncertainties so that instrument development cost is ininimized. 
We calculated measurement uncertainties that meet the four accountability performance goals for each UPAA and for several cases of instrument recalibration. For each UPAA, values for the measurement uncertainty components were restricted by specific ranges and by the materials balance standard deviation equations for abrupt and prot racted losses.

Table XIII lists materials balance standard deviations for each UPAA for both one-day and six-month materials balances using current measurement technology (Table VI). The feed preparation UPAA (UPAA 1) has larger materials balance standard deviations than the others because it has more in-process inventory, and the input transfer measurements (spent-fuel NDA) are not well characterized. Because the in-process inventory in either LPAA 2 or UPAA 3 is smaller than that of UPAA 23 (remember that UPAA 23 comprises UPAA 2 and UPAA 3), the one-day materials balance standard deviations are smaller for UPAA 2 and UPAA 3 than for UPAA 23 . The six-month materials balance standard deviations for UPAA 2 and UPAA 3 are larger than those of UPAA 23

TABLE XIII

MATERIALS BALANCE STANDARD DEVIATIONS WITH CURRENT MEASUREMENT TECHNOLOGY

\begin{tabular}{ll}
1 Day & 6 Months \\
$\underline{(\mathrm{kg} P u)}$ & $\underline{(\mathrm{kg} P \mathrm{Pu})}$ \\
\hline
\end{tabular}

UPAA 1

No recalibration $\quad 11.6 \quad 636$

Weekly recalibration $\quad 11.6 \quad 373$

UPAA 23

No recalibration $\quad 7.6 \quad 93$

$\begin{array}{lll}\text { Weekly recalibration } & 7.6 & 72\end{array}$

UPAA 2

No recalibration $\quad 5.9 \quad 289$

Weekly recalibration $\quad 5.9 \quad 109$

UPAA 3

No recalibration $\quad 5.5 \quad 284$

Weekly recalibration $\quad 5.5 \quad 114$ 
because the intermediate transfer measurement that divides the chemical separations process area into two UPAAs is of lower quality than either the accountability or the plutonium sample tank measurements.

Table XIV lists relative costs for developing the instrument systems that meet each performance goal. One cost unit is the relative cost of attaining a measurement uncertainty that is one-half that of current measurement technology. Each halving of measurement uncertainty costs twice what the previous halving did, plus 1. UPAA 23 with weekly recalibration of the plutonium concentration measuring instruments for the accountability and product sample tanks will meet goal 1. Hence, the total development cost of the system is zero. If periodic recalibration of key transfer measurements is performed, the relative cost of the system can be reduced by $30 \%$ or more. The relative cost of achieving goals 3 or 4 is between 20 and 50 times more than the cost for achieving goal 2.

We identified dominant inventory and transfer measurement uncertainty terms, which are those absolute measurement uncertainties that contribute most to materials balance uncertainty. Dominant inventory uncertainties result either

TABLE XIV

RELATIVE COST OF ACHIEVING THE PERFORMANCE GOALS

Goal 1 Goal 2 Goal 3 Goal 4

UPAA 1

No recalibration Weekly recalibration Daily recalibration

20

9

-

0.8

0

$-$

Weekly recalibration

Daily recalibration

UPAA 2

No recalibration

Weekly recalibration

Daily recalibration

UPAA 3

No recalibration

Weekly recalibration

Daily recalibration
11

2

$-$

9

1.7

$-$
111

64

53

32

22

19

74

36

28

1404

$-$

595

2023

$-$

853

2546

1350

1544

738

65

29

21
1263

1666

$-$

518 
from large inventories or poor measurements of the inventory. In feed preparation processes, the dominant inventory uncertainties result from in-process inventory estimates in the shear, voloxidizer, and continuous dissolver, and volume and concentration measurements in the digesters and feed solution surge tank. In chemical separations processes, the dominant inventory uncertainties result from volume and concentration measurements of the $\mathrm{HA}$ and $2 \mathrm{~A}$ feed tanks. The dominant transfer terms occur where the bulk of the material is transferred, that is, the input to the shear, the accountability tank, the IAPU stream, and the plutonium product sample tank. Of those transfer points, the NDA instrument for spent fuel and flow and concentration measurements for the IAPU stream require the most development.

We developed a dynamic computer model of the HEF feed preparation and chemical separations processes. Modeling and simulation of these processes allow prediction of the dynamic behavior of materials flows and inventories and materials measurements over any specified range of operating parameters. The model also allows rapid accumulation of data representative of relatively long operating periods. Because our optimization calculations used nominal values for process variables and did not include waste streams, we applied a dynamic model of the measurement system, based on the optimally calculated measurement uncertainties, to the simulated process data. Materials balance standard deviations obtained from these simulations agreed with the optimization results.

We considered the impact of the HEF process design on safeguards, with special emphasis on the ability to apply advanced materials measurement and accouriting techniques. Major areas of concern are the voloxidizer, the continuous dissolver, clarification of dissolver solutions, the accountability tank, the estimation of in-process inventories in solvent-extraction contactors and other process vessels, recycle streams, and the analysis of waste solutions.

\section{B. Conclusions}

For feed preparation processes, the performance goals cannot be met by current measurement technology. Materials accounting is complicated by in-process inventories and spent-fuel assembly transfers that are difficult to measure. To alleviate these problems, we should reduce inventories wherever possible, refine spent-fuel NDA techniques and develop standards, and consider frequent flushouts of the feed preparation process. 
For the chemical separations area (UPAA 2 3), we can attain an abrupt loss-detection sensitivity of $15 \mathrm{~kg}$ of plutonium and a protracted loss-detection sensitivity of $150 \mathrm{~kg}$ of plutonium with current measurement technology. These loss-detection sensitivities have $50 \%$ detection probability and $2.5 \%$ false-alarm probability. If it is desirable to subdivide the chemical separations process and maintain loss-detection sensitivity, then we must develop a flow meter with measurement uncertainties comparable to those for the accountability rank or add buffer accountability tanks at the $2 \mathrm{~A}$ feed tank location.

Achieving performance at the second level $(8 \mathrm{~kg}$ of plutonium abrupt and 40 $\mathrm{kg}$ of plutonium protracted) seems to be a reasonable goal for the chemical separations area of the HEF. This requires improving in-process inventory measurement uncertainty to $\approx 1 \%$ precision for process tank volume and concentration measurements. It also requires improving accountability and plutonium sample tank transfer measurement uncertainties to $20.04 \%$ RSD volume calibration, $20.04 \%$ RSD volume standards, $20.1 \%$ RSD concentration calibration, and $20.05 \%$ RSD concentration standards.

Goals 3 and 4 require inventory measurement or estimate errors $<0.2 \%$ RSD, transfer random errors $<0.03 \% \mathrm{RSD}$, and transfer correlated errors $<0.002 \%$ RSD. In comparison, today's primary standards have errors of $20.04 \%$. Clearly, proposed international and domestic safeguards goals cannot be achieved without major breakthroughs in measurement technology and standards preparation.

The optimization methodology developed for this study can identify measurement uncertainty components that dominate materials balance standard deviations and instruments that require development to meet specific performance goals. Further study is needed to determine the sensitivity of the results to costs and the constraints of measurement uncertainties.

The following will facilitate materials accounting in the HEF.

I. Development and implementation of measurement control programs are vital. Accountability instruments at key materials flow measurement points need frequent recalibration. Otherwise, correlat ons between flow measurements can degrade detection sensitivities to unacceptably low levels. Computer-controlled dynamic calibration techniques should be investigated for on-line measurements. Measurement control programs should identify error sources. 
2. Proper characterization of standards for key transfer measurement points is required. Errors in standards can dominate long-term lossdetection sensitivities.

3. Research and development resources should be concentrated on the development of measurement-control programs, of representative standards, and of volume, flow, and concentration measurements at key transfer measurement points.

4. In-process inventory of individual process vessels should be reduced. Large in-process inventories dominate the short-term detection sensitivity performance.

5. Further subdivision of process areas into unit process accounting areas is not always advantageous. The effectiveness of subdivision depends on the availability of appropriate measurement technology. 


\section{ACKNOWLEDGMENTS}

This work was supported by the US Department of Energy/Office of Safeguards and Security.

The cooperation and assistance of H. Kerr, R. Hurt, E. Blakeman, and T. Hebble of Oak Ridge National Laboratory are gratefully acknowledged. Measurements representative of current technology and cost functions were developed in consultation with Oak Ridge. Thanks are due to our colleagues J. P. Shipley, E. A. Hakkila, and D. D. Cobb for their helpful suggestions and to R. Marshall for his assistance in selecting measurements representative of current technology. We wish to express our gratitude to 5 . L. Klein and $K$. C. Eccleston for the preparation of the report and to M. S. Scott, M. J. Roybal, and L. Bonner for the preparation of the graphics. 
ORNL is designing the HEF as part of the CFRP. The conceptual design of the HEF, as presented in the Interim Design Report, ${ }^{7}$ represents a versatile pilot-scale reprocessing facility that is capable of storing and reprocessing breeder and light-water reactor spent fuels. The process flow sheets are designed to provide for reprocessing three broad classes of fuel:

- thorium-uranium,

- thorium-uranium-plutonium, and

- uranium-plutonium.

The flow sheets were revised in June 1979 and again in April 1980 to emphasize the uranium-plutonium breeder-reactor fuel cycle. 8,83 Hence, this study is concerned only with reprocessing uranium-plutonium fuels.

The basic design philosophy of minimizing personnel radiological exposure by limiting access to materials within the plant has led to a facility designed for remote maintenance. The cell complex is in the form of an $\mathrm{H}$, with two long parallel cells joined in the middle by a third cell. One of the parallel arms houses the high-level-radiation activities, such as fuel shearing, voloxidation, dissolution, feed adjustment, and waste disposal. The other long arm is dedicated to lower-level-radiation activities, such as product purification, mixed-oxide production, product packaging, and analytical chemistry. An extensive network of service corridors, plug galleries, operating galleries, decontamination and maintenance cells, contact maintenance facilities, cask and truck locks, and fuel receiving and storage facilities provides maintenance for the process cells. Remote, overhead cranes and manipulators and floor-mounted manipulators provide maintenance for process cell equipment. A computer-cont rolled, remote sampling vehicle is available for process sampling.

The HEF uses a modified Purex process flow sheet that incorporates coprocessing of uranium and plutonium instead of the usual plutonium purification process. The flow sheet is based on breeder reactor fuel having (1) a maximum burnup of 150000 megawatt-days per tonne, (2) a minimum 60-day decay period before shipment to the HEF, and (3) a minimum 90-day decay period before reprocessing. The facility design also provides for the conversion of mixed 
uranium-plutonium nitrate to oxide. The design capacity is 0.5 tonne of fuel per day. The process description presented in the following sections is based on information found in Refs. 7 and 83.

\section{FUEL RECEIVING AND STORAGE}

The fuel receiving and storage system receives spent fuel in rail or truck shipping casks. Next, the fuel assemblies are cleaned of any sodium, assayed to determine their fissile content, and then stored until they enter the mechanical processing and feed preparation steps. Three types of spent-fuel receipts are anticipated: (1) clean fuel assemblies received in helium-pressurized casks, (2) assemblies sealed in sodium-filled canisters within helium-pressurized casks, and (3) assemblies received in sadium-filled casks.

Clean fuel assemblies can be transferred directly to NDA and then to fuel storage, whereas other fuel assemblies must be cleaned to remove sodium contamination before assay and storage. Assembly fragments (scrap) from the cleaning operation are sent to the batch dissolver. Sediments from cleaning that contain nuclear material are recycled through the rework process. Effluents from the fuel-storage and waste-pool filters are transferred to the batch dissolver and to the decontamination waste treatment process, respectively.

\section{DISSOLUTION AND FEED PREPARATION}

The mechanical processing and feed preparation process, as diagrammed in Fig. A-1, consists of (1) mechanical disassembly and shearing, (2) voloxidation, (3) dissolution, (4) feed clarification, and (5) accountability measurement. Process stream characteristics are given in Table A-I.

Mechanical disassembly and shearing involve removal of the two fuelassembly end fittings (one by a plasma torch or laser and the other by a roller cutter) removal of the shroud, and shearing of the fuel rods (into short iengths) up to the gas plenum. The end fittings, shroud, and gas plenum are discarded to the metal scrap disposal system on a 3.14-h cycle. Metal fragments (swarf) from the plasma-torch operation are discarded to metal scrap on a 40-day cycle. 
TABLE A-I

MECHANICAL PROCESSING AND FEED PREPARATION STREAM CHARACTERISTICSa

\begin{tabular}{|c|c|c|c|c|c|c|c|c|c|}
\hline $\begin{array}{l}\text { Stream } \\
\text { Ident. }\end{array}$ & Description & $\begin{array}{c}\text { Uranium, } \\
\mathrm{kg} / \mathrm{h} \\
(\mathrm{kg} / \mathrm{batch}) \\
\end{array}$ & $\begin{array}{c}\text { Plutonium, } \\
\mathrm{kg} / \mathrm{h} \\
(\mathrm{kg} / \text { hatch })\end{array}$ & $\begin{array}{c}\text { Total Mass } \\
\mathrm{kg} / \mathrm{h} \\
(\mathrm{kg} / \mathrm{batch}) \\
\end{array}$ & $\begin{array}{l}\text { Cycle } \\
\text { Time } \\
\mathrm{h} \\
\end{array}$ & $\begin{array}{c}\text { Transfer } \\
\text { Time } \\
\text { min } \\
\end{array}$ & $\begin{array}{l}\text { Elow } \\
\text { Rate } \\
\mathrm{L} / \mathrm{h} \\
\end{array}$ & $\begin{array}{c}\mathrm{HNO}_{3} \\
\text { Molarity. }\end{array}$ & $\begin{array}{l}\text { Associated Vessel and } \\
\text { Maximum Plutonium Inventory }\end{array}$ \\
\hline \multirow{13}{*}{ Sware } & Disassembly shear input & $(50.90)$ & $(14.58)$ & $(210.29)$ & $3 \cdot 14$ & - & - & - & Disassembly shear, $15 \mathrm{~kg}$ \\
\hline & Disassembly shear scrap & - & - & $(93.86)$ & $3 \cdot 14$ & - & - & - & \\
\hline & Metal fragments & - & - & $(91.72)$ & 960.0 & - & - & - & \\
\hline & Voloxidizer input & $(50.90)$ & $(14.58)$ & $(116.13)$ & 3.14 & - & - & - & Voloxidizer, $27 \mathrm{~kg}$ \\
\hline & Continuous dissolver feed & 16.21 & 4.64 & 33.43 & - & - & - & - & Continuous dissolver, $19 \mathrm{~kg}$ \\
\hline & $\begin{array}{l}\text { Continuous dissolver feed } \\
\text { acid }\end{array}$ & - & - & 87.94 & - & - & 65.53 & 9.71 & \\
\hline & $\begin{array}{l}\text { Continuous dissolver rinse } \\
\text { acid }\end{array}$ & - & - & 36.38 & - & - & $34 \cdot 32$ & 0.527 & \\
\hline & Hulls to hull drier & $(0.01)$ & $(0.005)$ & $(6.90)$ & 0.5 & - & - & 0.104 & \\
\hline & $\begin{array}{l}\text { off-specification hulls } \\
\text { to batch dissolution }\end{array}$ & $(0.96)$ & $(0.48)$ & $(57.64)$ & $48 \cdot 0$ & - & - & - & \\
\hline & Digester feed solution & 16.19 & 4.63 & 153.36 & - & - & 106.62 & 3.66 & Digesters $1 \& 2,28 \mathrm{~kg}$ each \\
\hline & $\begin{array}{l}\text { Primary centrifuge feed } \\
\text { from digesters }\end{array}$ & $(97.14)$ & $(27.77)$ & $(863.85)$ & 6.0 & 30 & - & 3.83 & Primary centrifuge, o kg \\
\hline & $\begin{array}{l}\text { Primary centrifuge feed from } \\
\text { batch dissolver surge tanks }\end{array}$ & - & - & $(31 \cdot 14)$ & $6 \cdot 0$ & 10 & - & 12.94 & \\
\hline & $\begin{array}{l}\text { Primary centrifuge rinse from } \\
\text { batch dissolver surge tanks }\end{array}$ & - & - & $(41.02)$ & $6 \cdot 0$ & 10 & - & 0.508 & \\
\hline
\end{tabular}


TABLE A-I (cont)

\begin{tabular}{|c|c|c|c|c|c|c|c|c|c|}
\hline $\begin{array}{l}\text { Stream } \\
\text { Ident. }\end{array}$ & Description & $\begin{array}{c}\text { Uranium, } \\
\mathrm{kg} / \mathrm{h} \\
\text { (kg/batch) } \\
\end{array}$ & $\begin{array}{c}\text { Plutonium, } \\
\mathrm{kg} / \mathrm{h} \\
\text { (kg/batch) }\end{array}$ & $\begin{array}{c}\text { Total Mass } \\
\mathrm{kg} / \mathrm{h} \\
(\mathrm{kg} / \mathrm{batch}) \\
\end{array}$ & $\begin{array}{c}\text { Cycle } \\
\text { Time } \\
\mathrm{h} \\
\end{array}$ & $\begin{array}{c}\text { Transfer } \\
\text { Time } \\
\text { min } \\
\end{array}$ & $\begin{array}{l}\text { Flow } \\
\text { Rate } \\
\mathrm{L} / \mathrm{h} \\
\end{array}$ & $\begin{array}{c}\mathrm{HNO}_{3} \\
\text { Molarity }\end{array}$ & $\begin{array}{l}\text { Associated Vessel and } \\
\text { Maximum Plutonium Inventory }\end{array}$ \\
\hline & $\begin{array}{l}\text { Secondary dissolver surge } \\
\text { tank feed }\end{array}$ & $(2.21)$ & $(1.20)$ & $(43.97)$ & 6.0 & 10 & - & 9.62 & $\begin{array}{l}\text { Secondary dissolver surge tank, } \\
5 \mathrm{~kg}\end{array}$ \\
\hline & Secondary dissolver feed & $(8.84)$ & $(4.78)$ & $(181.15)$ & 24.0 & 30 & - & $9 \cdot 32$ & Secondary dissolver, $10 \mathrm{~kg}$ \\
\hline & Primary centrifuge centrate & $(95.60)$ & $(26.65)$ & $(891.72)$ & 6.0 & 30 & - & 3.63 & \\
\hline & $\begin{array}{l}\text { Leached solids centrifuge } \\
\text { feed }\end{array}$ & $(8.84)$ & $(4.78)$ & $(181.66)$ & 24.0 & 30 & & 8.50 & \\
\hline & $\begin{array}{l}\text { Leached solids centrifuge } \\
\text { centrate }\end{array}$ & $(8.84)$ & $(4.78)$ & $(302.35)$ & 24.0 & 30 & - & 4.58 & \\
\hline & $\begin{array}{l}\text { Solids sample tank feed from } \\
\text { leached solids centrifuge }\end{array}$ & $(0.49)$ & $(0.27)$ & $(171.47)$ & 24.0 & 10 & - & 0.653 & \\
\hline & $\begin{array}{l}\text { Solids sample tank feed from } \\
\text { HA centrifuge }\end{array}$ & - & - & $(13.67)$ & 7 days & 5 & - & 12.78 & \\
\hline & $\begin{array}{l}\text { Solids sample tank recycle } \\
\text { to leached solids centrifuge }\end{array}$ & $(0.49)$ & $(0.27)$ & $(141.89)$ & 24.0 & 30 & - & 0.731 & \\
\hline & $\begin{array}{l}\text { Solids sample tank to high- } \\
\text { level waste }\end{array}$ & $\left(0.52 \times 10^{-3}\right)$ & $\left(0.28 \times 10^{-3}\right)$ & 34.71 & 24.0 & 10 & - & 0.289 & \\
\hline & $\begin{array}{l}\text { Feed solution surge tank } \\
\text { input }\end{array}$ & (389) & $(111)$ & $(3860)$ & 24.0 & 20 & - & 3.72 & $\begin{array}{l}\text { Feed solution surge tank, } \\
111 \mathrm{~kg}\end{array}$ \\
\hline & Accountability tank feed & (389) & $(111)$ & $(3980)$ & 24.0 & 20 & - & 3.62 & Accountability tank, $111 \mathrm{~kg}$ \\
\hline
\end{tabular}

afrom drawings 52-B-201, 52-B-203, and 52-B-204 (Ref. 83 ). 


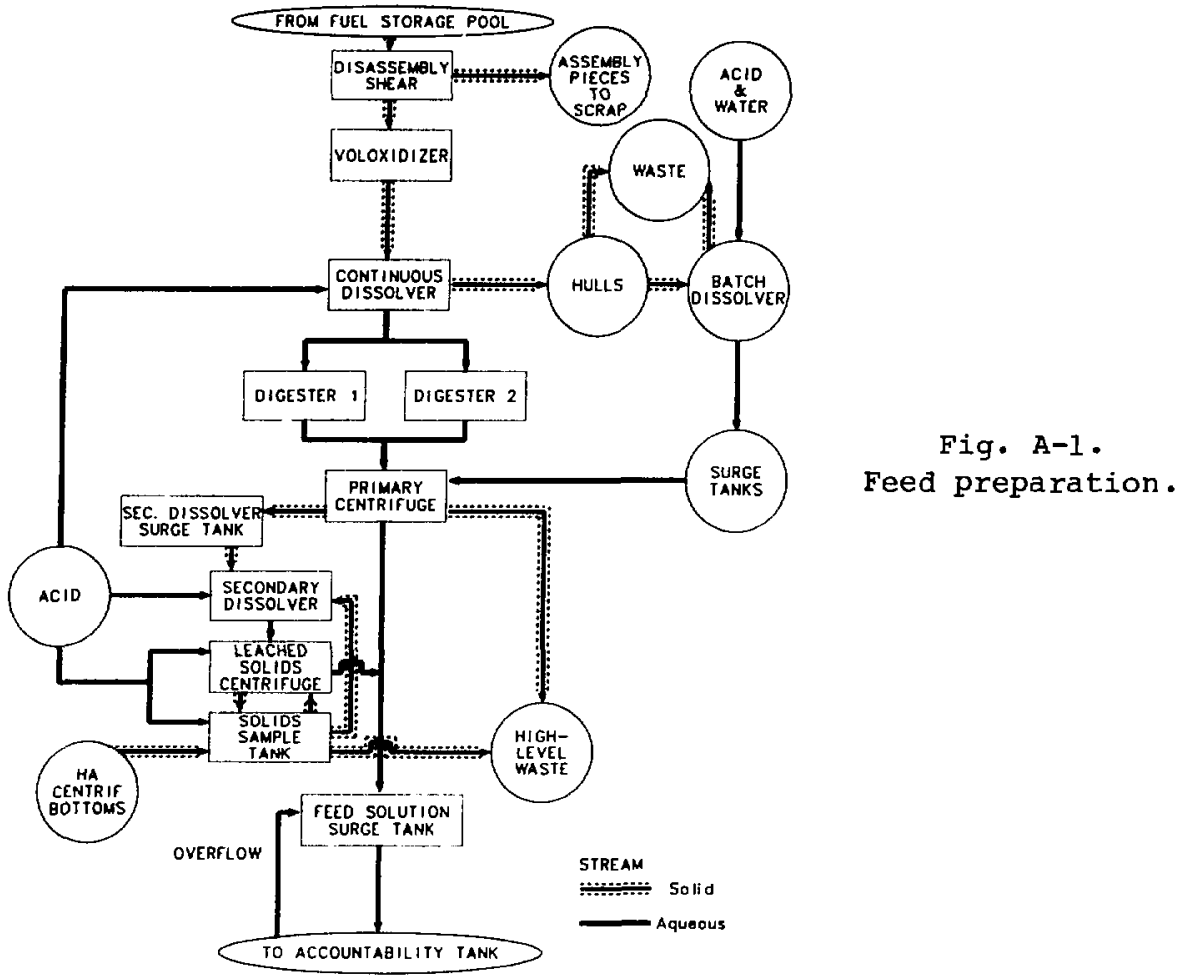

The short lengths of fuel rod are fed to the voloxidizer, which is a rotating electric kiln that heats the chopped fuel to between $450-650^{\circ} \mathrm{C}$ in oxygen or oxygen-augmented air. There, the crystal structure of the fuel is converted from $\mathrm{UO}_{2}$ to $\mathrm{U}_{3} \mathrm{O}_{8}$, releasing essentially all of the tritium, which combines with the excess oxygen to form tritiated water. In addition to removing tritium from the fuel before subsequent contact with aqueous processing streams, voloxidation oxidizes residual sodium in the fuel before aqueous contact. ${ }^{84}$ The oxidation of $\mathrm{UO}_{2}$ to $\mathrm{U}_{3} \mathrm{O}_{8}$ produces a fine powder, and the accompanying increase in volume is expected to crack the cladding. However, despite the concomitant larger surface area of $\mathrm{U}_{3} \mathrm{O}_{8}$, clad $\mathrm{UO}_{2}$ and powdered $\mathrm{U}_{3} \mathrm{O}_{8}$ fuel dissolve at about the same rate. In addition, voloxidation may convert a significant fraction of the total plutonium to forms that are insoluble at the dissolver acid concentration. ${ }^{71}$ In the HEF flow sheet, tritium frum this step and other off-gas streams is recovered for ultimate disposal as $\mathrm{Mg}(\mathrm{OH})_{2}$.

The continuous dissolution system consists of a steam-heated, rotating cylindrical drum having nine compartments (dissolver), followed by two digester 
surge tanks. The voloxidized fuel segments enter the dissolver at one end and are countercurrently contacted with $\imath_{8} \underline{M}$ nitric acid. Also entering the dissolver are acid feed (with soluble poison and iodine stripper bottoms), rinse water (with soluble poison), overflow from the hulls handling tank, and purge gas. Exit streams include the continuous dissolved-fuel product stream, the leached hulls batches, and the dissolver off-gas. The dissolved fuel flows alternately to one of two parallel digester surge tanks, after combining with an off-specification stream from the dissolver area catch tank, the rework decanter, and/or the solvent-wash waste decanter. The hulls batches are washed, dried, and monitored for nuclear materials. In-specification hulls are combined with other metal scrap for disposal. Off-specification hulls are releached in a batch dissolver, which also recovers fuel material from the assembly fragments produced in the fuel cleaning operation. The batch dissolver product stream is fed to the primary centrifuge.

The digester surge tanks provide an additional 12-h dissolution time for the undissolved, suspended solids ( $F$ ig. A-2). In addition to a 6-h fill time, the 12-h digester cycle includes an evaporation and $\mathrm{NO}_{2}$ sparge cycle to remove iodine. Product is clarified in the primary centrifuge, which feeds directly to the feed solution surge tank. Undissolved solids remaining in the primary centrifuge are monitored for nuclear material content. Batches meeting specification are sent

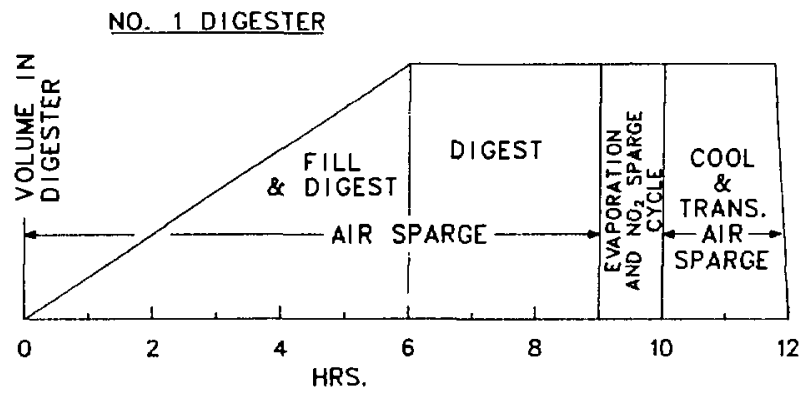

NO. 2 DIGESTER

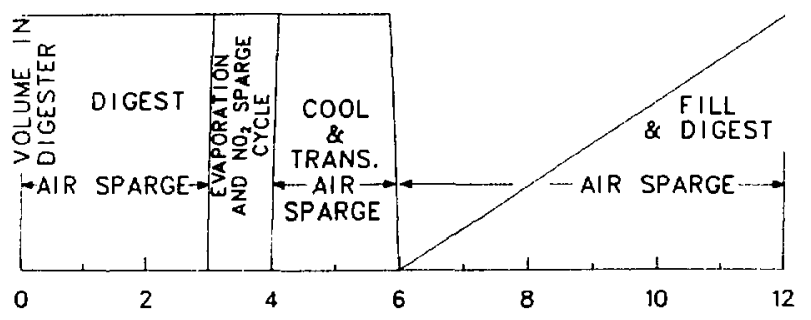

Fig. A-2.

Digester surge tank cycle. 
to high-level liquid waste. Off-specification batches are sent to a secondary dissolver surge tank where they are accumulated for $24 \mathrm{~h}$. Then, they are transferred to the secondary dissolver and treated with alternative procedures.

Contents of the secondary dissolver are jetted nominally every $24 \mathrm{~h}$ to the leached solids centrifuge; its centrate is fed to the feed solution surge tank. After solids in the leached solids centrifuge are rinsed, they are flushed to the solids sample tank for nuclear materials assay. Also, solids from the HA centrifuge are flushed to the solids sample tank every 7 days. When fissile content of the sample tank solids meets specification, the solids are jetted to high-level waste. Otherwise, they are recycled through the leached solids centrifuge and washed with acid until they meet specification. Solids with higher fissile content are jetted to the secondary dissolver.

The feed solution surge tank feeds the accountability tank. A precise volume measurement is made at the accountability tank and a sample (or samples) taken for assay as follows. First, the tank is filled above an overflow line in the necked-down section at its top. Then it is air-sparged to homogenize the feed solution before sampling. Excess solution is returned to the feed solution surge tank through the overflow line; flow in this line occurs only when the airlift is operating because the line runs uphill. These procedures assure that accountability tank volume is precisely known and is essentially identical from batch to batch.

\section{URANIUM-PLUTONIUM CODECONTAMINATION AND PARTITIONING}

Figure A-3 shows the block diagram for uranium-plutonium codecontamination and partitioning, and Table A-II summarizes the composition of principal streams.

The accountability tank contents are jetted to the feed adjustment tank where the solution acidity and nuclear materials concentrations are adjusted to the HA feed specifications. The adjusted feed is transferred to the HA feed tank. A recycle stream from the extraction backcycle system can be added to the feed. A continuous flow is maintained from the HA feed tank to the HA centrifuge where residual solids are removed. The centrate flows continuously to the HA centrifugal contactor of the first solvent-extraction cycle, and the residual solids are accumulated and then transferred to the solids sample tank every 7 days. 
TABLE A-I I

URANIUM-PLUTONIUM CODECONTAMINATION AND PARTITIONING STREAM CHARACTERISTICSa

\begin{tabular}{|c|c|c|c|c|c|c|c|c|c|}
\hline $\begin{array}{l}\text { Stream } \\
\text { Ident. }\end{array}$ & Description & $\begin{array}{c}\text { Urantum, } \\
\mathrm{kg} / \mathrm{h} \\
\text { (kg/batch) } \\
\end{array}$ & $\begin{array}{c}\text { Plutonium, } \\
\mathrm{kg} / \mathrm{h} \\
\text { (kg/batch) }\end{array}$ & $\begin{array}{c}\text { Total inass } \\
\mathrm{kg} / \mathrm{h} \\
(\mathrm{kg} / \mathrm{batch}) \\
\end{array}$ & $\begin{array}{l}\text { Cycle } \\
\text { Time } \\
\mathrm{h} \\
\end{array}$ & $\begin{array}{c}\text { Transfer } \\
\text { Time } \\
\text { min }\end{array}$ & $\begin{array}{l}\text { Flow } \\
\text { Rate } \\
\mathrm{L} / \mathrm{h} \\
\end{array}$ & $\begin{array}{c}\mathrm{HNO}_{3} \\
\text { Molarity } \\
\end{array}$ & $\begin{array}{l}\text { Associated Vessel and } \\
\text { Maximum Plutonium Inventory }\end{array}$ \\
\hline & Feed adjustment tank input & (389) & (111) & $(4100)$ & 24.0 & 20 & - & 3.48 & Feed adjustment tank, 111. kg \\
\hline FAP & HA feed tank Input No. 1 & $(388)$ & $(111)$ & $(4430)$ & 24.0 & 20 & - & 3.32 & HA feed tank, $115 \mathrm{~kg}$ \\
\hline \multirow[t]{3}{*}{ 2WB } & HA feed tank input No. 2 & trace & trace & 17.28 & - & - & 14.07 & 7.89 & \\
\hline & н/ centrifuge faed & 16.20 & 4.64 & 201.94 & - & - & 152.01 & 3.73 & \\
\hline & HA centrifuge solids out & - & - & $(13.67)$ & 168.0 & 5 & - & 12.78 & \\
\hline HAF & $\begin{array}{l}\text { HA contactor feed from HA } \\
\text { centrifuge }\end{array}$ & 16.20 & 4.64 & 201.94 & - & - & 152.01 & 3.73 & HA contactor, $0.4 \mathrm{~kg}$ \\
\hline \multirow[t]{2}{*}{ HSR } & $\begin{array}{l}\text { HA contactor feed (HS column } \\
\text { raffinate) }\end{array}$ & 1.27 & 0.67 & 55.68 & - & - & 47.02 & 3.09 & \\
\hline & Total HA contactor feed & 17.47 & 5.31 & 257.62 & - & - & 199.05 & $3 \cdot 58$ & \\
\hline HAX & HA contactor extractant & - & - & 207.50 & - & - & 257.76 & - & \\
\hline HAW & HA contactor waste & - & - & 213.88 & - & - & 182.22 & 3,52 & \\
\hline Hä & $\begin{array}{l}\text { HS column feed iHA contactor } \\
\text { product? }\end{array}$ & 17.46 & 5.31 & $251 \cdot 24$ & - & - & 272.57 & 0.233 & HS column, $3 \mathrm{~kg}$ \\
\hline HSS & HS column sc=ub & - & - & 31.20 & - & - & $: 2.34$ & 0.304 & \\
\hline
\end{tabular}


TABLE A-II (cont)

\begin{tabular}{|c|c|c|c|c|c|c|c|c|c|}
\hline $\begin{array}{l}\text { Stream } \\
\text { Ident. }\end{array}$ & Description & $\begin{array}{c}\text { Uranium, } \\
\mathrm{kg} / \mathrm{h} \\
\text { (kg/batch) } \\
\end{array}$ & $\begin{array}{c}\text { Plutonium, } \\
\mathrm{kg} / \mathrm{h} \\
\text { (kg/batch) }\end{array}$ & $\begin{array}{c}\text { Total Mass } \\
\mathrm{kg} / \mathrm{h} \\
\text { (kg/batch) }\end{array}$ & $\begin{array}{l}\text { Cycle } \\
\text { Time } \\
\text { h } \\
\end{array}$ & $\begin{array}{c}\text { Transfer } \\
\text { Time } \\
\text { min } \\
\end{array}$ & $\begin{array}{l}\text { Flow } \\
\text { Rate } \\
\mathrm{L} / \mathrm{h} \\
\end{array}$ & $\begin{array}{l}\mathrm{HNO}_{3} \\
\text { Molarity } \\
\end{array}$ & $\begin{array}{l}\text { Associated Vessel and } \\
\text { Maximum Plutonium Inventory }\end{array}$ \\
\hline HSIS & HS column intermediate scrub & - & - & 17.44 & - & - & 15.18 & 5.22 & \\
\hline HSP & $\begin{array}{l}\text { HC column feed (HS column } \\
\text { product) }\end{array}$ & 16.19 & 4.64 & 244.20 & - & - & 268.08 & 0.026 & HC column, $3 \mathrm{~kg}$ \\
\hline Hex & $\begin{array}{l}\text { HC column extractant, } \\
\text { reductant }\end{array}$ & - & - & 246.52 & - & - & 236.07 & 0.011 & \\
\hline HerX & $\begin{array}{l}\text { HC column intermediate } \\
\text { extractant }\end{array}$ & - & - & 29.32 & - & - & 26.87 & 3.02 & \\
\hline HCW & HC column waste & - & - & 207.50 & - & - & 260.35 & $6.09 \times 10^{-5}$ & \\
\hline \multirow[t]{2}{*}{ HCP } & HC product reducer feed & 16.19 & 4.64 & 312.20 & - & - & 271.86 & 0.334 & HCP reducer, $15 \mathrm{~kg}$ \\
\hline & $\begin{array}{l}\text { HC product reducer reductant } \\
\text { feed }\end{array}$ & - & - & 46.65 & $\sim$ & - & 44.66 & 0.018 & \\
\hline \multirow[t]{2}{*}{ IAER } & HC product reducer output & 16.19 & 4.65 & 358.62 & - & - & 317.46 & 0.399 & \\
\hline & IA feed tank acid & - & - & 67.13 & - & - & 49.75 & 13.07 & \\
\hline IAF & $\begin{array}{l}\text { IA feed tank Input and } \\
\text { IA column Feed }\end{array}$ & 16.20 & 4.65 & 425.69 & - & - & 362.65 & 2.14 & $1 \mathrm{~A}$ feed tank, $11 \mathrm{~kg}$ \\
\hline IAK & IA column extractant & - & - & 161.00 & - & - & 200.00 & - & la column, $3 \mathrm{~kg}$ \\
\hline IAR & $\begin{array}{l}\text { 1B column raffinate } \\
\text { (1A column serub) }\end{array}$ & 3.97 & - & 57.27 & - & - & 47.62 & 1.87 & \\
\hline
\end{tabular}


TABLE A-II (cont)

\begin{tabular}{|c|c|c|c|c|c|c|c|c|c|}
\hline $\begin{array}{l}\text { Stream } \\
\text { Ident. }\end{array}$ & Description & $\begin{array}{c}\text { Uranium, } \\
\mathrm{kg} / \mathrm{h} \\
(\mathrm{kg} / \text { batch }) \\
\end{array}$ & $\begin{array}{c}\text { Plutonium, } \\
\mathrm{kg} / \mathrm{h} \\
\text { (kg/batch) }\end{array}$ & $\begin{array}{c}\text { Total Mass } \\
\mathrm{kg} / \mathrm{h} \\
\text { (kg/batch) } \\
\end{array}$ & $\begin{array}{l}\text { Cycle } \\
\text { Time } \\
\text { h } \\
\end{array}$ & $\begin{array}{c}\text { Transfer } \\
\text { Time } \\
\text { min } \\
\end{array}$ & $\begin{array}{l}\text { Flow } \\
\text { Rate } \\
\mathrm{L} / \mathrm{h} \\
\end{array}$ & $\begin{array}{c}\mathrm{HNO}_{3} \\
\text { Molarity } \\
\end{array}$ & $\begin{array}{l}\text { Associated Vessel and } \\
\text { Maximum Plutonium Inventory }\end{array}$ \\
\hline IAP & IA column aqueous effluent & 0.59 & 4.65 & 449.99 & - & - & 401.38 & 2.10 & \\
\hline IAU & $\begin{array}{l}\text { 1A column organic effluent } \\
\text { (1B feed) }\end{array}$ & 19.58 & - & 194.97 & - & - & 208.75 & 0.119 & \\
\hline IBS & IB column strip & - & - & 35.25 & - & - & 33.36 & 0.105 & \\
\hline 1BIS & IB column intermediate strip & - & - & 13.97 & - & - & $12 \cdot 20$ & 5.07 & \\
\hline $1 \mathbf{B P}$ & $\begin{array}{l}\text { 18 column organic effluent } \\
\text { (1C feed) }\end{array}$ & 15.61 & - & 186.92 & - & - & 207.45 & 0.0061 & \\
\hline $1 c x$ & 1C columin extractant & - & - & 209.53 & - & - & 211.78 & 0.0097 & \\
\hline $1 \mathrm{CW}$ & IC column waste & - & - & 161.00 & - & - & 200.00 & 0.0064 & \\
\hline $1 \mathrm{Cu}$ & IC column product & 15.61 & - & 234.45 & - & - & 204.83 & 0.016 & \\
\hline $1 \mathrm{cuc}$ & IC evaporator product & 15.61 & - & 56.20 & - & - & 35.28 & 0.090 & \\
\hline
\end{tabular}

arom drawings 52-B-204, 53-8-201, and 53-B-202 (Ref. 83). 


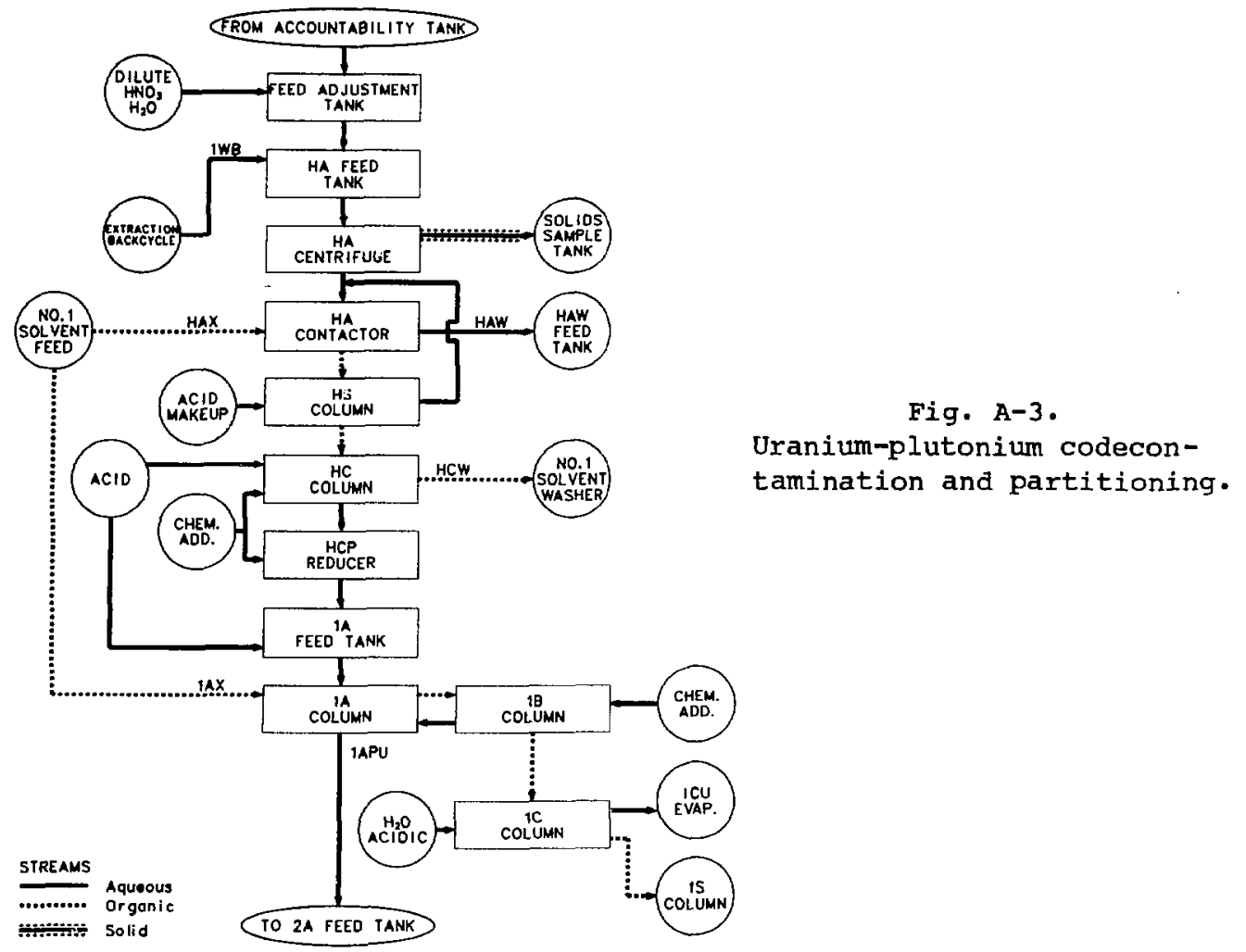

Initial decontamination of nuclear materials occurs in the HA centrifugal contactor, where heavy metals are selectively and quantitatively extracted into the organic stream (decontamination factor of $\sim 10^{3}$ ). Most of the fission products remain in the aqueous stream and flow to the high-activity waste (HAW) feed tank. The organic stream flows to the HS column where aqueous stream scrubbing removes ruthenium, zirconium, and niobium. The scrub stream is returned to the HA contactor for nuclear materials recovery. The decontaminated organic stream flows from the HS column to the HC column where the nuclear materials are back extracted (stripped) into the aqueous stream. The product-free organic stream leaving the HC column flows to the No. I solvent treatment system. The product-laden aqueous stream (HCP) is sent to the HCP reduction vessel where the plutonium is reduced from $\mathrm{Pu}(\mathrm{IV})$ to $\mathrm{Pu}^{\prime}$ (iII) with a solution of hydroxylamine nitrate and the holding reductant, hydrazine. The aqueous plutonium stream then flows to the IA column through the IA feed tank to begin the second solvent-extraction cycle (see Glossary). 
In the IA column, uranium is partitioned from plutonium by extraction into the organic stream. The uranium-to-plutonium ratio in the $1 \mathrm{~A}$ column aqueous stream is adjusted from $20.13: 1$ to $\sim 2: 1$ with ${ }^{238} \mathrm{U}$ as it flows to the $1 \mathrm{~A}$ decanter. The organic stream from the $I A$ column is stripped with a dilute nitric-acid stream in the $1 B$ column to remove traces of plutonium. This acid stream then flows to the $1 A$ column for plutonium recovery.

The organic stream from the $1 \mathrm{~B}$ column is treated with $0.0 \mathrm{I} \mathrm{M}$ acid in the IC column to strip the uranium into the aqueous stream. The acid stream used for the stripping is the overhead distillate from the IC concentrator. The organic stream from the IC column is routed to the IS column for recovery of residual nuclear materials, and the aqueous uranium stream flows to the $1 \mathrm{CU}$ evaporator and then to the third solvent-extraction cycle, uranium purification.

\section{URANIUM PURIFICATION}

Figure A-4 is a diagram of the uranium purification process, and Table A-III lists characteristics of the principal streams. This third solvent-extraction cycle provides uranium nitrate solution for denaturing plutonium and conversion to $\mathrm{UO}_{3}$.

The aqueous uranium stream from the IC column is concentrated in the ICU evaporator. The concentrated product is adjusted in the 2D feed adjustment tank to the required composition for solvent extraction and then is batchtransferred to the 2D feed tank, which continuously feeds the $2 \mathrm{D}$ column. Uranium is extracted into the organic stream in the 2D column, scrubbed in the $2 \mathrm{~S}$ column, and then stripped into the aqueous stream in the $2 \mathrm{E}$ column. Column waste streams are recycled internally within the purification cycle or through either the extraction backcycle or the No. 2 solvent treatment systems. The $2 E$ column aqueous uranium stream is concentrated in the $2 \mathrm{EU}$ evaporator and routed to the uranium catch tank. From there, the uranium solution is batch-transferred to the uranium sample tank. After sampling and assay, the solution is transferred to either the uranium surge tank or the off-specification uranium tank. Offspecification uranium is recycled to the 2D feed tank for repurification. Uranium product is drawn from the uranium surge tank for denaturing plutonium feed and product in the uranium-plutonium copurification process and for $\mathrm{UO}_{3}$ production, which includes concentration, denitration, and product packaging. 
TABLE A-III

URANIUM PURIFICATION STREAM CHARACTERISTICSa

\begin{tabular}{|c|c|c|c|c|c|c|c|c|c|}
\hline $\begin{array}{l}\text { Stream } \\
\text { Ident. }\end{array}$ & Description & $\begin{array}{c}\text { Uranium, } \\
\mathrm{kg} / \mathrm{h} \\
(\mathrm{kg} / \mathrm{batch})\end{array}$ & $\begin{array}{c}\text { Plutonium, } \\
\mathrm{kg} / \mathrm{h} \\
\text { (kg/batch) }\end{array}$ & $\begin{array}{c}\text { Total Mass } \\
\mathrm{kg} / \mathrm{h} \\
\text { (kg/batch) }\end{array}$ & $\begin{array}{l}\text { Cycle } \\
\text { Time } \\
\mathrm{h} \\
\end{array}$ & $\begin{array}{l}\text { Transfer } \\
\text { Time } \\
\text { min } \\
\end{array}$ & $\begin{array}{r}\text { Flow } \\
\text { Rate } \\
\mathrm{L} / \mathrm{h} \\
\end{array}$ & $\begin{array}{l}\mathrm{HNO}_{3} \\
\text { Molarity } \\
\end{array}$ & $\begin{array}{l}\text { Associated Vessel and } \\
\text { Maximum Plutonium Inventory }\end{array}$ \\
\hline 1cuc & 2D feed adjustment tank feed & 15.61 & - & 56.20 & - & - & 35.28 & 0.09 & 2D feed adjustment tank \\
\hline 2DF & 2D feed tank feed & $(250.12)$ & - & $(991.79)$ & 16 & 10 & - & 1.54 & 2D feed tank \\
\hline $2 \mathrm{DF}$ & 2D column feed & 15.61 & - & 61.99 & - & - & 39.17 & 1.52 & 2D column \\
\hline $2 D X$ & 2D column extractant & - & - & 152.95 & - & - & 190.00 & & \\
\hline 2 DW & 2D column waste & - & - & 65.91 & - & - & 60.29 & 1.62 & \\
\hline 2DU & $\begin{array}{l}\text { 2D column product } \\
\text { (25 column feed) }\end{array}$ & $16 \cdot 38$ & - & 183.24 & - & - & 198.60 & 0.254 & 2s column \\
\hline 2Ss & 25 column scrub & - & - & 21.06 & - & - & 21.40 & - & \\
\hline $2 \mathrm{sis}$ & 25 column intermediate scrub & - & - & 8.71 & - & - & 7.61 & 5.05 & \\
\hline $2 S R$ & 2S column raffinate & 0.77 & - & 34.21 & - & - & 29.06 & 3.05 & \\
\hline $\begin{array}{l}2 S U \\
2 E \text { Column }\end{array}$ & $\begin{array}{l}25 \text { column product } \\
\text { (2E column feed) }\end{array}$ & 15.61 & - & 178.80 & - & - & 196.81 & $8.06 \times 10^{-4}$ & \\
\hline $2 \mathrm{EX}$ & 2E column extractant & - & - & 164.44 & - & - & 167.00 & $9.5 \times 10^{-3}$ & \\
\hline $2 \mathbf{E W}$ & $2 E$ column waste & - & - & 152.95 & - & - & 191.91 & - & \\
\hline
\end{tabular}


TABLE A-III (cont)

\begin{tabular}{|c|c|c|c|c|c|c|c|c|c|}
\hline $\begin{array}{l}\text { Stream } \\
\text { Ident. }\end{array}$ & Description & $\begin{array}{c}\text { Uranium, } \\
\mathrm{kg} / \mathrm{h} \\
(\mathrm{kg} / \mathrm{batch}) \\
\end{array}$ & $\begin{array}{c}\text { Plutonium, } \\
\mathrm{kg} / \mathrm{h} \\
\text { (kg/batch) }\end{array}$ & $\begin{array}{c}\text { Total Mass } \\
\mathrm{kg} / \mathrm{h} \\
\text { (kg/batch) } \\
\end{array}$ & $\begin{array}{l}\text { Cycle } \\
\text { Time } \\
\text { h } \\
\end{array}$ & $\begin{array}{l}\text { Transfer } \\
\text { Time } \\
\text { min } \\
\end{array}$ & $\begin{array}{l}\text { Flow } \\
\text { Rate } \\
\mathrm{L} / \mathrm{h}\end{array}$ & $\begin{array}{c}\mathrm{HNO}_{3} \\
\text { Molarity } \\
\end{array}$ & $\begin{array}{l}\text { Associated Vessel and } \\
\text { Maximum Plutonium Inventory }\end{array}$ \\
\hline $2 \mathrm{EU}$ & $\begin{array}{l}\text { 2E column product } \\
\text { (2EU evaporator feed) }\end{array}$ & 15.61 & - & 190.29 & - & - & 163.02 & 0.011 & 2EU evaporator \\
\hline UP-1 & $\begin{array}{l}2 \text { 2EU evaporator product } \\
\left(238_{U} \text { catch tank feed }\right)\end{array}$ & 15.61 & - & 54.83 & - & - & 34.01 & 0.047 & $238_{U}$ catch tank \\
\hline UP-2 & $238_{U}$ sample tank feed & $(129.32)$ & - & $(459.4)$ & $\mathbf{8}$ & 10 & - & 0.044 & $238_{U}$ sample $\operatorname{tank}$ \\
\hline \multirow[t]{4}{*}{ UP-3 } & $238_{\mathrm{U}}$ surge tank feed & $(129.32)$ & - & $(473.2)$ & $\mathbf{8}$ & 10 & - & 0.042 & $238_{U}$ surge $\operatorname{tank}$ \\
\hline & Denaturant to Pu sample tank & $(55.44)$ & - & $(202.92)$ & 12 & 10 & - & 0.044 & Pu sample tank \\
\hline & $\begin{array}{l}\text { Denaturant to } 1 \mathrm{~A} \text { column } \\
\text { product }\end{array}$ & 8.71 & - & 32.46 & - & - & 20.54 & 0.044 & IA column \\
\hline & UNH concentrator feed & 2.27 & - & 8.28 & - & - & 5.25 & 0.030 & UNH concentrator \\
\hline UNH & Denitrator feed & 2.27 & - & 4.78 & - & - & 2.09 & - & Denitrator \\
\hline \multirow[t]{2}{*}{$\mathrm{UO}_{3}$} & Denitrator product & 2.26 & - & 2.72 & - & - & 1.36 & - & \\
\hline & Canned $\mathrm{UO}_{3}$ & $(151)$ & - & $(181.4)$ & 66.7 & - & - & - & \\
\hline
\end{tabular}

a From drawings 53-B-202, 53-B-203, and 54-B-202 (Ref. 83). 


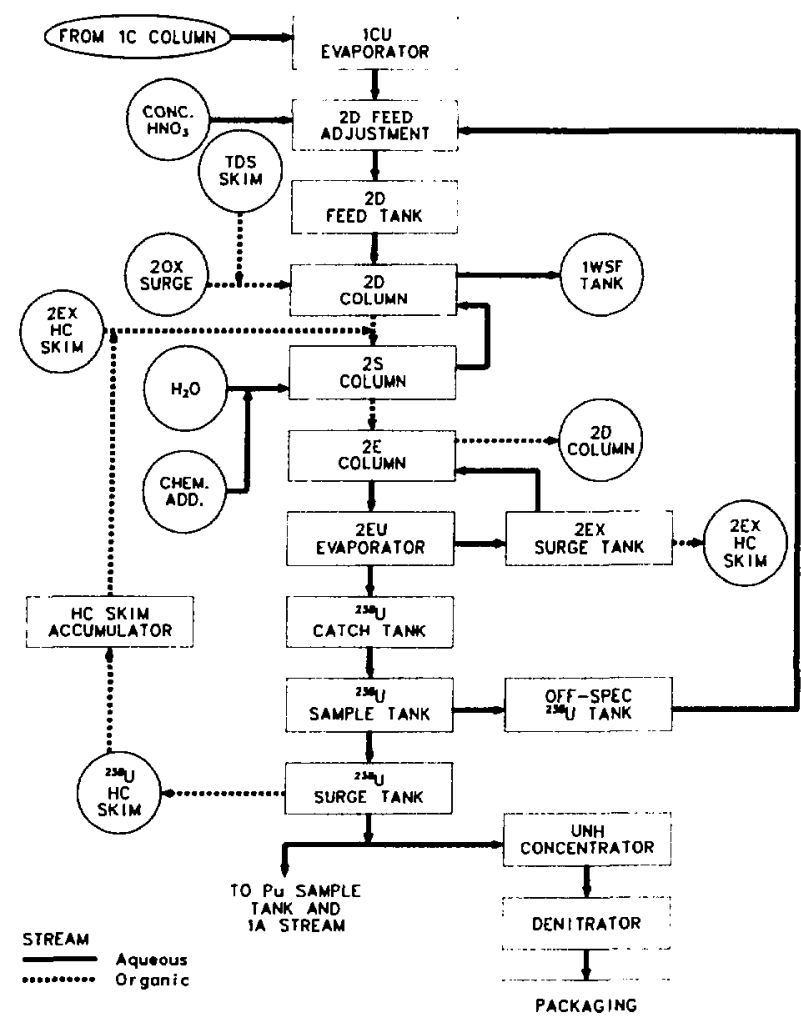

Fig. A-4.

Uranium purification.

\section{URANIUM-PLUTONIUM COPURIFICATION}

Figure A-5 is a block diagram for the fourth and fifth solvent-extraction cycles, and Table IV gives the compositions of principal streams. The aqueous plutonium stream from the $1 \mathrm{~A}$ column is denatured with ${ }^{238} \cup$ at the $1 \mathrm{~A}$ decanter to provide a uraniurn-to-plutonium ratio of $\sim 2: 1$ in the $2 \mathrm{~A}$ feed tank. The acid concentration in the $2 \mathrm{~A}$ feed tank is adjusted to oxidize the plutonium from Pu(III) to $\mathrm{Pu}(\mathrm{IV})$ for so. vent extraction.

The $2 \mathrm{~A}$ feed tank continuously feeds the $2 \mathrm{~A}$ extraction-scrub pulsed column where nuclear r.uaterials are extracted into the organic stream. The $2 A$ organic stream flows to the $2 \mathrm{~B}$ column where the riuclear materials are stripped into the aqueous stream. The aqueous stream then flows to the $3 \mathrm{~A}$ feed tank where its acidity is adjusted before the next extraction-scrub and stripping sequence in the $3 \mathrm{~A}$ and $3 \mathrm{~B}$ columns. 
TABLE A-IV

URANIUM-PLUTONIUM COPURIFICATION STREAM CHARACTERISTICS ${ }^{a}$

\begin{tabular}{|c|c|c|c|c|c|c|c|c|c|}
\hline $\begin{array}{l}\text { Siream } \\
\text { Ident. }\end{array}$ & Description & $\begin{array}{c}\text { Uranium, } \\
\mathrm{kg} / \mathrm{h} \\
\text { (kg/batch) } \\
\end{array}$ & $\begin{array}{c}\text { Plutonium, } \\
\mathrm{kg} / \mathrm{h} \\
(\mathrm{kg} / \mathrm{batch}) \\
\end{array}$ & $\begin{array}{c}\text { Total Mass } \\
\mathrm{kg} / \mathrm{h} \\
(\mathrm{kg} / \mathrm{batch}) \\
\end{array}$ & $\begin{array}{l}\text { Cycle } \\
\text { Time } \\
\mathrm{h} \\
\end{array}$ & $\begin{array}{l}\text { Transfer } \\
\text { Time } \\
\text { min } \\
\end{array}$ & $\begin{array}{l}\text { Flow } \\
\text { Rate } \\
\mathrm{L} / \mathrm{h} \\
\end{array}$ & $\begin{array}{c}\mathrm{HNO}_{3} \\
\text { Molarity } \\
\end{array}$ & $\begin{array}{l}\text { Associated Vessel and } \\
\text { Maximum Plutonium Inventory }\end{array}$ \\
\hline $1 \mathbf{X P}$ & 1A column product & 0.59 & 4.65 & 449.99 & - & - & 401.38 & 2.10 & \\
\hline UNF & $238 v$ denaturing feed & 8.71 & - & 32.46 & - & - & 20.54 & 0.425 & \\
\hline \multirow[t]{3}{*}{ LAPU } & 2A feed tank feed & 9.30 & 4.65 & 482.45 & - & - & 421.95 & 2.01 & 2A feed tank, $111 \mathrm{~kg}$ \\
\hline & 2A feed tank acid feed & - & - & 11.20 & - & - & 8.33 & 12.84 & \\
\hline & Off-spec Pu to $2 \mathrm{~A}$ feed tank & $(111.56)$ & $(55.68)$ & $(650.88)$ & As & Requi red & - & 2.93 & \\
\hline $2 A F$ & 2A column feed & 9.30 & $4 \cdot 64$ & 491.10 & - & - & 428.82 & 2.14 & 2A column, $3 \mathrm{~kg}$ \\
\hline 2As & 2A column scrub & - & - & 41.60 & - & - & 38.99 & 2.26 & \\
\hline $2 \mathrm{AX}$ & 2A colunn extractant (3BW) & - & - & 161.00 & - & - & 200.00 & - & \\
\hline $2 A X$ & $2 \mathrm{NX}$ makeup & - & - & 36.23 & - & - & 45.01 & - & \\
\hline $2 A P$ & $\begin{array}{l}2 B \text { colunn feed ( } 2 A \text { column } \\
\text { product) }\end{array}$ & 9.30 & 4.64 & 226.25 & - & - & 254.00 & 0.261 & $2 B$ columin, $3 \mathrm{~kg}$ \\
\hline $2 \mathbf{A N}$ & 2A column waste & trace & 0.002 & 503.68 & - & - & 455.13 & 2.06 & \\
\hline $2 \mathrm{BX}$ & 2B column extractant & - & - & 269.18 & - & - & 255.37 & 0.022 & \\
\hline $2 B I X$ & $\begin{array}{l}\text { 2B column intermediate } \\
\text { extractant }\end{array}$ & - & $=$ & 29.11 & - & - & 25.18 & 5.47 & \\
\hline
\end{tabular}


TABLE A-IV (cont)

\begin{tabular}{|c|c|c|c|c|c|c|c|c|c|}
\hline $\begin{array}{l}\text { Stream } \\
\text { Ident. }\end{array}$ & Description & $\begin{array}{c}\text { Uranium, } \\
\mathrm{kg} / \mathrm{h} \\
\text { (kg/batch) } \\
\end{array}$ & $\begin{array}{c}\text { Plutonium, } \\
\mathrm{kg} / \mathrm{h} \\
\text { (kg/oatch) }\end{array}$ & $\begin{array}{c}\text { Total Mass } \\
\mathrm{kg} / \mathrm{h} \\
(\mathrm{kg} / \mathrm{batch}) \\
\end{array}$ & $\begin{array}{l}\text { Cycle } \\
\text { Time } \\
\mathrm{h} \\
\end{array}$ & $\begin{array}{c}\text { Transfer } \\
\text { Time } \\
\text { min } \\
\end{array}$ & $\begin{array}{l}\text { Flow } \\
\text { Rate } \\
\text { L/h } \\
\end{array}$ & $\begin{array}{l}\mathrm{HNO}_{3} \\
\text { Molarity }\end{array}$ & $\begin{array}{l}\text { Associated Vessel and } \\
\text { Maximum Plutonium Inventory }\end{array}$ \\
\hline 2BW & $2 B$ column waste to 1 s column & trace & trace & 197.23 & - & - & 247.47 & $1.82 \times 10^{-4}$ & \\
\hline 2BP & $\begin{array}{l}3 \mathrm{~A} \text { feed tank feed ( } 2 \mathrm{~B} \text { column } \\
\text { product) }\end{array}$ & 9.30 & 4.64 & 327.26 & - & - & 290.81 & 0.739 & $3 \mathrm{~A}$ feed tank, $13 \mathrm{~kg}$ \\
\hline 3AFA & 3A feed tank acid feed & - & - & 48.35 & - & - & 35.85 & 13.03 & \\
\hline $3 \mathbf{A F}$ & 3A column feed & 9.30 & 4.64 & 375.15 & - & - & 324.90 & 2.07 & $3 \mathrm{~A}$ column, $3 \mathrm{~kg}$ \\
\hline $3 A X$ & $3 A$ column extractant & - & - & 161.00 & - & - & 200.00 & - & \\
\hline $3 \mathrm{AS}$ & 3A column scrub & - & - & 27.85 & - & - & 26.75 & 1.49 & \\
\hline \multirow[t]{2}{*}{ 3AH } & 3A column waste & - & 0.002 & 376.39 & - & - & 340.64 & 2.0 & \\
\hline & 2AW plus $3 A W$ to 1 WSF tank & trace & 0.005 & 880.07 & - & - & 795.77 & 2.0 & \\
\hline 3AP & $\begin{array}{l}\text { 3B column feed ( } 3 \text { A column } \\
\text { product) }\end{array}$ & 9.30 & 4.64 & 187.62 & - & - & 207.36 & 0.136 & 3B column, $3 \mathrm{~kg}$ \\
\hline $3 \mathrm{BX}$ & 3B column extractant & - & - & $252 \cdot 58$ & - & - & 239.62 & 0.021 & \\
\hline 3BIX & $\begin{array}{l}\text { 3B column intermediate } \\
\text { extractant }\end{array}$ & - & - & 27.64 & - & - & 23.58 & 5.47 & \\
\hline 3BW & 3B column waste & - & - & 161.00 & - & - & 200.00 & - & \\
\hline $\begin{array}{l}\text { 3BP- } \\
\text { PFF }\end{array}$ & $\begin{array}{l}\text { 3B column product-Pu stripper } \\
\text { feed tank feed }\end{array}$ & 9.30 & 4.64 & 306.43 & - & - & 273.89 & 0.611 & Pu stripper feed tank, $2 \mathrm{~kg}$ \\
\hline
\end{tabular}


TABLE A-IV (cont)

\begin{tabular}{|c|c|c|c|c|c|c|c|c|c|}
\hline $\begin{array}{l}\text { Strean } \\
\text { Ident. }\end{array}$ & Description & $\begin{array}{c}\text { Uranium, } \\
\mathrm{kg} / \mathrm{h} \\
\text { (kg/batch) }\end{array}$ & $\begin{array}{c}\text { Plutonium, } \\
\mathrm{kg} / \mathrm{h} \\
\text { (kg/batch) }\end{array}$ & $\begin{array}{c}\text { Total Mass } \\
\text { kg/h } \\
\text { (kg/batch) } \\
\end{array}$ & $\begin{array}{l}\text { Cycle } \\
\text { Time } \\
\mathrm{h} \\
\end{array}$ & $\begin{array}{l}\text { Transfer } \\
\text { Time } \\
\text { min } \\
\end{array}$ & $\begin{array}{r}\text { Flow } \\
\text { Rate } \\
\mathrm{L} / \mathrm{h} \\
\end{array}$ & $\begin{array}{l}\text { HNO }_{3} \\
\text { Molarity }\end{array}$ & $\begin{array}{l}\text { Associated Vessel and } \\
\text { Maximum Plutonium Inventory }\end{array}$ \\
\hline PSF & Pu stripper feed & 9.30 & 4.64 & 306.43 & - & - & 268.41 & 0.624 & Pu stripper, $4 \mathrm{~kg}$ \\
\hline PSC & $\begin{array}{l}\text { Pu concentrator feed } \\
\text { (stripper product) }\end{array}$ & 9.30 & 4.64 & 171.60 & - & - & $144 \cdot 95$ & 1.08 & Pu concentrator, $19 \mathrm{~kg}$ \\
\hline \multirow[t]{2}{*}{ PCP } & $\begin{array}{l}\text { Pu catch tank feed } \\
\text { (concentrator product) }\end{array}$ & 9.30 & 4.64 & 54.24 & - & - & 33.96 & 2.93 & Pu catch tank, $56 \mathrm{~kg}$ \\
\hline & $\begin{array}{l}\text { Pu sample tank input } \\
\text { (catch tank out) }\end{array}$ & $(111.56)$ & $(55.68)$ & $(650.88)$ & 12.0 & 30.0 & - & 2.93 & Pu sample tank, $56 \mathrm{~kg}$ \\
\hline $\mathrm{HNO}_{3}$ & Pu sample tank acid feed & - & - & $(54.00)$ & 12.0 & 10.0 & - & 0.317 & Off-spec Pu tank, $56 \mathrm{~kg}$ \\
\hline UN & $238_{U}$ denaturing feed & $(55.60)$ & - & $(203.16)$ & 12.0 & 10.0 & - & 0.044 & \\
\hline PUP & Pu sample tank product & $(167.16)$ & $(55.68)$ & $(908.04)$ & 12.0 & 30.0 & - & 2.07 & \\
\hline
\end{tabular}

a from drawings 53-B-202, 53-B-204, and 53-B-205 (Ref, 83). 


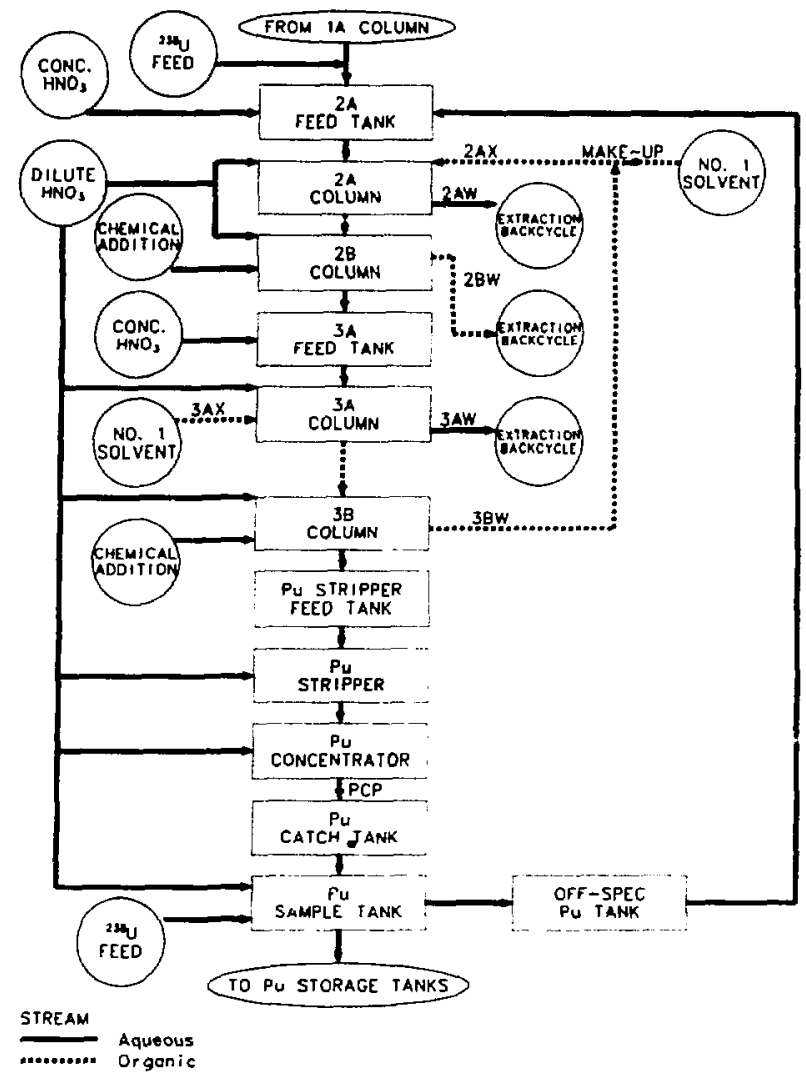

Fig. A-5. Uranium-plutonium copurification.

The aqueous product stream from the $3 \mathrm{~B}$ column flows to the plutonium stripper feed tank where the solution is steam stripped to remove organics. The stripper product stream then is concentrated in the plutonium concentrator, routed continuously to the plutonium catch tank, and transferred or a batch basis to the plutonium sample tank. The contents of the plutonium sample tank are sampled and assayed, and off-specification batches are transferred to the off-specification plutonium tank and then recycled to the $2 \mathrm{~A}$ feed tank as required. For batches meeting specifications, ${ }^{238_{U}} \mathrm{U}$ is added to bring the uranium-plutonium ratio to $3: 1$ and batch acidity is adjusted. The product is then transferred to the uranium-plutonium nitrate storage tanks. 


\section{NITRATE-TO-OXIDE COCONVERSION}

The uranium-plutonium nitrate solution is stored in seven parallel liquid product storage tanks. An eighth tank is used as a spare and for sump collection. These tanks have a 30-day production capacity but nominally will contain a maximum of 10 days of production. For coconversion, the nuclear materials solution is diluted, valence adjusted, precipitated, centrifuged, dried, calcined, blended, sampled, and packaged. A subsequent report will address these processes.

\section{EXTRACTION BACKCYCLE}

Organic and aqueous waste streams are processed in the extraction backcycle to recover residual nuclear materials before subsequent waste processing. The system includes an extraction column for processing organic streams, a stripping column, and an evaporator for processing aqueous strear. ..

\section{SOLVENT TREATMENT}

Radioactive impurities and solvent degradation products are removed from the organic solvent streams in two independent but identical systems. The No. 1 solvent treatment system processes solvent from the codecontamination/partitioning cycles (HCW), floor sumps, and rework system. The No. 2 system only treats solvent from the uranium purification cycle (2EW) to minimize plutonium contamination of the uranium product.

\section{LIQUID WASTES}

The aqueous waste processing and recovery systems reduce waste streams by concentration. All aqueous streams are recovered and fractionated to yield a strong acid solution and water. Excess nitric acid is removed by the NO, catalytic destruction system. Water from the fractimer overhead is either 
recycled to cold chemical make-up or discharged through the stack to maintain the plant water balance: tritiated water is concentrated and converted to $\mathrm{Mg}(\mathrm{OH})_{2}$ for final disposal.

\section{OFF-GAS TREATMENT}

The off-gas treatment system removes radioactive contaminants from the dissolver off-gas and the vessel off-gas systems to control plant emissions. It also reduces the level of other contaminants (such as $\mathrm{NO}_{x}$ and $\mathrm{R}-12$ refrigerant) in the effluent air from the plant. 


\section{APPENDIX B}

DYNAMIC MODEL OF THE HEF CHEMICAL SEPARATIONS PROCESS

\section{INTRODUCTION}

Computer modeling and simulation aided the design and evaluation of the NRTA system for the conceptual HEF chemical separations process. Modeling and simulation techniques allow prediction of the dynamic behavior of materials flows and measurements over any specified range of operating parameters and also rapid accumulation of data that represent relatively long operating periods. Alternative operating, measurement, and accounting strategies can be readily compared. In contrast, even if the HEF existed and had an NRTA system, its use in the design and evaluation of such strategies probably would be time-consuming and expensive.

The modeling and simulation approach has been used extensively in studies by the Los Alamos Safeguards Systems Group. $1-5,9,10$ This approach has included (1) a detailed dynamic model of the process based on actual design data and operator experience; (2) simulation of the process model on a digital computer; (3) a dynamic model of each measurement system based on best estimates of instrument performance and behavior; (4) simulation of accountability measurements applied to nuclear materials flow and in-process inventory data generated by the process model simulation; and (5) evaluation of simulated materials balance data from various materials accounting strategies.

This appendix describes briefly (1) the HEF feed preparation and chemical separations processes model and (2) the MODEL and HEF model (HEFMOD) computer programs, which together simulate operation of the HEF model. Sample process simulation results also are presented.

\section{DYNAMIC MODEL}

\section{A. Introduction}

The detailed HEF model was developed to estimate quantitatively the NRTA system sensitivity for the HEF feed preparation and chemical separations 
processes because process uncertainty (for example, undefined materials sidestreams and in-process inventories) can significantly affect materials control and accountability. Standard Monte Carlo techniques developed for dynamic systems are used to simulate operation of the HEF model. 85,86 The dynamics of each process step is described by the continuity equations for flows of bulk material and nuclear material:

$$
\frac{d I_{B L K}(t)}{d t}=\sum_{i} F_{i}(t)
$$

and

$$
\frac{d I_{N M}(t)}{d t}=\sum_{i} c_{i}(t) F_{i}(t) \text {. }
$$

where $I_{B L K}(t)$ is bulk material in process at time $t, I_{N M}(t)$ is nuclear material in process at time $t, F_{i}(t)$ is bulk volumetric or mass flow rate at time $t$ in stream i (inputs positive, outputs negative), and $C_{i}(t)$ is nuclear material concentration at time $\mathrm{t}$ in stream $\mathrm{i}$.

Dynamics for the entire HEF model is described by the solution of the complete set of coupled differential equations for all process operations, subject to initial condicions and subsidiary constraints. Random variation in the HEF model is determined by the statistics selected for independent random variables, which execute a random walk in time. These variables and their statistics were defined after a detailed examination of the conceptual process and operating procedures.

\section{B. HEF Model}

1. Introduction. The HEF model is based on ORNL's modified Purex process flow sheet for the conceptual HEF (see Appendix A). This flow sheet allows coprocessing uranium and plutonium instead of the usual plutonium purification process. Development of the HEF model required a detailed review and analysis of several reports (Refs. 71, 72, 84, 87-105) and of the HEF process 
information that URNL transmitted directly to Los Alamos. $7,8,83$ Process data and descriptions were clarified, supplemented, and updated in discussions with UKNL personnel.

The HEF model has three modules: feed preparation, codecontamination/ partitioning, and copurification. Brief descriptions follow of a few major process steps and modeling assumptions for each module. (See Appendix $A$ for details.)

2. Brief Description. Figure $A-1$ is a diagram of the feed preparation processes of the HEF model. Major process steps include (1) mechanical disassembly and shearing, (2) voloxidation, (3) fuel dissolution, and (4) feed clarification. A uranium-plutonium dissolved-fuel feed solution is prepared from spent-fuel assemblies for subsequent codecontamination, partitioning, and copurification by solvent extraction.

A spent-fuel assembly is received and disassembled every $3.14 \mathrm{~h}$ and then sheared into 157 batches [ $21.3 \mathrm{~cm}(0.5$-in.) fuel segments, or hulls], each of which is produced and transferred to the voloxidizer every $0.02 \mathrm{~h}(1.2 \mathrm{~min})$. For each voloxidizer feed batch received, a product batch is discharged, and these batches are accumulated for $0.5 \mathrm{~h}$ in the feed compartment of the seven-stage continuous dissolver. Every $0.5 \mathrm{~h}$ the feed compartment contents (hulls) are transferred into stage one of the continuous dissolver, and a batch of leached hulls is discharged from stage seven.

Hulls proceed in batches through the continuous dissolver with a $0.5-h / s t a g e$ residence time, while contarting a continuous countercurrent flow of nitric acid. Estimating in-process plutonium inventory in the continuous dissolver is complex. 106 In the HEF model, $90 \%$ of the plutonium in each batch of hulls dissolves in stage one, and $5 \%$ dissolves in stage two. After $0.5-\mathrm{h}$ hulls residence in stage two, the MODEL code generates a deviate representing the fraction of total undissolved plutonium in stage two that will ultimately be discharged from stage seven in the leached hulls (see Table B-I). The value of this deviate, which is sampled from a lognormal distribution, ${ }^{107}$ is subtracted from the total undissolved plutonium in stage two, and the difference yields the quantity of undissolved plutonium in stage two that will dissolve in stages three through seven. This quantity is modeled to dissolve $40 \%$ in stage three, $30 \%$ in stage four, $15 \%$ in stage five, $10 \%$ in stage six, and the remaining $5 \%$ in stage seven. The continuous dissolved-fuel product stream flows from the feed end af the continuous dissolver to the digester surge tanks, then to the primary centrifuge. 
HEFMOD INDEPENDENT PKOCESS VARIABLES

(FEEd PREPARATION, CODECONI'AMINATION AND PARTITIONING, AND COPURIFICATION)

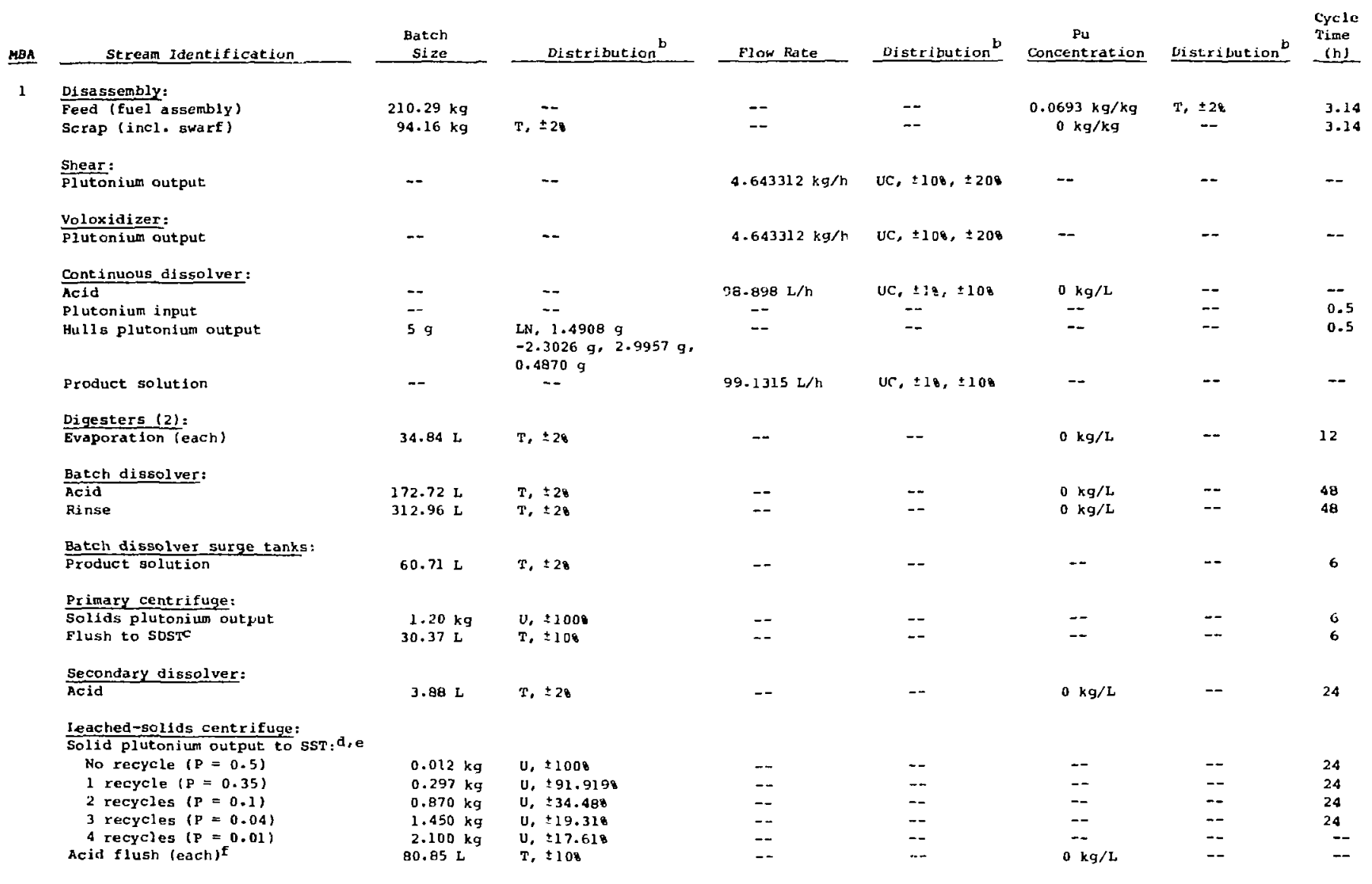


TABLE B-I (CONE)

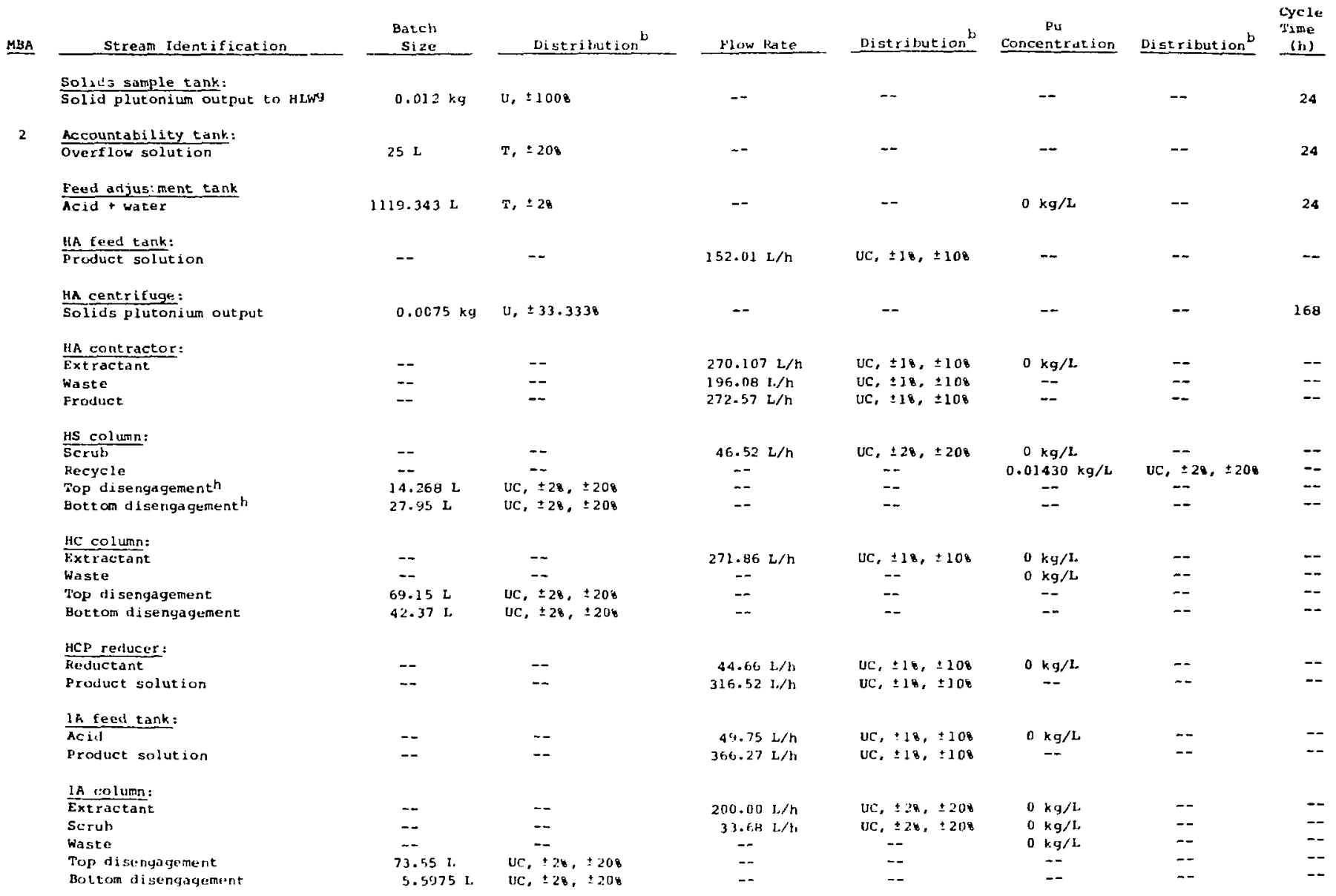




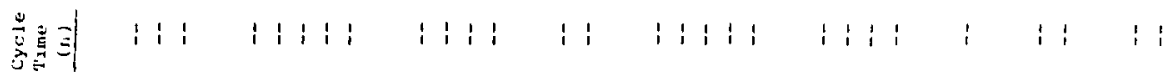

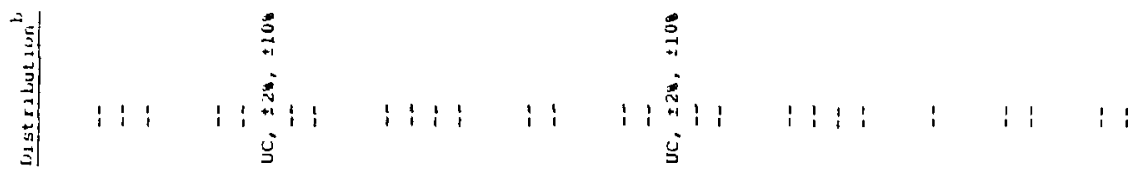

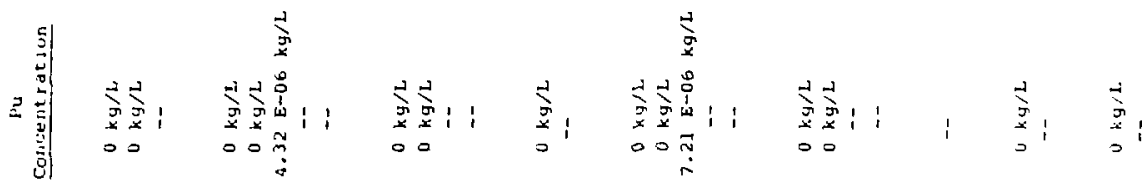

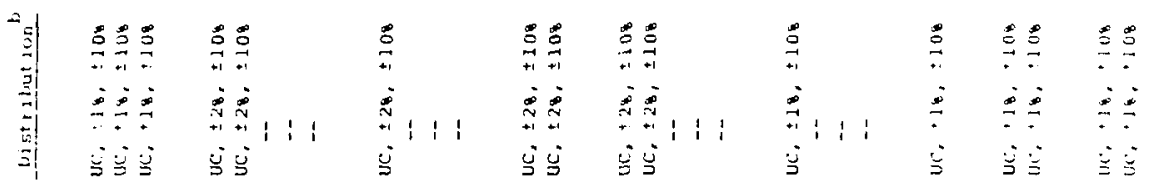

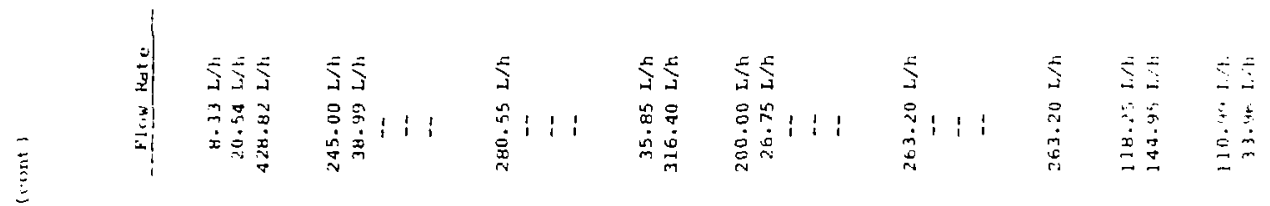

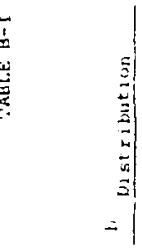

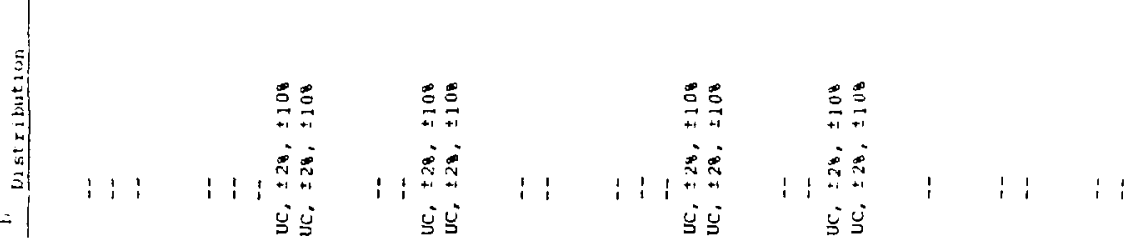

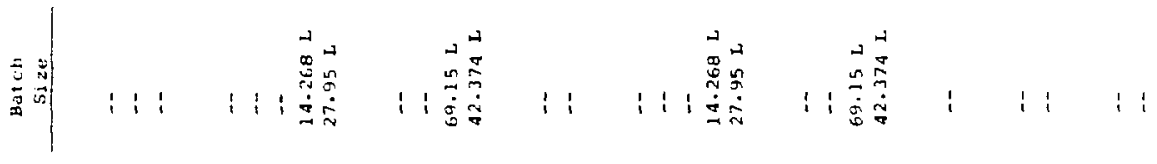

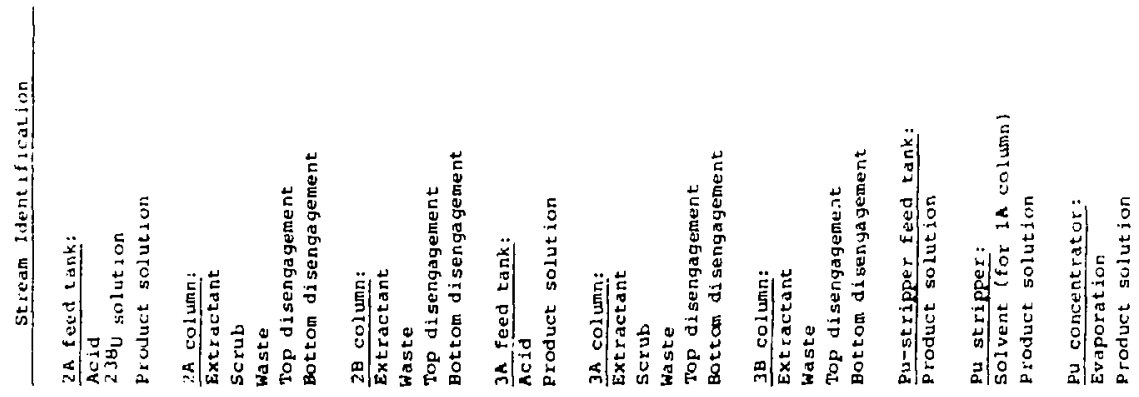

部 
TABLE B-I (cont)

\begin{tabular}{|c|c|c|c|c|c|c|c|}
\hline Stream Identification & $\begin{array}{r}\text { Bateh } \\
\text { Size } \\
\end{array}$ & Distribution & Flow Rate & Distribution & $\begin{array}{c}\mathrm{Pu} \\
\text { Concentration }\end{array}$ & bustribution $^{b}$ & $\begin{array}{l}\text { Time } \\
\text { (h) }\end{array}$ \\
\hline Pu sample tank: & & & & & & & \\
\hline $\begin{array}{l}\text { Acid } \\
238 \text { und }\end{array}$ & $54.01 \mathrm{~L}$ & $7, \pm 28$ & -- & -- & $0 \mathrm{~kg} / \mathrm{L}$ & -- & 12 \\
\hline
\end{tabular}

athese quantities are independent, stochastic variables in the computer simulation

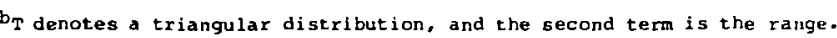

U denotes a uniform distribution, and the second term is the range.

UC denotes a constrained uniform distribution, the second term is the range, and the third term is the maximum change within the range for each time step.

LN denotes a four-parameter lognormal distribution, the second term is the normal mean, the third and fourth terms are the normal minimum and maximum values, respectively, and the fifth term is the nornal standard deviation.

CSDS: denotes secondary dissolver surge tank.

isst denotes sollds sample tank.

eValues represent the initlal (pre-recycle) quantities of solid plutonium output to the SST and the probabilities (for 6 d/wk without the addition of HA centrifuge solids) corresponding to each recycle case. These probabilities are lowered slightly 1 d/wk when HA centrlfuge solids are added to the SST.

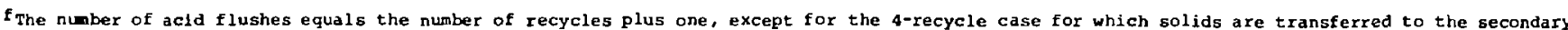
dibsolver after the fourth flush.

gHLW denotes high-level waste.

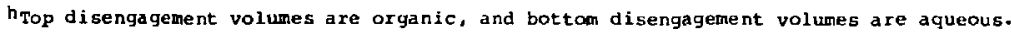


The leached hulls discharged from the continuous dissolver are transferred to metal scrap disposal, where individual batches are segregated on the basis of plutonium content. Ninety percent of the batches are modeled to meet specification ( $<8.3 \mathrm{~g}$ of plutonium/batch) and are transferred to waste as they are segregated. The off-specification batches are accumulated for $48 \mathrm{~h}$ and then transferred to the batch dissolver, where they are releached. Ninety-nine percent of the plutonium fed to the batch dissolver is recovered and transferred to the batch-dissolver surge tanks, and the releached hulls, containing the remainder of the plutonium, are transferred to waste. The product solution received in the batch-dissolver surge tanks is transferred to the primary centrifuge as eight separate batches, with one batch transfer made every $6 \mathrm{~h}$.

In the primary centrifuge, batches from the batch-dissolver surge tanks and alternately from one of the two digesters are combined and clarified every $6 \mathrm{~h}$. Solids collected in the centrifuge are segregated on the basis of their plutonium content. Only $\sim 1 \%$ of the solids batches meet specification $(<24 \mathrm{~g}$ of plutonium/batch) and these are transferred to HLW. The remaining offspecification batches are transferred to the secondary-dissolver surge tank and then to the secondary dissolver for additional dissolution treatment.

The secondary dissolver contents are transferred every $24 \mathrm{~h}$ to the leached.solids centrifuge, where the secondary dissolvent is clarified. Each batch of collected solids is washed with acid and then transferred to the solids sample tank. Solids from the HA centrifuge are transferred once every $7 \mathrm{~d}$ to the solids sample tank and combined with the solids transferred that day from the leached-solids centrifuge. Subsequent treatment of each batch depends on plutonium content. Off-specification batches ( $>24 \mathrm{~g}$ of plutonium/batch) are recycled to the leached-solids centrifuge up to three times and then, if the solids are still above specification, they are recycled to the secondary dissolver and combined with its contents for more intensive dissolution treatment. Batches meeting specification are transferred to HLW. Without the addition of HA centrifuge solids, $\imath 50 \%$ of the batches transferred to the solids sample tank require recycle. With the addition of HA centrifuge solids, once every 7 days $260 \%$ of the batches require recycle. Table $B-I$ gives the quantity of plutonium (five possible ranges) that a batch can contain when it is transferred from the leached-solids centrifuge to the solids sample tank for the first time. The probabilities associated with these ranges govern the likelihood that a batch will 
contain a certain amount of plutonium. When a batch requires $\leq 3$ recycles, each recycle reduces the quantity of undissolved plutonium to the next smaller range of plutonium values until the smallest range (no recycle) is reached. Then the batch is transferred to HLW. All recycling of batches requiring $\leq 3$ recycles is completed within $24 \mathrm{~h}$. When a batch requires four recycles, the first three recycles reduce the quantity of undissolved plutonium to a value within the one-recycle range, and then the batch is transferred from the solids sample tank to the secondary dissolver. Recycling time for batches requiring four recycles is $\geq 48 \mathrm{~h}$ and depends upon the subsequent recycle requirements of the secondary dissolver solids to which these batches are added.

Figures $A-3$ and $A-5$ represent the codecontamination/partitioning and copurification processes, respectively, of the HEF model. Together, these processes separate the fission products from the uranium and plutonium and produce (1) a purified, denatured uranium stream and (2) a purified, denatured plutonium stream having a uranium-to-plutonium ratio of $3: 1$.

The process equipment for codecontamination/partitioning and copurification includes a centrifuge, various process tanks, and a series of solventextraction contactors (one centrifugal contactor and the rest pulsed columns). In the contactors, uranium and plutonium are selectively transferred between relatively immiscible, countercurrent, aqueous and organic strearns. Estimation of in-process plutonium inventory in the solvent-extraction contactors is complex (Refs. 81, 82, 108-126). Modern systems identification and state estimation techniques potentially can provide the best possible estimates of contactor inventory. $124-126$

The full development of dynamic state estimation techniques for contactor inventory is a future goal for near-real-time materials accounting. A more restricted approach is used to estimate the contactor in-process inventories in the HEF model. We refer to this restricted state estimation scheme as "reduced-order" dynamic state estimation because, although the same three elements (models, measurements, and statistics) are required for its implementation, the scope of the required input information is restricted to a currently practicable level. The penalty is that the estimation model only applies over a limited range of near-steady-state run conditions.

Figures $B-1$ and $B-2$ give the basic equations for the restricted estimation model for the A-type (extraction/scrub) pulsed column of Fig. B-3. Figure B-1 lists the assumptions and the basic linear state and measurement equations. The 
Assumptions

1. The column is operating near a steady-stale operating point.

2. Tre column inventory near the operating Doint is linear in the concentrations.

3. Concentration measurements are available in near-real time.

4. The column inventory at the nominal operating

point has been previously determined from chemical model calculations and calibration experiments.
Fig. B-l.

Pulsed-column inventory linear estimator.

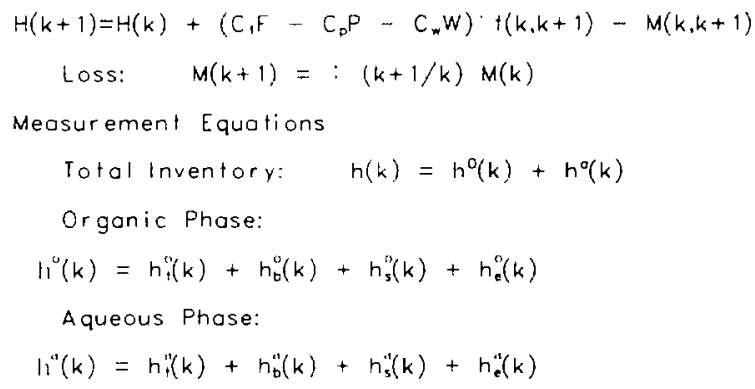

Fig. B-2.

"A" column measurement equations.
Top Section

$$
\begin{aligned}
& h_{1}^{0}(k)=h_{10}^{0}\left|\begin{array}{lll}
C_{p}(k) & V,(k) & 1 \\
C_{p 0} & V_{10} & 1
\end{array}\right| \\
& h_{1}^{\prime \prime}(k)=h_{10}^{\prime}
\end{aligned}
$$

Bottam Section

$$
\begin{aligned}
& h_{b}^{\circ}(k)=h_{b 0}^{0} \\
& h_{b}^{\prime \prime}(k)=h_{b 0}^{i} \mid \begin{array}{lll}
C_{m}(k) \\
C_{m 0}
\end{array} . \begin{array}{ll}
V_{D}(k) & 1 \\
V_{D 0} & 1
\end{array}
\end{aligned}
$$

Scrub Section

$$
\begin{aligned}
& h_{s}^{0}(k)=h_{s 0}^{0}\left|\begin{array}{l}
C_{p}(k) \\
C_{p 0}
\end{array}\right| \\
& h_{s}^{\prime \prime}(k)=h_{s 0}^{a}\left|\begin{array}{l}
C_{1}(k) \\
C_{10}
\end{array}\right| \\
& \text { Extraction section } \\
& h_{0}^{0}(k)=h_{00}^{0}\left|\begin{array}{l}
C_{p}(k) \\
C_{p 0}
\end{array}\right| \\
& h_{0}^{\prime a}(k)=h_{00}^{a}\left|\begin{array}{l}
C_{1}(k) \\
C_{10}
\end{array}\right|
\end{aligned}
$$

-The subscript 0 denotes nominal values at the operating point: $V_{\text {, }}$ and $V_{b}$ denope phase disengagement volumes at the top and battom ends of the column, respectively. 
"A" Column

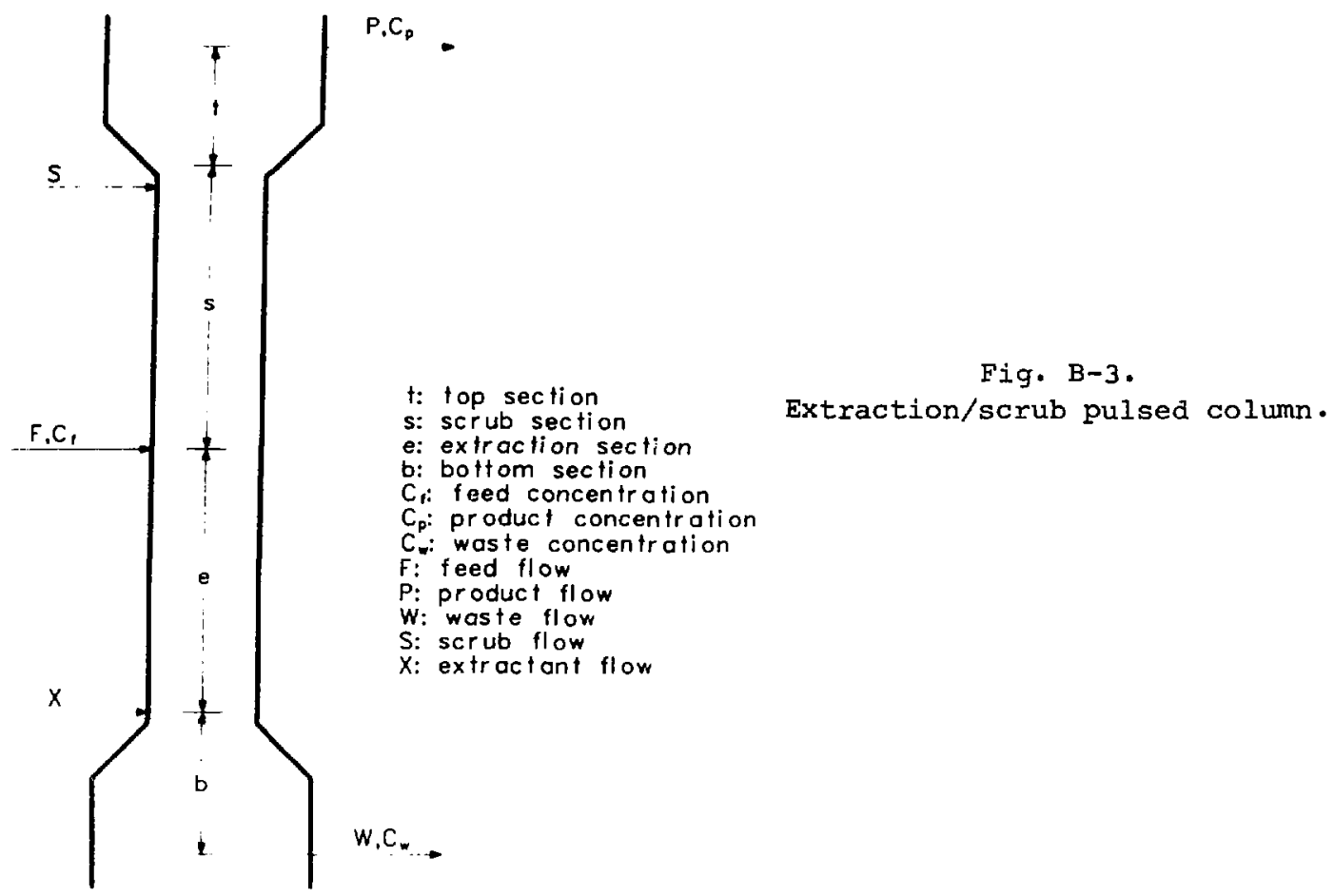

first state equation is the materials balance relating the column inventory $(H)$ at time $k+1$ to the inventory at time $k$. The remaining terms in the materials balance equation are the measured transfers of material across the column in the feed, product, and waste streams and any unmeasured losses $(M)$. The second state equation describes any postulated loss mechanism by choosing the specific form of the function $\phi$.

The inventory measurement equations in Figs. B-I and B-2 are linear equations for the inventories in the organic (superscript o) and the aqueous (superscript a) phases of the four sections of the column: top, bottom, scrub, and extraction. The inventory in each section is given by a first-order Taylor series expansion about the steady-state inventory. The first-order terms depend on ratios of the measured concentrations and volumes.

Steady-state column inventory values can be calculated for the expected runconditions using a detailed chemical model that has been validated experimentally for the particular contactor system. Alternatively, experiments 
can be performed to determine the expected inventories directly by bringing the columns to steady state and then drairing their contents into holding tanks for measurement. For the HEF model, we used ORNL's steady-state inventory estimate of $3 \mathrm{~kg}$ of plutonium for each pulsed column because design and operating information necessary for calculating steady-state inventory estimates was not availabie.

\section{MODEL Computer Code}

1. Introduction. The MODEL code ${ }^{127}$ was developed by the Los Alamos Safeguards Systems Group to model and simulate operation of nuclear materials processing facilities. Capability to address a variety of facility operations and ease of application were major considerations in the development of the code. MODEL is written in FORTRAN IV and employs the GASP IV simulation language $^{128}$ for event scheduling and overall integration of the process dynamics. The MODE.L code, in conjunction with the GASP IV simulation language, can model any processing facility where process behavior can be described by algebraic and differential equations. The primary outputs from the code are the important variables describing the process.

The MOUEL code has been under development for about four years. A

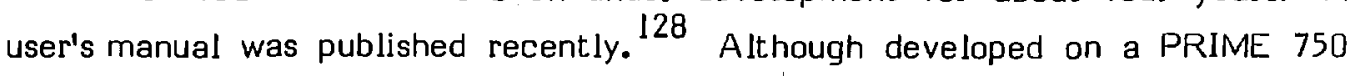
computer, the code is easily adapted to other machines. Recently it was implemented at the EURATOM Research Laboratories in Ispra, Italy, and Karlsruhe, Federal Republic of Germany.

2. Basic Structure. MODEL is divided into three parts for user convenience (Fig. B-4). Part I (MODFIX) is process independent and contains the main driver, input/output routines, and subroutines for modeling commonly occurring unit processes such as tanks and pulsed columns. Part II (GASP IV) is the GASP IV simulation package, which provides event scheduling, integration of differential equations, and other dynamic aspects of the modeling. Part III (MODVAR) is the user-supplied portion of the code and consists of process-dependent subroutines.

3. GASP IV Simulation Language. The MODEL code uses GASP IV simulation language primarily for integrating differential equations, scheduling events, and computing statistics for a given process. Process variables can be 


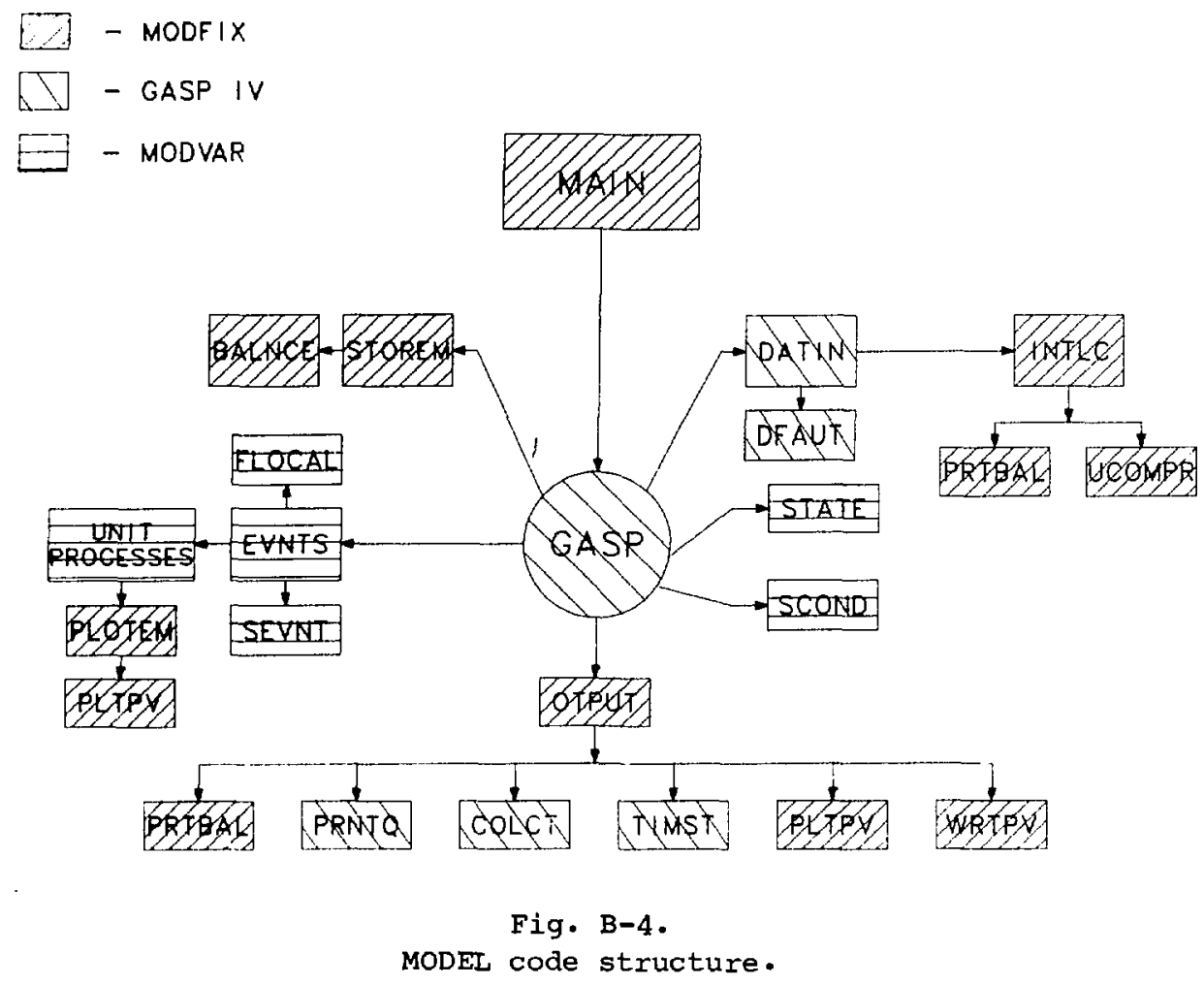

either discrete or continuous. GASP IV employs a fourth-order Runge Kutta algorithm for numerical integration of continuous process variables. GASP IV also can schedule both discrete and state events. Discrete events are scheduled to take place at a prescribed time and state events occur when a continuous variable crosses a prescribed boundary.

Any process variable can be modeled as a random variable by using the random-deviate generators within GASP IV. The five random-deviate generators that are currently available as function subroutines in the GASP IV portion of the MODEL code are the following.

UNFRM generates a deviate from a uniform distribution over some specified interval.

UNFRC is the same as UNFRM except that the change in the randoin variable on a given call to function UNFRC is limited to a specified subset of the uniform distribution interval.

RNORM generates a deviate from a normal distribution.

TRIAG generates a deviate from a triangular distribution.

RLOG generates a deviate from a lognormal distribution. 
D. HEFMOO Computer Code

1. Introduction. The HEFMOD computer code was developed by the Los Alamos Safeguards Systems Group to simulate operation of the HEF model. HEFMOD is written in FORTRAN IV and comprises the unit-process subroutines in parts I and III of the MODEL code. As part of the MOIJEL code, HEFMOD einploys GASP IV simulation language to schedule both discrete and state events and to provide other process dynamics. HEFMOD was developed and tested using a PRIME 750 computer and consists of $\sim 4000$ FORTRAN statements. Process simulations require $\sim 55000$ 16-bit words of storage, and additional storage is needed for graphics. A simulation of $1 \mathrm{yr}(8760 \mathrm{~h})$ of process operation requires ح $0.56 \mathrm{~h}$ of computer time.

2. Basic Structure. Subroutines in parts I and III of the MODEL code constitute HEFMOD and are used to model and simulate individual unit processes. Subroutines for the more common unit processes, such as the feed tanks, sample tanks, and solvent-extraction contactors, are available to the user in part 1 of the MODEL code. Part III of the MODEL code has subroutines for the more specialized unit processes, such as the continuous dissolver and solids sample tank. In many cases, a single subroutine models several unit processes of the same type to miniınize programming efforts.

When an event (for example, a mass transfer or an in-process inventory operation) occurs for a particular unit process, (1) a value for each independent random variable is sampled from the associated probability distributions, (2) the dependent process variables are calculated using mass conservation equations, and (3) all process variables are stored in the appropriate data array. The data arrays for all unit processes are stored sequentially in a data file. These data are available for further processing and as input to computer codes that simulate accountability measurements and materials balances.

To minimize FORTRAN coding changes required for evaluating alternative process operations, the input data contain much process-specific information. Input data include initial values for all process variables and values of the statistical parameters that describe each independent, stochastic variable. Nominal values and probability distributions for the independent random variables of the HEF model are given in Table B-I. 


\section{SAMPLE SIMULATION RESULTS}

Figures B-5 through B-20 are examples of nuclear material transfers and in-process inventories from a l-wk period of simulated steady-state process operation ( $24 \mathrm{~h} /$ day, 7 days/wk production). In each graph, the process variables plotted are either discrete (defined at prescribed times) or continuous. Except as noted in the text, the process variables are single-valued functions.

Collectively, Figs. B-5 through B-8 show plutonium content of the mass transfers and in-process inventory of the continuous dissolver. Figure B-5 shows the plutonium content (nominally $\sim 2.32 \mathrm{~kg}$ of plutonium) of the hulls accumulated every $0.5 \mathrm{~h}$ in the feed compartment of the continuous dissclver; the hulls are subsequently transferred into the first dissolver stage. Figure B-6 shows the plutonium mass flow rate (nominally $\sim 4.64 \mathrm{~kg} / \mathrm{h}$ of plutonium) in the continuous product stream of the dissolution process. Figure B-7 shows the plutonium in-process inventory (nominally $\sim 19 \mathrm{~kg}$ of plutonium) of the continuous dissolver. The inventory variation results from the $0.5-h$ dissolution cycle comprising hulls feed followed by hulls dissolution. Figure B-8 shows the lognormally distributed plutonium content (nominally $25 \mathrm{~g}$ of plutonium) of leached hulls discharged from stage seven of the continuous dissolver.

Figures $B-9$ and $B-10$ show the plutonium inventory of the in-specification and off-specification hulls, respectively. Figure B-9 shows the batch transfers of in-specification hulls to waste $(<28 \mathrm{~g}$ of plutonium/batch) and their subsequent accumulation over $24 \mathrm{~h}$. If each batch of leached hulls discharged from the continuous dissolver had met specification, transfers to waste would have occurred every $0.5 \mathrm{~h}$. However, $\sim 10 \%$ of the hulls batches are off specification and are accumulated for the batch dissolver rather than transferred to waste. Therefore, Fig. B-9 shows a few constant inventory periods of $>0.5 \mathrm{~h}$. Figure B- 10 shows three complete 48-h cycles during which off-specification batches are accumulated for $48 \mathrm{~h}$ and then transferred to the batch dissolver. Six batches are accumulated in the first cycle, nine in the second, and eight in the third.

Figure B-11 shows the plutonium content of the solids batches transferred from the leached-solids centrifuge to the solids sample tank. Solids meeting specification ( $<24 \mathrm{~g}$ of plutonium/batch) and thus requiring no additional recycle are received at $\sim 0 \mathrm{~h}, 272 \mathrm{~h}, 296 \mathrm{~h}$, and $\sim 120 \mathrm{~h}$, and subsequently transferred to HLW. Off-specification batches are received at $\sim 24 h, \sim 48 \mathrm{~h}$, and $\sim 144 \mathrm{~h}$, and 


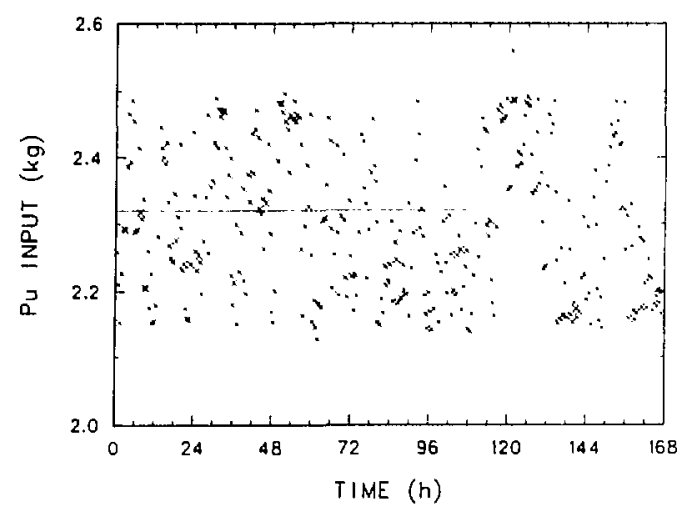

Fig. B-5.

Plutonium batch feed to the continuous dissolver.

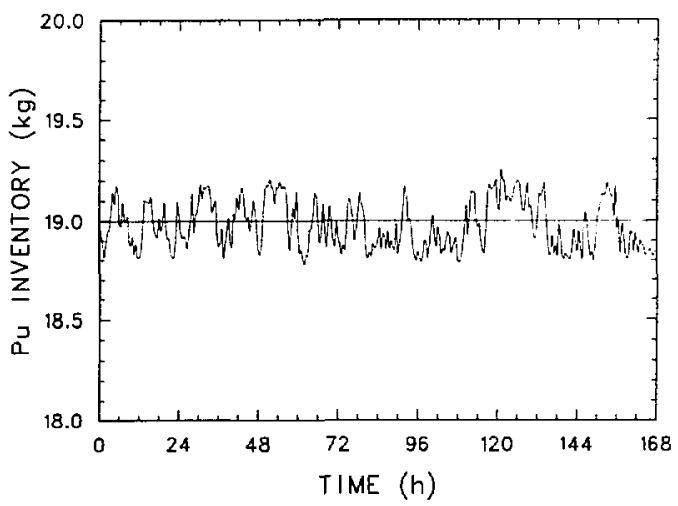

Fig. B-7.

Plutonium in-process inventory of the continuous dissolver.

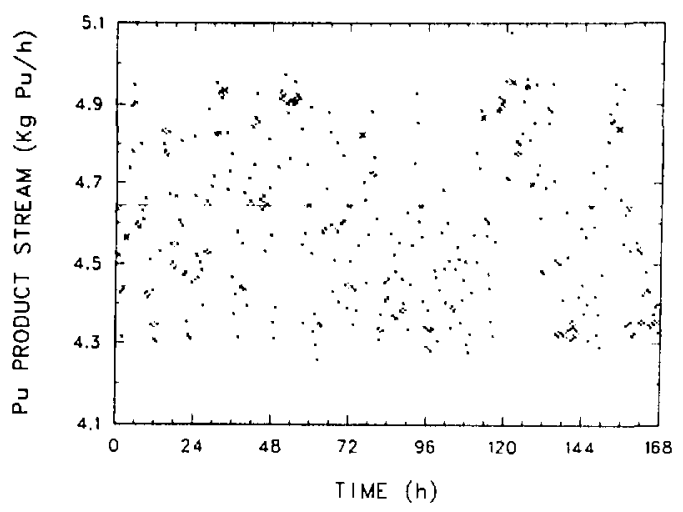

Fig. B-6.

Plutonium mass flow rate from the continuous dissolver.

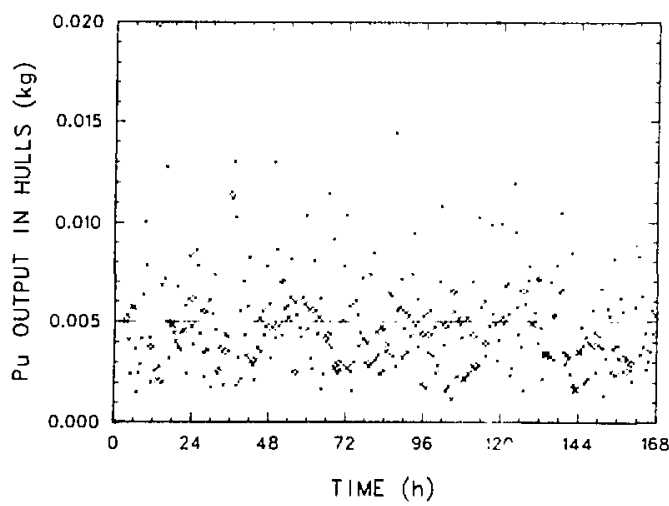

Fig. B-8. Plutonium content of leached hulls discharged from the continuous dissolver. 


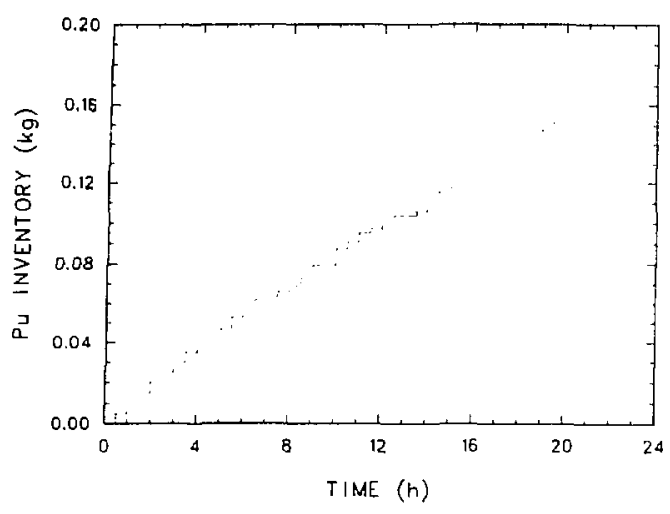

Fig. B-9.

Plutonium inventory of the inspecification leached hulls.

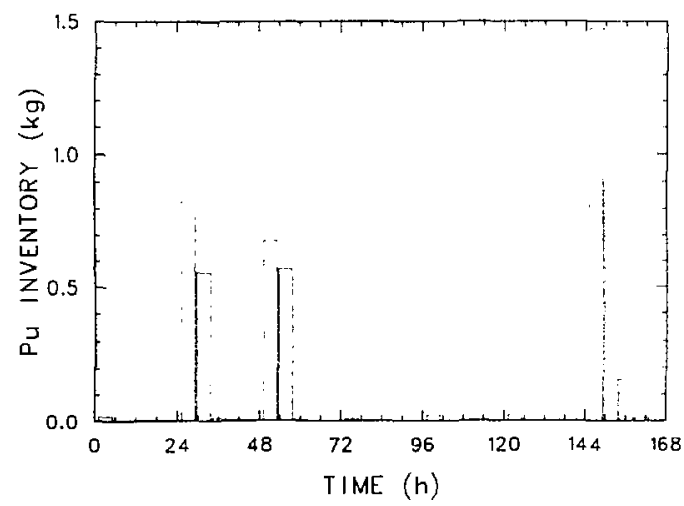

Fig. B-11. Plutonium inventory of the solids sample tank.

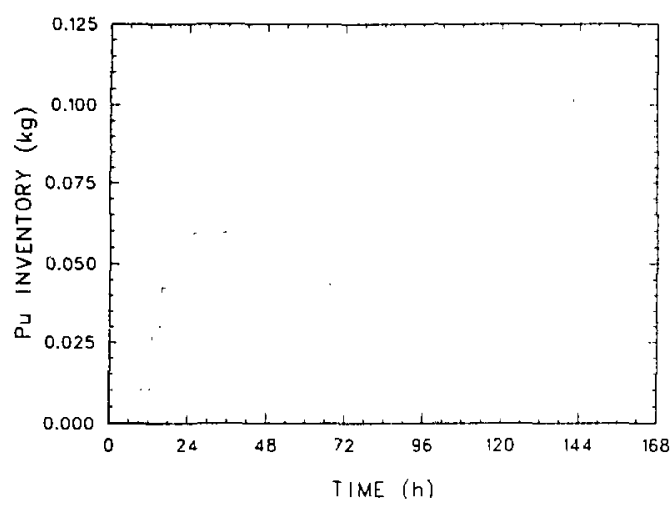

Fig. B-10.

Plutonium inventory of the of specification leached hulls.

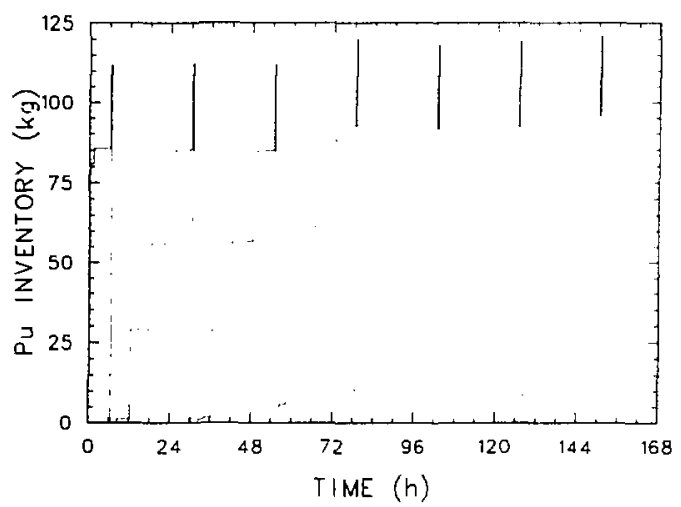

Fig. B-12

Plutonium inventory of the feed solution surge tank. 


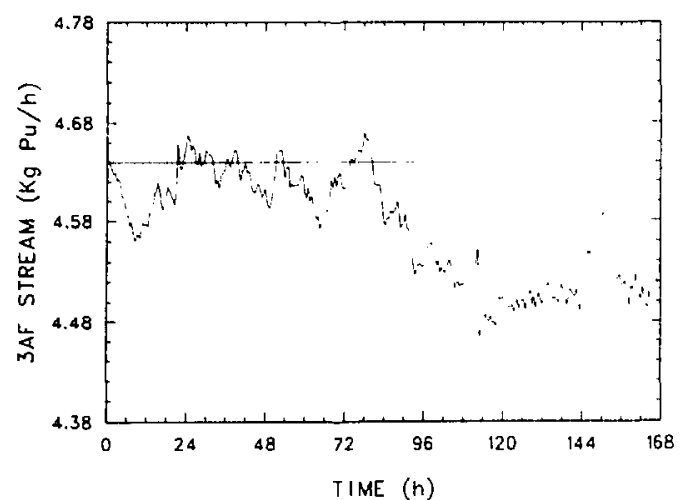

Fig. B-13.

Plutonium inventory of the accountability tank.

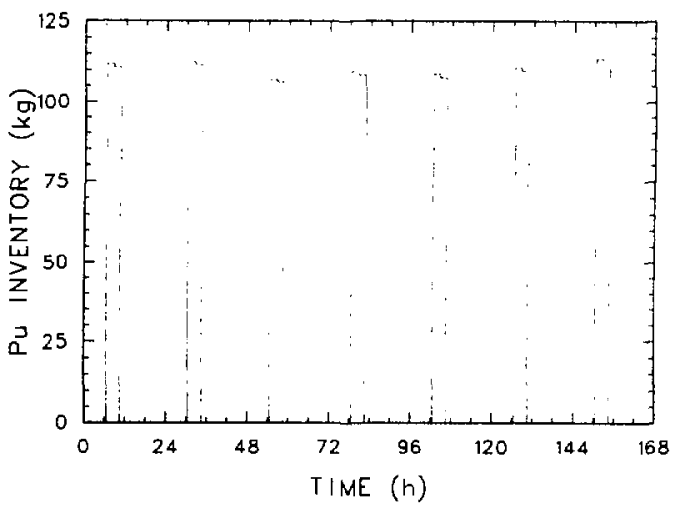

Fig. B-15.

Plutonium mass flow rate into the 3A pulsed column.

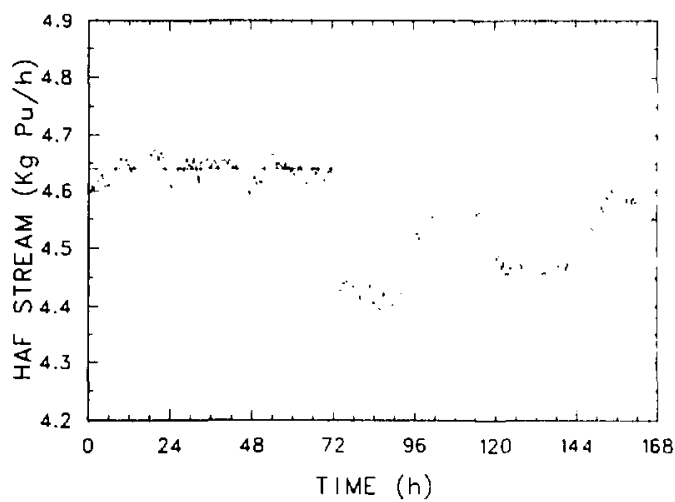

Fig. B-14. Plutonium mass flow rate into the HA centrifugal contactor.

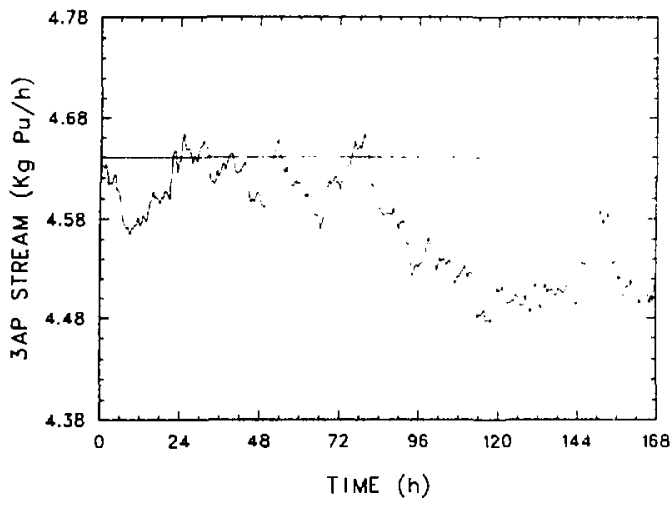

Fig. B-16.

Plutonium mass flow rate of the 3A pulsed-column product stream. 


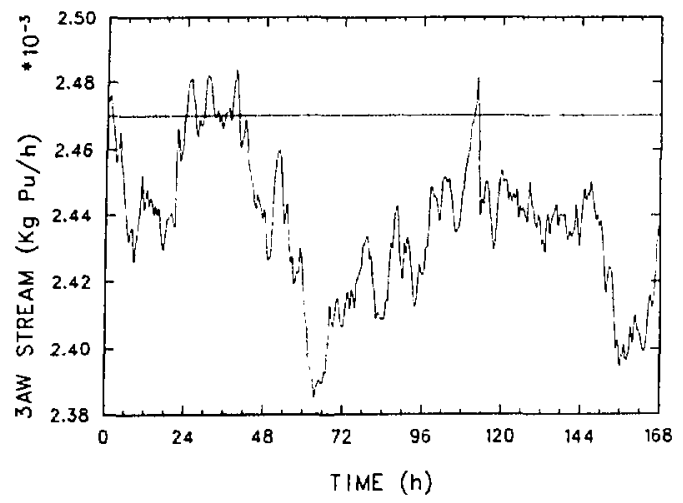

Fig. B-17.

Plutonium mass flow rate of the

3A pulsed-column waste stream.

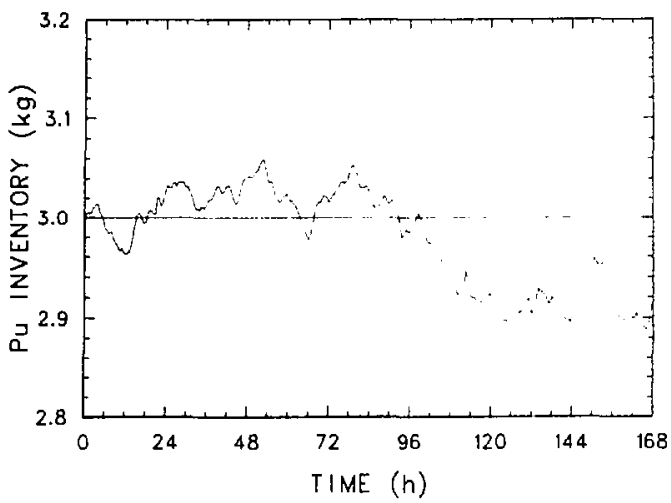

Fig. B-18.

Plutonium in-process inventory of the $3 \mathrm{~A}$ pulsed column.

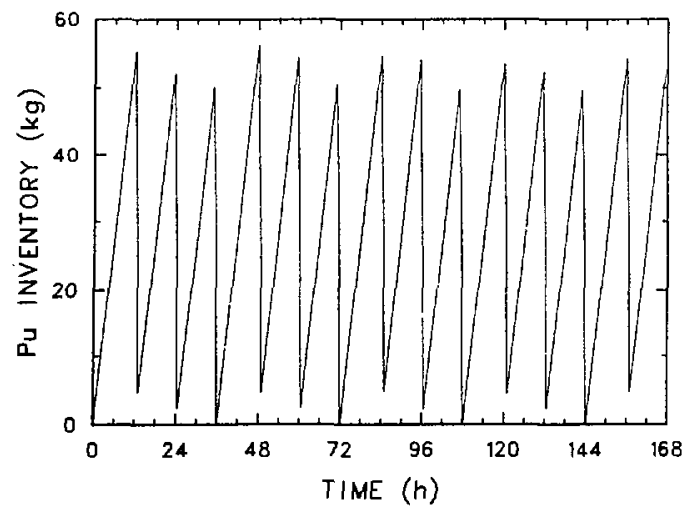

Fig. B-19. Plutonium inventory of the plutonium catch tank.

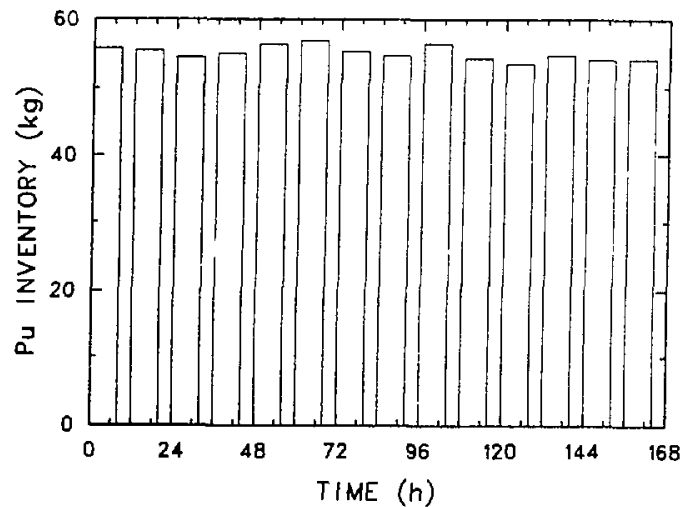

Fig. B-20. Plutonium inventory of the plutonium sample tank. 
these are recycled two, two, and three times, respectively, to meet specification. Each recycle reduces the quantity of undissolved plutonium to the next smaller range (Table $B-I$ ) until the smallest range (no recycle) is reached. Then the batch is transferred to $H L W$. All recycling of each batch requiring $\leq 3$ recycles is completed within $24 \mathrm{~h}$.

Figure B-12 shows the plutonium inventory of the feed solution surge tank. Six complete 24-h cycles of plutonium accumulation and discharge are shown, each comprising four batch receipts from the primary centrifuge, batch receipts from the leached-solids centrifuge and the accountability tank, and a single batch transfer to the accountability tank. For example, the third cycle begins at $\sim 54 \mathrm{~h}$ with a small inventory (heel) in the feed solution surge tank. Several batches are added to this heel, including those from : (1) the accountability tank (overflow) at $257 \mathrm{~h}$ (Fig. B-13); (2) the leached-solids centrifuge at $258 \mathrm{~h}$ and $273 \mathrm{~h}$ (Fig. B-14); and (3) the primary centrifuge at $\imath 60 \mathrm{~h}, \sim 66 \mathrm{~h}, 272 \mathrm{~h}$, and $\sim 78 \mathrm{~h}$. The third cycle finishes at $\sim 78 \mathrm{~h}, 24 \mathrm{~h}$ after it began, with a batch transfer to the accountability tank.

Figure B-13 shows the plutonium inventory of the accountability tank, which receives a batch from the feed solution surge tank every $24 \mathrm{~h}$. Two hours after a batch is received, the accountability tank volume is adjusted and the overflow (excess volume) is transferred back to the feed solution surge tank. Two hours later, the entire contents (nominally $\sim 112 \mathrm{~kg}$ of plutonium) of the accountability tank are transferred to the feed adjustment tank.

Figure B-14 shows the plutonium mass flow rate (nominally $24.63 \mathrm{~kg} / \mathrm{h}$ of plutonium) in the continuous feed stream of the HA centrifugal contactor. The smaller mass flow rates between $\imath 72$ and $\imath 96 \mathrm{~h}$ and again between $\sim 120$ and $\sim 144 \mathrm{~h}$ coincide with the smaller plutonium inventory transferred from the accountability tank at $\sim 58 \mathrm{~h}$ and $\sim 106 \mathrm{~h}$, respectively (see $\mathrm{Fig}$. B-13).

Together, Figs. B-15 through B-18 show plutonium content of the mass transfers and in-process inventory of the $3 \mathrm{~A}$ extraction-scrub pulsed column. Figure B- 15 shows plutonium mass flow rate (nominally $24.63 \mathrm{~kg} / \mathrm{h}$ of plutonium) in the continuous aqueous feed stream. Figure B-16 shows plutonium mass flow rate (nominally $24.63 \mathrm{~kg} / \mathrm{h}$ of plutonium) in the continuous organic product stream. Figure B-17 shows plutoniurn mass flow rate (nominally $<2.5 \mathrm{~g} / \mathrm{h}$ of plutonium) in the continuous aqueous waste stream. Figure B-18 shows total plutonium in-process inventory of the $3 \mathrm{~A}$ pulsed column. The in-process 
inventory was calculated using a reduced-order dynamic state estimation technique (see Appendix B, Sec. II.B.2) based on first-order perturbations about the expected steady-state column inventory. ORNL's steady-state inventory estimate of $3 \mathrm{~kg}$ of plutonium was used for each conceptual pulsed column in the HEF model because design and operating information necessary for calculating steady-state inventory estimates was not available.

Figure B- 19 shows plutonium inventory of the plutonium catch tank, which is fed continuously by the plutonium concentrator. The contents (nominally $\imath 56 \mathrm{~kg}$ of plutonium) of the plutonium catch tank are transferred every $12 \mathrm{~h}$ to the plutonium sample tank.

Figure B-20 shows the plutonium inventory of the plutonium sample tank. Eight hours after batch receipt from the plutonium catch tank, the contents (nominally $\sim 56 \mathrm{~kg}$ of plutonium) of the plutonium sample tank are transferred to either the off-specification plutonium tank (for off-specification batches) or the plutonium storage tanks (for in-specification batches). Batch transfer from the plutonium sample tank occurs every $12 \mathrm{~h}$. 


\section{APPENDIX C \\ MATERIALS ACCOUNTING EQUATIONS}

\section{INTRODUCTION}

Materials balance equations and their associated variance equations are derived in this appendix. The materials balance variance equations are used as constraints in the optimization calculations in Sec. IV. As indicated in Sec. 1 of the main text, materials accounting performance goals are based on the standard deviations of the short-term and long-term materials balances.

In the optimization calculations, materials inventories and transfers are assumed to be constants. This assumption simplities the constraint variance equations, and its effects are negligible, as demonstrated by the modeling and simulation results.

\section{MEASUREMENT MODELS}

Because the materials balances are computed using measured values of process variables, they contain measurement errors. Statistical properties for the errors can be determined from individual measurement error statistics.

In this study the measurements are modeled with the following equation:

$$
m=\mu(1+\varepsilon+\eta)+\theta,
$$

where $\mu$ is the actual value of a process variable, $m$ is the measured value of $\mu, \varepsilon$ is the precision measurement error, $\eta$ is the short-term correlated measurement error, and $\theta$ is the long-term correlated measurement error.

The above equation represents a mixed-mode measurement error model in that precision and short-term correlated errors are multiplicative and long-term correlated error is additive. The short-term correlated error ( $N$ ) changes when the measuring instrument is recalibrated, whereas the long-term correlated error 
$(\theta)$ remains constart. A major assumption in this study is tilat all measurement errors are mean-zero random variables.

\section{MATERIALS BALANCE}

In the general case, consider a UPAA where there are $L$ inventories and $K$ transfer locations. Then the conservation of mass, or materials balance (MB) equation over a time interval $t_{0}-t_{f}$ is

$$
M B=\sum_{k=1}^{L}\left[I_{k}(0)-I_{k}(f)\right]+\sum_{j=1}^{K} \sum_{i=1}^{N_{j}} T_{i j},
$$

where $I_{k}(0)$ is the $k^{\text {th }}$ initial inventory, $I_{k}(f)$ is the $k^{\text {th }}$ final inventory, $T_{i j}$ is the $i^{\text {th }}$ transfer at location $j$, and $N_{j}$ is the number of transfers at location $j$ over the interval $t_{0}-t_{f^{*}}$

The transfers, $T_{i j}$, are positive for inputs and negative for outputs. If the change in inventory, $\Delta \mathrm{I}_{\mathrm{k}}$, is defined by

$$
\Delta I_{k}=I_{k}(0)-I_{k}(f),
$$

then the materials balance becomes

$$
M B=\sum_{k=1}^{L} \Delta I_{k}+\sum_{j=1}^{K} \sum_{i=1}^{N j} T_{i j} .
$$

This equation is valid for both the short-term and long-term materials balances. $N_{j}$ is larger for long-term materials balances because of the longer time intervals. 
We now develop a general expression for the materials balance standard deviation. Random variable theory ${ }^{129}$ defines the mean value of a random variable $n$ as

$$
\mu=E\{n\},
$$

where $\mu$ is the mean value of $\eta$ and $E\{n\}$ is the expected value operator. The variance $\sigma_{\eta}^{2}$ of the random variable $\eta$ is defined as

$$
\sigma_{\eta}^{2}=E\left\{(\eta-\mu)^{2}\right\}
$$

Two mean-zero random variables $\eta$ and $\varepsilon$ are uncorrelated if

$$
E\{n \varepsilon\}=E\{n\} E\{\varepsilon\} .
$$

The variance of the sum of uncorrelated random variables is equal to the sum of the individual variances; that is, if $\varepsilon_{i}, \varepsilon_{j}, \eta_{k}, \ldots$ are uncorrelated random variables, then

$$
\sigma_{\left(\varepsilon_{i}+\varepsilon_{j}+n_{k}+\ldots\right)}^{2}=\sigma_{\varepsilon_{i}}^{2}+\sigma_{\varepsilon_{j}}^{2}+\sigma_{\eta_{k}}^{2}+\cdots
$$

If two random variables $\eta_{1}$ and $\eta_{2}$ are uncorrelated and $c_{1}$ and $c_{2}$ are constants, then $C_{1} \eta_{1}$ and $C_{2} \eta_{2}$ are also uncorrelated.

For the product of the constant $C$ and the random variable $n$,

$$
\sigma_{\mathrm{c} n}^{2}=\mathrm{c}^{2} \sigma_{n}^{2}
$$


The variance of constant $C$ is zero, that is,

$$
\sigma_{C}^{2}=0
$$

The above fundamentals from random variable theory are used below to develop an equation for the materials balance variance. The random variables in the materials balance equation [Eq. (C-4)] are the measurement errors in Eq. (C-1) for the general measurement model. A major simplifying assumption in this development is that the measurement error types, that is, $\varepsilon$, $n$, and $\theta$ in Eq. (C-1), are not correlated with each other. This leads to the conclusion that inventory changes $\Delta_{k}(k=1,2, \ldots, L)$ are not correlated with transfer sums $\sum \mathrm{T}_{\mathrm{ij}}(\mathrm{j}=1,2, \ldots, \mathrm{K})$. It follows from Eqs. $(\mathrm{C}-4)$ and $(\mathrm{C}-8)$ that

$$
\sigma_{\mathrm{MB}}^{2}=\sum_{\mathrm{k}=1}^{\mathrm{J}} \sigma_{\Delta \mathrm{I} k}^{2}+\sum_{j=1}^{K} \sigma_{\sum \mathrm{T}}^{2},
$$

where

$$
\sum T=\sum_{i=1}^{N} T_{i j}
$$

Eq. (C-11) forms the basis for the materials balance variance calculations.

\section{INDIVIDUAL INVENTORY VARIANCES}

In the preceding section the general expression for the materials balance variance was developed as in Eq. (C-11). In this section, individual inventory variances $\sigma_{\Delta 1_{k}}^{2}$ are derived for each inventory type encountered in the HEF 
process. There are two types of inventory determinations: (1) Type 1 is determined by a single measurement (for example, NDA) or estimate, and (2) Type 2 is determined by a product of two measurements (for example, volume and concentration).

A. Inventory as One Measured Value (Type 1)

The measured inventories at times $t_{0}$ and $t_{f}$ are, respectively,

$$
I_{m}(0)=I_{a}(0)\left(I+\varepsilon_{I}^{0}+\eta_{I}^{0}\right)+\theta_{I}
$$

and

$$
I_{m}(f)=I_{a}(f)\left(I+\varepsilon_{I}^{f}+\eta_{I}^{f}\right)+\theta_{I}
$$

where $I_{m}(0)$ is measured inventory at $t_{0}, I_{m}(f)$ is measured inventory at $t_{f}, I_{a}(0)$ is actual inventory at $t_{o}$, and $I_{a}(f)$ is actual inventory at $t_{f}$. Because by definition

$$
\Delta I=I_{m}(0)-I_{m}(E),
$$

it follows from Eqs. $(C-12)$ and $(C-13)$ that

$$
\Delta I=I_{m}(0)\left(I+\varepsilon_{I}^{O}+\eta_{I}^{O}\right)-I_{m}(f)\left(I+\varepsilon_{I}^{f}+\eta_{I}^{f}\right) \cdot(C-I 4)
$$

From Eqs. $(C-8)$ and $(C-9)$ it follows that the variance of the inventory change is 


$$
\sigma_{\Delta I}^{2}=\left[I_{a}(0)^{2}+I_{a}(f)^{2}\right] \sigma_{E_{I}}^{2}+\left[I_{a}(0)-I_{a}(f)\right]^{2} \sigma_{\eta_{I}}^{2},(C-15)
$$

where $\sigma_{\varepsilon}^{2}$ is the variance associated with precision inventory error and $\sigma_{\eta_{I}}^{2}$ is the variance associated with short-term correlated inventory error.

The actual value of the inventory is not known. Therefore, we estimate the variance by substituting the measured value for the actual value and will, henceforth, denote this estimate by an unsubscripted variable. We assume that the process is at steady state, that is, that it is in equilibrium about a constant mean. Thus, inventory in a given process vessel will not change significantly, that is, $I(0) \approx I(f)$. This condition implies that dependence of $\sigma_{\Delta I}^{2}$ on $\sigma_{\eta}^{2}$ is weak [Eq. $(C-15)]$; hence, a well-known value of $\sigma_{\eta_{I}}^{2}$ is not required and the variance associated with change in inventory is

$$
\sigma_{\Delta I}^{2}=2 I^{2} \sigma_{\varepsilon_{j}}^{2}
$$

B. Inventory as the Product of Two Measured Values (Type 2)

In this case, the measured inventory at any time is

$$
I_{m}(t)=I_{1 m}(t) I_{2 m}(t)
$$

where $I_{1 m}{ }^{(t)}$ and $I_{2 m}{ }^{(t)}$ are the two measured values (for example, volume and concentration) whose product yields the measured inventory $\left(\mathrm{I}_{\mathrm{m}}\right)$.

Using the same procedure as in the previous section, the variance of the inventory change is

$$
\sigma_{\Delta I}^{2}=2\left(I_{1} I_{2}\right)^{2}\left(\sigma_{\varepsilon I 1}^{2}+\sigma_{\varepsilon I 2}^{2}\right)
$$




\section{INDIVIDUAL TRANSFER VARIANCES}

Contributions of transfers to the materials balance variances are considered in this section. From Eq. (C-11), this contribution is

$$
\sum_{j=1}^{K} \sigma^{2} \mathrm{~T}
$$

where

$$
\sum \bar{i}=\sum_{i=1}^{N} T_{i j} .
$$

In this expression, $K$ represents the number of different locations in the accounting area where transfers occur and $N_{j}$ equals the number of transfers at a specific location over the materials balance interval. Transfers are positive for inputs and negative for outputs.

In considering the contribution of transfers to the overall materials balance variance, we cannot assume that correlated errors are zero. In most cases, these correlated errors are major contributors to the materials balance variance. Both short-term correlated errors $(n)$ and long-term correlated errors $(\theta)$ must be considered.

In deriving transfer variances, it is assumed that each short-term correlated error is recalibrated at regular intervals so that the number of transfers taking place between recalibrations is constant. Recalibration frequency, however, can be different for each short-term correlated error.

As with inventory variance calculations, we assume that transfers at a given process location are equal. This steady-state assumption simplifies the resulting transfer variance equations.

In the following two subsections, transfer variances are derived for the two cases occurring in the HEF process, (1) where the transfer equals a measured 
value and (2) where it equals the product of two measured values. The objective is to obtain the variance of transfer sums at a single location

$$
\sum T=\sum_{i=1}^{N} T_{i}
$$

where $N$ represents the number of transfers taking place over the materials balance interval.

\section{A. Transfer as One Measured Value (Type 1)}

The $\mathrm{i}^{\text {th }}$ transfer having one measured value is

$$
\mathrm{T}_{i \mathrm{~m}}=\mathrm{T}_{i}\left(I+\epsilon_{\mathrm{T}}^{i}+\eta_{\mathrm{T}}^{\mathrm{i}}\right)+\theta_{\mathrm{T}},
$$

where $T_{i m}$ is the measured value of the $i^{\text {th }}$ transfer at some location in the process, $T_{i}$ is the actual process value of the transfer, $\varepsilon_{T}^{j}$ is the precision for $i^{\text {th }}$ transfer, $n_{T}^{i}$ is the short-term correlated transfer error for $i^{\text {th }}$ transfer, and $\theta_{T}$ is the long-term correlated transfer error.

In general, the precision $\varepsilon_{T}^{i}$ is different for each transfer, the short-term correlated error $\eta_{T}^{i}$ changes only when the measuring instrument is recalibrated, and the long-term correlated error $\theta_{\mathbf{T}}$ is constant over the entire materials balance interval. For the short-term correlated errors we assume $M$ intervals separated by recalibrations, with $n$ transfers taking place in each interval. Thus, the total number of transfers $N$ is

$$
\mathbf{N}=\mathrm{Mn},
$$

where $N$ is the total number of transfers over the materials balance interval, $M$ is the number of intervals separated by recalibrations, and $n$ is the number of transfers in each recalibration interval. For the case of no recalibrations, $M=1$ and $n=N$. 
With $M$ and $n$ defined in the above manner, and letting

$$
\sum \mathrm{m}=\sum_{\mathrm{i}=1}^{\mathrm{N}} \mathrm{T}_{\mathrm{im}}
$$

it follows from Eq. (C-21) that

$$
\sum T=N T+T \sum_{i=1}^{N} \varepsilon_{T}^{i}+n T \sum_{j=1}^{M} n_{T}^{j}+N \theta_{T}
$$

In the above equation all error terms are uricorrelated. Hence, the variance of $\sum T$ can be found by adding the variances of each individual term. Because NT is a constant, it has a zero variance (Eq. C-10), and it follows that for a transfer consisting of one measured value

$$
\sigma^{2} \mathrm{~T}=\mathrm{N} \mathrm{m}^{2} \sigma_{\varepsilon_{\mathrm{T}}}^{2}+\mathrm{M}(\mathrm{Tn})^{2} \sigma_{\mathrm{n}_{\mathrm{T}}}^{2}+\mathrm{N}^{2} \sigma_{\theta_{\mathrm{T}}}^{2} .
$$

B. Transfer as the Product of Two Measured Values (Type 2)

The $\mathrm{i}^{\text {th }}$ transfer having two measured values is

$$
\begin{aligned}
\mathrm{T}_{\mathrm{im}}= & {\left[\mathrm{T}_{1}\left(1+\varepsilon_{\mathrm{T} 1}^{\mathrm{i}}+\mathrm{n}_{\mathrm{T} 1}^{\mathrm{i}}\right)+\theta_{\mathrm{T} 1}\right] } \\
& \cdot\left[\mathrm{T}_{2}\left(1+\varepsilon_{\mathrm{T} 2}^{\mathrm{i}}+\eta_{\mathrm{T} 2}^{\mathrm{i}}\right)+\theta_{\mathrm{T} 2}\right],
\end{aligned}
$$

where $T_{1}$ and $T_{2}$ are the actual process values whose product yields the transfer, and $\varepsilon_{T k}^{i}, \eta_{T k}^{i}$, and $\theta_{T k}(k=1,2)$ are the associated measurement errors. 
For $k=1$ or 2, let $N$ equal the total number of transfers over the materials balance interval, $M_{k}$ equal the number of intervals separated by recalibrations for ' $T{ }$ ' and $n_{k}$ equal the number of measurements in the recalibration interval for $\eta_{T k^{\cdot}}$. It follows that $N=M_{k} n_{k}(k=1,2)$. With no recalibrations, $M_{k}=1$ and $n_{k}=N$.

If we perform the indicated multiplications in Eq- (C-26) and neglect second-order error terms, we obtain

$$
\begin{aligned}
\mathrm{T}_{\mathrm{im}}= & \mathrm{T}_{1} \mathrm{~T}_{2}\left(1+\varepsilon_{\mathrm{T} 1}^{\mathrm{i}}+\varepsilon_{\mathrm{T} 2}^{\mathrm{i}}+\eta_{\mathrm{T} 1}^{\mathrm{i}}+\eta_{\mathrm{T} 2}^{\mathrm{i}}\right) \\
& +\mathrm{T}_{1} \theta_{\mathrm{T} 2}+\mathrm{T}_{2} \theta_{\mathrm{T} 1} .
\end{aligned}
$$

Using the definition of $\left[T\right.$ from Eq. $(C-23)$ and $N, M_{k}$, and $n_{k}(k=1,2)$ as defined above, it follows that

$$
\begin{gathered}
\sum \mathrm{r}=\mathrm{NT}_{1} \mathrm{~T}_{2}+\mathrm{T}_{1} \mathrm{~T}_{2} \sum_{\mathrm{i}=1}^{\mathrm{N}}\left(\varepsilon_{\mathrm{T} 1}^{\mathrm{i}}+\varepsilon_{\mathrm{T} 2}^{j}\right)+\mathrm{n}_{1} \mathrm{~T}_{1} \mathrm{~T}_{2} \sum_{j=1}^{\mathrm{M}_{1}} \mathrm{n}_{\mathrm{T} 1}^{\mathrm{j}} \\
+\mathrm{n}_{2} \mathrm{~T}_{1} \mathrm{~T}_{2} \sum_{j=1}^{\mathrm{M}_{2}} \mathrm{n}_{\mathrm{T} 2}^{\mathrm{j}}+\mathrm{NT}_{2} \theta_{\mathrm{T} 1}+\mathrm{NT}_{1} \theta_{\mathrm{T} 2}
\end{gathered}
$$

Again, because all error terms are uncorrelated, the variance of the sum equals the sum of the individual variances associated with each error. Applying Eqs. (C-9) and (C-10) gives

$$
\begin{aligned}
\sigma^{2} \mathrm{~T}= & \mathrm{N}\left(\mathrm{T}_{1} \mathrm{~T}_{2}\right)^{2}\left(\sigma_{\varepsilon \mathrm{T} 1}^{2}+\sigma_{\varepsilon \mathrm{T} 2}^{2}\right)+\left(\mathrm{n}_{1} \mathrm{~T}_{1} \mathrm{~T}_{2}\right){ }^{2} \mathrm{M}_{1} \sigma_{\mathrm{NT} 1}^{2} \\
& +\left(\mathrm{n}_{2} \mathrm{~T}_{1} \mathrm{~T}_{2}\right)^{2} \mathrm{M}_{2} \sigma_{\eta \mathrm{T} 2}^{2}+\left(\mathrm{NT}_{2}\right)^{2} \sigma_{\theta \mathrm{T} 1}^{2}+\left(\mathrm{NT}_{1}\right)^{2} \sigma_{\theta \mathrm{T} 2}^{2}
\end{aligned}
$$

as the variance equation for type 2 transfers. 


\section{MATERIALS BALANCE VARIANCES FUR HEF UPAA}

As indicated previously, this appendix derives materials balance variances associated with HEF UPAAs being considered in this study. Assuming uncorrelated measurement errors, we simplified materials balance variances to terms associated with individual inventory and transfer errors.

Section $\mathrm{V}$ of this appendix developed the inventory variance terms for the two types of inventories appearing in the HEF processes. In type 1 , the inventory equals a single measured value or an estimate, whereas type 2 is computed from the product of two measured values. Examples of type $I$ are the voloxidizer and the pulsed columns, where the plutonium inventories are estimated. An example of type 2 is the HA feed tank, where the inventory is the product of volume and concentration measurements.

The materials balance variances associated with the two types of transfers in the HEF accounting areas were derived in Sec. VI of this appendix. Type 1 is computed from a single measured value, whereas type 2 equals the product of two measured values. As an example, input to the disassembly is modeled as a type 1 transfer because plutonium content of the input fuel assembly is measured directly by NDA. Output from the accountability tank to the feed adjustment tank is an example of a type 2 transfer, where the transfer is the product of volume and concentration measurements. Because we assume constant process variables, we can consider the output of the $1 \mathrm{~A}$ column as a type 2 transfer. The two measurements in this case are flow rate and concentration. The transfer is the product of flow rate, concentration, and the interval $(\Delta T)$ between the measurements, which is assumed to remain constant. By including the constant $\Delta T$ with flow rate and considering the first measurement to be the product of flow rate and $\Delta T$, we can consider this transfer as type 2.

The materials balance variance for a given accounting area can be computed by summing its appropriate inventory and transfer variances. Equation (C-18) provides the variances for type 1 and type 2 inventories, respectively, and Eqs. (C-25) and (C-29) represent the corresponding variances for type 1 and type 2 transfers. Inspection of these equations reveals that they all have a similar structure, namely, a sum of terms where each term is the product of a constant and the variance of a measurement error. Hence, the total materials balance 
variance for a given accounting area can be written as the sum of terms consisting of the individual measurement variances multiplied by suitable constants; that is,

$$
\sigma_{M B}^{2}=\sum_{i=1}^{N_{m}} B_{i} \sigma_{i}^{2},
$$

where $\mathrm{N}_{\mathrm{m}}$ is the number of measurement errors contributing to the materials balance variance, $\mathrm{B}_{i}$ is the constant associated with the $i^{\text {th }}$ measurement errors, and $\sigma_{i}^{2}$ is the variance of the $i^{\text {th }}$ measurement error.

The constants $B_{i}$ in Eq. (C-30) can be obtained from Eq. (C-1B) for type 1 and type 2 inventories and from Eqs. (C-25) and ( $(-29)$, respectively, for type 1 and type 2 transfers. Because the amount of material processed is a function of time, a different constant is required for the abrupt $\left(B_{\alpha}\right)$ and protracted $\left(B_{p_{i}}\right)$ constraints.

Table C-I contains the information necessary to compute the materials balance variances for each accounting area considered. Measurement errors in the table contribute a term in the sum for the materials balance variance $\sigma_{\mathrm{MB}}^{2}$. The first column of the table gives the measurement location. Column 2 gives the particular measurement type. For these measurements

$$
\begin{aligned}
& T=\text { plutonium transfer, } \\
& \mathbf{I}=\text { plutonium inventory, } \\
& V=\text { volume, } \\
& \mathrm{C}=\text { concentration, } \\
& F=\text { flow rate, and } \\
& \Delta T=\text { interval between flow rate measurements. }
\end{aligned}
$$

The nominal values for these measured values are given in column 3 of the table. Transfers and inventories are in kilograms, volumes in liters, concentrations in kilograms per liter, flow rates in liters per hour, and time in hours. Measurement error types are given in the fourth column, where $\varepsilon$ is the precision error, $\eta$ is the short-term correlated error, and $\theta$ is the long-term correlated error. The corresponding measurement error relative standard deviations $(1 \sigma)$ are given in 
TABLE C-I

CONSTANTS FOR THE MATERIALS BALANCE VARIANCE EQUATIUN

$$
\sigma_{M B}^{2}=\sum_{i=1}^{N} B_{i} \sigma_{i}^{2}
$$

\begin{tabular}{|c|c|c|c|c|c|c|c|c|c|c|c|c|c|}
\hline & \multirow[b]{2}{*}{ Process } & \multirow[b]{2}{*}{ Measurement } & \multirow{2}{*}{$\begin{array}{l}\text { Nominal } \\
\text { Value }\end{array}$} & \multirow[b]{2}{*}{ Error } & \multirow[b]{2}{*}{$\underline{a_{i}}$} & \multirow[b]{2}{*}{ Type } & \multirow[b]{2}{*}{$\underline{B}_{\mathbf{i}}$} & \multicolumn{3}{|c|}{$\begin{array}{c}\text { Short Term } \\
\text { (Goal 1) }\end{array}$} & \multicolumn{3}{|c|}{$\begin{array}{c}\text { Long Term } \\
\text { (Goal } 1 \\
\text { Recalibration) }\end{array}$} \\
\hline & & & & & & & & $N$ & $M$ & $n$ & $N$ & $\mathbf{M}$ & $n$ \\
\hline 1 & Disassembly input & $\mathrm{T}$ & 14.58 & $\varepsilon$ & 0.04 & TI & $\mathrm{NT}^{2}$ & 8 & 1 & 8 & 1200 & 21 & 56 \\
\hline 2 & Disassembly input & $T$ & 14.58 & $\eta$ & 0.03 & $\mathrm{~T} I$ & $M(n T)^{2}$ & 8 & 1 & 8 & 1200 & 21 & 56 \\
\hline 3 & DisassembIy input & $\mathbf{T}$ & 14.58 & $\theta$ & 0.29 & $\mathrm{Tl}$ & $\mathrm{N}^{2}$ & 8 & 1 & 8 & 1200 & 21 & 56 \\
\hline 4 & Disassembly & $I$ & 14.58 & $E$ & 0.2 & Il & $2 \mathrm{I}^{2}$ & - & - & - & - & - & - \\
\hline 5 & Shear & I & 7.29 & $\varepsilon$ & 0.2 & I1 & $2 I^{2}$ & - & - & - & - & - & - \\
\hline 6 & Voloxidizer & I & 26.24 & $\varepsilon$ & 0.2 & Il & $2 \mathrm{I}^{2}$ & - & - & - & - & - & - \\
\hline 7 & Continous dissolver & $\mathbf{I}$ & 19.0 & $\varepsilon$ & 0.2 & Il & $2 I^{2}$ & - & - & - & - & - & - \\
\hline 8 & Digester (2) & $\mathrm{v}$ & 594.79 & $\varepsilon$ & 0.3 & I2 & $2(v c)^{2}$ & - & - & - & - & - & - \\
\hline 9 & Digester (2) & $c$ & 0.0468 & $\varepsilon$ & 0.015 & I2 & $2(\mathrm{vc})^{2}$ & - & - & - & - & - & - \\
\hline 10 & Hulls & $\mathbf{I}$ & 0.24 & $E$ & 0.1 & Il & $2 I^{2}$ & - & - & - & - & - & - \\
\hline 11 & Hulls to hulls waste & $\mathbf{T}$ & 0.005 & $\varepsilon$ & 0.1 & $\mathrm{~T} 1$ & $\mathrm{NT}^{2}$ & 8 & 1 & 8 & 1200 & 21 & 56 \\
\hline 12 & tulls to hulls waste & $\mathrm{T}$ & 0.005 & $\eta$ & 0.05 & $\mathrm{Tl}$ & $M(n T)^{2}$ & 8 & 1 & 8 & 1200 & 21 & 56 \\
\hline 13 & Hulls to hulls waste & $\mathrm{T}$ & 0.005 & $\theta$ & 0.00025 & $\mathrm{~T} 1$ & $\mathrm{~N}^{2}$ & 8 & $\perp$ & 8 & 1200 & 21 & 56 \\
\hline 14 & Batch dissolver & $v$ & 314.3 & $\varepsilon$ & 0.03 & I2 & $2(v c)^{2}$ & - & - & - & - & - & - \\
\hline 15 & Batch dissolver & c & 0.00137 & $\varepsilon$ & 0.015 & 12 & $2(v c)^{2}$ & - & - & - & - & - & - \\
\hline 16 & Acid surge tank & $v$ & 273.22 & $\varepsilon$ & 0.03 & I2 & $2(\mathrm{VC})^{2}$ & - & - & - & - & - & - \\
\hline 17 & Acid surge tank & C & 0.0009 & $\varepsilon$ & 0.015 & I 2 & $2(v c)^{2}$ & - & - & - & - & - & - \\
\hline
\end{tabular}




\begin{tabular}{|c|c|c|c|c|c|c|c|c|c|c|c|c|c|}
\hline & \multirow[b]{2}{*}{ Process } & \multirow[b]{2}{*}{ Measurement } & \multirow{2}{*}{$\begin{array}{c}\text { Nominal } \\
\text { value }\end{array}$} & \multirow[b]{2}{*}{ Error } & \multirow[b]{2}{*}{$\sigma_{i}$} & \multirow[b]{2}{*}{ Type } & \multirow[b]{2}{*}{$B_{\mathbf{i}}$} & \multicolumn{3}{|c|}{$\begin{array}{c}\text { Short Terin } \\
(\text { Goal } 1)\end{array}$} & \multicolumn{3}{|c|}{$\begin{array}{c}\text { Long Term } \\
\text { (Goal } 2 \\
\text { Recalibration) } \\
\end{array}$} \\
\hline & & & & & & & & $\mathbf{N}$ & $\underline{M}$ & $\mathrm{n}$ & $\mathbf{N}$ & $M$ & $\mathbf{n}$ \\
\hline 18 & Primary centrifuge to HLW & $\mathrm{T}$ & 0.024 & $E$ & 0.1 & $\mathrm{Tl}$ & $\mathrm{NT}^{2}$ & 0 & 0 & 0 & 6 & 1 & 6 \\
\hline 19 & Primary centrifuge to $\mathrm{HLH}$ & $\mathrm{T}$ & 0.024 & $n$ & 0.05 & Tl & $M(n T)^{2}$ & 0 & 0 & 0 & 6 & 1 & 6 \\
\hline 20 & Primary centrifuge to HLW & $\mathbf{T}$ & 0.024 & $\theta$ & 0.0012 & T1 & $\mathrm{N}^{2}$ & 0 & 0 & 0 & 6 & 1 & 6 \\
\hline 21 & $\begin{array}{l}\text { Secondary dissolver surge } \\
\text { tank }\end{array}$ & I & 2.4 & $\varepsilon$ & 0.1 & Il & $2 I^{2}$ & - & - & - & - & - & - \\
\hline 22 & Secondary dissol ver & $\mathrm{v}$ & 125.36 & $\varepsilon$ & 0.03 & $\mathrm{I} 2$ & $2(\mathrm{vc})^{2}$ & - & - & - & - & - & - \\
\hline 23 & Secondary dissolver & c & 0.03829 & $\varepsilon$ & 0.07 & I2 & $2(v c)^{2}$ & - & - & - & - & - & - \\
\hline 24 & SST to HLW & $\mathrm{T}$ & 0.012 & $\varepsilon$ & 0.1 & $\mathrm{~T} 1$ & $\mathrm{NT}^{2}$ & 1 & 1 & 1 & 150 & 21 & 7 \\
\hline 25 & SST to HLW & $\mathrm{T}$ & 0.012 & $n$ & 0.05 & $\mathrm{Tl}$ & $M(n T)^{2}$ & 1 & 1 & 1 & 150 & 21 & 7 \\
\hline 26 & SST to HLW & T & 0.012 & $\theta$ & 0.0006 & T1 & $\mathrm{N}^{2}$ & 1 & 1 & 1 & 150 & 21 & 7 \\
\hline 27 & HA centrifuge to SST & $\mathbf{T}$ & 0.0076 & $\varepsilon$ & 0.1 & $\mathrm{Tl}$ & $\mathrm{NT}^{2}$ & 0 & 0 & 0 & 22 & 1 & 22 \\
\hline 28 & HA centrifuge to SST & $\mathrm{T}$ & 0.0076 & $n$ & 0.05 & TI & $M(n T)^{2}$ & 0 & 0 & 0 & 22 & 1 & 22 \\
\hline 29 & HA centrifuge to SST & $\mathbf{T}$ & 0.0076 & $\theta$ & 0.00038 & Tl & $\mathrm{N}^{2}$ & 0 & 0 & 0 & 22 & 1 & 22 \\
\hline 30 & Feed solution surge tank & $\mathrm{v}$ & 1220.7 & E & 0.03 & I2 & $2(\mathrm{Vc})^{2}$ & - & - & - & - & - & - \\
\hline 31 & Feed solution surge tank & c & 0.044 & $\varepsilon$ & 0.015 & I2 & $2(\mathrm{vc})^{2}$ & - & - & - & - & - & - \\
\hline 32 & Accountability tank output & $\mathrm{v}$ & 2528.9 & E & 0.003 & $\mathrm{~T}^{2}$ & $\mathrm{~N}(\mathrm{vC})^{2}$ & 1 & 1 & 1 & 150 & 1 & 150 \\
\hline 33 & Accountability tank output & $\mathrm{v}$ & 2528.9 & $n$ & 0.001 & $\mathrm{~T} 2$ & $M(n V C)^{2}$ & 1 & 1 & 1 & 150 & 1 & 150 \\
\hline 34 & Accountability tank output & $\mathrm{v}$ & 2528.9 & $\theta$ & 2.529 & T2 & $(\mathrm{NC})^{2}$ & 1 & 1 & 1 & 150 & 1 & 150 \\
\hline $35^{*}$ & Accountability tank output & $\mathrm{c}$ & 0.044 & $\varepsilon$ & 0.01 & $\mathrm{~T} 2$ & $\mathrm{~N}(\mathrm{vc})^{2}$ & 1 & 1 & 1 & 150 & 21 & 7 \\
\hline 36 & Accountability tank output & c & 0.044 & $n$ & 0.003 & $\mathrm{~T} 2$ & $M(n V C)^{2}$ & 1 & 1 & 1 & 150 & 21 & 7 \\
\hline 37 & Accountability tank output & c & 0.044 & $\theta$ & 0.000132 & T2 & $(\mathrm{Nv})^{2}$ & 2 & 1 & 1 & 150 & 21 & 7 \\
\hline
\end{tabular}


TABLE C-I (cont)

\begin{tabular}{|c|c|c|c|c|c|c|c|c|c|c|c|c|c|}
\hline & \multirow[b]{2}{*}{ Process } & \multirow[b]{2}{*}{ Mea surement } & \multirow{2}{*}{$\begin{array}{c}\text { Nominal } \\
\text { Value }\end{array}$} & \multirow[b]{2}{*}{ Error } & \multirow[b]{2}{*}{$\sigma_{i}$} & \multirow[b]{2}{*}{ Type } & \multirow[b]{2}{*}{$B_{i}$} & \multicolumn{3}{|c|}{$\begin{array}{c}\text { Short Term } \\
\text { (Goal } 1)\end{array}$} & \multicolumn{3}{|c|}{$\begin{array}{c}\text { Long Term } \\
\text { (Goal } 2 \\
\text { Recalibration) } \\
\end{array}$} \\
\hline & & & & & & & & $\mathrm{N}$ & $\underline{M}$ & $\bar{n}$ & $\mathrm{~N}$ & $M$ & $n$ \\
\hline 38 & HA feed tank & $\mathrm{v}$ & $3648 \cdot 24$ & $\varepsilon$ & 0.03 & I 2 & $2(v c)^{2}$ & - & - & - & - & - & - \\
\hline 39 & HA feed tank & C & 0.0305 & $\varepsilon$ & 0.015 & I 2 & $2(v c)^{2}$ & - & - & - & - & - & - \\
\hline 40 & HA centrifuge & I & 0.00374 & $E$ & 0.2 & Il & $2 I^{2}$ & - & - & - & - & - & - \\
\hline 41 & HA contactor & I & 0.4 & $E$ & 0.2 & Il & $2 I^{2}$ & - & - & - & - & - & - \\
\hline 42 & HS column & I & 3.0 & $E$ & 0.1 & Il & $2 I^{2}$ & - & - & - & - & - & - \\
\hline 43 & HC column & I & 3.0 & $\varepsilon$ & 0.1 & Il & $2 \mathrm{I}^{2}$ & - & - & - & - & - & - \\
\hline 44 & HCP reducer & $\mathrm{v}$ & 1024.59 & $\varepsilon$ & 0.03 & I 2 & $2(v C)^{2}$ & - & - & - & - & - & - \\
\hline 45 & HCP reducer & C & 0.01468 & $E$ & 0.01 & I 2 & $2(V C)^{2}$ & - & - & - & - & - & - \\
\hline 46 & lA Eeed tank & $\mathrm{v}$ & 869.565 & $\varepsilon$ & 0.03 & I2 & $2(v c)^{2}$ & - & - & - & - & - & - \\
\hline 47 & lA feed tank & $\ddot{c}$ & 0.01268 & $\varepsilon$ & 0.01 & I 2 & $2(\mathrm{vc})^{2}$ & - & - & - & - & - & - \\
\hline 48 & IA column & I & 3.0 & $\varepsilon$ & 0.01 & Il & $2 I^{2}$ & - & - & - & - & - & - \\
\hline 49 & IA column output & $\mathbf{F} \Delta \mathbf{T}$ & 199.975 & $\varepsilon$ & 0.025 & $\mathrm{~T} 2$ & $\mathbf{N}(\mathrm{F} \Delta \mathrm{TC})^{2}$ & 48 & 1 & 48 & 7200 & 21 & 336 \\
\hline 50 & IA column output & $\mathrm{F} \Delta \mathrm{T}$ & 199.975 & $n$ & 0.015 & $\mathrm{~T} 2$ & $M(\mathrm{nF} \Delta \mathrm{TC})^{2}$ & 48 & 1 & 48 & 7200 & 21 & 336 \\
\hline 51 & IA column output & $F \triangle T$ & 199.975 & $\theta$ & 2.00 & $\mathrm{~T} 2$ & $(\mathrm{NC} \Delta \mathrm{T})^{2}$ & 48 & 1 & 48 & 7200 & 21 & 336 \\
\hline 52 & IA column output & C & 0.0116 & $\mathrm{~F}$ & 0.01 & T2 & $\mathrm{N}(\mathrm{F} \Delta \mathrm{TC})^{2}$ & 48 & 1 & 48 & 7200 & 21 & 336 \\
\hline 53 & IA column output & C & 0.0116 & $n$ & 0.005 & $\mathrm{~T} 2$ & $M(n F \triangle T C)^{2}$ & 48 & 1 & 48 & 7200 & 21 & 336 \\
\hline 54 & 1A column output & C & 0.0116 & $\theta$ & 0.000023 & T2 & $(N F \Delta T)^{2}$ & 48 & 1 & 48 & 7200 & 21 & 336 \\
\hline 55 & 2A feed tank & $\mathrm{v}$ & 10268.27 & $E$ & 0.03 & I 2 & $2(\mathrm{VC})^{2}$ & - & - & - & - & - & - \\
\hline 56 & 2A feed tank & C & 0.010817 & $\varepsilon$ & 0.01 & I 2 & $2(v c)^{2}$ & - & - & - & - & - & - \\
\hline 57 & $2 A$ column & I & 3.0 & $\varepsilon$ & 0.05 & I1 & $2 I^{2}$ & - & - & - & - & - & - \\
\hline
\end{tabular}




\begin{tabular}{|c|c|c|c|c|c|c|c|c|c|c|c|c|c|}
\hline & & & Nominal & & & & & & $t T_{6}$ & & $\begin{array}{r}\text { Lon } \\
\text { (G } \\
\text { Recal }\end{array}$ & $\begin{array}{l}\text { Tern } \\
\text { a } 2 \\
\text { brat; }\end{array}$ & \\
\hline & Process & Measurement & value & Error & $\sigma_{i}$ & Type & $B_{i}$ & $\mathrm{~N}$ & $M$ & $n$ & $\mathbf{N}$ & $M$ & $\mathbf{n}$ \\
\hline 58 & 2B colunn & I & 3.0 & $\varepsilon$ & 0.05 & Il & $2 I^{2}$ & - & - & - & - & - & - \\
\hline 59 & 3A feed tank & $\mathrm{v}$ & 885.702 & $\Xi$ & 0.03 & I2 & $2 I^{2}$ & - & - & - & - & - & - \\
\hline 60 & 3A feed tank & c & 0.0147 & $\varepsilon$ & 0.01 & I2 & $2 I^{2}$ & - & - & - & - & - & - \\
\hline 61 & 3A column & I & 3.0 & $\varepsilon$ & 0.05 & Il & $2 \mathrm{I}^{2}$ & - & - & - & - & - & - \\
\hline 62 & 3B column & I & 3.0 & $\varepsilon$ & 0.05 & Il & $2 I^{2}$ & - & - & - & - & - & - \\
\hline 63 & Pu stripper feed tank & $\mathrm{v}$ & 113.4 & $\varepsilon$ & 0.03 & 12 & $2(\mathrm{vC})^{2}$ & - & - & - & - & - & - \\
\hline 64 & Pu stripper feed tank & c & 0.0176 & $\varepsilon$ & 0.01 & 12 & $2(\mathrm{VC})^{2}$ & - & - & - & - & - & - \\
\hline 65 & Pu stripper & I & 4.0 & $\varepsilon$ & 0.10 & Il & $2 \mathrm{I}^{2}$ & - & - & - & - & - & - \\
\hline 66 & Pu concentrator & $\mathrm{v}$ & 139.23 & $\varepsilon$ & 0.03 & 12 & $2(\mathrm{VC})^{2}$ & - & - & - & - & - & - \\
\hline 67 & Pu concentrator & c & 0.1366 & $\varepsilon$ & 0.01 & 12 & $2(v c)^{2}$ & - & - & - & - & - & - \\
\hline 68 & Pu sample $\operatorname{tank}$ output & $\mathrm{v}$ & 590.249 & $\varepsilon$ & 0.003 & T2 & $N(v C)^{2}$ & 2 & 1 & 2 & 300 & 1 & 300 \\
\hline 69 & Pu sample tank output & $\mathrm{v}$ & 590.249 & $n$ & 0.001 & T2 & $M(n V C)^{2}$ & 2 & 1 & 2 & 300 & 1 & 300 \\
\hline 70 & Pu sample tank output & $\mathrm{v}$ & 590.249 & $\theta$ & 0.59 & T2 & $(\mathrm{NC})^{2}$ & 2 & 1 & 2 & 300 & 1 & 300 \\
\hline 71 & Pu sample tank output & c & 0.0942 & $\varepsilon$ & 0.003 & T2 & $\mathrm{N}(\mathrm{VC})^{2}$ & 2 & 1 & 2 & 300 & 21 & 14 \\
\hline 72 & Pu sample tank output & c & 0.0942 & $\eta$ & 0.002 & T2 & $M(n V C)^{2}$ & 2 & 1 & 2 & 300 & 21 & 14 \\
\hline 73 & Pu sample tank output & c & 0.0942 & $\theta$ & 0.00018 & T2 & $(\mathrm{NV})^{2}$ & 2 & 1 & 2 & 300 & 21 & 14 \\
\hline
\end{tabular}


column 5. These standard deviations are generally thought to be achievable with current technology (see Sec. II.D of the main text). The sixth column with the heading "Type" indicates the type of transfer or inventory associated with the measurements; that is, $\mathrm{Tl}$ is a type 1 transfer or a transfer as one measured value, T2 is a type 2 transfer or a transfer as the product of two measured values, II is a type 1 inventory or an inventory as one measured value, and 12 is a type 2 inventory or an inventory as the product of two measured values.

In the " $\mathrm{B}_{i}$ " or seventh column are the actual coefficients associated with individual measurement error variances in the materials balance variance equation. The $\mathrm{N}, \mathrm{M}$, and $\mathrm{n}$ integer values appearing in the coefficients relating to transfers represent the following:

$\mathrm{N}$ is the total number of measurements in the overall simulation,

$M$ is the total number of intervals separated by recalibrations, and

$n$ is the total number of measurements per recalibration interval ( $n=N$ and $M=1$ for no recalibration).

The particular values of $N, M$, and $n$ used in the HEF simulations for goal 1 are presented in the last six columns of the table. The short-term materials balance case applies to a l-day interval, whereas the long-term materials balance is computed on the basis of a 150-day interval. Selected instruments are recalibrated at 7-day intervals. In a type 2 transfer consisting of a volume and a concentration, the volume measuring instrument is not recalibrated. Also, because of their infrequency, the transfers from HLW to the primary centrifuge and from the HA centrifuge to the solids sample tank (SST) are not recalibrated. The $N, M$, and $n$ integer values for long-term materials balances correspond to the case with recalibration. For long-term materials balances with no recalibration, $N$ remains the same, $M$ equals 1 , and $n$ equals $N$.

Inventories for digester 1 , the primary centrifuge, the leached solids centrifuge, the SST, the feed adjustment tank, and the plutonium catch tank do not appear in the table because these units are empty when measurements are made. In addition, the accountability tank and the plutonium sample tank inventories are not included because these inventories are considered as output transfers in the materials accounting equations.

The materials balance variance for a given UPAA can be computed from the table by summing the products of $B_{i}$ and $\sigma_{i}^{2}$ for each measurement error 
associated with that UPAA. UPAA $\perp$ includes all the unit processes from the disassembly through the feed adjustment tank. Hence, the materials balance variance $\sigma_{M B 1}^{2}$ for UPAA I is

$$
\sigma_{\mathrm{MB1}}^{2}=\sum_{i=1}^{37} \mathrm{~B}_{i} \sigma_{i}^{2}
$$

UPAA 2 includes the feed adjustment tank through the $1 \mathrm{~A}$ column. It follows that

$$
\sigma_{\mathrm{MB} 2}^{2}=\sum_{i=27}^{29} \mathrm{~B}_{i} \sigma_{i}^{2}+\sum_{i=32}^{54} \mathrm{~B}_{i} \sigma_{i}^{2} .
$$

The first three terms $(i=27,28$, and 29$)$ in the above equation represent the transfer from the HA centrifuge to the 5ST. UPAA 3 includes the $2 A$ feed tank through the plutonium sample tank. Hence,

$$
\sigma_{\mathrm{MB} 3}^{2}=\sum_{i=49}^{73} \mathrm{~B}_{i} \sigma_{i}^{2} .
$$

Finally, for UPAA 23 , the accounting area for combined UPAA 2 and UPAA 3,

$$
\sigma_{\text {MB23 }}^{2}=\sum_{i=27}^{29} B_{i} \sigma_{i}^{2}+\sum_{i=32}^{48} B_{i} \sigma_{i}^{2}+\sum_{i=55}^{73} B_{i} \sigma_{i}^{2} .
$$




\section{INTRODUCTION}

An optimization problem can be characterized as maximizing or minimizing a numerical function of one or more variables, which can be independent or related through constraints. Often such problems arise in allocating scarce product resources so that the products meet certain specifications. The general optimization problem can be formulated as follows. $130-132$ Determine the values for $n$ variables $x_{1}, \ldots, x_{n}$ that satisfy the $m$ inequalities or equations

$$
\begin{aligned}
& \leq \\
g_{i}\left(x_{1}, x_{2}, \ldots, x_{n}\right) & =b_{i} \quad(i=1,2, \ldots, m) \quad(D-1) \\
& \geq
\end{aligned}
$$

and in addition maximize or minimize the scalar, real-valued function

$$
z=f\left(x_{1}, x_{2}, \ldots, x_{n}\right)
$$

The restrictions in Eq. (D-1) are called the constraints, and Eq. (D-2) is the objective function. The values of $m$ and $n$ need not be related; that is, $m<n$, $m=n$, or $m>n$ are allowed. A solution to the problem in Eqs. (D-1) and (D-2) is any set of numerical values for $x_{1}, x_{2}, \ldots, x_{n}$ that minimizes (maximizes) Eq. (D-2) while satisfying the constraints in Eq. (D-1).

\section{LINEAR OPTIMIZATION}

Linear problems are a special class of optimization problems for which effective solution methods have been developed. ${ }^{133}$ For this class both the 
constraint equations and the objective function are linear in the unknowns $x_{1}, x_{2}$, $\ldots, x_{n}$. The general linear problem has the constraints

$$
\begin{aligned}
g_{i}\left(x_{1}, x_{2}, \ldots, x_{n}\right)=\sum_{j=1}^{n} a_{i j} x_{j} & \leq b_{i} \\
& \geq
\end{aligned}
$$

where $a_{i j}$ and $b_{i}$ are known constants, and the objective function

$$
f\left(x_{1}, x_{2}, \ldots, x_{n}\right)=\sum_{j=1}^{n} c_{j} x_{j},
$$

where $c_{j}$ are known constants. Frequently for such problems, the additional constraint that each $x_{j} \geq 0$ is imposed as a convenience in making numerical calculations. This is not a real restriction because any problem in which the unknowns are unrestricted in sign can be transformed to one with all variables nonnegative.

Figure D-1 gives an example of a linear optimization problem. The constraints are

$$
x_{1}+x_{2} \leq 3, x_{1} \geq 1, \text { and } x_{2} \geq 0 \text {, }
$$

and the objective function is

$$
\max z_{1}=x_{1}+2 x_{2}
$$

The maximum is attained at the point $(1,2)$. 


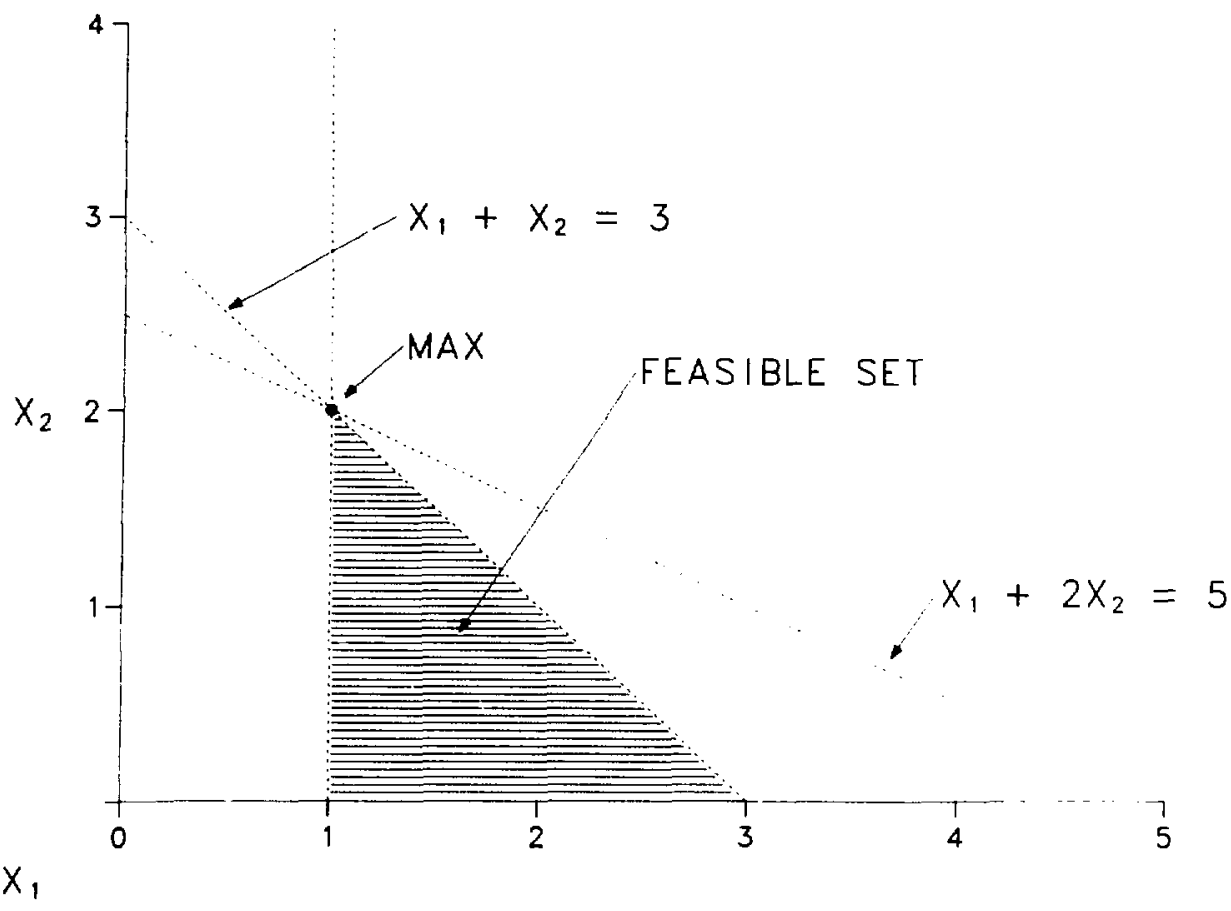

Fig. D-1.

Linear optimization example.

This problem illustrates some general characteristics of a linear optimization problem.

(1) The set of all feasible points, that is, those points that satisfy all consiraints, is a convex set and has a finite number of corners.

(2) A local maximum (minimum) of the objective function is always a global maximum (minimum).

(3) If the optimal value of the objective function is finite, then at least one of the corner points is an optimal solution.

These characteristics are exploited by the simplex method for solving such problems, which is an iterative procedure that yields an optimum solution in a finite number of steps. The solution procedure consists of an efficient method for evaluating the objective function at corner points until an optimum point is found. 


\section{NONLINEAR OPTIMIZATION}

In a nonlinear optimization problem, either the constraints and/or the objective function may be nonlinear. ${ }^{131}$ There are several differences between linear and nonlinear optimization problems that make solution of the nonlinear problem more difficult. Unlike local minimums of objective functions in linear problems, those in nonlinear problems may not be global. Thus, without additional restrictions on the objective function and the constraint equations, there is no general method comparable to the simplex method that guarantees a global minimum. Further, because the minimum need not occur at some finite set of predetermined points as in the linear problem, there is no method that finds a solution in a finite number of iterations as the simplex method does.

If the objective function $f$ is convex,

$$
\{[f(\alpha x+B y) \leq \alpha f(x)+\beta f(y), 0 \leq \alpha, \beta \leq 1, \alpha+\beta=1\} .
$$

and the set of feasible points is also convex, then a local minimum will also be a global minimurn. The set of points where the global minimum is attained reduces to a single point if $f$ is strictly convex $f(\alpha x+\beta y)<\alpha f(x)+\beta f(y)$.

An example of a nonlinear optimization problem in which the constraints and the objective function are convex is shown in Fig. D-2. The constraints are

$$
x^{2}+y^{2} \leq 2, x \geq 0, \text { and } y \geq 0 \text {, }
$$

and the objective function is

$$
\max z=x y \quad
$$

The objective function assumes its maximum at the point $(1,1)$, which is the unique maximizing solution to this problem because of the strict convexity of $f$. Note that in general the objective function may assume its optimum value either on the boundary or in the interior of the constraint set. 
Fig. D-2 . Nonlinear optimization example.
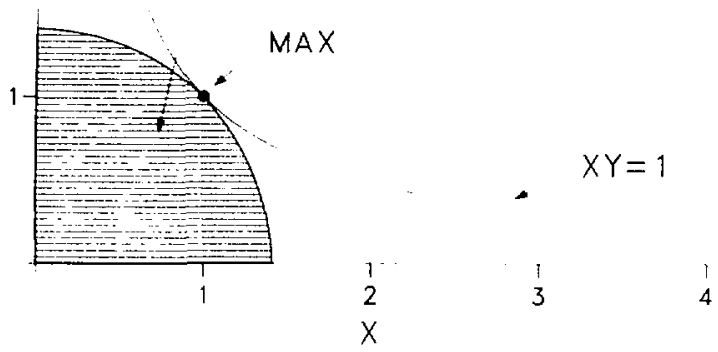

There are numerous methods for solving the nonlinear optimization problem. $130,131,133$ Many of these methods, however, are an inefficient use of computation time when the number of variables is large. When such is the case, the gradient and direct-search methods appear to be most efficient. Gradient methods tend to search along a path of steepest descent on the objective function hypersurface. However, they usually require first and sometimes second derivatives of the objective and constraint functions with respect to each of the variables. Direct-search techniques, on the other hand, do not require derivative functions. Hence, they are more useful from the standpoint of possible convergence with a variety of problems and they also make problem preparation easier. A particularly efficient direct-search method (PCON) was used to calculate minimum cost measurement uncertainties to HEF instrumentation.

\section{PCON COMPUTER PROGRAM}

Calculating measurement uncertainties for the HEF requires a computerized solution method because of the large number of variables. PCON (Powell CONstrained) is an efficient, direct-search method for finding the constrained minimum of a general, nonlinear, multivariable function. ${ }^{134}$ The minimization 
algorithm employed in PCON combines Powell's direct-search conjugate-direction method ${ }^{135}$ with the technique of Fiacco and McCormick for handling the constraints. 136 Analytic derivatives are not required for the Powell method, which makes the program easy to use and applicable to a large range of problems.

Powell's method was originally developed for unconstrained minimization problems. It employs one-dimensional searches in a direction that reduces the objective function. When no further reductions are possible, a new airection of search is chosen that is conjugate or orthogonal to the previous direction. Sequentially, applied conjugate directions ensure convergence to a minimum of a quadratic function of $n$ variables in $n$ searches, one in each of $n$ conjugate directions. The algorithm of Fiacco and McCormick converts the constrained minimization problem to an artificial unconstrained problem that can be solved with Powell's conjugate-search method. With this algorithm, the constraints are included in the objective function by means of a penalty function approach. The modified objective function is

$$
u=f-r \sum_{i} \frac{1}{g_{i}},
$$

where $U$ is the modified objective function, $f$ is the unconstrained function to be minimized, $r$ is a constant, and $g_{i}$ is an inequality constraint with $g_{i}<0$. As the minimum of $U$ is approached, the constant $\Gamma$ is decreased, thus allowing the modified objective function $U$ to approach the unconstrained function $f$. PCON extends the Fiacco and McCormick method by introducing automatic scaling of the constraints as compared both to other constraints and to the objective function.

The Powell conjugate-search method makes it possible for PCON to minimize complex objective functions with only modest computer time requirements. Minimization of an objective function with 5 variables and 12 inequality constraints requires 3-4 s on a PRIME 750 minicomputer. Objective functions with $\sim 40$ variables coupled with $\sim 80$ inequality constraints require $\sim 150 \mathrm{~s}$. 
The PCON code was designed to minimize functions having a maximum of 30 variables. For the HEF problem, the PCON code was modified to handle a maximum of 50 variables. In addition, the direct-search step sizes were individually scaled to provide faster and more dependable convergence.

Computer central memory requirements are relatively modest. The complete PCON code, along with the necessary arrays for minimizing objective functions with up to 50 variables and 100 inequality constraints, requires $\imath 17000$ 16-bit words of computer central memory. All floating point arithmetic is in double precision to minimize convergence difficulties caused by computer roundoff and truncation errors. 


\section{APPENDIXE \\ OPTIMAL MEASUREMENT UNCERTAINTIES}

Tables E-I through E-XXXVI list measurement uncertainties for each UPAA that will meet the performance goals specified in Sec. I of the main text. These uncertainties are a result of optimization calculations. They yield materials loss-detection sensitivities that meet a given performance objective while minimizing total instrument systems development cost. These results are discussed in Sec. IV of the main text. 
TABLE E-I

MEASUREMENT UNCERTAINTIES: UPAA 1, GOAL 1, NO RECALIBRATION

No.

a INVENTORY - DISASSEMBLY

C INVENTORY - SHEAR

C INVENTORY - VOLOXIDIZER

I INVENTORY - CONTINUOUS DISSOLVER

e VOL UME - DIGESTER

C CONCENTRATION - DIGESTER

INVENTORY - HULLS

\& VOLUME - BATCH DISSOLVER

C CONCENTRATION - BATCH DISSOLVER

C VOLUME - ACIO SURGE TANK

E CONCENTRATION - ACID SURGE TANK

\& INVENTORY - SECONDARY DISSOLVER SURGE TANK

C VOLUME - SECONOARY DISSOLVER

- CONCENTRATION - SECONDARY DISSOLVER

e VOLUME - SST

- CONCENTRATION - SST

c VOLUME - FEED SOLUTION SURGE TANK

C CONCENTRATION - FEED SOLUTION SURGE TANK

$E$ VOLUME - ACCOUNTABILITY TANK

C CONCENTRATION - ACCOUNTABILITY TANK

\& TRANSFER - INPUT TO DISASSEMBLY

$\eta$ TRANSFER - INPUT TO DISASSEMBLY

* TRANSFER - INPUT TO DISASSEMBLY

C TRANSFER - HULLS TO HULLS WASTE

T TRANSFER - HULLS TO HULLS WASTE

TRANSFER - HULLS TO HULLS WASTE

C TRANSFER - PRIMARY CENTRIFIJGE TO HLW

T TRANSFER - PRIMARY CENTRIFUGE TO HLW

TRANSFER - PRIMARY CENTRIFUGE TO HLW

C TRANSFER - SST TO HLW

$\eta$ TRANSFER - SST TO HLW

G TRANSFER - SST TO HLW

- TRANSFER - ha CENTRIFUge to SST

$\eta$ TRANSFER - HA CENTRIFUGE TO SST

$\theta$ TRANSFER - HA CENTRIFUGE TO SST

\& VOLUME - ACCOUNTABILITY TANK OUTPUT

$\eta$ VOLUME - ACCOUNTABILITY TANK OUTPUT

- VOLUME - ACCOUNTAB IL 1 TY TANK OUTPUT

- CONCENTRATION - ACCOUNTABILITY TANK OUTPUT

$\eta$ CONCENTRATION - ACCOUNTABILITY TANK OUTPUT

O CONCENTRATION - ACCOUNTABILITY TANK OUTPUT
MEASUREMENT ERRORS

CALCULATED CURRENT

$(1 \sigma)$

$(1 \sigma)$

$3.96-2$

$1.99-1$

$1.48-1$

$1.67-1$

$2.98-2$

1. $49-2$

1. $00-1$

3. $00-2$

$1.58-2$

3. $60-2$

1. $58-2$

9.98-2

3. $00-2$

6.95-2

3. . $0-2$

7. $00-2$

2.97-2

1. 49-2

3. $00-3$

1. $90-2$

3. 29-2

2. 84-3

2. $48-3$

$1.00-1$

5. $00-$ ?

4. 99-2

$1.00-1$

5. $00-2$

5. $00-2$

1. $.00-1$

4. $98-2$

$5.00-2$

$1.00-1$

5. $00-2$

$5.00-2$

2. $98-3$

$9.21-4$

9.23-4

9. 58-3

1. 37-3

1. 38-3
4. $00-2$

$2.09-1$

$2.00-1$

$2.00-1$

$3.80-2$

$1.50-2$

$1.00-1$

$3.00-2$

$1.5 b-2$

3. $80-2$

1. $50-2$

1. $00-1$

$3.00-2$

$7.00-2$

$3.00-2$

$7.00-2$

$3.00-2$

$1.50-2$

$3.00-3$

1. $.00-2$

4. $.00-2$

$3.00-2$

$2.00-2$

1. $00-1$

$5.00-2$

$5.00-2$

$1.07-1$

5. $80-2$

$5.60-2$

$1.00-1$

$5.00-2$

$5.00-2$

$1.00-1$

5. $000-2$

$5.00-2$

$3.00-3$

$1.00-3$

$1.08-3$

$1.0 \theta-2$

$3.04-3$

$3.00-3$

\section{MATERIALS BALA}

(Kg PU 6 MONTHS

8. 17-1

5.19

4.49

1.17

5. $88-1$

3. 39-2

1.83-2

9. 13-3

1.04-2

$5.21-3$

3.39-1

2. $.04-1$

1. 72-1

ต.

0.00

2.26

1.13

อ. 0.8

๑.

1.36

3. $31-1$

2. $98-1$

$1.41-3$

$2.00-3$

$2.00-3$

0.00

0.00

0.00

1. 2 (9)-3

$5.9 \%-4$

$6.00-4$

0.00

$\varnothing .00$

0.00

3. $31-1$

1. $03-1$

1.03-1

1.07

1. $52-1$

1.53-1

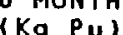

8.17-

2.05

4.49

1.17

5. 88-1

1.83-2

9.13-3

1.04-2

5. 21-3

3. 39-1

2. $04-1$

4.72-1

0.09

๑.

2.26

1.13

0.00

ช. . ค6

1. $66+1$

4. $96+1$

$4.35+1$

1. $73-2$

3. $00-1$

2. $99-1$

5. $88-3$

$7.28-3$

$7.20-3$

1. 47-2

8. $96-2$

9. $06-2$

3. $56-3$

8. $36-3$

8. 36-3

4. 86

1. $54+1$

$1.54+1$

1. $31+1$

$2 \cdot 28+1$

2. $3 \theta+1$
RELATIVE

$\operatorname{COST}$

9.62-3

7. $06-3$

1.31-1

.96-1

6. 49-3

4.95-3

7.95-5

2.85-4

7.43-4

2.85-4

$2.87-4$

$2.27-3$

$1.7 \not 1-4$

$6.51-3$

2.85-4

2.84-4

9. $34-3$

6. $96-3$

3. 35-4

1.42-4

$2.16-1$

9.57

7.65

$2.3 \theta-5$

3. $3 \theta-4$

1.72-3

2.29-5

$1.13-4$

$1.13-4$

2.29-5

.72-3

. $97-4$

.29-5

1.13-4

1. 13-4

$7.24-3$

8.53-2

8. 37-2

4. $39-2$

1.19

1.18 
TABLE E-II

MEASUREMENT UNCERTAINTIES: UPAA 1, GOAL 1, WEEKLY RECALIBRATION

No.

DE SCR IPTION

E INVENTORY - DISASSEMBLY

\& INVENTORY - SHEAR

E INVENTORY - VOLOXIDIZER

\& INVENTORY - CONTINUOUS DISSOLVER

$\epsilon$ VOLUME - DIGESTER

E CONCENTRATION - DIGESTER

E INVENTORY - HULLS

$\epsilon$ VOLUME - BATCH DISSOLVER

$\epsilon$ CONCENTRATION - BATCH DISSOLVER

* VOLUME - ACID SURGE TANK

E CONCENTRATION - ACIO SURGE TANK

E INVENTORY - SECONDARY DISSOLVER SURGE TANK

\& VOLUME - SECONDARY DISSOLVER

$\epsilon$ CONCENTRATION - SECONDARY DISSOLVER

E VOLUME - SST

E CONCENTRATION - SST

$\epsilon$ VOLUME - FEED SOLUTION SURGE TANK

$\epsilon$ CONCENTRATION - FEED SOLUTION SURGE TANK

\& VOLUME - ACCOUNTABILITY TANK

$E$ CONCENTRATION - ACCOUNTABILITY TANK

\& TRANSFER - INPUT TO DISASSEMBLY

T TRANSFER - INPUT TO DISASSEMBLY

$\theta$ TRANSFER - INPUT TO DISASSEMBLY

E TRANSFER - HULLS TO HULLS WASTE

$\eta$ TRANSFER - HULLS TO HULLS WASTE

A TRANSFER - HULLS TO HULLS WASTE

\& TRANSFER - PRIMARY CENTRIFUGE TO HLW

n TRANSFER - PRIMARY CENTRIFUGE TO HLW

O TRANSFER - PRIMARY CENTRIFUGE TO HL

E TRANSFER - SST TO HLW

$n$ TRANSFER - SST TO HLW

O TRANSFER - SST TO HLW

E TRANSFER - HA CENTRIFUGE TO SST

n TRANSFER - HA CENTRIFUGE TO SST

$O$ TRANSFER - HA CENTRIFUGE TO SST

$E$ VOLUME - ACCOUNTABILITY TANK OUTPUT

$\eta$ VOLUME - ACCOUNTABILITY TANK OUTPUT

$\theta$ VOLUME - ACCOUNTABILITY TANK OUTPUT

$\epsilon$ CONCENTRATIDN - ACCOUNTABILITY TANK OUTPUT

$\eta$ CONCENTRATION - ACCOUNTABILITY TANK OIJTPUT
$\theta$ CONCENTRATION - ACC'JUNTABILITY TANK OUTPUT
MEASUREMENT ERRORS

$\begin{array}{cc}\text { CALCULATED } & \text { CURRENT } \\ (1 \sigma) & (1 \sigma)\end{array}$

4. $800-2$

$2.08-1$

1. 33-1

1. $78-1$

$3.00-2$

1. $5 \theta-2$

9. $99-2$

$3.96-2$

$1.50-2$

3. $00-2$

$1.50-2$

$3.00-2$

7. $00-2$

$3.09-2$

$7.060-2$

1. $.59-2$

$3.09-3$

9.99-3

$3.78-2$

$1.61-2$

$3.12-3$

9.99-2

$5.00-2$

$5.0 \theta-2$

9. 99-2

5. $\varnothing \varnothing-2$

$5.00-2$

9. 99-2

5. $08-2$

5. $\varnothing 0-2$

9.99-2

$5.00-2$

5. . $10-2$

2. $99-3$

9. $94-4$

9.94-4

9.93-3

2. 99-3

$1.61-3$
4. $80-2$

2. $00-1$

2. .00-1

$2.00-1$

3. $80-2$

1. $5 \theta-2$

1. $.0 \theta-1$

$3.00-2$

$1.5 \theta-2$

3. $60-2$

$1.58-2$

1. $.08-1$

3. $\theta \theta-2$

$7.080-2$

$3.08-2$

$7.06-2$

$3.00-2$

1. $5 B-2$

$3.80-3$

1. $06-2$

4. $.00-2$

$3.00-2$

$2.80-2$

$1.00-1$

$5.00-2$

$5.00-2$

1. $.00-1$

5. $00-2$

5 . $90-2$

$1.00-1$

$5.09-2$

$5.00-2$

1. $\theta \theta-1$

$5.00-2$

$5.00-2$

$3.08-3$

1. $00-3$

1. $0 x-3$

1. $00-2$

3. $05-3$

$3.00-3$
MATERIALS BALANCE $\sigma$

1 DAY 6 MONTHS

RELATIVE

COST

8. 24-1

2.06

4.93

4.56

1.18

$5.90-1$

3. 39-2

1. $83-2$

9.13-3

1.04-2

5. $21-3$

3. 39-1

2. $84-1$

4.75-1

0. 80

9.00

2.27
1.14

1.14

8.086

1.53

1.18

3. 64-1

1. $41-3$

$2.000-3$

$2.00-3$

6. .00

0.00

0.00

1. $20-3$

$6.00-4$

$6.860-4$

0.00

0.00

0.00

3. 33-1

1. $11-1$

1. 11-1

1. 10

3. $33-1$

( $\mathrm{Kg} \mathrm{Pu}$ )

6 . $38-4$

2. 47-3

1. $78-1$

1. 64-3

7. 53-4

5. $91-4$

5. 77-4

5.78-4

5.78-4

5.78-4

$6.44-4$

5. 72-4

$4 \cdot 34-4$

$5.78-4$

2.72-3

4. $28-4$

5.78-4

5. 75-4

B. $01-2$

1.97

5.41

$5.78-4$
$5.77-4$

4.93-4

5. $78-4$

5. $78-4$

$5.78-4$

$5.78-4$

5.78-4

5. $77-4$

5. $78-4$

5.85-4

5. $78-4$

$2.86-3$

6. $08-3$

6. 39-3

7. 46-3

3. 49-3

8. 68-1 
NO.

DESCR I PTION

E INVENTORY - DISASSEMBLY

E INVENTORY - SHEAR

E INVENTORY - VOLOXIDIZER

E INVENTORY - CONTINUOUS DISSOLVER

$\epsilon$ VOLUME - DIGESTER

E CONCENTRATION - DIGESTER

E INVENTORY - HULLS

E VOLUME - BATCH DISSOLVER

E CONCENTRATION - BATCH DISSOLVER

E VOLUME - ACID SURGE TANK

E CONCENTRATION - ACID SURGE TANK

E INVENTORY - SECONDARY DISSOLVER SURGE TANK

- VOLUME - SECONDARY DISSOLVER

\& CONCENTRATION - SECONDARY DISSOLVER

\& VOLUME - SST

E CONCENTRATION - SST

\& VOLUME - FEED SOLUTION SURGE TANK

- COMCENTRATION - FEED SOLUTION SURGE TANK

\& VOLUME - ACCOUNTABILITY TANK

$\epsilon$ CONCENTRATION - ACCOUNTABIL ITY TANK

E TRANSFER - INPUT TO DISASSEMBLY

$\eta$ TRANSFER - INPUT TO DISASSEMBLY

$\theta$ TRANSFER - INPUT TO DISASSEMBLY

E TRANSFER - HULLS TO HULLS WASTE

TRANSFER - HULLS TO HULLS WASTE

TRANSFER - HULLS TO HULLS WASTE

$\epsilon$ TRANSFER - PRIMARY CENTRIFUGE TO HLW

O TRANSFER - PRIMARY CENTRIFUGE TO HLW

$\theta$ TRANSFER - PRIMARY CENTRIFUGE TO HLW

E TRANSFER - SST TO HLW

n TRANSFER - SST TO HLW

$\theta$ TRANSFER - SST TO HLW

E TRANSFER - HA CENTRIFUGE TO SST

TRANSFER - HA CENTRIFUGE TO SST

TRANSFER - HA CENTRIFUGE TO SST

\&OLUME - ACCOUNTABILITY TANK OUTPUT

7 VOLUHE - ACCOUNTABILITY TANK OUTPUT

$\theta$ VOLUME - ACCOUNTABILITY TANK OUTPUT

- CONCENTRATION - ACCOUNTAB ILITY TANK OUTPUT

$\eta$ CONCENTRATION - ACCOUNTABILITY TANK OUTPUT

$\theta$ CONCENTRATION - ACCOUNTABILITY TANK OUTPUT
MEASUREMENT ERRORS

CALCULATED CURRENT

$(\mid \sigma)$

$(1 \sigma)$

$3.61-2$

$1 \cdot 35-1$

$5.78-2$

$7 \cdot 18-2$

$2.62-2$

1. 46-2

$1.0 .0-1$

$3.00-2$

1. $5 g-2$

3. $\varnothing \varnothing-2$

$1.5 \theta-2$

$1.0 \theta-1$

$3.00-2$

$6.69-2$

3. $80-2$

$7.00-2$

$1.85-2$

1. $3 g-2$

$3.00-3$

1. $0.8-2$

$8.82-3$

$6.87-4$

$6.61-4$

1. $00-1$

4. 98-2

4. $99-2$

$1.0 \theta-1$

5. $00-2$

$5.00-2$

1. $\theta \theta-1$

$5.0 \varnothing-2$

$5.80-2$

$1 . \tan \theta-1$

$5.0 \varnothing-2$

5. . $00-2$

1. $81-3$

$2.31-4$

2. $31-4$

2. 63-3

3. $31-4$

3. $31-4$
4. . $00-2$

$2.000-1$

2. . $00-1$

2. $900-1$

$3.00-2$

$1.50-2$

1. $D D-1$

$3.00-2$

1. $50-2$

$3.08-2$

1. $50-2$

$1,0,0-1$

3. $06-2$

$7.80-2$

3. $0.0-2$

$7.00-2$

$3.00-2$

1. $58-2$

$3.00-3$

1. . $00-2$

4. $00-2$

3. $.00-2$

2. $00-2$

$1.00-1$

5. $00-2$

5. $0 \partial-2$

1. $D D-1$

5.,$B b-2$

$5.00-2$

1. $00-1$

$5.00-2$

$5.90-2$

$1.00-1$

$5.0 .0-2$

5. $90-2$

3. $0 \theta-3$

1. $00-3$

1. $.00-3$

$1.06-2$

3. $.00-3$

3. $00-3$
MATERIALS BALANCE 1 DAY 6 MONTHS ( $\mathrm{Kg} \mathrm{Pu}$ ) (Kg PU)

7. 45-1

1.39

2.11

1.93

1.03

5. 74-1

$3.39-2$

1. 83-2

9.13-3

$1.04-2$

5. 22-3

3. 39-1

2. $03-1$

4. 54-1

0.00

0.00

1.41

9. $91-1$

0.60

$6.6 D$

3. 64-1

$7.01-2$

$1.41-3$

1. $99-3$

1. $99-3$

0.06

0.00

D.

1. $20-3$

$6.0 \theta-4$

$6.00-4$

ด. .0

$\theta .00$

0.00

2. $02-1$

$2.57-2$

2.57-2

2. $92-1$

$3.68-2$

3. $68-2$
7. 45-1

1.39

2.11

1.93

1.03

5.74-1

$3.39-2$

1. 83-2

9.13-3

$1.04-2$

5. 22-3

3. 39-1

2. $83-1$

4. 54-1

0.00

0.08

1.41

9.91-1

อ. 00

0.06

4.46

1. $20+1$

1. $.05+1$

1. 73-2

2. 99-1

2. 99-1

5. $88-3$

$7.20-3$

$7.2 \theta-3$

1. 47-2

$9.00-2$

$9.00-2$

$3.56-3$

8. 36-3

8. 36-3

2.47

3.85

3.86

3.58

5.52

5.52
RE LATIVE COST

1. $67-1$

4.79-1

2.51

1.79

1. 43-1

4. 26-5

4. $96-5$

3. 65-6

8. 14-6

1.14-5

4. 58-4

7. 47-4

4. $66-2$

4. $.00-5$

2. 29-5

6. $18-1$

1. 58-1

3. 47-5

3.97-5

3.53

$4.27+1$

$3.23+1$

3. $71-7$

3. 66-3

2. $96-3$

1. 59-5

1. $94-5$

1. 87-5

5. 81-5

3. $97-4$

$.25-4$

8. $06-6$

2. $50-5$

4. 32-6

6. 53-1

3.33

3.32

2.81

8.07

8.07 
TABLE E-IV

MEASUREMENT UNCERTAINTIES : UPAA 1, GOAL 2, WEEKLY RECALIBRATION

No.

E INVENTORY - DISASSEMBLY

E INVENTORY - SHEAR

$\epsilon$ INVENTORY - VOLOXIDIZER

E INVENTORY - CONTINUOUS DISSOLVER

$\&$ VOLUME - DIGESTER

\& CONCENTRATION - DIGESTER

E INVENTORY - HULLS

\& VOLUME - BATCH DISSOLVER

E CONCENTRATION - BATCH DISSOLVER

E VOLUME - ACID SURGE TANK

- CONCENTRATION - aCid SURge taNK

\& INVENTORY - SECONDARY DISSOL VER SURGE TANK

- VOLUME - SECONDARY DISSOLVER

C CONCENTRATION - SECONDARY DISSOLVER

\& VOLUME - SST

\& CONCENTRATION - SST

\& VOLUME - FEED SOLUTION SURGE TANK

- CONCENTRATION - FEED SOLUTION SURGE TANK

E VOLUME - ACCOUNTABILITY TANK

\& CONCENTRATION - ACCOUNTABILITY TANK

E TRANSFER - INPUT TO DISASSEMBLY

$\eta$ TRANSFER - INPUT TO DISASSEMBLY

a TRANSFER - INPUT TO DISASSEMBLY

E TRANSFER - HULLS TO HULLS WASTE

$\eta$ TRANSFER - HULLS TO HULLS WASTE

o tRANSFER - hULLS TO HULLS WASTE

- TRANSFER - PRIMARY CENTRIFUGE TO HLW

$\eta$ TRANSFER - PRIMARY CENTRIFUGE TO HLH

$\theta$ TRANSFER - PRIMARY CENTRIFUGE TO HLW

- TRANSFER - SST TO HLW

T TRANSFER - SST TO HLW

$\theta$ TRANSFER - SST TO HLW

E TRANSFER - HA CENTRIFUGE TO SST

I TRANSFER - HA CENTRIFUGE TO SST

- TRANSFER - HA CENTRIFUge to SST

- VOLUME - ACCOUNTAB ILITY TANK OUTPUT

7 VOLUME - ACCOUNTABILITY TANK OUTPUT

$\theta$ VOLUME - ACCOUNTABILITY TANK OUTPUT

- CONCENTRATJON - ACCOUNTABILITY TANK OUTPUT

7 CONCENTRATION - ACCOUNTABILITY TANK OUTPUT

O CONCENTRATION - ACCOUNTABILITY TANK OUTPUT
MEASUREMENT ERRORS

CALCULATED CURRENT

$(1 \sigma)$

$(1 \sigma)$

$3.79-2$

1. 33-1

$7.14-2$

$2.68-2$

$1.5 \theta-2$

$1 . \varnothing 9-1$

$3 . \varnothing 0-2$

$1.5 \theta-2$

$3.00-2$

1. $5 \theta-2$

1. $.00-1$

3. $00-2$

$6.99-2$

3. $00-2$

7. $000-2$

1.85-2

I. $32-2$

3. $00-3$

$1.00-2$

9.84-3

2. 34-3

7.09-4

$1.00-1$

$5.00-2$

$5.00-2$

1. $.00-1$

$5.00-2$

$5.00-2$

$1.00-1$

5. $00-2$

5. $00-2$

$1.00-1$

$5.00-2$

$5.00-2$

2.09-3

2.79-4

$2.76-1$

3. $12-3$

$1.11-3$

3.99-4
$4.00-2$

$2.00-1$

$2.00-1$

$2.00-1$

$3.00-2$

$1.50-2$

$1.00-1$

$3.00-2$

$1.5 \theta-2$

$3.00-2$

$1.58-2$

$1.08-1$

$3.08-2$

$7.00-2$

3. $08-2$

$7.000-2$

$3.00-2$

$1.50-2$

$3.00-3$

$1.00-2$

$4.00-2$

$3.000-2$

$2.000-2$

1. $.00-1$

$5.00-2$

$5.00-2$

$1.00-1$

$5.06-3$

5. $80-2$

$1.08-1$

$5.00-2$

$5.000-2$

$1.00-1$

$5.000-2$

$5.00-2$

$3.00-3$

1. $808-3$

$1.0 \theta-3$

$1.00-2$

3. $00-3$

$3.00-3$
MATERIALS BALANCE $\sigma$

1 DAY 6 MONTHS

( $\mathrm{Kg} P u) \quad(\mathrm{Kg} \mathrm{Pu})$

RELATIVE COST

$7.81-$

2.37

2.14

1.92

1.06

$5.90-1$

$3.39-2$

I.83-2

9.13-3

$1.04-2$

$5.22-3$

3. 39-1

2. $04-1$

$4.75-1$

0.00

ต.

1.48

1,81

$\varnothing .80$

0.80

4. $.06-1$

2.73-1

8.27-2

1. $41-3$

2. $00-3$

$2.00-3$

0.08

0.00

8.00

1. $20-3$

$6.00-4$

$6.00-4$

D. 00

0.00

0.00

2. 32-1

3. $10-2$

3. $07-2$

3. 47-1

1. $24-1$

1. 44-2
7.81-1

1.37

2.14

1.92

1. . 06

3. 39-2

1.83-2

9.13-3

$1.04-2$

5. 22-3

3.39-1

2. $04-1$

$4.75-1$

0.00

0.00

1.46

1.01

0.00

0.98

4.97

8,74

1. $24+1$

1. $73-2$

6. 42-2

$3.08-1$

5. 88-3

$7.2 \theta-3$

$7.20-3$

1. 47-2

1. $92-2$

9. $00-2$

3. $56-3$

8. 36-3

8. $36-3$

2.84

4.66

4.66

4.26

3.98

6.65
5. 62-2

5. $93-1$

2.47

1.80

1. 19-1

$1.24-3$

$5.30-6$

1. $57-5$

1.27-5

4.79-5

3. 23-5

2.78-4

6. $6 \theta-5$

1. $28-3$

3. 34-5

3. 34-5

6. 24-1

1. $33-1$

1. 52-5

3.27-5

3.87

$1.18+1$

$2.72+1$

3. 39-5

4. 93-5

$4.51-4$

3. 36-5

3. 36-5

3. 36-5

3. 38-5

2. 93-5

2.96-5

3. 35-5

3. $37-5$

3. 36-5

4. 39-1

2.58

2.63

2.26

1.69

6.53 
TABLE E-V

MEASUREMENT UNCERTAINTIES: UPAA 1, GOAL 2, DAILY RECAI_IBRATION

No.

DESCR IPTION

E INVENTORY - DISASSEMBLY

E INVENTORY - SHEAR

$\epsilon$ INVENTORY - VOLOXIDIZER

$\epsilon$ INVENTORY - CONTINUOUS DISSOLVER

$\epsilon$ VOLUME - DIGESTER

$\epsilon$ CONCENTRATION - DIGESTER

$\epsilon$ INVENTORY - HULLS

$\epsilon$ VOLUME - BATCH DISSOLVER

$\epsilon$ CONCENTRATION - BATCH DISSOLVER

$\epsilon$ VOLUME - ACID SURGE TANK

$\epsilon$ CONCENTRATION - ACID SURGE TANK

$\epsilon$ INVENTORY - SECONDARY DISSOLVER SURGE TANK

$\epsilon$ VOLUME - SECONDARY DISSOLVER

$\epsilon$ CONCENTRATION - SECONDARY DISSOLVER

$\epsilon$ VOL UME - SST

E CONCENTRATION - SST

$\epsilon$ VOLUME - FEED SOLUTION SURGE TANK

$\epsilon$ CONCENTRATION - FEED SOLUTION SURGE TANK

$\varepsilon$ VOLUME - ACCOUNTAB ILITY TANK

$\subseteq$ CONCENTRATION - ACCOUNTAB IL ITY TANK

E TRANSFER - INPUT TO DISASSEMBLY

7 TRANSFER - INPUT TO DISASSEMBLY

O TRANSFER - INPUT TO DISASSEMBLY

$\epsilon$ TRANSFER - HULLS TO HULLS WASTE

$\eta$ TRANSFER - HULLS TO HULLS WASTE

o TRANSFER - HULLS TO hULLS WASTE

C TRANSFER - PRIMARY CENTR IFUGE TO HLW

$\eta$ TRANSFER - PRIMARY CENTRIFUGE TO HLW

$\theta$ TRANSFER - PRIMARY CENTRIFUGE TO HLW

E TRANSFER - SST TO HLW

7 TRANSFER - SST TO HLW

$\theta$ TRANSFER - SST TO HLW

$\epsilon$ TRANSFER - HA CENTRIFUGE TO SST

7 TRANSFER - HA CENTRIFUGE TO SST

$\theta$ TRANSFER - HA CENTRIFUGE TO SST

$\epsilon$ VOLUME - ACCOUNTABILITY TANK OUTPUT

$\eta$ VOLUME - ACCOUNTABILITY TANK OUTPUT

$\theta$ VOLUME - ACCOUNTABILITY TANK OUTPUY

E CONCENTRATION - ACCOUNTAB ILITY TANKY OUTPUT

$\eta$ CONCENTRATION - ACCOUNTABILITY TANY OUTPUT

$\theta$ CONCENTRATION - ACCOUNTABILITY TANK OUTPUT
MEASUREMENT ERRORS

CALCULATED CURRENT

$(1 \sigma)$

$(1 \sigma)$

$3.86-2$

1. $31-1$

$5.45-2$

$7.27-2$

$2.65-2$

$1.5 x-2$

1. . $00-1$

3. $08-2$

$1.50-2$

3. $00-2$

1. $5 \theta-2$

$1.800-1$

3. $000-2$

7. $.00-2$

$3.06-2$

$7.00-2$

1.88-2

1. $34-2$

3. $\varnothing 0-3$

$1.0 \theta-2$

1. $83-2$

$4.70-3$

$7.65-4$

$1.00-1$

5.

$5.00-2$

$1.00-1$

$5.00-2$

$5.000-2$

1. . $08-1$

5. $180-2$

$5.00-2$

$1.00-1$

$5.00-2$

$5.00-2$

2. 16-3

$2.88-4$

2.93-4

$3.3 \theta-3$

$2.22-3$

4.27-4
4. $08-2$

$2.00-1$

$2.00-1$

2. $90-1$

$3.8 \theta-2$

$1.5 \theta-2$

1. $00-1$

$3.00-2$

1. 50-2

$3.00-2$

1. $5 \theta-2$

$1.0 \varnothing-1$

$3.00-2$

$7.00-2$

$3.00-2$

7. $00-2$

$3.000-2$

1.50-2

$3.60-3$

$1.08-2$

4. $.0-2$

$3.00-2$

$2.00-2$

$1.00-1$

$5.00-2$

$5.00-2$

$1.00-1$

$5.00-2$

$5.00-2$

1. $\theta 0-1$

5. $00-2$

5. $00-2$

$1.00-1$

$5.60-2$

5. $\theta \theta-2$

$3.00-3$

1. $\theta 0-3$

$1.00-3$

$1 . \theta \theta-2$

3. $00-3$

$3.08-3$
MATERIALS BALANCE $\sigma$ 1 DAY 6 MONTHS

( $\mathrm{Kg} \mathrm{Pu}$ )

( $\mathrm{Kg} \mathrm{Pu}$ )

7. 95-1

1. .35

1.95

5. $90-1$

3. $39-2$

1. $83-2$

9.13-3

1. $84-2$

5. 22-3

3. 39-1

2.84-1

4. 75-1

0.80

0.00

1.43

1.02

6.00

0.00

4.23-1

5. 48-1

8. $86-2$

1. 41-3

$2.80-3$

$2.00-3$

$\forall .00$

$\varnothing .00$

0.00

$1.20-3$

$6.00-4$

$6.00-4$

D. 00

0.00

๑.

2. $4 \theta-1$

$3.20-2$

3. $26-2$

$3.68-1$

2.47-1

4.75-2
$7.95-1$
1.35

1.35
2.82

2.02

1.04

5. 9 - 1

3. 39-2

1. 83-2

9.13-3

1. $04-2$

5.22-3

3.39-1

2. $04-1$

4.75-1

ต.

0.08

1.43

1.02

0.00

0.00

5.10

6.71

1. $33+1$

$1.73-2$

2. 45-2

$3.80-1$

5. $88-3$

$7.28-3$

$7.28-3$

1. 47-2

7.35-3

9. $00-2$

3. $56-3$

8. 36-3

8. $36-3$

2.94

4.81

4.96

4.50

3.02

7.13
RELATIVE

COST

3.71-2

5.23-1

2.67

1.75

1.33-1

$1.16-3$

6.71-5

$6.87-5$

$6.58-5$

$6.51-5$

6.34-5

$3.26-5$

$7.23-5$

$2.66-4$

6.35-5

$6.30-5$

5. $97-1$

1.21-1

$4.99-5$

$6.36-5$

2.96

5.38

$2.53+1$

6. 52-5

$6.47-5$

2.51-5

6. 38-5

$6.48-5$

6. 41-5

6. 12-5

$6.38-5$

$4.88-5$

$6.34-5$

$6.46-5$

6. 44-5

3.91-1

2.47

2.41

2.03

3.53-1

6.82 
MEASUREMENT UNCERTAINTIES: UPAA 1, GOAL 3, NO RECALIBRATION

NO.

E INVEHTORY - DISASSEMBLY

INVENTORY - SHEAR

E INVENTORY - VOLOXIDIZER

C INVENTORY - CONTINUOUS DISSOLVER

\& VOLUME - DIGESTER

\& CONCENTRATION - DIGESTER

$\epsilon$ INVENTORY - HULLS

๔ VOLUME - BATCH DISSOLVER

$E$ CONCENTRATION - BATCH DISSOLVER

$\epsilon$ VDLUME - ACID SURGE TANK

$\varepsilon$ CONCENTRATION - ACID SURGE TANK

$\epsilon$ INVENTORY - SECONDARY DISSOLVER SURGE TANK

$€$ VOLUME - SECONDARY DISSOLVER

E CONCENTRATION - SECONDARY DISSOLVER

$\epsilon$ VOLUME - SST

E CONCENTRATIOH - SST

E VOLUME - FEED SOLUTION SURGE TANK

$\epsilon$ CONCENTRATION - FEED SOLUTION SURGE TANK

$\epsilon$ VOLUME - ACCOUNTABIL ITY. TANK

$\leftarrow$ CONCENTRATION - ACCOUNTABIL ITY TANK

E TRANSFER - INPUT TO DISASSEMBLY

$\eta$ TRANSFER - INPUT TO DISASSEMBLY

$\theta$ TRANSFER - INPUT TO DISASSEMBLY

C TRANSFER - HULLS TO HULLS WASTE

7 TRANSFER - HULLS TO HULLS WASTE

O TRANSFER - HULLS TO HULIS WASTE

$\epsilon$ TRANSFER - PRIMARY CENTRIFUGE TO HLW

$\eta$ TRANSFER - PRIMARY CENTRIFUGE TO HLW

$\theta$ TRANSFER - PRIMARY CENTRIFUGE TO HLW

E TRANSFER - SST TO HLW

I TRANSFER - SST TO HLW

$\theta$ TRANSFER - SST TO HLW

E TRANSFER - HA CENTRIFUGE TO SST

$\eta$ TRANSFER - HA CENTRIFUGE TO SST

$\theta$ TRANSFER - HA CENTRIFUGE TO SST

$\epsilon$ VOLUME - ACCOUNTABILITY TANK OUTPUT

$n$ VOLUME - ACCOUNTABILITY TANK OUTPUT

$\theta$ VOLUME - ACCOUNTABILITY TANK OUTPUT

E CONCENTRATION - ACCOUNTAB ILITY TANK OUTPUT

$\eta$ CONCENTRATION - ACCOUNTABILITY TANK OUTPUT

$\theta$ CONCENTRATION - ACCOUNTAB ILITY TANK OUTPUT
MEASUREMENT ERRORS

CALCULATED CURRENT

$(10)$

B. $43-3$

2. 33-2

8. $08-3$

1. $.06-2$

$4 \cdot 23-3$

3. $45-3$

$1.08-1$

3. $00-2$

$1.5 \theta-2$

$3.00-2$

$1.50-2$

3. 49-2

1. 46-2

1. $96-2$

$3.000-2$

$7.00-2$

2.75-3

2. 19-3

3. $0 \theta-3$

$1.000-2$

6. 14-4

4. 13-5

3. $61-5$

1. . $00-1$

1. 13-2

1. 15-2

$1.00-1$

$5.000-2$

$5.00-2$

$1.000-1$

2.71-2

$2.56-2$

1. $00-1$

5. $00-2$

5. . $08-2$

1. 37-4

1. 38-5

1. $38-5$

$2.00-4$

1. 99-5

1.99-5

$4.000-2$

2. $60-1$

$2.00-1$

3. $00-2$

1. $5 \theta-2$

1. $\theta \theta-1$

$3.0 \theta-2$

1. $50-2$

3.. $08-2$

1. $58-2$

$1.00-1$

$3.95-2$

$7.06-2$

$3.00-2$

$7.8 \theta-2$

3. $.00-2$

1. 50-2

$3.00-3$

$1.00-2$

4.06-2

$3.00-2$

$2.00-2$

1. $.00-1$

$5.000-2$

$5.00-2$

1. $.00-1$

5. . $00-2$

$5.000-2$

1. . $60-1$

5. $00-2$

$5.00-2$

1. . $00-1$

$5.00-2$

$5.00-2$

$3.00-3$

$1.00-3$

$1.00-3$

1. . $0-2$

3. $08-3$

$3.00-3$

\section{MATERIALS BAL}

1 DAY

$(\mathrm{kg} \mathrm{Pu})$

1. 74-1
2. $40-1$

$3.60-1$

2. $86-1$

1. $67-1$

1. 36-1

$3.39-2$

1. 83-2

9. 13-3

1.64-2

5. 22-3

1. $18-1$

9.91-2

1. 33-1

.88

. 80

2.09-1

1. 66-1

0.00

\subsection{8}

$6.78-2$

3. $37-2$

2. 95-2

3. 74-3

3.17-3

3. 22-3

$2.48-3$

1. $2 x-3$

$1.20-3$

3. $17-3$

2. $28-3$

2. $15-3$

$7.60-4$

$3.80-4$

$3.89-4$

4. $83-2$

1. $68-2$

1. $88-2$

$5.98-2$

$1.55-2$

1. 55-2
6 MONTHS

Kg Pul

1. 74-1

2. $40-1$

3. $68-1$

2. 86-1

1. $67-1$

1. 36-1

3. 39-2

1. 83-2

9. 13-3

1.64-2

$5.22-3$

1. $18-1$

9.91-2

1. 33-1

g. 50

. .00

2. $09-1$

1. 66-1

6. 06

0.00

4. 39-1

1.44

1. 26

2. 45-2

1. $36-1$

1. $38-1$

8. $31-3$

1. 44-2

1. 44-2

$2.68-2$

9.75-2

9. 21-2

$5.84-3$

1.67-2

1. 67-2

2. 64-1

4. 62-1

4. 62-1

3. 86-1

6. 63-1

6. 63-1
RELATIVE

COST

3.74

7.68

$2 \cdot 38+1$

1. $78+1$

.89

3.34

3. 79-5

2.39-5

$1.41-5$

4. 35-5

7. 55-6

1.87

1.06

2.57

2.76-5

$2.76-5$

9.91

5.84

1. $86-5$

1. 75-5

$6.41+1$

$7 \cdot 26+2$

$5.53+2$

.32-7

3.42

3.35
$4.71-5$

1. 27-6

3. 33-5

2.64-5

8.45-1

9.54-1

3.81-5

$2.73-5$

3. 58-5

$2.09+1$

$7.12+1$

$7.13+1$

$4.89+1$

1. $5 \varnothing+2$

1. $5 \theta+2$ 
TABLE E-VII

MEASUREMENT UNCERTAINTIES: UPAA 1, GOAL 3, DAILY RECALIBRATION

No.

DESCR IPTION

C INVENTORY - DISASSEMBLY

$\epsilon$ INVENTORY - SHEAR

E INVENTORY - VOLOXIDIZER

$\epsilon$ INVENTORY - CONTINUOUS DISSOLVER

$\Leftrightarrow$ VOLUME - DIGESTER

E CONCENTRATION - DIGESTER

- INVENTORY - HULLS

$\epsilon$ VOLUME - BATCH DISSOLVER

$€$ CONCENTRATION - BATCH DISSOLVER

$\epsilon$ VOLUME - ACID SURGE TANK

$\epsilon$ CONCENTRATION - ACID SURGE TANK

$\epsilon$ INVENTORY - SECONDARY DISSOLVER SURGE TANK

$\epsilon$ VOLUME - SECONDARY DISSOLVER

E CONCENTRATION - SECONDARY DISSOLVER

$\epsilon$ VOLUME - SST

E CONCENTRATION - SST

$\epsilon$ VOLUME - FEED SOLUTION SURGE TANK

$\epsilon$ CONCENTRATION - FEED SOLUTION SURGE TANK

$\epsilon$ VOLUME - ACCOUNTABILITY TANK

$\epsilon$ CONCENTRATION - ACCOUNTABILITY TANK

$\epsilon$ TRANSFER - INPUT TO DISASSEMBLY

$\eta$ TRANSFER - INPUT TO DISASSEMBLY

$\theta$ TRANSFER - INPUT TO DISASSEMBLY

$\epsilon$ TRANSFER - HULLS TO HULLS WASTE

I TRANSFER - HULLS TO HULLS WASTE

TRANSFER - HULLS TO HULLS WASTE

- TRANSFER - PRIMARY CENTRIFUGE TO HLW

I TRANSFER - PRIMARY CENTRIFUGE TO HLW

TRANSFER - PRIMARY CENTRIFUGE TO HLW

E TRANSFER - SST TO HLW

I TRANSFER - SST TO HLW

$\theta$ TRANSFER - SST TO HLW

- TRANSFER - HA CENTPIFUGE TO SST

TRANSFER - HA CENTRIFUGE TO SST

TRANSFER - HA CENTRIFUGE TO SST

$\epsilon$ VOLUME - ACCOUNTABILITY TANK OUTPUT

$\eta$ VOLUME - ACCOUNTABILITY TANK DUTPUT

0 VOLUME - ACCOUNTABILITY TANK OUTPUT

$E$ CONCENTRATION - ACCOUNTABILITY TANK OUTPUT

I CONCENTRATION - ACCOUNTABILITY TANK OUTPUT

CONCENTRATION - ACCOUNTABILITY TANK OUTPUT
MEASUREMENT ERRORS

CALCULATED CURRENT

$(1 \sigma) \quad(1 \sigma)$

8. $67-3$

$2.34-2$

$9.86-3$

$1.26-2$

$5.2 \theta-3$

$4.01-3$

9. $99-2$

$3.06-2$

$1.50-2$

2.99-2

1. $50-2$

3. 86-2

$1.58-2$

2.14-2

3. $60-2$

$7.89-2$

$3.45-3$

2. $65-3$

$3.00-3$

$1.00-2$

7. 79-1

3. 54-4

4. $68-5$

9. 99-2

4. 66-2

1. 35-2

9. $95-2$

4. $98-2$

4. 97-2

9. 43-2

4. 98-2

2.91-2

9. $96-2$

4. $87-2$

4. $91-2$

$1.76-4$

$1.77-5$

1. $76-5$

2. 55-4

$1.71-4$

2.52-5
$(1 \sigma)$

4. $00-2$

$2.00-1$

$2.00-1$

2. $.00-1$

3. $00-2$

1. $5 \theta-2$

$1.00-1$

3. $00-2$

1. $58-2$

3. $00-2$

1. $50-2$

$1.00-1$

3. $00-2$

$7.000-2$

3. $00-2$

7. . $60-2$

$3.00-2$

1. $5 \theta-2$

$3.00-3$

$1.00-2$

$4.00-2$

$3.00-2$

$2.000-2$

$1 . \theta \theta-1$

$5.00-2$

$5.00-2$

1. $\theta \theta-1$

$5.00-2$

$5.90-2$

$1.08-1$

$5.90-2$

5. $.00-2$

$1.00-1$

$5.00-2$

$5 . \varnothing \theta-2$

$3.00-3$

$1.00-3$

$1.8 \theta-3$

$1.0 \theta-2$

3. $90-3$

$3.90-3$
MATERIALS BALANCE $\sigma$ 1 DAY 6 MONTHS

( $\mathrm{KgPu}) \quad(\mathrm{KgPu})$

1.79-1

2.41-1

3.66-1

3. $22-1$

2.85-1

$1.58-1$

$3.39-2$

1.82-2

9.12-3

$1.84-2$

$5.21-3$

$1.31-1$

$1.67-1$

$1.45-1$

6.60

月.

2.62-1

$2.82-1$

ถ. 80

๑. 00

8.50-2

$1.09-1$

3.75-2

$3.74-3$

4.93-3

3.77-3

$2.39-3$

$1.19-3$

$1.19-3$

$3.010-3$

$1.58-3$

2. 45-3

$7.57-4$

3. $7 \theta-4$

$3.73-4$

5.17-2

1. $38-2$

$1.37-2$

$7.52-2$

$5.02-2$

$1.97-2$

\section{79-1}

2. $11-1$

3.66-1

3. 22-1

2.05-1

1. 58-1

3. 39-2

1.82-2

9.12-3

1. $84-2$

5.21-3

1. $31-1$

1.67-1

1. 45-1

0.00

0.00

2.62-1

$2.02-1$

0.00

0.60

5. 56-1

1.61

2. 45-2

3.23-2

1. $62-1$

8. 27-3

1. 43-2

$1.43-2$

$1.96-2$

$1.03-2$

$1.05-1$

5.62-3

1.63-2

$1.64-2$

3. 39-1

$5.96-1$

5.87-1

4. $92-1$

3.29-1

8.43-1
RELATIVE COST

3.61

7.57

$1.93+1$

1. $57+1$

4.77

$5.62-4$

1. 46-3

2.52-3

$1.69-3$

1.59

B. 98-1

2.28

$4.86-4$

$4.86-4$

7.69

4.65

. 14-4

4.86-4

$5.83+1$

8. $37+1$

4. $34+2$

1. $16-3$

$7.24-2$

2.71

4. $97-3$

4.87-3

6.14-3

$6.60-2$

4. 18-3

$7.16-1$

4.23-3

2.68-2

$1.80-2$

$1,61+1$

5. $56+1$

$5.59+1$

$3.81+1$

$1.66+1$

$1.18+2$ 
MEASUREMENT UNCERTAINTIES: UPAA 1, GOAL 4, NO RECALIBRATION

No.

\section{DESCRIPTION}

C INVENTORY - DISASSEMBLY

E INVENTORY - SHEAR

- INVENTORY - VOLOXIDIZER

- INVENTORY - CONTINUOUS DISSOLVER

E VOLUME - DIGESTER

- CONCENTRATION - Digester

- INVENTORY - hULLS

- VOLUME - BatCh DISSOLVER

- concentration - batch dissolver

- VOLUME - ACIO SURGE TANK

- CONCENTRATION - ACID SURGE TANK

- INVENTORY - SECONDARY DISSOLVER SURGE TANK

\& VOLUME - SECONDARY DISSOLVER

- CONCENTRATION - SECONDARY DISSOLVER

C VOLUME - SST

- CONCENTRATION - SST

C VOLUME - FEED SOLUTION SURGE TANK

C CONCENTRATION - FEED SOLUTION SURGE TANK

C VOLUME - ACCOUNTABILITY TANK

C CONCENTRATION - ACCOUNTABILITY TANK

C TRANSFER - INPUT TO DISASSEMRLY

7 TRANSFER - INPUT TO DISASSEMBLY

O TRANSFER - INPUT TO DISASSEMBLY

- TRANSFER - HULLS TO HULLS WASTE

$\eta$ TRANSFER - HULLS TO HULLS WASTE

a TRANSFER - HULLS TO HULLS WASTE

C TRANSFER - PRIMARV CENTRIFUGE TO HLW

T TRANSFER - PRIMARY CENTRIFUGE TO HLW

O TRANSFER - PRIMARY CENTRIFUGE TO HLW

- transfer - SST to hLW

TRANSFER - SST TO HLW

J TRANSFER - SST TO HLW

- TRANSFER - HA CENTRIFUgE TO SST

$\eta$ TRANSFER - HA CENTRIFUGE TO SST

- TRANSFER - HA CENTRIFUGE TO SST

$\epsilon$ VOLUME - ACCOUNTABILITY TANK OUTPUT

7 VOLUME - ACCOUNTABILITY TANK OUTPUT

O VOLUME - ACCOUNTABILITY TANK OUTPUT

E CONCENTRATION - ACCOUNTABILITY TANK OUTPUT

7 CONCENTRATION - ACCOUNTABILITY TANK OUTPUT

O CONCENTRATION - ACCOUNTABILITY TANK OUTPUT
MEASUREMENT ERRORS

CALCULATEO CURRENT

$(1 \sigma)$

$(1 \sigma)$

$3 \cdot 30-3$

1. $81-2$

4. 3 v-3

1. $58-3$

$1.94-3$

2.12-3

8. $78-2$

2.71-2

1. 46-2

2. $80-2$

$1.49-2$

$1.75-2$

6.93-3

9. 59-3

3. 0-2

6. 99-2

1. $31-3$

1.15-3

2. $99-3$

9.98-3

3.94-4

3.31-5

2.76-5

9. 14-2

9.73-3

8.23-3

$1.08-$

4.71-2

4.63-2

9.88-2

2.19-2

1. $94-2$

9.84-2

4.75-2

4. $66-2$

9.17-5

1. $20-5$

1. $27-5$

1. $56-4$

1.65-5

1. $58-5$
4. .

2. $.00-1$

$2.80-1$

2. $\theta \theta-1$

$3.800-2$

1. $58-2$

1. $. \theta \theta-1$

3. $8 \theta-2$

1. $50-2$

$3.00-2$

1. $50-2$

$1.00-1$

$3.00-2$

$7.000-2$

$3.060-2$

$7.00-2$

3. $.80-2$

1. $5 \theta-2$

$3.08-3$

$1.80-2$

$4.00-2$

3. $80-2$

$2.80-2$

$1.00-1$

5. $00-2$

$5.80-2$

1. $.00-$

$5.00-2$

$5.00-2$

1. $00-1$

$5.8 B-2$

$5.0 .0-2$

$1.08-$

$5.80-2$

$5.00-2$

3. $\theta \theta-3$

1. $00-3$

1. $. B Q-.3$

1. $8 \theta-2$

3. $636-3$

3. $6 x-3$
MATERIALS BALANCE

BALANCE

( $\mathrm{Kg} P u)$ (KgPu)

RELATIVE COST

$6.80-26.80-2$

$1.84-1$

$1.63-1$

$1.23-1$

$7.62-2$

$8.33-2$

$2.95-2$

$1.65-2$

$8.87-3$

$9.75-3$

$5.17-3$

$5.94-2$

4. 7 g-2

$6.51-2$

0.00

0.80

9.94-2

8.74-2

0.00

.

1. 62-2

3.86-3

$3.22-3$

$1.29-3$

$3.89-4$

3. $29-4$

0.00

(1)

0.00

$1.09-3$

2.62-4

2. 32-4

0.0

0.88

0.00

I. $.02-2$

1. $34-3$

1. 41-3

$1.74-2$

1. $83-3$

1.67-3

$6.88-2$

$1.04-1$

1. $63-1$

1.23-1

7. 62-2

8. 33-2

2. $95-2$

1. $65-2$

8. 87-3

9.75-3

$5.17-3$

5.94-2

$4.78-2$

6.51-2

0.08

0,0

9.94-2

8.74-2

ช.

$0.0 \%$

1.99-1

5.79-1

4.83-1

1. $58-2$

5. $84-2$

4. $94-2$

5. 88-3

6. 78-3

6. 67-3

1. 33-2

3.94-2

3. $49-2$

3. $51-3$

$7.94-3$

7.79-3

1. 25-1

2.81-1

2. 1)-1

2.13-1

2.75-1

$2.58-1$
$1.11+1$

$1.88+1$

$4.47+1$

$4.27+1$

$1.45+1$

6.99

1. 49-1

1. 67-1

$2.94-2$

$7.010-2$

9. 14-3

4.71

3.33

$6.3 \%$

1.64-3

1. 58-3

$2.19+1$

$1.2 \theta+1$

1. 87-3

$1.84-3$

1. $1+2$

$9.85+2$

$7 \cdot 24+2$

$9.44-2$

4. 14

5.08

9.07-5

6.13-2

7.92-2

1. $02-1$

1.29

1.58

1. $67-2$

5. 35-2

7.27-2

$3 \cdot 17+1$

B. $2 \theta+1$

$7.8 \varnothing+1$

$6.29+1$

$1.81+2$

$1.81+2$
$.99+2$ 
TABLE E-IX

MEASUREMENT UNCERTAINTIES: UPAA 1, GOAL 4, DAILY RECAJIBRATION

No.

DESCRIPTION

- INVENTORY - DISASSEMBLY

C INVENTORY - SHEAR

- INVENTORY - VOLOXIDIZER

- INVENTORY - CONTINUOUS DISSOL VER

e VOLUME - DIGESTER

C CONCENTRATION - DIGESTER

C INVENTORY - HULLS

C VOLUME - BATCH DISSOLVER

- CONCENTRATION - BATCH DISSOLVER

$\Leftrightarrow$ VOLUME - ACID SURGE TANK

C CONCENTRATION - ACID SURGE TANK

C INVENTORY - SECONDARY DISSOLVER SURGE TANK

6 VOLUME - SECONDARY DISSOL VER

C CONCENTRATION - SECONDARY DISSOLVER

VOLUME - SST

C CONCENTRATION - SST

E VOLUME - FEED SOLUTION SURGE TANK

C CONCENTRATION - FEED SOLUTION SURGE TANK

\& VOLUME - ACCOUNTABILITY TANK

C CONCENTRATION - ACCOUNTABILITY TANK

- transfer - INPUT to dISASSEMBLy

7 TRANSFER - INPUT TO DISASSEMBLY

o TRANSFER - INPUT TO DISASSEMBLY

e TRANSFER - HULLS TO HULLS WASTE

$\eta$ TRANSFER - HULLS TO HULLS WASTE

TRANSFER - HULLS TO HULLS WASTE

- TRANSFER - PRIMARY CENTRIFUGE TO HLW

7 TRANSFER - PRIMARY CENTRIFUGE TO HLW

TRANSFER - PRIMARY CENTRIFUGE TO HLW

- transfer - SST to hLW

7 TRANGFER - SST TO HLW

$O$ TRANSFER - SST TO HLW

- TRANSFER - hA CENTRIFUGE TO SST

D TRANSFER - HA CENTRIFUGE TO SST

- TRANSFER - HA CENTRIFUGE TO SST

c VOLUME - ACCOUNTABILITY TANK OUTPUT

VOLUME - ACCOUNTABILITY TANK OUTPUT

\& VOLUME - ACCOUNTABILITY TANK OUTPUT

- CONCENTRATION - ACCOUNTABILITY TANK OUTPUT

I CONCENTRATION - ACCOUNTABILITY TANK OUTPUT

O CONCENTRATION - ACCOUNTABILITY TANK OUTPUT
MEASUREMENT ERRORS

CALCULATED CURRENT

$(\mid \sigma)$

$(1 \sigma)$

$4.56-3$

$1.28-2$

$5.18-3$

$6.18-3$

2.65-3

$2.28-3$

$9.37-2$

$3.00-2$

1. $5 \theta-2$

$3.00-2$

$1.50-2$

2. $2-2$

$9.88-3$

1. 13-2

3. $00-2$

$7.08-2$

$1.78-3$

1. $40-3$

$3.00-3$

1. $.00-2$

4. 94-4

$2.11-4$

3.41-5

1. . $80-1$

$4.86-2$

1.23-2

1. $60-1$

5.06-2

5. 12-2

1.03-1

5. $08-2$

2.15-2

$1.00-1$

5.62-2

5.12-2

1. $200-4$

1. $45-5$

$1.42-5$

1. $66-4$

1. $14-4$
4. $00-2$

$2.00-1$

$2.00-1$

$2.00-1$

$3.00-2$

$1.50-2$

1. . $00-1$

$3.00-2$

1. $5 \theta-2$

$3.00-2$

$1.5 \theta-2$

1. $.00-1$

$3.00-2$

$7.08-2$

$3.00-2$

$7.000-2$

$3.68-2$

1. $5 \theta-2$

$3.08-3$

$1.00-2$

4.00-2

$3.00-2$

$2.00-2$

$1.00-1$

5. $60-2$

$5.00-2$

$1.00-1$

$5.08-2$

$5.00-2$

1. $.00-1$

$5.00-2$

$5.0 \varnothing-2$

$1.00-1$

$5.00-2$

$5 . x 6-2$

$3.08-3$

$1.00-3$

$1.00-3$

$1.00-2$

$3.00-3$

$3.00-3$
MATERIALS BALANCE $\sigma$

$\begin{array}{ll}1 & \text { DAY MONTHS } \\ (\mathrm{KgPU}) & (\mathrm{Kg} \mathrm{Pu})\end{array}$

9. 40-2

$1.23-1$

1. $92-1$

1. $66-1$

1. $.04-1$

8. $66-2$

3. 18-2

$1.83-2$

9.13-3

1.04-2

$5.21-3$

$6.85-2$

6.65-2

$7.78-2$

6. 80

1. 35-1

$1.66-1$

$\varnothing .00$

$\varnothing .00$

$2.04-2$

2. 46-2

$3.98-3$

$1.41-3$

1. $94-3$

4. $91-4$

6.00

0.00

0.00

1. 23-3

2.58-4

g. 00

0.00

6. 80

1. 33-2

1. $61-3$

1. $58-3$

1. 85-2

1. 27-2

2. 24-3
9.48-2

1.23-1

1. 92-1

1.66-1

1.04-1

8. 66-2

3.18-2

1. $83-2$

9.13-3

1. $64-2$

5. 21-3

6.85-2

6.65-2

$7.7 \theta-2$

6.00

6.08

1.35-1

1. $.06-1$

0.00

0.00

2. 49-1

3. $92-1$

5.97-1

1. $73-2$

2. 38-2

7. 36-2

5.88-3

7. $28-3$

7.37-3

1.51-2

$7.35-3$

3.87-2

3. 56-3

8. 39-3

8.56-3

1. 63-1

?. $12-1$

2. 37-1

2.26-1

1. 56-1

3. 36-1
RELAT IVE

COST

7.78

$1.57+1$

$3.76+1$

$3.14+1$

5.82

6.68-2

4.51-4

3.84-6

9.95-14

4. $98-4$

3.96

2.66

5.17

4.73-4

$4.98-4$

$.59+$

9.73

4.87-4

$80+1$

$1.4+2$

$5.86+2$

6.38-5

2.93-2

3.68

2.48-6

$1.16-2$

2.29-2

2.65-2

5.67-4

1.33

8.95-6

3. $68-3$

2.39-2

$2.48+1$

$6.80+1$

$6.94+1$

$5.93+1$

$2.52+1$

$1,48+2$ 
TABLE E-X

MEASUREMENT UNCERTAINTIES: UPAA 2 3, GOAL J, NO RECALIBRATION

No.

DESCRIPTION

\& VOLUME - FEED ADJUSTMENT TANK

C CONCENTRATION - FEED ADJUSTMENT TANK

\& VOLUME - HA FEED TANK

- CONCENTRATION - ha fEed tank

e Pu SOLIDS - HA CENTRIFUGE

- INVENTORY - HA CONTACTOR

C INVENTORY - HS COLUMN

- INVENTORY - HC COLUMN

- VOLUME - HCP REDUCER

$C$ CONCENTRATION - HCP REDUCER

- VOLUME - IA FEED TANK

E CONCENTRATION - la FEED TANK

E INVENTORY - 1A COLUMN

$\epsilon$ VOLUAE - $2 A$ FEED TANK

e CONCENTRATION - 2A FEED TANK

E INVENTORY - 2A COLUMN

C INVENTORY - 2B COL UMN

a VOLUME - 3A FEED TANK

e CONCENTRATION - 3A FEED TANK

- INVENTORY - 3A COLUMN

E INVENTORY - 3B COLUMN

\& VOLUME - PU STRIPPER FEED

C CONCENTRATION - PU STRIPPER FEED

E INVENTORY - PU STRIPPER

$\epsilon$ VOL UME - PU CONCENTRATOR

C CONCENTRATION - PU CONCENTRATOR

\& VOLUME - PU CATCH TANK

C CONCENTRATION - Pu CATCH TANK

$E$ VOLUME - FEED ADJUSTMENT TANK INPUT

$n$ VOLUME - FEED ADJUSTMENT TANK INPUT

$\theta$ VOLUME - FEED ADJUSTMENT TANK INPUT

C CONCENTRATION - FEED ADJUSTMENT TANK INPUT

$\eta$ CONCENTRATION - FEED ADJUSTMENT TANK INPUT

$\theta$ CONCENTRATION - FEED ADJUSTMENT TANK INPUT

$\epsilon$ VOLUME - PU SAMPLE TANK OUTPUT

$\eta$ VOLUME - PU SAMPLE TANK OUTPUT

$\theta$ VOLUME - Pu SAMPLE TANK OUTPUT

C CONCENTRATION - PU SAMPLE TANK OUTPUT

$\eta$ CONCENTRATION - PU SAMPLE TANK OUTPUT

$\theta$ CONCENTRATION - PU SAMPLE TANK OUTPUT

C TRANSFER - HA CENTRIFUGE TO SST

$\eta$ TRANSFER - HA CENTRIFUGE TO SST

$\theta$ TRANSFER - HA CENTRIFUGE TO SST

\begin{tabular}{|c|c|}
\hline $\begin{array}{l}\text { MEASUREMENT } \\
\text { ALCULATED } \\
(1 \sigma)\end{array}$ & $\begin{array}{l}\text { ERRORS } \\
\text { CURRENT } \\
(1 \sigma)\end{array}$ \\
\hline $\begin{array}{l}3.00-2 \\
1.50-2 \\
2.99-2 \\
1.50-2 \\
2.00-1 \\
2.000-1 \\
1.000-1 \\
1.00-1 \\
3.60-2 \\
1.000-2 \\
3.00-2 \\
1.000-2 \\
1.00-1 \\
2.99-2 \\
1.00-2 \\
5.00-2 \\
5.00-2 \\
3.00-2 \\
1.000-2 \\
5.000-2 \\
5.00-2 \\
3.00-2 \\
1.000-2 \\
1.00-1 \\
3.00-2 \\
1.000-2 \\
3.00-2 \\
1.000-2 \\
2.98-3 \\
9.82-4 \\
9.76-4 \\
9.80-3 \\
2.42-3 \\
2.34-3 \\
3.000-3 \\
9.87-4 \\
9.84-4 \\
2.99-3 \\
1.85-3 \\
1.84-3 \\
1.000-1 \\
5.00-2 \\
5.00-2\end{array}$ & 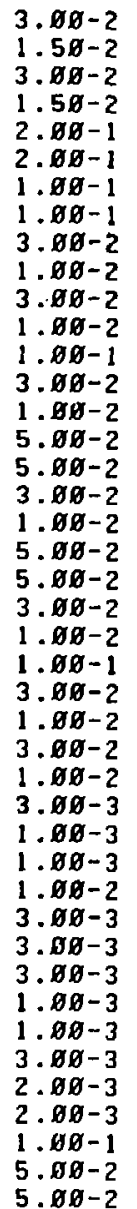 \\
\hline
\end{tabular}

MATERIALS BALANCE

$(\mathrm{KgPu}) \quad(\mathrm{KgPu})$

RELATIVE

COST

\begin{tabular}{|c|c|c|}
\hline 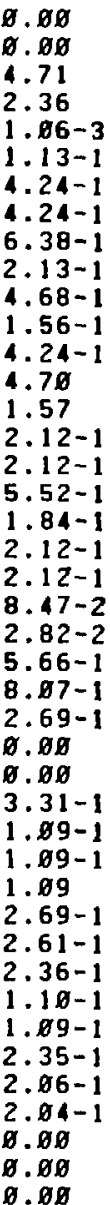 & $\begin{array}{l}9.80 \\
9.806 \\
4.71 \\
2.36 \\
1.86-3 \\
1.13-1 \\
4.24-1 \\
4.24-1 \\
6.38-1 \\
2.13-1 \\
4.68-1 \\
1.56-1 \\
4.24-1 \\
4.76 \\
1.57 \\
2.12-1 \\
2.12-1 \\
5.52-1 \\
1.84-1 \\
2.12-1 \\
2.12-1 \\
8.47-2 \\
2.82-2 \\
5.66-1 \\
8.87-1 \\
2.69-1 \\
6.98 \\
8.889 \\
4.866 \\
1.64+1 \\
1.63+1 \\
1.34+1 \\
4.84+1 \\
3.91+1 \\
2.89 \\
1.65+1 \\
1.64+1 \\
2.88 \\
3.899+1 \\
3.87+1 \\
3.56-3 \\
8.36-3 \\
8.36-3\end{array}$ & $\begin{array}{l}2.99-5 \\
3.93-5 \\
2.74-3 \\
4.47-6 \\
4.66-5 \\
4.87-5 \\
2.78-5 \\
2.76-5 \\
2.56-5 \\
2.32-5 \\
2.55-5 \\
2.77-5 \\
2.77-5 \\
2.23-3 \\
4.98-5 \\
2.32-5 \\
2.32-5 \\
2.89-5 \\
2.51-5 \\
2.32-5 \\
2.32-5 \\
2.93-5 \\
2.87-5 \\
8.17-5 \\
5.34-5 \\
2.41-5 \\
2.94-5 \\
2.99-5 \\
7.82-3 \\
1.84-2 \\
2.44-2 \\
2.66-2 \\
2.48-1 \\
2.79-1 \\
2.98-4 \\
1.33-2 \\
1.64-2 \\
2.15-3 \\
7.86-2 \\
8.77-2 \\
2.95-5 \\
4.68-5 \\
2.91-5\end{array}$ \\
\hline
\end{tabular}


TABLE E-XI

MEASUREMENT UNCERTAINTIES: UPAA 2 3, GOAL 1, WEEKLY RECALIBRATION

No.

DESCRIPTION

$\epsilon$ VOLUME - FEED ADJUSTMENT TANK

$\epsilon$ CONCENTRATION - FEED ADJUSTMENT TANK

$\epsilon$ VOLUME - HA FEED TANK

$\epsilon$ CONCENTRATION - HA FEED TANK

$\epsilon$ PU SOL IDS - HA CENTRIFUGE

$\epsilon$ INVENTORY - HA CONTACTOR

$\epsilon$ IIVENTORY - HS COLUMN

E INVENTORY - HC COLUMN

$\&$ VOLUME - HCP REDUCER

$\epsilon$ CONCENTRATION - HCP REDUCER

$\epsilon$ VOLUME - IA FEED TANK

E CONCENTRATION - IA FEED TANK

C INVENTORY - IA COLUMN

C VOLUME - $2 A$ FEED TANK

$\epsilon$ CONCENTRATION - 2A FEED TANK

C INVENTORY - 2A COLUMN

E INVENTORY - 28 COLUMN

- VOLUME - 3A FEED TANK

C CONCENTRATION - 3A FEED TANK

- INVENTORY - 3A COLUMN

C INVENTORY - 3B COLUMN

$\epsilon$ VOLUME - PU STRIPPER FEED

E CONCENTRATION - PU STRIPPER FEED

C INVENTORY - PU STRIPPER

$\epsilon$ VOLUME - PU CONCENTRATOR

- CONCENTRATION - Pu CONCENTRATOR

$\&$ VOLUME - PU CATCH TANK

E CONCENTRATION - PU CATCH TANK

$\epsilon$ VOLUME - FEED ADJUSTMENT TANK INPUT

$\eta$ VOLUME - FEED ADJUSTMENT TANK INPUT

$\theta$ VOLUME - FEED ADJUSTMENT TANK INPUT

$\epsilon$ CONCENTRATION - FEED ADJUSTMENT TANK INPUT

$\eta$ CONCENTRATION - FEED ADJUSTMENT TANK INPUT

$\theta$ CONCENTRATION - FEED ADJUSTMENT TANK INPUT

- VOLUME - PU SAMPLE TANK OUTPUT

$\eta$ VOLUME - Pu SAMPLE TANK OUTPUT

$\theta$ VOL UME - PU SAMPLE TANK OUTPUT

$\epsilon$ CONCENTRATION - PU SAMPLE TANK OUTPUT

7 CONCENTRATION - PU SAMPLE TANK OUTPUT

- CONCENTRATION - PU SAMPLE TANK OUTPUT

C TRANSFER - HA CENTRIFUGE TO SST

$\eta$ TRANSFER - HA CENTRIFUGE TO SST

o tRANSFER - HA CENTRIFUGE TO SST
MEASUREMENT ERRORS

CALCULATED CURENT
$(1 \sigma)$

$3.00-2$

$1.5 \theta-2$

$3.08-2$

$1.50-2$

$2.00-1$

$2.00-1$

$1.00-1$

$1.00-1$

$3.00-2$

$1.00-2$

$3.00-2$

$1.00-2$

1. $00-1$

$3.00-2$

$1 . \varnothing \varnothing-2$

5. $.00-2$

$5.00-2$

$3.00-2$

$1.08-2$

5. $000-2$

$5.00-2$

$3 . \varnothing \varnothing-2$

$1.00-2$

1. $.00-1$

$1.00-2$

$3.00-2$

$1.00-2$

$3.00-3$

1. $\varnothing \varnothing-3$

$1.60-3$

$1 . \theta \theta-2$

$3.00-3$

$3.60-3$

3. $00-3$

$1 . \theta \theta-3$

$1.00-3$

$3.00-3$

$2.00-3$

$2.00-3$

1. $\varnothing 0-1$

$5.00-2$

$5.60-2$

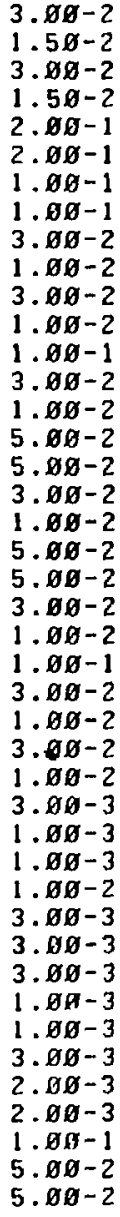

MATERIALS BALANCE 1 DAY
$(\mathrm{Kg} P \mathrm{Pu})$

RELATIVE COST

ต. 00

$\varnothing . \varnothing 0$

4.72

2.36

$1.06-3$

1. 13-1

4. $24-1$

$4.24-1$

6. $38-1$

2.13-1

$4.68-1$

1. 56-1

4.24-1

4.71

1.57

2.12-1

2.12-1

$5.52-1$

$1.84-1$

2.12-1

2. 12-1

8. 47-2

2.82-2

5. 66-1

8. $87-1$

2. 69-1

อ. 00

๑. 00

3. 34-1

1. $11-1$

1.11-1

1.11

3. $34-1$

3. $34-1$

2. $36-1$

1. $11-1$

1. $11-1$

2. $36-1$

$2.22-1$

2. 22-1

๑.

0.00

0.00
0.00

0.88

4.72

1. $66-3$

1.13-1

4.24-1

4.24-1

6. 38-1

2.13-1

1.68-1

1. 56-1

1. 24-1

4.71

$2.12-1$

5.52-1

1. 84-1

2. 12-1

2.12-1

8.47-2

2.82-2

5.66-1

$8.67-1$

2.69-1

0.00

0.00

4.09

$1.67+1$

1. $67+1$

1. $36+1$

$1.07+1$

$5.01+1$

2.89

$1.67+1$

$1.67+1$

2.89

7.13

$3.34+1$

3. $56-3$

B. 36-3

B. $36-3$
0.00

0.00

0.00

0.00

0.00

0.00

0.00

0.00

0.00

.00

0.06

0.00

0.00

0.08

ต.

๑. .

0.00

0.06

0.06

0.00

0.00

0.60

0.00

0.60

๑. ๓6

0.00

0.00

0.00

0.00

Ø.

0.00

$\varnothing .00$

0.00

0.00

$\varnothing .00$

ஜ.

$\varnothing .06$

0.00

0.06

$\varnothing .06$

Ø.๑ต 
MEASUREMENT UNCERTAINTIES: UPAA 2 3, GOAL 2, NO RECALIBRATION

No.

\section{DESCR IPTION}

\& VOLUME - FEED ADJUSTMENT TANK

$C$ CONCENTRATION - FEED ADJUSTMENT TANK

- Volume - ha FEed tank

C CONCENTRATION - HA FEED TANK

$\epsilon$ Pu SOLIDS - HA CENTRIFUGE

- INVENTORY - HA CONTACTOR

E INVENTORY - HS COLUMN

\& INVENTORY - HC COLUMN

C VOLUME - HCP REDUCER

- CONCENTRATION - HCP REDUCER

- VOLUME - IA FEED TANK

e CONCENTRATION - IA FEED TANK

e INVENTORY - IA COLUMN

$\in$ VOLUME - $2 A$ FEED TANK

C CONCENTRATION - $2 A$ FEED TANK

C INVENTORY - 2A COLUMN

C INVENTORY - 2B COLUMN

\& VOLUME - 3A FEED TANK

e CONCENTRATION - 3A FEED TANK

E INVENTORY - 3A COLUMN

C INVENTORY - 3B COLUMN

- VOLUME - PU STRIPPER FEED

- CONCENTRATION - PU STRIPPER FEED

E INVENTORY - PU STRIPPER

e VOLUME - PU CONCENTRATOR

- CONCENTRATION - Pu CONCENTRATOR

$\epsilon$ VOLUME - PU CATCH TANK

$\in$ CONCENTRATION - Pu CATCH TANK

E VOLUME - FEED ADJUSTMENT TANK INPUT

$\eta$ VOLUME - FEED ADJUSTMENT TANK INPUT

$\theta$ VOLUME - FEED ADJUSTMENT TANK INPUT

$\epsilon$ CONCENTRATION - FEED ADJUSTMENT TANK INPUT

$\eta$ CONCENTRATION - FEED ADJUSTMENT TANK INPUT

0 CONCENTRATION - FEED ADJUSTMENT TANK INPUT

$C$ VOLUME - PU SAMPLE TANK OUTPUT

$\eta$ VOLUME - PU SAMPLE TANK OUTPUT

$\theta$ VOL UME - PU SAMPLE TANK DUTPUT

- CONCENTRATION - PU SAMPLE TANK OUTPUT

$n$ CONCENTRATION - PU SAMPLE TANK OUTPUT

$\theta$ CONCENTRATION - PU SAMPLE TANK OUTPUT

C TRANSFER - HA CENTRIFUGE TO SST

n TRANSFER - HA CENTRIFUGE TO SST

$\theta$ TRANSFER - HA CENTRIFUGE TO SST
MEASUREMENT ERRORS

CALCULATED CURRENT

$3.00-2$

$1.5 \varnothing-2$

$1.27-2$

$1.08-2$

$2.00-1$

$2.00-1$

9.96-2

$9.96-2$

2. 93-2

$1.00-2$

2.99-2

$1.00-2$

9.81-2

1.29-2

B.81-3

$5.00-2$

4. 99-2

2.95-2

1. $00-2$

5. $00-2$

5. $00-2$

3. $00-2$

$1.00-2$

9.76-2

2.91-2

9.98-3

$3.06-2$

$1.00-2$

2.14-3

3.27-4

$3.27-4$

3. $76-3$

4.73-4

4.68-4

2. 92-3

3. $25-4$

3. 27-4

2.85-3

$4.00-4$

4.07-4

$1.00-1$

$5.00-2$

$5.00-2$
(10)

3. $00-2$

1. $58-2$

3. $60-2$

1. $5 \theta-2$

$2.00-1$

$2.00-1$

$1.00-1$

1. $00-1$

$3.00-2$

1. $00-2$

$3.00-2$

$1.00-2$

1. $.00-1$

3. $\theta 00-2$

1. $00-2$

$5.00-2$

5. $00-2$

3. $.08-2$

$1.000-2$

$5.00-2$

5. $00-2$

$3.00-2$

$1.00-2$

$1.00-1$

3. $00-2$

1. $.60-2$

$3.00-2$

1. $600-2$

$3.00-3$

1. $\theta \theta-3$

1. $.00-3$

1. $80-2$

$3.000-3$

$3.00-3$

$3.0 \theta-3$

1. $0 \theta-3$

$1.00-3$

$3.00-3$

$2.00-3$

$2.00-3$

1. $.00-1$

5. $.100-2$

$5.00-2$
MATERIALS BALANCE $\sigma$ 1 DAY 6 MONTHS

RELATIVE COST

D. .06

0.00
2.00

1.78

1. $06-3$

1. 13-1

4.23-1

4. $23-1$

6. 24-1

$2.13-1$

4.66-1

1. 56-1

4. $16-1$

2.03

1.38

2. $12-1$

$2.12-1$

5. 44-1

1.84-1

2. 12-1

$2.12-1$

8. 47-2

$2.82-2$

$5.52-1$

7. $83-1$

2. 69-1

0.00

0.00

2. $71-1$

3. 64-2

3. 64-2

4. 12-1

$5.26-2$

5. $2 \theta-2$

2. $30-$

3. 61-2

$3.64-2$

2. 24-1

4. 45-2

4. 52-2

0.00

0.00

0.00
( $\mathrm{Kg} \mathrm{Pu}$ )

1. $31-5$

1.37

3. 85-1

1. $78-5$

$3.98-3$

$3.64-3$

2. 31-2

$1.06-4$

$3.99-3$

4. $98-5$

1. 93-2

1.32

1. 35-1

2. $56-5$

2. $67-3$

$1.53-2$

3. $75-4$

$2.33-4$

2. $22-4$

4. 99-5

1. 52-5

2. 43-2

$3.03-2$

1. $680-3$

1. 31-5

$1.31-5$

2.06

2.06

1.76

5.35

5.42

$2.66-2$

2.08

2.06

$5.3 \theta-2$

4.00

3.92

1. $31-5$

$1.31-5$
$1.31-5$ 
TABLE E-XIII

MEASUREMENT UNCERTAINTIES: UPAA 2 3, GOAL 2, WEEKLY RECALIBRATION

No.

DESCRIPTION

E VOLUME - FEED ADJUSTMENT TANK

C CONCENTRATION - FEED ADJUSTMENT TANK

- VOL UME - HA FEED TANK

- CONCENTRATION - ha FEED tank

\& Pu SOLIDS - HA CENTRIFUge

E INVENTORY - HA CONTACTOR

E INVENTORY - HS COLUMN

C INVENTORY - HC COLUMN

C VOLUME - HCP REDUCER

$\epsilon$ CONCENTRATION - HCP REDUCER

e VOLUME - 1A FEED TANK

- concentration - ia feEd tank

$C$ INVENTORY - 1A COLUMN

- volUME - 2A FEED tank

- concentration - 2A FEED tANK

- INVENTORY - 2A COLUMN

- INVENTORY - $2 B$ COLUMN

C VOLUME - 3A FEED TANK

E CONCENTRATION - 3A FEED TANK

- INVENTORY - 3a COLUMN

- INVENTORY - 3B COLUMN

- VOLUME - PU STRIPPER FEED

C CONCENTRATION - PU STRIPPER FEED

- INVENTORY - PU STRIPPER

- Volume - Pu concentrator

- CONCENTRATION - Pu CONCENTRATOR

E VOLUME - PU CATCH TANK

E CONCENTRATION - PU CATCH TANK

$\epsilon$ VOLUME - FEED ADJUSTMENT TANK INPUT

$\eta$ VOLUME - FEED ADJUSTMENT TANK INPUT

$\theta$ VOLUME - FEED ADJUSTMENT TANK INPUT

- CONCENTRATION - FEED ADJUSTMENT TANK INPUT

7 CONCENTRATION - FEED ADJUSTMENT TANK INPUT

CONCENTRATION - FEED ADJUSTMENT TANK INPUT

e VOLUME - PU SAMPLE TANK OUTPUT

$\eta$ VOLUME - Pu SAMPLE TANK OUTPUT

$\theta$ VOL UME - PU SAMPLE TANK OUTPUT

C CONCENTRATION - Pu SAMPLE TANK OUTPUT

$\eta$ CONCENTRATION - PU SAMPLE TANK OUTPUT

- CONCENTRATION - PU SAMPLE TANK OUTPUT

- TRANSFER - HA CENTRIFUGE TO SST

$\eta$ TRANSFER - HA CENTRIFUGE TO SST

O TRANSFER - HA CENTRIFUGE TO SST
MEASUREMENT ERRORS

CALCULATED CURRENT

$\{1 \sigma\}$

$(1 \sigma)$

$3.00-2$

$1.5 \varnothing-2$

$1.34-2$

$1.06-2$

$2.00-1$

2. $00-1$

$1.00-1$

9.99-2

2.92-2

$1.00-2$

2.96-2

$1.00-2$

9.76-2

$1.28-2$

8. 31-3

4. $96-2$

4. $91-2$

2.95-2

9.89-3

4.89-2

4. $9 \theta-2$

3. $00-2$

$1.00-2$

9.76-2

2. $66-2$

9. $82-3$

$3.00-2$

$1.00-2$

2.66-3

3.61-4

3.61-4

4. $13-3$

1. 45-3

5.19-4

2.77-3

3. $61-4$

$3.64-4$

2.72-3

$1.28-3$

4.55-4

$1.00-1$

$5.00-2$

$5.00-2$
$3.00-2$

$1.5 \theta-2$

3. $80-2$

1. 50-2

$2.00-1$

2. $.00-1$

$1.00-1$

1. $\theta \theta-1$

$3.00-2$

$1.00-2$

$3.00-2$

$1.00-2$

$1.00-1$

$3.00-2$

$1.00-2$

$5.00-2$

$5.00-2$

3. $.00-2$

$1.00-2$

5. $00-2$

$5.00-2$

3. $\theta 0-2$

$1.00-2$

$1.00-1$

$3.000-2$

$1.00-2$

$3.00-2$

$1.00-2$

3. $00-3$

$1.00-3$

1. $.00-3$

$1.00-2$

$3.00-3$

$3.00-3$

$3.00-3$

$1.00-3$

$1.00-3$

$3.00-3$

$2.00-3$

$2.00-3$

1. $.0 \theta-1$

$5.00-2$

$5.00-2$ $\begin{array}{cc}\text { MATERIALS } & \text { BALANCE } \sigma \\ 1 \text { DAY } & 6 \text { MONTHS } \\ (\mathrm{Kg} \mathrm{Pu}) & (\mathrm{Kg} \mathrm{Pu})\end{array}$

RELATIVE COST

อ. 00

0.00

2.10

1.67

1. .66-3

1. 13-1

4. 24-1

4. 24-1

$6.28-1$

2. 13-1

4. $61-1$

1. 56-1

4. 14-1

2.01

1.30

$2.10-1$

5.43-

1.82-1

2.07-1

2. $08-1$

B. 46-2

2. B2-2

5. 52-1

7. $15-1$

2. 64-1

อ. 00

$\varnothing .00$

2. 96-1

4. $02-2$

4. $02-2$

4. 59-1

1. 62-1

5.77-2

2. $18-1$

4. . $1-2$

4.064-2

2. 14-1

1. 42-1

5.06-2

0.06

0.00

0.00

\begin{tabular}{|c|c|}
\hline 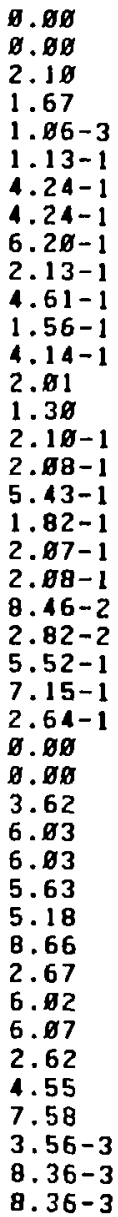 & $\begin{array}{l}2.73-5 \\
2.73-5 \\
1.24 \\
1.18-1 \\
2.74-5 \\
1.41-5 \\
1.66-4 \\
5.71-4 \\
2.87-2 \\
3.36-4 \\
1.46-2 \\
1.67-4 \\
2.43-2 \\
1.34 \\
2.63-1 \\
8.68-3 \\
1.91-2 \\
1.82-2 \\
1.68-2 \\
2.38-2 \\
2.13-2 \\
1.61-3 \\
2.75-5 \\
2.43-2 \\
1.28-1 \\
1.88-2 \\
2.73-5 \\
2.73-5 \\
1.29-1 \\
1.77 \\
1.77 \\
1.42 \\
1.67 \\
4.79 \\
8.15-2 \\
1.77 \\
1.75 \\
1.62-1 \\
5.68-1 \\
3.48 \\
2.73-5 \\
2.73-5 \\
2.73-5\end{array}$ \\
\hline
\end{tabular}


MEASUREMENT UNCERTAINTIES: UPAA 23 , GOAL 2, DAILY RECALIBRATION

No.

\section{DESCR IPTION}

- VOLUME - FEED ADJUSTMENT TANK

\& CONCENTRATION - FEED ADJUSTMENT TANK

a VOLUME - HA FEED TANK

- CONCENTRATION - HA FEED TANK

\& Pu SOLIDS - HA CENTRIFUGE

E INVENTORY - HA CONTACTOR

a INVENTORY - HS COLUMN

- INVENTORY - HC COLUMN

- VOLUME - HCP REDUCER

- CONCENTRATION - HCP REDUCER

- VOLUME - IA FEED TANK

\& CONCENTRATION - IA FEED TANK

- INVENTORY - IA COLUMN

\& VOLUME - 2A FEED TANK

\& CONCENTRATION - ZA FEED TANK

- INVENTORY - $2 A$ COLUMN

- INVENTORY - $2 B$ COLUMN

- VOLUME - 3A FEED TANK

- CONCENTRATION - 3A FEED TANK

E INVENTORY - 3A COLUMN

\& INVENTORY - 3B COLUMN

\& VOLUME - PU STRIPPER FEED

- CONCENTRATION - PU STRIPPER FEED

\& INVENTORY - PU STRIPPER

\& VOLUME - PU CONCENTRATOR

\& CONCENTRATION - PU CONCENTRATOR

$€$ VOLUME - PU CATCH TANK

E CONCENTRATION - Pu CATCH TANK

\& VOLUME - FEED ADJUSTMENT TANK INPUT

7 VOLUME - FEED ADJUSTMENT TANK INPUT

$\theta$ VOLUME - FEED ADJUSTMENT TANK INPUT

- CONCENTRATION - FEED ADJUSTMENT TANK INPUT

$\cap$ CONCENTRATION - FEER ADJUSTMENT TANK INPUT

O CONCENTRATION - FEED ADJUSTMENT TANK INPUT

- VOLUME - PU SAMPLE TANK OUTPUT

$\eta$ VOLUME - Pu SAMPLE TANK OUTPUT

$\theta$ VOL UME - PU SAMPLE TANK OUTPUT

C CONCENTRATION - PU SAMPLE TANK OUTPUT

$n$ CONCENTRATION - PU SAMPLE TANK OUTPUT

$\theta$ CONCENTRATION - PU SAMPLE TANK OUTPUT

C TRANSFER - HA CENTRIFUGE TO SST

T TRANSFER - HA CENTRIFUGE TO SST

O TRANSFER - HA CENTRIFUGE TO SST
MEASUREMENT ERRORS

$\begin{array}{cc}\text { CALCULATED } & \text { CURRENT } \\ (1 \sigma) & (1 \sigma)\end{array}$

$3.00-2$

$1.58-2$

$1.28-2$

$1.02-2$

$2.00-1$

$2.08-$

$1.6 \theta-1$

$1.00-1$

$2.98-2$

$1.80-2$

$2.99-2$

$1.00-2$

$1.00-1$

1. $29-2$

8. 84-3

$5.00-2$

$5.90-2$

$2.99-2$

1. . $00-2$

5. $80-2$

$5.000-2$

3. $00-2$

1. $00-2$

9. 97-2

2. $91-2$

9. $99-3$

3. $00-2$

1. $00-2$

2. 72-3

3. $72-4$

3. $78-4$

4. $3 \theta-3$

2. 77-3

5.43-4

2. $99-3$

3. $71-4$

3. $77-4$

2. $98-3$

1. $98-3$

4.66-4

$1.00-1$

5. $00-2$

5. $00-2$

\section{$3.00-2$}

1. $5 \theta-2$

$3.00-2$

1. $50-2$

$2.0 \theta-1$

$2.00-1$

1. $000-1$

1. $.00-1$

3. $.00-2$

1. $\theta \theta-2$

$3.60-2$

1. $00-2$

1. $.00-1$

3. $00-2$

1. . $00-2$

$5.60-2$

$5.00-2$

3. $00-2$

1. $60-2$

$5.00-2$

$5.00-2$

3. $89-2$

1. $00-2$

1. $00-1$

$3.0 \theta-2$

$1.00-2$

$3.00-2$

1. $00-2$

$3.60-3$

$1.00-3$

$1.00-3$

1. $.00-2$

$3.00-3$

$3.00-3$

$3.00-3$

$1.00-3$

$1.00-3$

$3.0 \theta-3$

$2.00-3$

$2.00-3$

$1.90-$

$5.06-2$

5.00-2
MATERIALS BALANCE $\sigma$

1 DAY 6 G MONTHS

RE LAT IVE

COST

อ. 06

0.00

2.81

1.56

1. $06-3$

1. 13-1

4. 24-1

4. $24-1$

6. 34-1

2.13-1

4. 66-1

1. 56-1

4. $24-1$

2.03

1.39

2. 12-1

2. 12-1

5. 51-1

1. $84-1$

2. 12-1

2. 12-1

$8.47-2$

$2.82-2$

5. 64-1

7.84-1

2. 69-1

0.00

G. 00

3. $2-1$

4.14-2

4. 21-2

4. $78-1$

$3.09-1$

6. $04-2$

2. 35-1

4.12-2

4.19-2

$2.35-1$

2. $20-1$

5. 18-2

ด. 00

0.00

8.08
( $\mathrm{Kg} \mathrm{Pu}$ )

อ. 00

0.00

1.60

1. $06-3$

1.13-1

4. 24-1

4. 24-1

6. 34-1

2. 13-1

4. 66-1

1. 56-1

1. 24-1

2.63

1.39

2. 12-1

$2.12-1$
$5.51-1$

1.84-1

2. 12-1

2. 12-1

8. 47-2

2. $82-2$

5. 64-1

7. $84-1$

2. 69-1

ด. 0

0.00

3.70

6.20

6.31

5.85

3.78

9.06

2.88

6.18

6.28

2.87

2.69

7.77

3. 56-3

8. $36-3$

8. 36-3
1. 38-5

1. 38-5

1.34

4. 78-1

1. 38-5

9. 95-6

1. $04-4$

5. 99-3

3. 55-4

3. $97-3$

4. 72-4

3.67-4

1.32

1. $31-1$

4. 41-4

4. 78-4

$2.03-3$

$3.63-4$

2. 54-4

2.75-5

1. 64-5

3. $21-3$

2. 94-2

$7.51-4$

1. $38-5$

1. 38-5

$1.01-1$

1.69

1.65

1. 33

8. $18-2$

4.53

4. 38-3

1.70

1.66

5. . 6 6-3

1. 22-2

3.29

1. $38-5$

1. $38-5$ 
TABLE E-XV

MEASUREMENT UNCERTAINTIES: UPAA 23 , GOAL 3, NO RECALIBRATION

No.

DESCRIPTION

\& VOLUME - FEED ADJUSTMENT TANK

E CONCENTRATION - FEED AOJUSTMENT TANK

\& VOLUME - HA FEED TANK

E CONCENTRATION - HA FEED TANK

\& PU SOLIDS - HA CENTRIFUGE

C INVENTORY - HA CONTACTOR

E INVENTORY - HS COL UMN

C INVENTORY - HC COLUMN

E VOLUME - HCP REDUCER

\& CONCENTRATION - HCP REDUCER

\& VOLUME - IA FEED TANK

C CONCENTRATION - IA FEED TANK

E INVENTORY - IA COLUMN

e VOLUME - 2A FEED TANK

- CONCENTRATION - $2 A$ FEED TANK

- INVENTORY - $2 A$ COLUMN

C INVENTORY - 2B COL UMN

E VOLUME - 3A FEED TANK

E CONCENTRATION - 3A FEED TANK

E INVENTORY - 3A COLUMN

E INVENTORY - 3B COLUMN

e VOLUME - PU STRIPPER FEED

C CONCENTRATION - PU STRIPPER FEED

E INVENTORY - PU STRIPPER

E VOLUME - Pu CONCENTRATOR

C CONCENTRATION - Pu CONCENTRATOR

\& VOLUME - PU CATCH TANK

C CONCENTRATION - Pu CATCH TANK

- VOLUME - FEED ADJUSTMENT TANK INPUT

$n$ VOLUME - FEED ADJUSTMENT TANK INPUT

$\theta$ VOLUME - FEED ADJUSTMENT TANK INPUT

\& CONCENTRATION - FEED ADJUSTMENT TANK INPUT

$n$ CONCENTRATION - FEED ADJUSTMENT TANK INPUT

$\theta$ CONCENTRATION - FEED ADJUSTMENT TANK INPUT

\& VOLUME - PU SAMPLE TANK OUTPUT

$n$ VOLUME - PU SAMPLE TANK OUTPUT

$\theta$ VOLUME - Pu SAMPLE TANK OUTPUT

\& CONCENTRATION - PU SAMPLE TANK OUTPUT

$\eta$ CONCENTRATION - PU SAMPLE TANK OUTPUT

O CONCENTRATION - Pu SAMPLE TANK OUTPUT

E TRANSFER - HA CENTRIFUGE TO SST

$\eta$ TRANSFER - HA CENTRIFUGE TO SST

$\theta$ TRANSFER - HA CENTRIFUGE TO SST

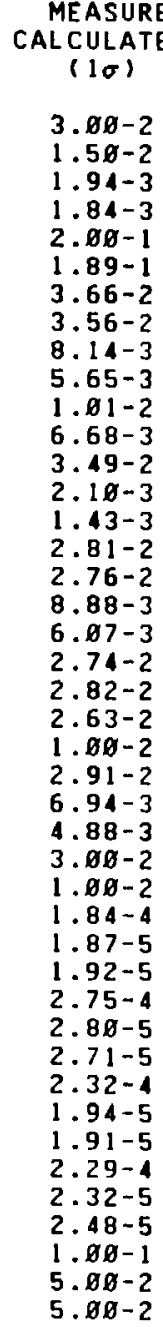

MATERIALS BALANCE O

$\begin{array}{ll}1 \text { DAY } & 6 \text { MONTHS } \\ (\mathrm{Kg} \mathrm{Pu}) & (\mathrm{Kg} \mathrm{PU})\end{array}$

RELATIVE COST

$$
(1 \sigma)
$$

$3 . \mathscr{0 - 2}$

$1.5 \theta-2$

$3.08-2$

1. $5 \theta-2$

2. $6 \theta-1$

$2.00-1$

1.

$1.00-1$

$3.00-2$

1. . $00-2$

$3.00-2$

$1.00-2$

$1.00-1$

3. $00-2$

1. $.00-2$

$5.000-2$

$5.000-2$

3. $00-2$

1. $00-2$

$5.00-2$

$5.000-2$

$3.0 B-2$

1. $.00-2$

1. $.00-1$

$3.00-2$

1. $\theta 0-2$

$3.00-2$

1. $00-2$

$3.00-3$

1. $00-3$

1. $.00-3$

1. $.00-2$

$3.00-3$

$3.00-3$

$3.00-3$

$1.00-3$

$1.00-3$

$3.00-3$

2. . $00-3$

$2.00-3$

1. $09-1$

5. $00-2$

5. 60-2
0. 00

0.00

3. 65-1

2.89-1

1. . $66-3$

1. $87-1$

1. 55-1

1. 5 I-1

1. 73-1

1. $20-1$

1. 58-1

1. $64-1$

1. 48-1

3. 29-1

2. 25-1

1. 19-1

$1.17-1$

1. $64-1$

1. $12-1$

1. 16-1

1. $2 \theta-1$

7. 42-2

2. 82-2

1. 65-1

1. 87-1

1. $31-1$

0.00

Ø. 00

5. 40-2

1. 46-2

1. 49-2

8. 11-2

2. $18-2$

2. $11-2$

4. 82-2

1. 51-2

1. 49-2

4. 77-2

1. $81-2$

1. 93-2

7. $60-4$

$3.8 \theta-4$

$3.80-4$
0.00

0.06

3. $.05-1$

1. $86-3$

1. . $07-1$

1. 55-1

1. 51-1

1. 73-1

1. 26-1

1. 58-1

1. $.84-1$

1. $48-1$

3. 29-1

2. $25-1$

1.19-1

1. 17-1

1. 64-1

1. 12-1

1. 16-1

1. $26-1$

7. 42-2

2. 82-2

1. $65-1$

1. $87-1$

1. $31-1$

0.06

0. 80

6. 24-1

6. 41-1

5. $31-1$

9. 33-1

9.04-1

3. 16-1

6. 47-1

6. 37-1

3. 12-1

7.75-1

8. 26-1

5. $04-3$

1. $67-2$

1. $67-2$
6. $61-5$

3. 19-5

1. $45+1$

7.17

3. 66-5

5. 99-2

1.73

1.81

2.68

7. $79-$

1.96
$4.96-1$

1.86

1. $33+1$

5.97

7. 78-1

8. 14-1

2.38

6. 47-1

8. 24-1

7. 73-1

$1.41-1$
$3.37-5$

2. 43

3. 32

1. 65

3. 52-5

2. $98-5$

1. $53+1$

5. $25+1$

5. $11+1$

$3 \cdot 53+1$

1. $.66+2$

$1.18+2$

$1.19+1$

$5.06+1$

5. $14+1$

1. $21+1$

$8.51+1$

$7 \cdot 98+1$

3. $7 \theta-5$

5. $84-5$

4. $80-5$ 
TABLE E-XVI

MEASUREMENT UNCERTAINTIES: UPAA 23 , GOAL 3, DAILY RECALIBRATION

กо.

- VOLUME - FEED ADJUSTMENT TANK

C CONCENTRATION - FEED aDJUSTMENT TANK

- VOLUME - HA FEED TANK

C CONCENTRATION - HA FEED TANKK

E PU SOL IDS - HA CENTRIFUGE

E INVENTORY - HA CONTACTOR

C INVENTORY - HS COLUMN

E INVENTORY - HC COLUMN

C VOLUME - HCP REDUCER

C CONCENTRATION - HCP REDUCER

$\epsilon$ VOLUME - IA FEED TANK

e concentration - Ia fEEd tANK

- INVENTorv - Ia col umn

a VOLUME - $2 A$ FEED TANK

C CONCENTRATION - 2A FEED TANK

E INVENTORY - 2A COL UMN

E INVENTORY - 2B COL UMN

e VOLUME - 3A FEED TANK

C CONCENTRATION - 3A FEED TANK

E INVENTORY - 3A COLUMN

E INVENTORY - 3B COLUMN

e VOLUME - PU STRIPPER FEED

- CONCENTRATION - Pu STRIPPER FEED

C INVENTORY - PU STRIPPER

E VOLUME - PU CONCENTRATOR

E CONCENTRATION - PU CONCENTRATOR

E VOLUME - Pu CATCH TANK

E CONCENTRATION - PU CATCH TANK

C VOLUME - FEED ADJUSTMENT TANK INPUT

$\eta$ VOLUME - FEED ADJUSTMENT TANK INPUT

$\theta$ VOLUME - FEED ADJUSTMENT TANK INPUT

C CONCENTRATION - FEED ADJUSTMENT TANK INPUT

$\eta$ CONCENTRATION - FEED ADJUSTMENT TANK INPUT

$\theta$ CONCENTRATION - FEED ADJUSTMENT TANK INPUT

$\epsilon$ VOLUME - PU SAMPLE TANK OUTPUT

$\eta$ VOLUME - PU SAMPLE TANK OUTPUT

0 VOLUME - PU SAMPLE TANK OUTPUT

$\epsilon$ CONCENTRATION - Pu SAMPLE TANK OUTPUT

$\eta$ CONCENTRATION - PU SAMPLE TANK OUTPUT

o CONCENTRATION - PU SAMPLE TANK OUTPUT

$\epsilon$ TRANSFER - HA CENTRIFUGE TO SST

$\eta$ TRANSFER - HA CENTRIFUGE TO SST

$\theta$ TRANSFER - HA CENTRIFUGE TO SST
MEASUREMENT ERRORS

$(1 \sigma)$ CURRENT

$3.00-2$

$1.50-2$

$2.24-3$

$2.07-3$

2.0.0-1

$1.97-1$

4.17-2

$3.98-2$

9.66-3

$6.21-3$

1. $12-2$

7.71-3

4. $01-2$

2. $36-3$

1. $66-3$

3. 15-2

3.17-2

9.89-3

6.93-3

3. 14-2

3.14-2

2.71-2

$1.00-2$

3.27-2

7. $75-3$

5. $41-3$

$3.60-2$

1. $60-2$

2.11-4

$2.16-5$

2. 16-5

3. 12-4

2.09-4

3. $88-5$

2.63-1

2. 16-5

2. 15-5

2.63-4

$1.83-1$

$2.70-5$

1.

$5.00-2$

$5.000-2$
3. $00-2$

$1.50-2$

3. $00-2$

$1.50-2$

2. $.00-1$

$2.00-1$

$1.00-1$

$1.000-1$

$3.80-2$

$1.0 \theta-2$

$3.06-2$

$1.00-2$

$1.00-1$

$3.00-2$

$1.00-2$

与. $80-2$

5. $00-2$

$3.00-2$

1. $000-2$

$5.00-2$

$5.00-2$

$3.000-2$

$1.00-2$

$1.00-1$

$3.00-2$

$1.060-2$

$3.00-2$

$1.000-2$

$3.0 \theta-3$

$1.00-3$

$1.06-3$

1. $0 \theta-2$

$3.00-3$

$3.00-3$

$3.00-3$

1. $00-3$

1. $00-3$

$3.000-3$

$2.00-3$

$2.000-3$

$1.00-1$

$5.00-2$

$5.00-2$ 1 DAY

( $\mathrm{Kg} \mathrm{Pu}$ )

6 MONTHS

0.00

6.69

$3.25-1$

1. $66-3$

1. 12-1

1. 77-1

1.69-1

1. $93-1$

1. 32-1

1.75-1

$1.20-1$

$1.78-1$

$3.7 \theta-1$

$2.60-1$

1. 34-1

1. $35-1$

1. 82-1

$1.28-1$

1. 33-1

1. 33-1

7.64-2

2. $82-2$

$1.85-1$

$2.68-1$

1. 45-1

0.80

0.00

6.21-2

$1.69-2$

1. 68-2

9.18-2

6.16-2

$2.48-2$

5.46-2

1. $68-2$

1. $68-2$

5. 17-2

5. 38-2

2. $18-2$

7. $6 \theta-4$

$3.80-4$

3. $8 \theta-4$

\subsection{8}

0. 00

3. 53-1

3.25-1

$1.12-1$

1.77-1

1.69-1

1.93-1

$1.32-1$

$1.75-1$

$1.2 \theta-1$

$1.7 \varnothing-1$

$3.7 \varnothing-1$

2. $68-1$

$1.34-1$

1. $35-1$

1. 82-1

1. $28-1$

1. 33-1

1. $33-1$

7.64-2

2.82-2

1.85-1

2. $.08-1$

1. 45-1

0.00

0.00

4. .07-1

7.22-1

7.20-1

6.01-1

$4.04-1$

1.83

3.58-1

7.19-1

7.19-1

3.58-1

$3.52-1$

9.01-1

5. $04-3$

1. $67-2$

1. 67-2
RE LATIVE

COST

9. $98-5$

$3.68-5$

6.26

3.69-5

1. $42-2$

1.40

6. $11-1$

1.67

2.96-1

$1.5 \%$

1. $17+1$

5.64

5. 86-1

5.76-1

2.03

4. 43-1

5.95-1

5.91-1

$1.89-1$

5.67-5

2.05

2.87

8. 50-1

4. 92-5

3. 68-5

$1.32+1$

$4.52+1$

$4.53+1$

$3.11+1$

$1.33+1$

$9.63+1$

$1.04+1$

$4.54+1$

$4.54+1$

$1.04+1$

9.93

$7.31+1$

3. $64-5$

4.75-5

3. $94-5$ 
MEASUREMENT UNCERTAINTIES: UPAA 23 , GOAL 4, NO RECALIBRATION

No.

\section{DESCR IPTION}

E VOLUME - FEED ADJUSTMENT TANK

$\&$ CONCENTRATION - FEED ADJUSTMENT TANK

$\epsilon$ VOLUME - HA FEED TANK

$E$ CONCENTRATION - HA FEED TANK

$\epsilon$ Pu SOLIDS - HA CENTRIFUGE

\& INVENTORY - HA CONTACTOR

E INVENTORY - HS COLUMN

C INVENTORY - HC COLUMN

$\epsilon$ VOL UME - HCP REDUCER

C CONCENTRATION - HCP REDUCER

$\epsilon$ VOL UME - IA FEED TANK

E CONCENTRATION - IA FEED TANK

E INVENTORY - IA COLUMN

$C$ VOLUME - $2 A$ FEED TANK

C CONCENTRATION - $2 A$ FEED TANK

C INVENTORY - 2A COLUMN

E INVENTORY - 2B COLUMN

C VOLUME - 3A FEED TANK

$\epsilon$ CONCENTRATION - 3A FEED TANK

E INVENTORY - 3A COLUMN

E INVENTORY - 3B COLUMN

\& VOLUME - PU STRIPPER FEED

C CONCENTRATION - PU STRIPPER FEED

\& INVENTORY - PU STRIPPER

$\varepsilon$ VOLUME - Pu CONCENTRATOR

C CONCENTRATION - Pu CONCENTRATOR

\& VOLUME - PU CATCH TANK

E CONCENTRATION: - PU CATCH TANK

$\Leftrightarrow$ VOLUME - FEED ADJUSTMENT TANK INPUT

$\eta$ VOLUME - FEED ADJUSTMENT TANK INPUT

$O$ VOLUME - FEED ADJUSTMENT TANK INPUT

$\epsilon$ CONCENTRATION - FEED ADJUSTMENT TANK INPUT

$\eta$ CONCENTRATION - FEED ADJUSTMENT TANK INPUT

$\theta$ CONCENTRATION - FEED ADJUSTMENT TANK INPUT

$\epsilon$ VOLUME - PU SAMPLE TANK OUTPUT

7 VOLUME - PU SAMPLE TANK OUTPUT

0 VOLUME - PU SAMPLE TANK OUTPUT

E CONCENTRATION - PU SAMPLE TANK OUTPUT

$\eta$ CONCENTRATION - PU SAMPLE TANK OUTPUT

O CONCENTRATION - PU SAMPLE TANK OUTPUT

E TRANSFER - HA CENTRIFUGE TO SST

$\eta$ TRANSFER - HA CENTRIFUGE TO SST

O TRANSFER - HA CENTRIFUGE TO SST
MEASUREMENT ERRORS

CALCULATED CURRENT

(10)

$(1 \sigma)$

$3.00-2$

$1.58-2$

$1.79-3$

$1.46-3$

$2.00-1$

$1.16-1$

$3.30-2$

4. $92-2$

7.79-3

4. 34-3

9. $93-3$

8. 22-3

3. 55-2

1. 67-3

1. $06-3$

$2.96-2$

2. 89-2

7.71-3

6. 67-3

2.84-2

2. $79-2$

2. $98-2$

$1.90-2$

2.83-2

6. 41-3

5.5 h -3

$3.00-2$

$1.90-2$

1.64-4

$1.57-5$

1. 25-5

1. 56-4

9.77-6

9.73-6

1.83-4

1. 47-5

1. $01-5$

6. 89-5

9.73-6

9.67-6

9. 99-2

5. $00-2$

5. $00-2$
3. $00-2$

1. $50-2$

3. $.00-2$

$1.50-2$

2. (n) 1

2. $.00-1$

$1.00-1$

1. $.10-1$

3. $00-2$

1. $.96-2$

$3.90-2$

$1.90-2$

$1.00-1$

3. $.99-2$

1. $.110-2$

$5.90-2$

$5.00-$ ?

$3.00-2$

$1.510-2$

5. $.00-2$

$5.00-2$

$3.90-2$

1. . $199-2$

1. $90-1$

$3.09-2$

$1.0 w-2$

$3.00-2$

$1.001-2$

3. $A Q-3$

$1.4 y-3$

1. กी -3

$1.00-2$

$3.9(9)-3$

$3 . \pi(a-3$

$3.00-3$

$1.00-3$

$1.00-3$

$3.00-3$

$2.00-3$

$2.00-3$

$1.09-1$

5. $.90-2$

$5.000-2$
MATERIALS BALANCE $\sigma$

$\begin{array}{ll}1 \mathrm{DAY} & 6 \text { MONTHS } \\ (\mathrm{Kg} \mathrm{Pu}) & (\mathrm{Kg} \mathrm{Pu})\end{array}$

RELATIVE

COST

$\varnothing .00$

0.00

$2.81-1$

2. $3 x-1$

$1.06-3$

8.29-2

$1.40-1$

$1.71-1$

$1.66-1$

$9.22-2$

$1.55-1$

1. $28-1$

1.51-1

2.61-1

$1.67-1$

$1.25-1$

$1.23-1$

1. $42-1$

1.23-1

$1.20-1$

$1.19-1$

8. $41-2$

2.82-2

$1.60-1$

$1.73-1$

$1.48-1$

อ. 00

0.00

1. $83-2$

$1.74-3$

$1.39-3$

1.74-2

$1.69-3$

$1.08-3$

$1.44-2$

$1.64-3$

1. $13-3$

$5.42-3$

1. $68-3$

$1.08-3$

6.00

0.00

0.00

\subsection{0}

0.08

2. $81-1$

2. $3 \theta-1$

$1.06-3$

B. 29-2

$1.40-1$

$1.71-1$

$1.66-1$

$9.22-2$

. $55-1$

1. $28-1$

1. $51-1$

2.61-1

$1.67-$

1. 25-1

$1.23-1$

$1.12-1$

1. $23-1$

1. $20-1$

1.19-1

$8.41-2$

2.82-2

$1.60-1$

$1.73-1$

$1.48-1$

0.00

0.00

2.24-1

$2.61-1$

2.09-1

2.13-1

1. $63-1$

$1.62-1$

1.77-1

$2.46-1$

1. $69-1$

6. 61-2

1. $62-1$

1. $61-1$

3. $56-3$

8. $36-3$

8. $35-3$
5.97-4

4.58-4

$1.58+1$

9.27

4.67-4

3.65-1

2.63

1.49

2.85

1.31

.82

$2.16-1$

1.82

1. $7 \varnothing+1$

B. 42

6. 92-1

7.29-1

2.89

4. $99-1$

$7.61-1$

$7.96-1$

6.95-3

3. 14-4

2.53

3.68

8. 19-1

4. 58-4

4. 58-4

$1.73+1$

$6.29+1$

$7.98+1$

6. $29+1$

$3.06+2$

$3.67+2$

$1.53+1$

$6.69+1$

9. $76+1$

4. $25+1$

$2.05+2$

$2.86+2$

6.73-4

5.89-4

6.12-4 
NO. OESCR IPTION

- VOLUME - FEED ADJUSTMENT TANK

C CONCENTRATION - FEED ADJUSTMENT TANK

\& VOLUME - HA FEED TANK

C CONCENTRATION - HA FEED TANK

C PU SOLIOS - HA CENTRIFUGE

E INVENTORY - HA CONTACTOR

E INVENTORY - HS COLUMN

E INVENTORY - HC COLUMN

- VOLUME - HCP REDUCER

E CONCENTRATION - HCP REOUCER

\& VOLUME - IA FEED TANK

$\epsilon$ CONCENTRATION - IA FEED TANK

C INVENTORY - IA COLUMN

\& VOLUME - 2A FEED TANK

C CONCENTRATION - 2A FEED TANK

E INVENTORY - 2A COLUMN

C INVENTORY - 2B COLUMN

\& VOLUME - 3A FEED TANK

C CONCENTRATION - 3A FEED TANK

E INVENTORY - 3A COLUMN

C INVENTORY - 3B COLUMN

\& VOLUME - PU STRIPPER FEED

C CONCENTRATION - PU STRIPPER FEEO

- INVENTORY - PU STRIPPER

e VOLUME - PU CONCENTRATOR

- CONCENTRATION - PU CONCENTRATOR

$\&$ VOLUME - Pu CATCH TANK

- CONCENTRATION - Pu CATCH TANK

\& VOLUME - FEED AOJUSTMENT TANK INPUT

$\eta$ VOLUME - FEED AOJUSTMENT TANK INPUT

- VOLUME - FEED AOJUSTMENT TANK INPUT

- CONCENTRATION - FEED ADJUSTMENT TANK INPUT

7 CONCENTRATION - FEED ADJUSTMENT TANK INPUT

$\theta$ CONCENTRATION - FEED ADJUSTMENT TANK INPUT

- VOLUME - Pu SAMPLE TANK OUTPUT

I VOLUME - PU SAMPLE TANK OUTPUT

a VOLUME - PU SAMPLE TANK OUTPUT

$E$ CONCENTRATION - Pu SAMPLE TANK OUTPUT

$\eta$ CONCENTRATION - PU SAMPLE TANK OUTPUT

- CONCENTRATION - PU SAMPLE TANK OUTPUT

- TRANSFER - HA CENTRIFUGE TO SST

$\eta$ TRANSFER - HA CENTRIFUGE TO SST

$\theta$ TRANSFER - HA CENTRIFUGE TO SST
MEASUREMENT ERRORS

CALCULATED CURRENT

(10)

$3.60-2$

1. $5 \emptyset-2$

1. $17-3$

$9.26-4$

$2.06-1$

9.52-2

1. $94-2$

1. $94-2$

4. 41-3

$3.06-3$

$5.44-3$

$3.77-3$

1. 93-2

1. 16-3

8. $67-4$

1. 53-2

1. 53-2

4. $86-3$

3. $37-3$

1. 53-2

1. 53-2

1. 69-2

9. $99-3$

1. 58-2

3. 77-3

2. 62-3

3. $80-2$

1. $00-2$

1. $28-4$

1. 67-5

1. 67-5

1. $91-4$

1. $28-4$

2. $41-5$

1. 61-4

1. 67-5

1.67-5

1. $61-4$

1. $12-4$

2. 10-5

$1.00-1$

$5.00-2$

$5.00-2$
(IO)

3. $08-2$

1. $5 \theta-2$

3. $600-2$

1. $5 \theta-2$

2. $00-1$

$2.00-1$

1. . $00-1$

1. $.00-1$

3. $00-2$

1. $00-2$

$3: \theta \varnothing-2$

1. $.00-2$

1. $.00-1$

$3.60-2$

1. $0 \theta-2$

$5.60-2$

$5.00-2$

3. $0.0-2$

1. $.00-2$

5. $\theta 0-2$

$5.00-2$

$3.00-2$

1. $.0-2$

1. $.08-1$

$3.00-2$

1. $\theta \varnothing-2$

3. $08-2$

1. $\theta \theta 0-2$

3. $00-3$

1. $00-3$

$1.08-3$

1. $\theta 0-2$

3. $.00-3$

$3.0 .8-3$

3. $0 \theta-3$

1. $.00-3$

$1.08-3$

3. $00-3$

2. $\theta \theta-3$

2. $\theta g-3$

1. $00-1$

5. $.00-2$

$5.60-2$
MATERIALS BALANCE $\sigma$ 1 DAY 6 MONTHS

$(\mathrm{Kg} P u) \quad(\mathrm{Kg} P u)$

D. O.

0.00

1.83-1

$1.06-3$

5. 39-2

8. 23-2

8. 24-2

$6.52-2$

8. $48-2$

5. $88-2$

8. 19-2

$1.83-1$

$1.27-1$

6. $51-2$

6. $58-2$

8. $94-2$

$6.20-2$

6. 49-2

$6.48-2$

4. 77-2

2. 82-2

8. $97-2$

$1.01-1$

$7.04-2$

0.00

0.00

$1.42-2$

$1.86-3$

$1.85-3$

2. $13-2$

$1.42-2$

2. $68-3$

1. 27-2

$1.86-3$

$1.86-3$

1. $27-2$

1. 24-2

$2.34-3$

0.00

0.00

D. 00

\section{B. 00}

6. . 8.

$1.83-1$

1. 46-1

5. $106-3$

8. 23-2

8. 24-2

9. 38-2

6. 52-2

8. 48-2

5. 88-2

8. 19-2

1.83-1

1. 27-1

6. 51-2

$6.50-2$

8. 94-2

$6.29-2$

6. 49-2

6. 48-2

4. 77-2

2.82-2

8. 97-2

1. . 1-1

7. 04-2

0.00

0.00

1. 74-1

2.79-1

2.78-1

2. $60-1$

1. 74-1

4.62-1

1. 55-1

2. 78-1

2. 78-1

1. 55-1

1. 52-1

$3.50-1$

3. 56-3

B. $36-3$

B. $36-3$
RELATIVE

COST

1. 35-5

$.45-5$

$2.47+1$

1. $52+1$
1. $27-5$

1.18

4. 16

4.15

5.81

2.26

4.51

1.65

$2.48+1$

1. $14+1$

2.26

2.26

5.18

1.97

2.27

2.27

7. 75-1

9, 63-4

5.31

6.97

2.82

1. $18-5$

1. 46-5

$2.25+1$

$5.89+1$

5. $90+1$

$5.14+1$

$2.25+1$

1. $24+2$

$1.76+1$

$5.89+1$

$5.89+1$

1. $76+1$

$1.69+1$

$9.42+1$

1. 33-5

1. 74-5

1. 89-5 
TABLE E-XIX

MEASUREMENT UNCERTAINTIES: UPAA 2, GOAL 1, NO RECALIBRATION

No.

DESCRIPTION

e VOLUME - FEED ADJUSTMENT TANK

\& CONCENTRATION - FEED ADJUSTMENT TANK

E VOLUME - HA FEED TANK

C CONCENTRAT ION - HA FEED TANK

e Pu SOLIDS - HA CENTRIFUGE

C INVENTORY - HA CONTACTOR

G INVENTORY - HS COLUMN

- INVENTORY - HC COLUMN

c VOLUME - HCP REDUCER

$\epsilon$ CONCENTRATION - HCP REDUCER

C VOLUME - IA FEED TANK

C CONCENTRATION - IA FEE D TANK

E INVENTORY - IA COLUMN

$C$ VOLUME - FEED ADJUSTMENT TANK INPUT

$n$ VOLUME - FEED ADJUSTMENT TANK INPUT

$\theta$ VOLUME - FEED ADJUSTMENT TANK INPUT

C CONCENTRATION - FEED ADJUSTMENT TANK INPUT

$n$ CONCENTRATION - FEED ADJUSTMENT TANK INPUT

$\theta$ CONCENTRATION - FEED ADJUSTMENT TANK INPUT

E FLOW RATE - IA COLUMN OUTPUT

I FLOW RATE - IA COL UMN OUTPUT

$\theta$ FLOW RATE - IA COLUMN OUTPUT

E CONCENTRATION - IA COLUMN OUTPUT

$n$ CONCENTRATION - IA COLUMN OUTPU

concentrat ION - ia col UMn OUTPUi

C TRANSFER - HA CENTRIFUGE TO SST

$\eta$ TRANSFER - HA CENTRIFUGE TO SST

$\theta$ TRANSFER - HA CENTRIFUGE TO SST
MEASUREMENT ERRORS

CALCULATED CURRENT

$(1 \sigma)$

$(1 \sigma)$

3. $.080-2$

1. $58-2$

$3.60-2$

2. $.00-1$

2.

1. $.00-1$

1. $\theta \theta-1$

3. $\theta \theta-2$

$1.00-2$

$3.60-2$

1. $00-2$

$1.00-1$

$3.06-3$

9.19-4

9.56-4

9. 58-3

1. $58-3$

1. 57-3

2. $50-2$

2. $65-3$

1. 83-3

$1.000-2$

1. 84-3

1. 33-3

1. . $00-1$

5. $00-2$

5. $00-2$

3. $00-2$

$3.5 \theta-2$

$1.5 \theta-2$

2. . $00-1$

$2.00-1$

1. $.0 \theta-1$

$1.00-1$

$3.00-2$

$1.00-2$

$3.00-2$

1. $00-2$

1. $\theta \theta-1$

$3.00-3$

1. $.0 \theta-3$

$1.09-3$

1. $.00-2$

$3.0 \theta-3$

3. $\theta 0-3$

2. $50-2$

1. $50-2$

$5.00-3$

$1.00-2$

$5.00-3$

$2.00-3$

1. $.00-1$

$5.00-2$

$5.00-2$
MATERIALS BALANCE $\sigma$

$(\mathrm{Kg} \mathrm{Pu}) \quad(\mathrm{Kg} \mathrm{Pu})$
1 DAY 6 MONTHS

0.00
0.00
4.72
2.36
$1.06-3$
$1.13-1$
$4.24-1$
$4.24-1$
$6.38-1$
$2.13-1$
$4.68-1$
$1.56-1$
$4.24-1$
$3.34-1$
$1.02-1$
$1.06-1$
1.07
$1.67-1$
$1.75-1$
$4.02-1$
$2.96-1$
$2.04-1$
$1.61-1$
$2.05-1$
$1.48-1$
0.00
0.00
0.00

0.60

D. 00

4.72

2.36

$1,06-3$

1. 13-1

4. 24-1

4. 24-1

$6 \cdot 38-1$

2.13-1

4. $68-1$

1. $56-1$

4. 24-1

4.69

1. $53+1$

1. $60+1$

1. $31+1$

$2.51+1$

$2.63+1$

4.92

4. $43+1$

$3.66+1$

1.97

$3.98+1$

$2.22+1$

3. $56-3$

B. 36-3

B. 36-3

RELAT IVE COST

$1,26-5$

4. $88-5$

1. $29-5$

4. 67-5

4. 88-5

$5.18-5$

$5.29-5$

5. 25-5

5.64-5

7. 55-6

$5.48-5$

$3.58-5$

$5.36-5$

$1.34-5$

8. 84-2

4. $61-2$

4. 34-2

9. 98-1

9.05-1

6. 14-5

4.65

1.73

3. 19-5

1.71

5.05-1

4. 88-5

4. 88-5

4. 88-5 
TABLE E-XX

MEASUREMENT UNCERTAINTIES: UPAA 2, GOAL 1, WEEKLY RECALIBRATION

No.

DESCRIPTION

$\epsilon$ VOLUME - FEED ADJUSTMENT TANK

6 CONCENTRATION - FEED ADJUSTMENT TANK

E VOLUME - HA FEED TANK

$E$ CONCENTRATION - HA FEED TANK

$\epsilon$ PU SOLIDS - HA CENTRIFUGE

E INVENTORY - HA CONTACTOR

$\epsilon$ INVENTORY - HS COLUMN

$\epsilon$ INVENTORY - HC COLUMN

$\epsilon$ VOLUME - HCP REDUCER

$\epsilon$ CONCENTRATION - HCP REDUCER

$\epsilon$ VOLUME - IA FEED TANK

$E$ CONCENTRATION - IA FEED TANK

$\epsilon$ INVENTORY - IA COLUMN

$\epsilon$ VOLUME - FEED ADJUSTMENT TANK INPUT

$\eta$ VOLUME - FEED ADJUSTMENT TANK INPUT

$\theta$ VOL UME - FEED ADJUSTMENT TANK INPUT

$\epsilon$ CONCENTRATION - FEED ADJUSTMENT TANK INPUT

CONCENTRATION - FEED ADJUSTMENT TANK INPUT

$\theta$ CONCENTRATION - FEED ADJUSTMENT TANK INPUT

E FLOW RATE - IA COLUMN OUTPUT

$\eta$ FLOW RATE - IA COLUMN OUTPUT

$\theta$ FLOW RATE - IA COLUMN OUTPUT

\& CONCENTRATION - IA COLUMN OUTPUT

$\eta$ CONCENTRATION - IA COLUMN OUTPUT

$\theta$ CONCENTRATION - IA COLUMN OUTPUT

$E$ TRANSFER - HA CENTRIFUGE TO SST

$\eta$ TRANSFER - HA CENTRIFUGE TO SST

O TRANSFER - HA CENTRIFUGE TO SST
MEASUREMENT ERRORS CALCULATED CURRENT

$$
(1 \sigma)
$$

$$
(1 \sigma)
$$

$3.00-2$

$1.50-2$

2. $99-2$

1. $5 \theta-2$

$2.00-1$

$2.00-1$

$1.00-1$

1. $\theta 0-1$

3. $\varnothing 0-2$

$1.00-2$

$3.00-2$

1. $\theta \theta-2$

1. $\theta \theta-1$

$3.00-3$

9. $58-4$

9.82-1

9. $96-3$

2. $99-3$

2. $11-3$

2. $49-2$

1. $.00-2$

$2.63-3$

$1.00-2$

4. $99-3$

1. $62-3$

1. $.00-1$

5. $00-2$

$5.000-2$
$3.00-2$

1. $5 \theta-2$

$3.00-2$

1. $56-2$

$2.00-1$

$2.00-1$

$1.00-1$

$1.000-1$

3. $\varnothing 0-2$

1. $.00-2$

$3.00-2$

1. $\theta \theta-2$

1. $6 \theta-1$

$3.00-3$

$1.00-3$

$1.00-3$

$1.06-2$

3. $0.0-3$

$3.00-3$

$2.5 \varnothing-2$

$1.50-2$

$10 \varnothing-2$

5. $\theta 0-3$

$2.00-3$

1. $00-1$

5. $6 x-2$

$5.00-2$
MATERIALS BALANCE $\sigma$ $\begin{array}{ll}1 \text { DAY } & 6 \text { MONTHS } \\ (\mathrm{Kg} \mathrm{Pu}) & (\mathrm{Kg} \mathrm{Pu})\end{array}$

RELATIVE $\operatorname{COST}$

0.00
$0.00 \quad 0.00$

2.36

$1.06-3$

1. 13-1

1. 24-1

4. 24-1

6. 38-1

2.13-1

4.68-1

1. 56-1

4. $24-1$

3.34-1

$1.07-1$

1. $09-1$

1.11

3. 33-1

2. 34-1

4. $01-1$

1.12

2. 93-1

1. 61-1

5.55-1

1. $81-1$

0.00

$\varnothing .00$

0.00

0.00

2.36

1. $.66-3$

1. 13-1

4. 24-1

4.24-1

6. 38-1

2.13-1

4. $68-1$

1. $56-1$

4.24-1

4.09

1. $68+1$

$.36+1$

$1.07+1$
$3.51+1$

4.91

$3.58+1$

$4.48+1$

1. 97

$1.78+1$

$2.71+1$

3. $56-3$

8. $36-3$

8. 36-3

8.10-7

4.99-5

3. 52-3

4.84-5

1.97-5

4.98-5

1. 98-5

4.98-5

4.99-5

4.98-5

5. 75-5

4.98-5

1.98-5

1.21-5

1. $38-2$

$1.81-2$

3.77-3

3.53-3

4.25-1

2.09-3

4.96-1

8. 98-1

2. 39-5

$2.83-3$

2.33-1

4.97-5

4. $98-5$

$4.98-5$ 


\section{TABLE E-XXI}

MEASUREMENT UNCERTAINTIES: UPAA 2, GOAL 2, NO RECALIBRATION

No.

E VOLUME - FEED ADJUSTMENT TANK

$\epsilon$ CONCENTRATION - FEED ADJUSTMENT TANK

$\epsilon$ VOLUME - HA FEED TANK

$\epsilon$ CONCENTRATION - HA FEED TANK

e Pu SOLIDS - HA CENTRIFUGE

$\epsilon$ INVENTORY - HA CONTACTOR

INVENTORY - HS COLUMN

E INVENTORY - HC COLUMN

$\epsilon$ VOLUME - HCP REDUCER

$\epsilon$ CONCENTRATION - HCP REDUCER

$\epsilon$ VOLUME - IA FEED TANK

$\epsilon$ CONCENTRATION - IA FEED TANK

E INVENTORY - IA COLUMN

$\epsilon$ VOLUME - FEED ADJUSTMENT TANK INPUT

$\eta$ VOLUME - FEED ADJUSTMENT TANK INPUT

$\theta$ VOLUME - FEED ADJUSTMENT TANK INPUT

$\epsilon$ CONCENTRATION - FEED ADJUSTMENT TANK INPUT

I CONCENTRATION - FEED ADJUSTMENT TANK INPUT

CONCENTRATION - FEED ADJUSTMENT TANK INPUT

E FLOW RATE - IA COLUMN OUTPUT

FLOW RATE - IA COLUMN DUTPUT

$\theta$ FLOW RATE - IA COLUMN OUTPUT

E CONCENTRATION - IA COLUMN OUTPUT

CONCENTRATION - IA COLUMN OUTPUT

CONCENTRATION - IA COLUMN OUTPUT

$\epsilon$ TRANSFER - HA CENTRIFUGE TO SST

TRANSFER - HA CENTRIFUGE TO SST

O TRANSFER - HA CENTRIFUGE TO SST
MEASUREMENT ERRORS CALCULATED CURRENT

$(1 \sigma)$

$(1 \sigma)$

$3.00-2$

$1.50-2$

1.75-2

1. 39-2

2. $00-1$

2. $00-1$

$1.00-1$

$1.00-1$

3. $00-2$

$1.00-2$

2.99-2

1 :

9. $98-2$

1. $9 !-3$

$2.54-4$

$2.54-4$

$2.92-3$

3. $66-4$

$3.66-4$

$1.42-2$

$6.28-4$

4. $33-4$

8.69-3

4. $32-4$

3.17-4

1. $.00-1$

5. $00-2$

5. $\varnothing-2$
$3.000-2$

$1.50-2$

$3.00-2$

1. $50-2$

$2.00-1$

$2.00-1$

$1.00-1$

$1.80-1$

$3.00-2$

1. $.0 \mathrm{D}-2$

$3.500-2$

$1.00-2$

1. $.00-1$

$3.00-3$

1. . $00-3$

$1.0 .0-3$

1.00-2

3. $00-3$

$3.00-3$

2. $50-2$

$1.5 \theta-2$

5. $0 \theta-3$

$1.00-2$

$5.00-3$

$2.00-3$

$1.00-1$

$5.00-2$

$5.00-2$
MATERIALS BALANCE O

1 DAY 6 MONTHS

( $\mathrm{Kg} \mathrm{Pu}$ )

( $\mathrm{Kg} P \mathrm{P}$ )

๓.

0.00

2.75

2.19

$1.66-3$

1. $13-1$

$4.24-1$

$4.24-1$

$6.38-1$

$2.13-1$

$4.67-1$

$1.56-1$

$4.24-1$

2.13-1

$2.83-2$

$2.83-2$

$3.25-1$

$4.07-2$

$4.07-2$

2. $28-1$

$6.99-2$

$4.82-2$

$1.40-1$

$4.81-2$

$3.53-2$

0.00

a. 00

$\varnothing .00$

$\begin{array}{ll}0.00 & 4.66-5 \\ 0.00 & 4.67-5 \\ 2.75 & 7.18-1 \\ 2.19 & 7.60-2 \\ 1.06-3 & 4.69-5 \\ 1.13-1 & 4.52-5 \\ 4.24-1 & 1.22-5 \\ 4.24-1 & 1.11-4 \\ 6.38-1 & 1.56-5 \\ 2.13-1 & 4.86-5 \\ 4.67-1 & 1.91-3 \\ 1.56-1 & 4.97-5 \\ 4.24-1 & 1.69-3 \\ 2.6 \varnothing & 5.71-1 \\ 4.24 & 2.94 \\ 4.24 & 2.94 \\ 3.98 & 2.42 \\ 6.11 & 7.19 \\ 6.11 & 7.19 \\ 2.86 & 7.59-1 \\ 1.05+1 & 2.29+1 \\ 7.23 & 1.66+1 \\ 1.71 & 1.51-1 \\ 7.22 & 1.66+1 \\ 5.30 & 5.31 \\ 3.56-3 & 4.68-5 \\ 8.36-3 & 4.32-5 \\ 8.36-3 & 4.33-5\end{array}$


TABLE E-XXII

MEASUREMENT UNCERTAINTIES : UPAA 2, GOAL 2, WEEKLY RECALIBRATION

No.

E VOLUME - FEED ADJUSTMENT TANK

C CONCENTRATION - FEED ADJUSTMENT TANK

C VOLUME - HA FEEO TANK

a CONCENTRATION - HA FEED TANK

e PU SOLIDS - HA CENTRIFUGE

- INVENTORY - ha cONTACTOR

- INVENTORY - HS COLUMN

C INVENTORY - HC COLUMN

\& VOLUME - HCP REDUCER

C CONCENTRATION - HCP REDUCER

- VOLUME - IA FEED TANK

C CONCENTRATION - IA FEED TANK

- INVENTORY - IA COLUMN

E VOLUME - FEED ADJUSTMENT TANK INPUT

$n$ VOLUME - FEED ADJUSTMENT TANK INPUT

$\theta$ VOLUME - FEED ADJUSTMENT TANK INPUT

C CONCENTRATION - FEED ADJUSTMENT TANK INPUT

$\eta$ CONCENTRATION - FEED ADJUSTMENT TANK INPUT

2 CONCENTRATION - FEED ADJUSTMENT TANK INPUT

C FLOW RATE - IA COLUMN OUTPUT

$n$ FLOW RATE - IA COLUMN OUTPUT

$\theta$ FLOW RATE - IA COLUMN OUTPUT

C CONCENTRATION - IA COLUMN OUTPUT

$\eta$ CONCENTRATION - IA COLUMN OUTPUT

o CONCENTRATION - IA COLUMN OUTPUT

C TRANSFER - HA CENTRIFUGE TO SST

T TRANSFER - HA CENTRIFUGE TO SST

I TRANSFER - HA CENTRIFUGE TO SST
MEASUREMENT ERRORS

CALCULATED CURRENT

$(1 \sigma)$

$3.60 \mathrm{~g}-2$

$1.50-2$
$2.01-2$

$1.26-2$

2. $80-1$

2. $00-1$

1. $00-1$

$1.00-1$

$3.00-2$

$1.00-2$

$3.00-2$

1. $60-2$

1. $.00-1$

2. $29-3$

$3.16-1$

3. 14-4

3. 68-3

1.26-3

4. 48-4

1. $68-2$

2.15-3

5. $26-4$

8.23-3

1. 47-3

3.85-1

$1.00-1$

$5.00-2$

$5.06-2$
3.60-2

$1.5 \theta-2$

3.

1. $5 \theta-2$

$2.00-1$

$2.00-1$

$1.60-1$

1.

$3.60-2$

$1.00-2$

$3.09-2$

$1.60-2$

$1.00-1$

$3.00-3$

$1.00-3$

1. .

$1.00-2$

$3.000-3$

$3.000-3$

$2.5 \%-2$

$1.5 \theta-2$

$5.000-3$

$1.00-2$

$5.00-3$

$2.00-3$

$1.00-1$

$5.000-2$

5. $08-2$
1 DAY

( $\mathrm{Kg} \mathrm{Pu}$ )

6 MONTHS

RELATIVE

COST

๑.

9.98
3.16

1.98

1.06-3

$1.13-1$

$4.24-1$

$4.24-1$

6.38-1

. $13-1$

$4.68-1$

1.56-1

$4.24-1$

2.55-

$3.52-2$

$3.50-2$

4.10-1

$1.48-1$

4. $98-2$

7. $78-1$

2.39-1

5. $86-2$

1. 32-1

1.64-1

4. 29-2

0.00

0.08

ด.68

\section{ด.}

0.08
3.16

1.98

1.86-3

1. 13-1

$4.24-$

4. $24-$

6. 38-1

2.13-1

4.68-1

$1.56-1$

4. 24-1

3.13

5.28

5.25

5.62

4.58

7.47

3.38

7.67

8.78

1.62

5.26

6.43

$3.56-3$

8. 36-3

8. 36-3
4. 94-5

4. $94-5$

1.98-1

4.94-5

4.9B-5

$6.7 \%-5$

7.76-5

4.71-5

5. 48-5

4.96-5

7.37-5

5.97-5

3. $88-1$

2.16

2.18

1.72

1.38

5.76

$4.98-1$

5.99

8.51

2.15-1

2.39

4.20

4. $94-5$

4.89-5

4.59-5 
TABLE E-XXIII

MEASUREMENT UNCERTAINTIES: UPAA 2, GOAT, 2, DAILY RECALIBRATION

NO.

\section{OESCRIPTION}

\& VOLUME - FEED ADJUSTMENT TANK

\& CONCENTRATION - FEED ADJUSTMENT TANK

C VOLUME - HA FEED TANK

C CONCENTRATION - HA FEED TANK

e PU SOL IOS - HA CENTRIFUGE

E INVENTORY - HA CONTACTOR

C INVENTORY - HS COLUMN

E INVENTORY - HC COLUMN

- VOL UME - HCP REDUCER

C CONCENTRATION - HCP REDUCER

C VOLUME - IA FEED TANK

E CONCENTRATION - IA FEED TANK

E INVENTORY - IA COLUMN

\& VOLUME - FEED ADJUSTMENT TANK INPUT

7 VOL UME - FEED ADJUSTMENT TANK INPUT

$\theta$ VOL UME - FEED ADJUSTMENT TANK INPUT

C CONCENTRATION - FEED ADJUSTMENT TANK INPUT

$n$ CONCENTRATION - FEED ADJUSTMENT TANK INPUT

- CONCENTRATION - FEED ADJUSTMENT TANK INPUT

E FLOW RATE - IA COLUMM OUTPUT

$\eta$ FLOW RATE - IA COLUMN OUTPUT

F FLOW RATE - IA COLUMN OUTPUT

- CONCENTRATION - IA COLUMN OUTPUT

$\eta$ CONCENTRATION - IA COLUMN OUTPUT

$\theta$ CONCENTRATION - IA COLUMN OUTPUT

C TRANSFER - HA CENTRIFUGE TO SST

$\eta$ TRANSFER - HA CENTRIFUGE TO SST

$\theta$ TRANSFER - HA CENTRIFUGE TO SST
MEASUREMENT ERRORS

CALCULATED CURRENT

$(1 \sigma)$

$(1 \sigma)$

$3.00-2$

$1.50-2$

1. 59-2

1. $38-2$

$2.00-1$

$2.00-1$

1. $00-1$

1. $00-1$

3. $00-2$

1. $.80-2$

$3.80-2$

1. $8.00-2$

9.85-2

$2.65-3$

$3.21-4$

3. 17-4

3. 47-3

1. $94-3$

4.91-4

1. 42-2

4. $04-3$

6. 71-4

8. $12-3$

2. 41-3

4. $21-4$

1. $\theta 0-1$

5. $090-2$

$5.00-2$
$3.00-2$

1. $5 \theta-2$

3. $60-2$

$1.5 \varnothing-2$

$2.00-1$

$2.00-1$

$1.00-1$

$1.00-1$

$3.00-2$

$1.00-2$

3. $00-2$

1. $.00-2$

$1.00-1$

$3.8 .8-3$

1. $.00-3$

$1.60-3$

$1.00-2$

$3.00-3$

$3.68-3$

$2.58-2$

1. $50-2$

$5.00-3$

1. . $00-2$

5. $\theta \theta-3$

$2.08-3$

$1.00-1$

$5.00-2$

$5.00-2$
MATERIALS BALANCE

1 DAY 6 MONTHS

( $\mathrm{Kg} \mathrm{Pu}_{\mathrm{u}}$ )

( $\mathrm{Kg} \mathrm{PU}$ )

8.00
6.00
2.51
2.18
$1.06-3$
$1.13-1$
$4.24-1$
$4.24-1$
$6.38-1$
$2.13-1$
$4.68-1$
$1.56-1$
$4.18-1$
$2.28-1$
$3.57-2$
$3.53-2$
$3.87-1$
$2.16-1$
$5.47-2$
$2.28-1$
$4.58-1$
$7.47-2$
$1.21-1$
$2.69-1$
$1.69-2$
0.00
6.06
0.90

0.00

0.00

2.51

1. $186-3$

1. 13-1

4. 24-1

4. 24-1

$6.38-1$

2. 13-1

4. $68-1$

1.56-1

4. $18-1$

2.79

5.36

5.29

4.73

2.65

8. 20

8.20
2.79

5.52

1. $12+1$

1.60

3.29

7.03

3. 56-3

8. 36-3

8. $36-3$
RELATIVE COST

$1.95-5$

$1.49-6$

8. 37-2

1.97-5

3. $12-5$

4. 34-5

$1.75-4$

1. 18-4

2.94-6

4. 28-5

3. 38-5

$1.51-2$

4. 65-1

2.11

2.16

1. 88

5. 44-1

5.11

7. 65-1

2.71

6.45

2. 31-1

1.07

3.75

3.16-5

4. 58-5 
MEASUREMENT UNCERTAINTIES: UPAA 2, GOAL 3, NO RECALIBRATION

No.

\section{DESCRIPTION}

C VOLUME - FEED ADJUSTMENT TANK

CONCENTRATION - FEED ADJUSTMENT TANK

E VOLUME - HA FEED TANK

C CONCENTRATION - HA FEED TANK

\& PU SOLIDS - HA CENTRIFUGE

- INVENTORY - HA CONTACTOR

E INVENTORY - HS COLUMN

C INVENTORY - HC COLUMN

C VOLUME - HCP REDUCER

- CONCENTRATION - HCP REDUCER

VOLUME - IA FEED TANK

- CONCENTRATION - IA FEED TANK

- INVENTORY - la COLUMN

VOLUME - FEED ADJUSTMENT TANK IMPUT

$\eta$ VOLUME - FEED ADJUSTMENT TANK INPUT

$\theta$ VOLUME - FEED ADJUSTMENT TANK INPUT

- CONCENTRATION - FEED ADJUSTMENT TANK INPUT

CONCENTRATION - FEED ADJUSTMENT TANK INPUT

$\theta$ CONCENTRATION - FEED ADJUSTMENT TANK INPUT

- FLOW RATE - IA COLUMN DUTPUT

9 FLOW RATE - IA COLUMN OUTPUT

$\theta$ FLOW RATE - 1A COLUMN OUTPUT

E CONCENTRATION - IA COLUMN OUTPUT

$n$ CONCENTRATION - IA COLUMN OUTPUT

$\theta$ CONCENTRATION - IA COLUMN OUTPUT

- TRANSFER - HA CENTRIFUGE TO SST

$\eta$ TRANSFER - HA CENTRIFUGE TO SST

$\theta$ TRANSFER - HA CENTRIFUGE TO SST
MEASUREMENT ERRORS CALCULATEO CURRENT $(1 \sigma)$

$(10)$

$3.6 \theta-2$

$1.5 \theta-2$

$1.72-3$

$1.37-3$

$2.00-1$

1. 44-1

2. $93-2$

$2.90-2$

6. 65-3

4.62-3

B. 24-3

5.75-3

2.89-2

1.54-1

$1.57-5$

1. 55-5

2. 24-4

2. $22-5$

2.23-5

$1.10-3$

3.79-5

2.63-5

8. 22-4

2. $64-5$

1. $95-5$

1. $00-1$

$5.00-2$

5. $00-2$

1. $.90-1$

$5.000-2$
(Kg DAY

6 MONTHS

( $\mathrm{Kg} \mathrm{Pu}$ )

$6.6 \%$

0.60

2.16-1

1.66-3

8.14-2

1. $25-1$

1.23-1

1. 42-1

9.83-2

1. $28-1$

8. $97-2$

1. $22-1$

4.52-2

1. $22-2$

1. $21-2$

6. $60-2$

1.73-2

$1.74-2$

4. $67-2$

2. $96-2$

2. $05-2$

$3.58-2$

2.86-2

$1.52-2$

7. $6 \theta-4$

$3.8 x-4$

3. $80-4$

0.00

$2.71-1$

$2.16-1$

$1.86-3$

8. 14-2

1. 25-1

1. $23-1$

1. 42-1

9. 83-2

1. 28-1

8. 97-2

1. $22-1$

2. $96-1$

5.23-1

5. 18-1

4. $32-1$

7. $43-1$

7. 44-1

3.06-1

1.27

8. 80-1

2. 29-1

8.81-1

6.51-1

$5.64-3$

$.67-2$

1.67-2
RELAT IVE COST

1.03-5

4. 26-5

$1.64+1$

9.93

9. 76-6

3. $90-1$

2.41

2.45

3.51

1.16

2.64

7. 39-1

2.47

$1.85+1$

$6.28+1$

$6 \cdot 34+1$

4. $36+1$

1. $34+2$

1. $34+2$

$2.18+1$

$3.94+2$

1. $89+2$

$1.12+1$

1. $89+2$

$1.02+2$

1. 73-5

2.99-5

2.54-5 
TABLE E-XXV

MEASUREMENT UNCERTAINTIES: UPAA 2, GOAL 3, DAILY RECALIBRATION

NO.

\section{DESCRIPTION}

\& VOLUME - FEED ADJUSTMENT TANK

\& CONCENTRATION - FEED ADJUSTMENT TANK

$\varepsilon$ VOLUME - HA FEED TANK

c CONCENTRATION - HA FEED TANK

E PU SOLIDS - HA CENTRIFUGE

- INVENTORY - HA CONTACTOR

- INVENTORY - HS COLUMH

a INVENTORY - HC COLUMN

C VOLUME - HCP REDUCER

E CONCENTRATION - HCP RE DUCER

c VOLUME - IA FEED TANK

C CONCENTRATION - IA FEED TANK

E INVENTORY - IA COLUMN

\& VOLUME - FEED ADJUSTMENT TANK INPUT

$\eta$ VOLUME - FEED ADJUSTMENT TANK INPUT

$\theta$ VOL UME - FEED ADJUSTMENT TANK INPUT

$€$ CONCENTRATION - FEED ADJUSTMENT TANK INPUT

$\eta$ CONCENTRATION - FEED ADJUSTMENT TANK INPUT

$\theta$ CONCENTRATION - FEED ADJUSTMENT TANK INPUT

E FLOW RATE - IA COLUMN OUTPUT

$\eta$ FLOW RATE - IA COLUMN OUTPUT

$\theta$ FLOW RATE - IA COLUMN OUTPUT

E CONCENTRATION - IA COLUMN OUTPUT

$\eta$ CONCENTRATION - IA COLUMN OUTPUT

a CONCENTRATION - IA COLUMN OUTPUT

- TRANSFER - HA CENTRIFUGE TO SST

$\eta$ TRANSFER - HA CENTRIFUGE TO SST

O TRANSFER - HA CENTRIFUGE TO SST
MEASUREMENT ERRORS

CALCULATED CURRENT

$(1 \sigma)$

$(1 \sigma)$

$3.00-2$

1. $5 \theta-2$

2. $26-3$

$1.86-3$

$2.00-1$

1.83-1

3. $86-2$

3. 77-2

8. 68-3

$6.04-3$

$1.96-2$

$7.42-3$

3. 84-2

1. $98-4$

2.05-5

2. .03-5

2. $96-4$

1. $98-4$

2. 95-5

1. $46-3$

$3.38-4$

3. $48-5$

1. $08-3$

2. 34-4

2. $57-5$

$1.00-1$

$5.00-2$

$5.00-2$

3. $00-2$

1. $5 \theta-2$

$3.00-2$

1. $5 \theta-2$

$2.00-1$

$2.00-1$

1. $00-1$

1. $.00-1$

3. $00-2$

$1.00-2$

3. $08-2$

$1.00-2$

1. $00-1$

$3.00-3$

1. $0 \theta-3$

$1.60-3$

1. $.0-2$

3. $00-3$

$3.0 \%-3$

$2.50-2$

1. $5 \theta-2$

5. $.06-3$

1. $00-2$

$5.00-3$

2. . $00-3$

1. $.00-1$

5. $00-2$

$5.00-2$
MATERIALS BALANCE $\sigma$

1 DRY 6 MONTHS

(kgPu)

( $\mathrm{kg} \mathrm{Pu}$ )

\subsection{0}

.00

$3.56-1$

$2.83-1$

1. $06-3$

$1.03-1$

$1.64-1$

1. $60-1$

1.85-1

1. 29-1

1. 66-1

$1.16-1$

$1.63-$

$5.83-2$

$1.68-2$

$1.58-2$

8. 78-2

$5.81-2$

2. $3 \emptyset-2$

$6.21-2$

$9.96-2$

$2.71-2$

$6.57-2$

$6.88-2$

$2.1-2$

$7.60-4$

$3,8 \theta-4$

$3.80-4$

\subsection{0}

3. $56-1$

$2.83-1$

1. $06-3$

1. $183-1$

$1.64-1$

$1.68-1$

1. $85-1$

1. 29-1

1. $66-1$

$1.16-1$

1. 63-1

3. 82-1

$6.86-1$

$6.79-1$

$5.70-1$

3.81-1

9.85-1

4. $96-1$

$6.52-$

1.16

2.99-1

4. $51-1$

8. 59-1

$5.84-3$

1. 67-2

1. $67-2$
RELATIVE

COST

4. 61-5

$4.78-5$

1. $23+1$

7.35

9. 25-5

9.54-2

1.59

1.65

2.46

6. 54-1

1.82

3. 48-1

1. 61

1. $41+1$

$4.77+1$

4. $82+1$

3. $28+1$

1. $42+1$

1. $61+2$

1. $61+1$

4. $34+1$

$1.43+2$

8. 30

$2.04+1$

$7.67+1$

4. $97-5$

2. $07-5$

5. $18-5$ 
TABLE E-XXVI

MEASUREMENT UNCERTAINTIES: UPAA 2, GOAL 4, NO RECALIBRATION

No.

- VOLUME - FEED ADJUSTMENT TANK

C CONCENTRATION - FEED ADJUSTMENT TANK

C VOLUME - HA FEED TANK

E CONCENTRATION - HA FEED TANK

E PU SOLIDS - HA CENTRIFUGE

$\epsilon$ INVENTORY - HA CONTACTOR

$E$ INVENTORY - HS COLUMN

E INVENTORY - HC COLUMN

$\epsilon$ VOLUME - HCP REDUCER

C CONCENTRATION - HCP REDUCER

C VOLUME - IA FEED TANK

$\varepsilon$ CONCENTRATION - IA FEED TANK

$C$ INVENTORY - 1 A COLUMN

\& VOLUME - FEED ADJUSTMENT TANK INPUT

$\eta$ VOLUME - FEED ADJUSTMENT TANK INPUT

$\theta$ VOLUME - FEED ADJUSTMENT TANK INPUT

\& CONCENTRATION - FEED ADJUSTMENT TANK INPUT

I CONCENTRATION - FEED ADJUSTMENT TANK INPUT

$\theta$ CONCENTRATION - FEED ADJUSTMENT TANK INPUT

C FLOW RATE - IA COLUMN OUTPUT

7 FLOW RATE - 1 A COLUMN OUTPUT

\& FLOW RATE - IA COLUMN OUTPUT

- CONCENTRATION - IA COLUMN OUTPUT

$\eta$ CONCENTRATION - IA COLUMN OUTPUT

$\theta$ CONCENTRATION - IA COLUMN OUTPUT

E TRANSFER - HA CENTRIFUGE TO SST

$\eta$ TRANSFER - HA CENTRIFUGE TO SST

$\theta$ TRANSFER - HA CENTRIFUGE TO SST
MEASUREMENT ERRORS CALCULATED CURRENT

$(1 \sigma)$

$(1 \sigma)$

$3.00-2$

$1.56-2$

$7.29-4$

$7.59-4$

2. $00-1$

1. 55-1

1. 38-2

1. 45-2

3. 14-3

2.71-3

4. $87-3$

3. 16-3

$1.98-2$

1. $67-4$

$1.33-5$

1. $28-5$

1. 57-4

2. 39-5

8. $98-6$

9. $67-4$

3. $26-5$

1. 35-5

6. $01-4$

$2.23-5$

1. $62-5$

$1.00-1$

$5.90-2$

5. $\varnothing 0-2$
3. $88-2$

1. $50-2$

$3.00-2$

1. $5 \theta-2$

2. $00-1$

2. $000-1$

1. $.00-1$

1. $.00-1$

$3.00-2$

$1.00-2$

$3.96-2$

1. $.0-2$

1. $.00-1$

3. $000-3$

1.00-3

$1.00-3$

1. $00-2$

$3.00-3$

$3.00-3$

$2.50-2$

1. $5 \theta-2$

$5.00-3$

$1.00-2$

$5 \cdot 68-3$

$2.00-3$

1. $000-1$

$5.00-2$

$5.000-2$
MATERIALS BALANCE $\sigma$ 1 DAY

( $\mathrm{Kg} \mathrm{Pu}$ ) 6 MONTHS

อ. .00

0.06
$1.15-1$

1. 19-1

$1.06-3$

8. 7B-2

5. 86-2

$6.13-2$

6. $68-2$

$5.77-2$

6. 34-2

4. 92-2

8.05-2

1.19-2

1. $48-3$

1. 33-3

1. 74-2

2.66-3

9.99-4

1. 55-2

3. 55-3

1. $5 \theta-3$

9.66-3

2. 48-3

1. $81-3$

0.00

0.00

$\varnothing .00$

\subsection{0}

6.08

1. 19-1

196-3

8. 78-2

$5.86-2$

$6.13-2$

6. 68-2

5.77-2

$6.34-2$

4. 92-2

8. $05-2$

1. .46-1

2. 22-1

2. . $80-1$

2. 14-1

3. 99-1

1. $5 b-1$

1. $90-1$

5. 35-1

2. 25-1

1. $18-1$

3. 73-1

2. 71-1

$3.56-3$

8. $36-3$

8. 36-3
RELATIVE COST

4. 93-6

9.83-6

$4.82+1$

1. $88+1$

3. 46-6

2.89-1

6.24

5.92

8. 55

69

6.37

2.17

4.27

$2 \cdot 78+1$

8. $26+1$

$6.28+1$

$1.24+2$

$3.33+2$

$2.48+$

4. $68+2$

3. $69+2$

1. $56+1$

$2.23+2$

$1.22+2$

4. 53-5

3. 46-5

4.44-5 
TABLE E-XXVII

MEASUREMEN" UNCERTAINTIES: UPAA 2, GOAL 4, DAILY RECALIBRATION

No.

DESCRIPTION

- VOLUME - FEED ADJUSTMENT TANK

E CONCENTRATION - FEED ADJUSTMENT TANK

$\epsilon$ VOL UME - HA FEED TANK

$\&$ CONCENTRATION - HA FEED TANK

E PU SOLIDS - HA CENTRIFUGE

C INVENTORY - HA CONTACTOR

E INVENTORY - HS COLUMN

C INVENTORY - HC COLUMN

\& VOLUME - HCP REDUCER

\& CONCENTRATIDN - HCP REDUCER

\& VOLUME - IA FEED TANK

C CONCENTRATION - IA FEED TANK

\& INVENTORY - IA COLUMN

$C$ VOLUME - FEED ADJUSTMENT TANK INPUT

$\eta$ VOLUME - FEED ADJUSTMENT TANK INPUT

$\theta$ VOLUME - FEED ADJUSTMENT TANK INPUT

\& CONCENTRATION - FEED ADJUSTMENT TANK INPUT

$\eta$ CONCENTRATION - FEED ADJUSTMENT TANK INPUT

$\theta$ CONCENTRATION - FEED ADJUSTMENT TANK INPUT

E FLOW RATE - IA COLUMN OUTPUT

I FLOW RATE - IA COLUMN OUTPUT

$\theta$ FLOW RATE - IA COLUMN OUTPUT

E CONCENTRATION - IA COLUMN OUTPUT

7 CONCENTRATION - IA COL UMN DUTPUT

$\theta$ CONCENTRATION - IA COLUMN OUTPUT

E TRANSFER - HA CENTRIFUGE TO SST

7 TRANSFER - HA CENTRIFUGE TO SST

$\theta$ TRANSFER - HA CENTRIFUGE TO SST
MEASUREMENT ERRORS

CALCULATED CURRENT

$(1 \sigma)$

$(1 \sigma)$

3. $600-2$

1. $50-2$

1. $29-3$

$9.86-1$

$2.60-1$

$1.05-1$

2. $88-2$

$2.04-2$

$4.76-3$

$3.28-3$

$5.78-3$

3. $99-3$

2. $09-2$

$1.27-4$

$1.63-5$

$1.70-5$

1. $62-4$

1. $25-4$

2. $46-5$

9. 12-4

2. $05-1$

2. $62-5$

$6.58-4$

1. $47-4$

1. $82-5$

$1.00-1$

$5.00-2$

$5.00-2$
$3.00-2$
$1.50-2$
$3.00-2$
$1.50-2$
$2.00-1$
$2.00-1$
$1.00-1$
$1.00-1$
$3.00-2$
$1.00-2$
$3.00-2$
$1.00-2$
$1.00-1$
$3.00-3$
$1.06-3$
$1.00-3$
$1.00-2$
$3.00-3$
$3.00-3$
$2.50-2$
$1.50-2$
$5.00-3$
$1.00-2$
$5.00-3$
$2.00-3$
$1.00-1$
$5.00-2$
$5.00-2$
MATERIALS BALANCE 1 DAY 6 MONTHS

( $\mathrm{Kg} \mathrm{Pu}$ )

( $\mathrm{kg} \mathrm{Pu}$ )

0.00

0.00

$2.103-$

$1.55-$

1. $66-3$

5. $93-2$
$8.81-2$

8.67-2

1. $B 1-1$

6. $98-2$

8. 89-2

$6.22-2$

8. 85-2

1. 11-2

1. $81-3$

1. 89-3

1. $86-2$

1. 39-2

2. 74-3

1. $47-2$

2. 28-2

$2.91-3$

1.06-2

1. $63-2$

2.03-3

0.0

อ. 00

0.00
0.00

0.00

2.63-1

1. 55-1

1.06-3

5. 93-2

8. $81-2$

$8,67-2$

1. $01-1$

6. $98-2$

8. 89-2

$6.22-2$

8. 85-2

1.73-1

2.71-1

2.83-1

$2.28-1$

1. $78-1$

4.11-1

1. $80-1$

$2.80-1$

4. 37-1

1. $3 \theta-1$

2. $000-1$

3. $04-1$

3. 56-3

8. $36-3$

8. $36-3$
RELATIVE

$\cos T$

$6.22-5$

6. $22-5$

$2.23+1$

1. $42+1$

$2.85-5$

$9.08-1$

3.81

3.89

5.30

5.30

2.05

4.26

1.51

3.79

$2.27+1$

$6.05+1$

$5.8 \theta+1$

$6.88+1$

2. $3 \theta+1$

$1.21+2$

$2.64+1$

$7.21+1$

$1.90+2$

1. $42+1$

$3.31+1$

$7.57-5$

5. 55-5

7. $23-5$ 
TABLE E-XXVIII

MEASUREMENT UNCERTAINTIES: UPAA 3, GOAL 1, NO RECALIBRATION

No.

DE SCR I PT ION

¿ VOLUME - 2A FEED TANK

CONCENTRATION - ZA FEED TANK

\& INVENTORY - $2 A$ COLUMN

E INVENTORY - 2B COLUMM

E VOLUME - 3A FEED TANK

C CONCENTRATION - 3A FEED TANK

E INVENTORY - 3A COLUMN

E INVENTORY - 3B COL UMN

\& VOLUME - PU STRIPPER FEED

E CONCENTRATION - PU STRIPPER FEED

E INVENTORY - PU STRIPPER

\& VOLUME - PU CONCENTRATOR

\& CONCENTRATION - PU CONCENTRATOR

\& VOLUME - PU CATCH TANK

E CONCENTRATION - PU CATCH TANK

\& FLOW RATE - $2 A$ FEED TANK INPUT

$n$ FLOW RATE - 2A FEED TANK INPUT

$\theta$ FLOW RATE - $2 A$ FEED TANK INPUT

$\leftarrow$ CONCENTRATION - $2 A$ FEED TANK INPUT

$n$ CONCENTRATION - 2A FEED TANK INPUT

$O$ CONCENTRATION - $2 A$ FEED TANK INPUT

C VOLUME - PU SAMPLE TANK OUTPUT

$n$ VOLUME - PU SAMPLE TANK OUTPUT

$\theta$ VOLUME - PU SAMPLE TANK OUTPUT

$\&$ CONCENTRATI ON - PU SAMPLE TANK OUTPUT

$n$ CONCENTRATION - PU SAMPLE TANK OUTPUT

$\theta$ CONCENTRATION - PU SAMPLE TANK OUTPUT
MEASUREMENT ERRORS

$\begin{array}{cc}\text { CALCULATED } & \text { CURRENT } \\ (1 \sigma) & (1 \sigma)\end{array}$

3. $\varnothing \varnothing-2$

1. $6 a-2$

5. $000-2$

$5.00-2$

$3.60-2$

1. $00-2$

5. . $00-2$

5. $00-2$

3. $60-2$

1. $06-2$

1. . $00-1$

3. $60-2$

1. $.00-2$

3. $00-2$

$1.00-2$

2. $50-2$

$2.75-3$

1. $90-3$

1. $.80-2$

$1.92-3$

1. 44-3

$3.00-3$

9. $88-4$

$9.87-4$

3. $60-3$

1. $37-3$

1. $39-3$
3. $00-2$

1. $00-2$

5. $.00-2$

5. $.00-2$

$3.09-2$

1. $00-2$

$5.00-2$

5. $00-2$

1. $80-2$

$1.00-1$

$3.09-2$

1. $60-2$

$3.00-2$

$1.09-2$

$2.50-2$

1. $50-2$

$5.00-3$

1. $.00-2$

$5.00-3$

$2.000-3$

3. $00-3$

1. $.00-3$

1. $00-3$

$3.00-3$

$2.00-3$

2. $00-3$
MATERIALS BALANCE

1 DAY 6 MONTHS

$(\mathrm{KgPu})$ ( $\mathrm{Kg} \mathrm{Pu})$

4.71

1. 57

$2.12-1$

2. $12-1$

$5.52-1$

$1.84-1$

2. $12-1$

2. $12-1$

8. 47-2

$2.82-2$

5. 66-1

8. $87-1$

2.69-1

D. 00

0.00

4. $.02-1$

3. $87-1$

2. $11-1$

1. 61-1

2.14-1

$1.60-1$

2. 36-1

$1.10-1$

1. $10-1$

2.36-1

$1.52-1$

$1.55-1$

4.71

1.57

2. $12-1$

2. $12-1$

$5.52-1$

$1.84-1$

2. 12-1

2. 12-1

8. 47-2

$2.82-2$

5. $66-1$

8. $67-1$

2. 69-1

6. 00

6. 80

4.92

4. $60+1$

3. $17+1$

1.97

3. $20+1$

$2.41+1$

2.89

1. $65+1$

1. $65+1$

2.89

2. $28+1$

$2.33+1$
RELAT IVE COST

4. 95-5

4. $95-5$

5. 17-5

5.17-5

3. $98-5$

5. 23-5

5.17-5

$4.97-5$

4. $12-5$

3. 96-5

4. $18-5$

4. $95-5$

4.12-5

4. 12-5

3.05-5

4.45

1.63

6. $78-5$

1. 61

3. 88-1

4. $95-5$

1. 19-2

1. 33-2

4. $87-5$

4. 64-1 
TABLE E-XXIX

MEASUREMENT UNCERTAINTIES: UPAA 3, GOAL 1, WEEKLY RECALIBRATION

No.

DESCRIPTION

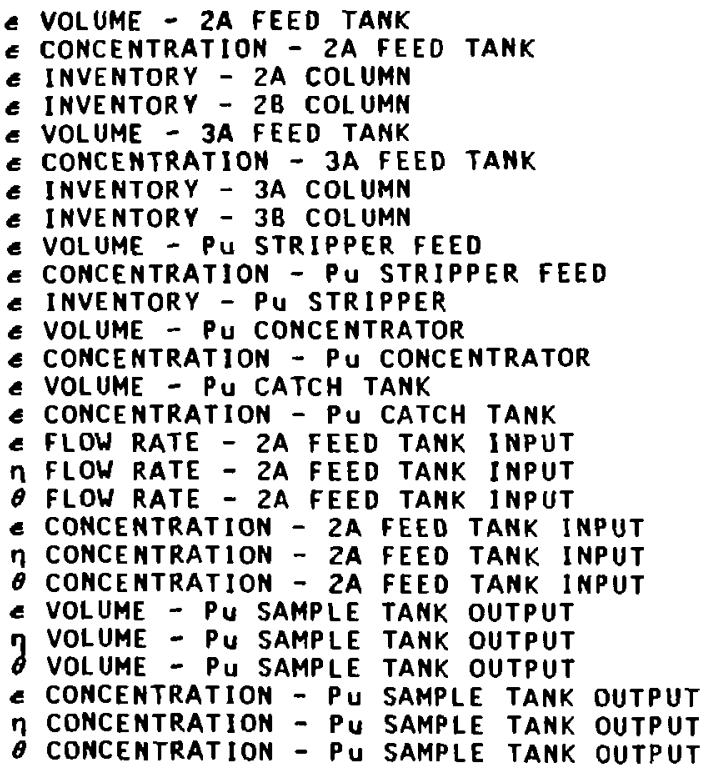

MEASUREMENT ERRORS CALCULATEO

$(1 \sigma)$

2.88-2

$1.00-2$
$5.00-2$

$5.00-2$

$3.00-2$

$1.08-2$

5. $\theta \theta-2$

5. $00-2$

3. $.00-2$

$1.00-2$

3. $00-2$

$1.00-2$

$3.00-2$

1. $00-2$

2. 43-2

1. $10-2$

2. $92-3$

1. $80-2$

$1.73-3$

2. 94-3

$9.62-4$
$9.49-4$

3. $00-3$

1. $94-3$

1. $62-3$
CURRENT

(IO)

$3.00-2$

$1.00-2$

5. $.00-2$

$3.00-2$

$1.0 \theta-2$

$5.00-2$

$5.00-2$

3.

$1.60-2$

$1.00-1$

$3.00-2$

1. $00-2$

$3.00-2$

$1.00-2$

$2.50-2$

1. $5 \theta-2$

$5.00-3$

$1.08-2$

$5.00-3$

2. $.98-3$

$3.00-3$

1. $.00-3$

$1.00-3$

3. $.00-3$

$2.00-3$
$2.00-3$

\section{MATERIALS BALANCE O RELATIVE 1 OAY 6 MONTHS \\ COST}

$(\mathrm{Kg} \mathrm{Pu}) \quad(\mathrm{Kg} \mathrm{Pu})$

4.53

1.57

2. $12-1$

$2.12-1$

5. 52-1

1. $84-1$

2. $12-1$

2.12-1

8. 47-2

2.82-2

5. 56-1

8. $07-1$

2. $69-1$

๑. 00

0.00

$3.98-1$

1.23

3. 25-1

1. $61-1$

5. 35-1

1. 92-1

2. 31-1

1.07-1

1. $06-1$

2. 36-1

2.16-1
4.53

1.57

2. 12-1

2. 12-1

5. 52-1

1.84-1

2.12-1

2. $12-1$

B. 47-2

2. 82-2

5.66-1

8. $07-1$

2.69-1

0.06

0.08

4.77

$3.93+1$

$4.87+1$

1.97

1. $72+1$

$2.89+1$

2.83

1. $6 \theta+1$

1. $58+1$

2.89

6.93

2. $78+1$
3. 99-2

2. $12-5$

1. $40-5$

3. $99-5$

2 . $00-5$

4. $78-5$

3. $04-5$

$3.28-5$

$4.05-5$

4. 44-5

4. 25-5

3. 32-5

3. $14-5$

3. 67-5

3. $08-2$

3. $62-1$

7.14-1

1. 24-5

4. . 55-2

1. 58-1

2.69-2

3.99-2

5. $39-2$

1. 68-5

3.02-2

2. 36-1 
TABLE E-XXX

MEASUREMENT UNCERTATNTIES: UPAA 3, GOAL 2, NO RECALIBRATION

No.

DESCR IPTION

C VOLUME - 2A FEED TANK

E CONCENTRATION - za FEEd tank

E INVENTORY - 2A COLUMN

E INVENTORY - $2 B$ COLUMN

$E$ VOL UME - 3A FEED TANK

E CONCENTRATION - 3A FEED TANK

E INVENTORY - 3A COLUMN

- INVENTORY - 3B COLUMN

C VOLUME - PU STRIPPER FEED

E CONCENTRATION - PU STRIPPER FEED

C INVENTORY - PU STRIPPER

\& VOLUME - PU CONCENTRATOR

$\epsilon$ CONCENTRATION - Pu CONCENTRATOR

$\&$ VOLUME - Pu CATCH TANK

E CONCENTRATION - PU CATCH TANK

- FLOW RATE - 2A FEED TANK INPUT

$\eta$ FLOW RATE - 2A FEED TANK INPUT

O FIOW RATE - 2A FEED TANK INPUT

E CONCENTRATION - 2A FEED TANK INPUT

I CONCENTRATION - 2A FEED TANK INPUT

$\theta$ CONCENTRATION - 2A FEED TANK INPUT

E VOLUME - PU SAMPLE TANK OUTPUT

$n$ VOLUME - Pu SAMPLE TANK OUTPUT

$\theta$ VOLUME - PU SAF LE TANK OUTPUT

- CONCENTRATION - PU SAMPLE TANK OUTPUT

$\eta$ CONCENTRATION - PU SAMPLE TANK OUTPUT

a CONCENTRATION - Pu SAMPLE TANK OUTPUT
MEASUREMENT ERRORS CALCULATED CURRENT $(1 \sigma)$

$(1 \sigma)$

$1.89-2$

$9.38-3$

$5.000-2$

$5.00-2$

$2.93-2$

9.99-3

5. $06-2$

$5.00-2$

3. $08-2$

$1.00-2$

9.75-2

2.84-2

1. $00-2$

3. $00-2$

1. $00-2$

1. 53-2

6. 11-4

4. 58-4

8.72-3

4. $54-4$

2.74-4

2.68-1

2. 23-3

3. $35-4$

3. 37-1

\begin{tabular}{|c|c|c|}
\hline $\begin{array}{l}\text { MATERIALS } \\
1 \text { DAY } \\
(\mathrm{Kg} \mathrm{Pu})\end{array}$ & $\begin{array}{c}\text { BALANCE } \sigma \\
6 \text { MONTHS } \\
(\mathrm{Kg} \mathrm{PUI)}\end{array}$ & $\begin{array}{c}\text { RELATIVE } \\
\text { COST }\end{array}$ \\
\hline $\begin{array}{l}2.96 \\
1.47 \\
2.12-1 \\
2.12-1 \\
5.40-1 \\
1.84-1 \\
2.12-1 \\
2.12-1 \\
8.47-2 \\
2.82-2 \\
5.51-1 \\
7.65-1 \\
2.69-1 \\
0.06 \\
9.00 \\
2.46-1 \\
7.13-2 \\
5.18-2 \\
1.48-1 \\
5.06-2 \\
3.75-2 \\
1.80-1 \\
3.05-2 \\
2.98-2 \\
1.75-1 \\
3.73-2 \\
3.75-2\end{array}$ & $\begin{array}{l}2.96 \\
1.47 \\
2.12-1 \\
2.12-1 \\
5.18-1 \\
1.84-1 \\
2.12-1 \\
2.12-1 \\
8.47-2 \\
2.82-2 \\
5.51-1 \\
7.65-1 \\
2.69-1 \\
8.89 \\
8.89 \\
3.81 \\
1.87+1 \\
7.65 \\
1.72 \\
7.59 \\
5.63 \\
2.29 \\
1.57 \\
4.47 \\
2.15 \\
5.59 \\
5.62\end{array}$ & $\begin{array}{l}5.89-1 \\
6.65-2 \\
3.77-5 \\
2.59-4 \\
2.25-2 \\
6.65-1 \\
4.16-5 \\
1.87-4 \\
4.45-5 \\
4.81-5 \\
2.61-2 \\
5.47-2 \\
4.94-5 \\
2.26-5 \\
3.88-5 \\
6.32-1 \\
2.24+1 \\
9.92 \\
1.46-1 \\
1.68+1 \\
4.94 \\
3.12-1 \\
2.65 \\
2.73 \\
3.45-1 \\
4.97 \\
4.93\end{array}$ \\
\hline
\end{tabular}


TABLE E-XXXI

MEASUREMENT UNCERTAINTIES: UPAA 3, GOAL 2, WEEKLY RECALIBRATION

No.

DE SCR IPTION

- Vol UMe - 2A FEEd tANK

E CONCENTRATION - $2 A$ FEED TANK

E INVENTORY - 2A COLUMN

E INVENTORY - 2B COL UMN

E VOLUME - 3A FEED TANK

E CONCENTRATION - 3A FEED TANK

E INVENTORY - 3A COLUMN

- INVENTORY - 3B COLUMN

C VOLUME - PU STRIPPER FEED

- CONCENTRATION - PU STRIPPER FEED

- INVENTORY - PU STRIPPER

- VOLUME - PU CONCENTRATOR

- CONCENTRATION - PU CONCENTRATOR

\& VOLUME - Pu CATCH TANK

E CONCENTRATION - Pu CATCH TANK

- FlOW RATE - $2 A$ FEE T TANK INPUT

$n$ FLOW RATE - 2A FEED TANK INPUT

- flon RATE - $2 A$ FEEd tank INPUt

E CONCENTRATION - 2A FEED TAMK INPUT

$n$ CONCENTRATION - 2A FEED TANK INPUT

$\theta$ CONCENTRATION - $2 A$ FEED TANK INPUT

- VOLUME - PU SAMPLE TANK OUTPUT

$n$ VOLUME - PU SAMPLE TANK OUTPUT

$\theta$ VOLUME - PU SAMPLE TANK OUTPUT

- CONCENTRATION - PU SAMPLE TANK DUTPUT

I CONCENTRATION - PU SAMPLE TANK OUTPUT

$\theta$ CONCENTRATION - PU SAMPLE TANK OUTPUT
MEASUREMENT ERRORS

CALCULATED CURRENT

$(1 \sigma)$

$(1 \sigma)$

2. 12-2

5. $00-2$

5. $00-2$

3. $\theta \theta-2$

1. $\theta 0-2$

5. $800-2$

5. $9 \theta-2$

3. $D B-2$

1. $.00-2$

$1.00-1$

$3.000-2$

1. $\theta 00-2$

$3.00-2$

1. $60-2$

1. $82-2$

$2.25-3$

$5.68-4$

$9.99-3$

$1.55-3$

4. $17-4$

2.89-3

3. $24-4$

3. $27-4$

2.79-3

1. $15-3$

$4.08-4$
$3.00-2$

$1.00-2$

$5.80-2$

5. .06-2

$3.06-2$

1. $. \theta \theta-2$

$5.00-2$

$5.60-2$

$3.0 \theta-2$

1. $00-2$

$1.00-1$

$3 . \theta \theta-2$

$1.68-2$

$3.00-2$

$1.68-2$

$2.5 \theta-2$

$1.5 \theta-2$

$5.9 \theta-3$

$1.00-2$

$5.00-3$

$2.00-3$

$3.98-3$

$1.00-3$

$1.00-3$

3.0日-3

2. $.0 \theta-3$
MATERIALS BALAMCE 1 DAY

6 MONTHS

( $\mathrm{kg} \mathrm{Pu}$ )

3.33

3.33

2. $12-1$

2. $12-1$

5. 52-1

1. 84-1

$2.12-1$

2.12-1

8. 47-2

$2.82-2$

5. 66-1

8. $67-1$

2. 69-1

0.00

0.00

2. 93-1

2. 51-1

6. 24-2

1. $600-1$

1. 73-1

4. 64-2

2. $27-1$

3. $61-2$

3. $63-2$

2. 19-1

1. $27-1$
3.33
1.57

2. 12-1

$2.12-1$

5. 52-1

1. 84-I

2. 12-1

2. 12-1

8. 47-2

2. 8z-2

5. 66-1

8. $07-1$

2. 69-1

6. 06

6.06

3.59

8.04

9.35

1.97

5. 55

6. 96

2. 78

5.41

5.45

2.68

4.69

6.80
RELATIVE COST

4.15-1

$3.36-5$

$2.78-5$

$2.78-5$

4.86-5

$1.98-5$

2. 78-5

$2.78-5$

4. $86-5$

2.39-6

$4.86-5$

$5.3 \varnothing-5$

$2.79-5$

5. 81-6

2. 44-5

3. $72-1$

5.67

7.93

1. 49-3

2.22

3.80

3. $94-2$

2.88

2.06

$7.61-2$

7. 46-1

3.91 
TABLE E-XXXII

MEASUREMENT UNCERTAINTIES: UPAA 3, GOAL 2, DAILY RECALIBRATION

No.

DESCR IPTION

E VOLUME - 2A FEED TANK

$e$ CONCENTRATION - $2 A$ FEED TANK

$\epsilon$ INVENTORY - $2 A$ COLUMN

E INVENTORY - 2B COLUMN

$\epsilon$ VOLUME - 3A FEED TANK

\& CONCENTRATION - 3A FEED TANK

I INVENTORY - 3A COLUNIN

INVENTORY - 3B COLUMN

E VOLUME - PU STRIPPER FEED

$\epsilon$ CONCENTRATION - PU STRIPPER FEED

$\epsilon$ INVENTORY - PU STRIPPER

\& VOLUME - PU CONCENTRATOR

C CONCENTRATION - PU CONCENTRATOR

\& VOLIINE - PU CATCH TANK

E CONCENTRATION - Pu CATCH TANK

E FLOW RATE - 2A FEED TANK INPUT

$\eta$ FLOW RATE - $2 A$ FEED TANK INPUT

- FLOW RATE - 2A IEED TANK INPUT

E CONCENTRATION - 2A FEED TANK INPUT

$\eta$ CONCENTRATION - 2A FEED TANK INPUT

$\theta$ CONCENTRATION - $2 A$ FEED TANK INPUT

$\epsilon$ VOLUME - PU SAMPLE TANK OUTPUT

$\eta$ VOLUME - PU SAMPLE TANK OUTPUT

$\theta$ VOLUME - Pu SAMPLE TANK OUTPUT

E CONCENTRATION - PL SAMPLE TANK OUTPUT

$\eta$ CONCENTRATION - PU SAMPLE TANK OUTPUT
$\theta$ CONCENTRATION - PU SAMPLE TANK OUTPUT
MEASUREMENT ERRORS

CALCULATED CURRENT

$(1 \sigma)$

$(I \sigma)$

$2.08-2$

$1.00-2$

5. $00-2$

$5 \cdot 00-2$

$3.00-2$

1. $.00-2$

$5.00-2$

$5 \cdot 9 \theta-2$

$3.00-2$

$1.00-2$

$1.00-1$

$3.00-2$

1. $.00-2$

$3.00-2$

1. $00-2$

1. $96-2$

4. $72-3$

6. $09-4$

1. $.00-2$

3. 22-3

4. $51-4$

$2.84-3$

3. 53-4

$3.54-4$

2. 87-3

1. $88-3$
3. $\varnothing \varnothing-2$

1. $00-2$

$5.06-2$

$5.00-2$

3. $80-2$

$1.00-2$

$5.90-2$

$5.00-2$

$3.88-2$

1. $00-2$

$1.00-1$

$3.00-2$

1. $.80-2$

3. $.00-2$

1. $.09-2$

2. $50-2$

$1.50-2$

$5.00-3$

$1.00-2$

$5.00-3$

$2.00-3$

$3.00-3$

$1.00-3$

$1.80-3$

$3.00-3$

$2.00-3$

$2.60-3$
MATERIALS BALANCE $\sigma$

1 DAY 6 MONTHS

( $\mathrm{Kg} \mathrm{Pu}$ ) ( $\mathrm{Kg} \mathrm{PU})$

3.26

1. 57

2. $12-1$

$2.12-1$

5. 52-1

1.84-1

2. $12-1$

2. 12-1

8. 47-2

2. $82-2$

5. 66-1

8. $07-1$

2. 69-1

$\varnothing .00$

0.00

3.15-1

5. 25-1

6. 78-2

1. $61-1$

3. 58-1

5. $02-2$

2. 23-1

3. $92-2$

3. $94-2$

2. 25-1

2. $09-1$

4. 92-2
3.26
1.57

2. 12-1

2. $12-1$

5. 52-1

$1.84-1$

2. 12-1

2. 12-1

8.47-2

2. 82-2

5. $66-1$

8.67-1

2.69-1

0.00

Б. 00

3.85

6.43

1. $.02+1$

1.97

4.39
7.53

2.73

5.88

5.91

2.76

2.56
RELATIVE COST

4. 45-1

6.33-5

4. $28-5$

3. 16-5

2. 49-5

1.81-6

3.62-5

2. 29-5

2.69-5

1. 53-5

3.67-5

9. 42-5

2. 42-5

2. $20-5$

2. 41-5

2.77-1

2. 18

7.21

4. $15-7$

5. 55-1

3.43

5. 73-2

1.84

1.82

4. $79-2$

6. $47-2$

3.52 
TABLF E-XXXIII

MEASUREMENT UNCERTAINTIES: UPAA 3, GOAL 3, NO RECALIBRATION

No.

DESCRIPTION

E VOLUME - 2A FEED TANK

E CONCENTRATION - 2A FEED TANK

E INVENTORY - 2A COLUMN

E INVENTORY - 2B COLUMN

E VOLUHE - 3A FEED TANK

E CONCENTRATION - 3A FEED TANK

E INVENTORY - 3A COLUMN

E INVENTORY - 3B COLUMN

$\Leftrightarrow$ VOLUME - PU STRIPPER FEED

E CONCENTRATION - PU STRIPPER FEED

E INVENTORY - PU STRIPPER

\& VOLUME - PU CONCENTRATOR

C CONCENTRATION - Pu CONCENTRATOR

$\epsilon$ VOLUME - PU CATCH TANK

\& CONCENTRATION - PU CATCH TANK

E FLOW RATE - $2 A$ FEED TANK INPUT

$\eta$ FLOW RATE - 2A FEED TANK INPUT

G FLOW RATE - 2A FEED TANK INPUT

E CONCENTRATION - 2A FEED TANK INPUT

$n$ CONCENTRATION - $2 A$ FEED TANK INPUT

$\theta$ CONCENTRATION - $2 A$ FEED TANK INPUT

E VOLUME - Pu SAMPLE TANK OUTPUT

$\eta$ VOLUME - Pu SAMPLE TANK OUTPUT

$\theta$ VOL UME - Pu SAMPLE TANK OUTPUT

E CONCENTRATION - PU SAMPLE TANK OUTPUT

$\eta$ CONCENTRATION - PU SAMPLE TANK OUTPUT

$\eta$ CONCENTRATION - PU SAMPLE TANK OUTPUT
$\theta$ CONCENTRATION - PU SAMPLE TANK OUTPUT

MEASURE
CALCULATE
$(1 \sigma)$
$1.87-3$
$1.18-3$
$2.82-2$
$2.64-2$
$7.72-3$
$5.58-3$
$2.47-2$
$2.48-2$
$2.33-2$
$1.68-2$
$2.51-2$
$6.18-3$
$4.21-3$
$3.66-2$
$1.69-2$
$1.14-3$
$3.88-5$
$2.75-5$
$8.63-4$
$2.75-5$
$2.65-5$
$1.95-4$
$1.69-5$
$1.62-5$
$1.97-4$
$2.63-5$
$1.87-5$

MATERIALS
1 OAY

CURRENT

(10)

3. $6 \theta-2$

1. $.00-2$

5. . $00-2$

5. $. \theta \theta-2$

$3.00-2$

1. $.00-2$

$5.00-2$

$5.000-2$

$3.08-2$

1. $.00-2$

1. $.0 \varnothing-1$

3. $000-2$

1. $\theta 0-2$

$3.000-2$

1. $\theta \theta-2$

2. 50-2

1. $50-2$

5. $00-3$

$1.00-2$

$5.000-3$

$2.00-3$

$3.06-3$

1. $.00-3$

1. $\theta \theta-3$

3. $\theta \theta-3$

2. $\theta \theta-3$

2. .00-3
2. $93-1$

2. $32-1$

1. $20-1$

1. 42-1

$1.03-1$

1. $.05-1$

1. .05-1

6. 57-2

2. $82-2$

1. 42-1

1. 64-1

1. 13-1

ต.

0.00

4.87-2

3. $02-2$

2. 14-2

3. 67-2

2.14-2

1. $68-2$

4. $05-2$

1. 31-2

1. 26-2

4.09-2

1. $58-2$

1. 46-2
BALANCE $\sigma$ 6 MONTHS

( $\mathrm{Kg} \mathrm{Pu}$ )

2. 93-

2. $32-1$

1. $12-1$

1. $12-1$

1. $83-1$

1. $65-1$

1. . 55-1

$6.57-2$

2. 82-2

1. 42-1

1. 64-1

1. 13-1

6. 00

0.00

3. 19-1

1. 29

9. $18-1$

2. $48-1$

9.19-1

6. 84-1

2. $65-1$

5. 63-1

5. 42-1

2. $68-1$

6.77-1

6. 25-1
RELATIVE COST

1. $51+1$ 5.77

7. 74-1

8. 93-1

2.88

7. $91-1$

1.02

1.01

2. $89-1$

4. 28-6

2.99

3. 92

1. 38

5.05-5

7. $98-5$

2. $68+1$

3. $86+2$

1. $81+2$

1. $.86+1$

$1.81+2$

9. $66+1$

1. $44+1$

$5.83+1$

6. $06+1$

$1.43+1$

$9.75+1$

1. $.66+2$ 
TABLE E-XXXIV

MEASUREMENT UNCERTAINTIES: UPAA 3, GOAL 3, DAILY RECALIBRATION

No.

\section{DESCRIPTION}

- vol UME - zA FEED tANK

e CONCENTRATION - 2A FEED tANK

E INVENTORY - 2A COLUMN

E INVENTORY - 2B COLUMM

$\epsilon$ VOLUME - 3A FEED TANK

E CONCENTRATION - 3A FEED TANK

E INVENTORY - 3A COLUMM

- INVENTORY - 3B COL UMM

$\epsilon$ VOLUME - PU STRIPPER FEED

C CONEENTRATION - PU STRIPPER FEED

\& INVENTORY - PU STRIPPER

- VOL UME - PU CONCENTRATOR

- CONCENTRATION - Pu CONCENTRATOR

- VolUMe - pu catch tank

E CONCENTRATION - Pu CATCH TANK

E FLOW RATE - 2A FEED TANK INPUT

$\eta$ FLOW RATE - 2A FEED TANK INPUT

FLOW RATE - 2A FEED TANK INPUT

- CONCENTRATIOA - 2A FEED TANK INPUT

$\eta$ CONCENTRATION - 2A FEED TANK INPUT

$\theta$ CONCENTRATION - 2A FEED TANK INPUT

\& VOLUME - PU SAMPLE TANK OUTPUT

$n$ VOLUME - PU SAMPLE TANK OUTPUT

$\theta$ VOLUME - PU SAMPLE TANK OUTPUT

$\epsilon$ CONCENTRATION - PU SAMPLE TANK OUTPUT

$\eta$ CONCENTRATION - PU SAMPLE TANK OUTPUT

a CONCENTRATION - PU SAMPLE TANK OUTPUT
MEASUREMENT ERRORS

CALCULATED CURRENT

$(1 \sigma)$

$(1 \sigma)$

2. $35-3$

$3.12-2$

$3.32-2$

$9.56-3$

6.94-3

$3 \cdot 19-2$

$3.00-2$

1.

3.18-2

7. $48-3$

5. 52-3

$3.0 \theta-2$

1. $08-2$

1. $56-3$

3.52-4

3. 63-5

1. $12-3$

2.49-4

$2.68-5$

2. $65-4$

2. $16-5$

2.15-5

2.62-4

$1.86-4$

$3.00-2$

$1.00-2$

5. $00-2$

$5.00-2$

3.00-2

$1.00-2$

5. $00-2$

5. $.00-2$

$3.06-2$

1. .

$1.00-1$

$3.00-2$

$1.90-2$

$3.09-2$

1. $00-2$

2.5 $50-2$

$1.50-2$

$5.00-3$

$1.0 \theta-2$

$5.00-3$

$2.00-3$

$3.00-3$

$1.00-3$

$1 . \theta \theta-3$

$3.00-3$

$2.00-3$

$2.00-3$
MATERIALS BALANCE O 1 DAY 6 MONTHS ( $\mathrm{Kg} \mathrm{Pu}$ ) ( $\mathrm{Kg} \mathrm{Pu})$

RELATIVE CosT

3.69-1 3.69-

2.75-1

1. 32-1

1. 41-1

1. 76-1

2.75-1

1. 32-1

1. $41-1$

1. $28-1$

1. 76-1

1. $28-1$

$1.35-1$

1. 35-1

1. $29-1$

8. $2 \theta-2$

2.82-2

$1.80-1$

1. $29-1$

$8.20-2$

2. $82-2$

1. $8 \theta-1$

2.61-1

1. $48-1$

$1.48-1$

0.08

0.00

6. 65-2

1. .84-1

2.83-2

4.77-2

7. 35-2

2.09-2

5. 51-2

1. 68-2

1. 68-2

5. 44-2

$5.3 \varnothing-2$

2. $67-2$

1. 48-1

0.00

๑. 08

4. 36-1

6. 79-1

1. 21

3.12-1

4. $81-1$

8. 94-1

3.61-1

7. 19-1

$7.18-1$

3.56-1

3. 47-1

8. 87-1

$1.18+1$

4.71

6.81-1

5.86-1

2.14

4. 41-1

5.70-1

6. 43-1

3. 36-2

4. $96-5$

2.14

3.0

8. 11-1

7. 62-5

5. 52-6

$1.50+1$

4. $16+1$

1. $37+2$

7.91

1. $91+1$

$7.37+1$

1. $63+1$

4. $54+1$

$4.54+1$

$1.05+1$

$1.01+1$

$7.43+1$ 
TABLE E-XXXV

MEASUREMENT UNCERTAINTIES: UPAA 3, GOAL 4, NO RECALIBRATION

No.

\section{DESCRIPTION}

$\&$ VOLUME - $2 A$ FEED TANK

C CONCENTRATION - 2A FEED TANK

- INVENTORY - 2A COLUMN

E INVENTORY - 2B COLUMN

$\Leftrightarrow$ VOLUME - 3A FEED TANK

C CONCENTRATION - 3A FEED TANK

- INVENTORY - 3A COLUMN

- INVENTORY - 3B COLUMN

C VOLUME - PU STRIPPER FEED

C CONCENTRATION - PU STRIPPER FEED

C INVENTORY - PU STRIPPER

$\&$ VOLUME - PU CONCENTRATOR

\& CONCENTRATION - PU CONCENTRATOR

C VOL UME - Pu CATCH TANK

$\epsilon$ CONCENTRATION - Pu CATCH TANK

C FLOW RATE - ZA FEED TANK INPUT

$\eta$ FLOW RATE - $2 A$ FEED TANK INPUT

- FLOW RATE - $2 A$ FEED TANK INPUT

C CONCENTRATION - 2A FEED TANK INPUT

7 CONCENTRATION - 2A FEED TANK INPUT

$\theta$ CONCENTRATION - $2 A$ FEED TANK INPUT

$\epsilon$ VOLUME - PU SAMPLE TANK OUTPUT

$\eta$ VOLUME - PU SAMPLE TANK DUTPUT

$\theta$ VOLUME - PU SAMPLE TANK OUTPUT

- CONCENTRATION - PU SAMPLE TANK OUTPUT

$n$ CONCENTRATION - PU SAMPLE TANK OUTPUT

$\theta$ CONCENTRATION - Pu SAMPLE TANK OUTPUT
MEASUREMENT ERRORS CALCULATED CURRENT $(1 \sigma)$ $(1 \sigma)$

8.18-4 3. $00-2$

6. 93-4

1. 22-2

1. 43-2

4. 57-3

3. 27-3

1.29-2

$1.44-2$

1. $37-2$

9. 57-3

1. $4 !-2$

3. $38-3$

$1.94-3$

3. $900-2$

1. $.00-2$

$7.32-4$

$2.62-5$

$2.601-5$

5. 24-4

2.25-5

$1.85-5$

1. $31-4$

1. 27-5

1. $42-5$

1. $25-4$

1. $72-5$

$3.00-2$
$1.00-2$

$5.00-2$

$5.00-2$

$3.00-2$

$1.00-2$

$5.90-2$

$5.00-2$

$3.00-2$

1. $.00-2$

$1.080-1$

$3.00-2$

1. $.00-2$

$3.00-2$

1. $00-2$

$2.50-2$

1. $5 \theta-2$

$5.00-3$

$1.00-2$

$5.00-3$

$2.00-3$

$3.90-3$

1. $80-3$

$1.00-3$

$3.00-3$

$2.00-3$

$2.90-3$
MATERIALS BALANCE 1 DAY 6 MONTHS $(\mathrm{KgPu}) \quad(\mathrm{kgPu})$

$1.28-1$
$1.09-1$
$5.16-2$
$6.08-2$
$8.41-2$
$6.02-2$
$5.45-2$
$6.12-2$
$3.87-2$
$2.70-2$
$7.97-2$
$9.10-2$
$5.22-2$
6.98
9.008
$1.18-2$
$2.91-3$
$2.98-3$
$8.43-3$
$2.51-3$
$2.06-3$
$1.93-2$
$1.42-3$
$1.58-3$
$9.84-3$
$1.91-3$
$1.71-3$

1. $28-1$

1. $69-1$

$5.16-2$

6. $88-2$

8. 41-2

$6.02-2$

5. 45-2

$6.12-2$

3. $87-2$

$2.78-2$

7.97-2

9. 1 .

5. 22-2

0.09

0.06

$1.44-1$

4. 37-

4. 35-1

1.03-1

3. $76-1$

3.89-

1. 26-1

2.12-1

2. 37-1

1. $21-$

2. $87-1$

2. 57-1
RELATIVE $\cos T$

\section{$3.57+1$}

$1.34+1$

3.11

2.49

5.57

2.66

2.46

1.19

4. 49-2

6.99

7.87

4.16

1. $08-5$

8. $15-5$

$3.32+1$

$5.72+2$

$1.91+2$

$1.81+1$

$2.21+2$

$1.87+2$

$2.20+1$

$7.75+1$

$6.95+1$

2. $38+1$

1. $15+2$

1. $29+2$ 
TABLE E-XXXVI

MEASUREMENT UNCERTAINTIES: UPAA 3, GOAL 4, DAILY RECALIBRATION

No.

DESCRIPTION

- volume - 2A FEED tANK

- CONCENTRATION - 2A FEED TANK

I INVENTORY - $2 A$ COLUMN

INVENTORY - 2 B COLUMN

- VOLUME - 3A FEED TAMK

- CONCENTRATION - 3A FEED TANK

C INVENTORY - 3A COLUMN

- INVENTORY - 3B COLUMN

VOLUME - PU STRIPPER FEED

- CONCENTRATION - PU STRIPPER FEED

INVENTORY - PU STRIPPER

- VOL UME - Pu CONCENTRATOR

- CONCENTRAT ION - PU CONCENTRATOR

E VOLUME - PU CATCH TANK

e CONCENTRAT ION - Pu CATCH TANK

E FLOW RATE - 2A FEED TANK INPUT

$n$ FLOW RATE - $2 A$ FEED TANK INPUT

$\theta$ FLOW RATE - $2 A$ FEED TANK INPUT

E CONCENTRATION - 2A FEED TANK INPUT

$\eta$ CONCENTRATION - 2A FEED TANK INPUT

$\theta$ CONCENTRATION - $2 A$ FEED TANK INPUT

a VOLUME - Pu SAMPLE TANK OUTPUT

n VOLUME - Pu SAMPLE TANK OUTPUT

$\theta$ VOLUHE - Pu SAMPLE TANK OUTPUT

- CONCENTRATION - Pu SAMPLE TANK OUTPUT

$\eta$ CONCENTRATION - PU SAMPLE TANK OUTPUT

$O$ CONCENTRATION - Pu SAMPLE TANK OUTPUT CALCULATED

$( \pm \sigma)$

CURRENT

$1.18-3$

8. $16-1$

1. $55-2$

1. 55-2

$4.91-3$

3. 4. -3

1. 55-2

1. 55-2

$1.60-2$

1. $68-2$

3. 79-3

$2.64-3$

3. $90-2$

$1.00-2$

9.51-4

2. $19-4$

$2.87-5$

6. $93-1$

1. 52-4

2. $11-5$

1. $62-4$

i. $68-5$

1. $68-5$

1. $62-4$

1. $12-4$

2. $11-5$
(10)

$3.0 \varnothing-2$

1. $.00-2$

5. $.09-2$

5. $00-2$

3. $00-2$

1. .

5. . $08-2$

$5.00-2$

$3.00-2$

$1.00-2$

$1.08-1$

$3.60-2$

$1.00-2$

$3.00-2$

1. $90-2$

2. $5 g-2$

$1.5 \theta-2$

$5.00-3$

1. . $00-2$

5. $48-3$

2. $60-3$

3. $\varnothing x-3$

1. . $00-3$

1. .08-3

3. $90-3$

$2.96-3$

$2.00-3$
MATERIALS BALANCE $\sigma$

1 DAY 6 MONTHS

( $\left.\mathrm{kg} \mathrm{Pu}_{\mathrm{u}}\right)$

( $\mathrm{kg} \mathrm{Pu}$ )

1. $85-1$

1. $28-1$

6.56-2

6.57-2

9.03-2

$6.26-2$

$6.56-2$

6. 56-2

4. 81-2

$2.82-2$

$9.67-2$

1. $02-1$

7. $16-2$

0.00

0.00

1. 53-2

2. 44-2

3.19-3

1. 12-2

1. $76-2$

2. 35-3

$1.27-2$

1. $87-3$

1. 86-3

I. $27-2$

$1.25-2$

$2.35-3$
1.85-1

1. $28-1$

6. 56-2

6.57-2

9. $3-2$

6. 26-2

$6.56-2$

6. 56-2

1. 81-2

2.8 2-2

9. $57-2$

1. $02-1$

$7.10-2$

0.00

5.00

1. B 7-1

2.99-1

4.79-

1. 37-1

2.68-1

3. 53-1

1. 56-

$2.8 \%-$

2. $80-$

1. $56-$

1. 53-1

3. 52-1
RELATIVE

COST

$2.45+1$

1. $12+1$

2.24

2.23

5.11

1.94

2.24

2.23

$7.6 \theta-1$

1. 3d-5

5.21

6.91

2.79

8. 44-6

9. $33-6$

$2.53+1$

$6.74+1$

$1.73+2$

1. $33+1$

3. $18+1$

$9.36+1$

1. $75+1$

$5.86+1$

$5.86+1$

1. $75+1$

1. $68+1$ 
1. J. P. Shipley, D. D. Cobb, R. J. Dietz, M. L. Evans, E. P. Schelonka, D. B. Smith, and R. B. Walton, "Coordinated Safeguards for Materials Management in a Mixed-Oxide Fuel Facility," Los Alamos Scientific Laboratory report LA-6536 (February 1977).

2. E. A. Hakkila, D. D. Cobb, H. A. Dayem, R. J. Dietz, E. A. Kern, E. P. Schelonka, J. P. Shipley, D. B. Smith, R. H. Augustson, and J. W. Barnes, "Coordinated Safeguards for Materials Management in a Fuel Reprocessing Plant," Los Alamos Scientific Laboratory report LA-688I, Vols. I and II (5eptember 1977).

3. H. A. Dayem, D. D. Cobb, R. J. Dietz, E. A. Hakkila, E. A. Kern, J. P. Shipley, D. B. Smith, and D. F. Bowersox, "Coordinated Safeguards for Materials Management in a Nitrate-tu-Oxide Conversion Facility," Los Alamos Scientific Laboratory report LA-7011 (April 1978).

4. H. A. Dayem, D. D. Cobb, R. J. Dietz, E. A. Hakkila, E. A. Kern, E. P. Schelonka, J. P. Shipley, and D. B. Smith, "Coordinated Safeguards fur Materials Management in a Uranium-Plutonium Nitrate-to-Oxide Coconversion Facility: Coprecal," Los Alamos Scientific Laboratory report LA-752I (February 1979).

5. E. A. Hakkila, D. D. Cobb, H. A. Dayem, R. J. Dietz, E. A. Kern, J. T. Markin, J. P. Shipley, J. W. Barnes, and L. Scheinman, "Materials Management in an Internationally Safeguarded Fuels Reprocessing Plant," Los Alamos Scientific Laboratory report LA-8042, Vols. I and II (April 1980).

6. J. L. Marley and E. D. North, "Reference Sample Plan for Analytical Chemistry and Process Control of the Hot Experimental Facility, Modified Purex Flow Sheet (200 Series)," Oak Ridge National Laboratory report ORNL/CFRP-79/40 (F ebruary 1980).

7. "Hot Experimental Facility Interim Design Report," Oak Ridge National Laboratory report ORNL/AFRP-78/6, Vols. I and II (October 1978).

8. "SK-B-200 Series Process Flow Diagrams, Rev. 1," Bechtel National, Inc., San Francisco, California (June 29, 1979).

9. C. C. Thomas, Jr., C. A. Ostenak, R. G. Gutmacher, H. A. Dayem, and E. A. Kern, "Materials Measurement and Accounting in an Operating Plutonium Conversion and Purification Process. Phase I: Process Modeling and Simulation," Los Alamos National Laboratory report LA-8809-MS (April 1981 ).

10. D. D. Cobb and D. B. Smith, "Modeling and Simulation in the Design and Evaluation of Conceptual Safeguards Systems," Nucl. Mater. Manage. VI(III), $171-184$ (1977). 
11. W. D. Chadwick, G. E. Rochau, W. C. Fienning, R. B. Mcknight, and A. E. Winblad, "A Concept Definition of an Engineered Safeguards System for a Spent Fuel Reprocessing Facility," Sandia National Laboratories report SAND77-1539 (March 1979).

12. R. D. Hurt, J. W. Wachter, T. L. Hebble, A. B. Crawford, and S. J. Hurrell, "Microscopic Process Monitoring," Nucl. Mater. Manage. IX $(1)$, 53-55 (Spring 1980).

13. "The Structure and Content of Agreements Between the Agency and States Required in Connection with the Treaty on the Non-Proliferation of Nuclear Weapons," International Atomic Energy Agency information circular INFCIRC/153 (June 1972).

14. V. Sukhoruchkin, "Safeguarding of Reprocessing Facilities," International Atomic Energy Agency report STR-77 (January 1979).

15. C. G. Hough, T. Shea, and D. Tolchenkov, "Technical Criteria for the Application of IAEA Safeguards," Nucl. Safeguards Technol., Proc. Symp. Nucl. Mater. Safeguards, Vienna, October 2-6, 1978 (International Atomic Energy Agency, Vienna, 1979), IAEA-SM-231/112, Vol. I, pp. 25-35.

16. T. Shea and D. Tolchenkov, "The Role of Containment and Surveillance in IAEA Safeguards," Nucl. Safeguards Technol., Proc. Symp. Nucl. Niater. Safeguards, Vienna, October 2-6, 1978 (International Atomic Energy Agency, Vienna, 1979), IAEA-SM-231/110, Vol. I, pp. 547-559.

17. V. Sukhoruchkin, L. Thorne, D. Perricos, D. Tolchenkov, J. Lovett, and T. Shea, "Development of the Safeguards Approach for Reprocessing Plants," Nucl. Safeguards Techriol., Proc. Symp. Nucl. Mater. Safeguards, Vienna, October 2-6, 1978 (International Atomic Energy Agency, Vienna, 1979), IAEA-SM-231/113, Vol. II, pp. 583-592.

18. "The Agency's Safeguards System," International Atomic Energy Agency information circular INFCIRC/66, Rev. 2 (September 16, 1968).

19. D. Tolchenkov, A. Bilyk, and M. Honami, "Study on Estimation of Nuclear Material, Facilities Under Safeguards and Inspection Manpower Requirements for 1978-1984," International Atomic Energy Agency report STR-74 (October 1978).

20. E. A. Hakkila, R. G. Gutmacher, J. T. Markin, J. P. Shipley, and W. J. Whitty, "The Role of Materials Accounting in Integrated Safeguards Systems for Reprocessing Plants," Proc. Third Ann. Symp. Safeguards Nucl. Mater. Manage., Karlsruhe, Federal Republic of Germany, May 6-8, 1981 (European Safeguards Research and Development Association, 1981), ESARDA 13, pp. $241-246$. 
21. M. E. Bleck, C. P. Cameron, and A. L. Camp, "The Potential Role of Containment/Surveillance in Integrated Safeguards Systems for Reprocessing Plants," Proc. Third Ann. Symp Safeguards Nucl. Mater. Manage., Karlsruhe, Federal Republic of Germany, May 6-8, 1981 (European Safeguards Research and Development Association, 1981), ESARDA 13, pp. 375-378.

22. R. D. Hurt, "A Baseline Material Accounting System for the Hot Experimental Facility," Oak Ridge National Laboratory report ORNL/CFRP-79/12 (July 1979).

23. D. D. Cobb, H. A. Dayem, and R. J.'Dietz, "Preliminary Concepts: Safeguards for Spent Light-Water Reactor Fuels," Los Alamos Scientific Laboratory report LA-7730-MS (June 1979).

24. C. C. Thomas, Jr., D. D. Cobb, and C. A. Ostenak, "Spent-Fuel Composition: A Comparison of Predicted and Measured Data," Los Alamos National Laboratory report LA-8764-MS (March 1981).

25. D. D. Cobb, J. R. Phillips, G. E. Bosler, G. W. Eccleston, J. K. Halbig, C. R. Hatcher, and S-T. Hsue, "Nondestructive Verification and Assay Systems for Spent Fuels, Volume I," Los Alamos National Laboratory report LA-904 I, Vol. I (April 1982).

26. D. D. Cobb, J. R. Phillips, G. E. Bosler, G. W. Eccleston, J. K. Halbig, S. L. Klein, H. O. Menlove, C. A. Ostenak, and C. C. Thomas, Jr., "Nondestructive Verification and Mssiv Systems for Spent Fuels, Volume II, Technical Appendixes," Los Alamos Nai. onal Laboratory report LA-9041, Vol. II (April 1982).

27. E. D. Blakeman, C. W. Ricker, G. L. Ragan, F. C. Difilippo, and G. G. Slaughter, "Nondestructive Assay of Spent Boiling Water Reactor Fuel by Active Neutron Interrogation," Nucl. Mater. Manage. $\underline{X}$ (Proceedings Issue), 99-104 (1981).

28. E. A. Hakkila, C. C. Thomas, Jr., D. B. Smith, C. A. Ostenak, and R. G. Gutmacher, "Conventional Measurement Techniques," Appendix $K$ in "Materials Management in an Internationally Safeguarded Fuels Reprocessing Plant," Los Alamos Scientific Laboratory report 1_A..8042, Vol. III (April 1980).

29. E. A. Hakkila, C. A. Ostenak, and C. C. Thomas, Jr., "Near-Real-Time Measurement Techniques," Appendix $L$ in "Materials Management in an Internationally Safeguarded Fuels Reprocessing Plant," Los Alamos Scientific Laboratory report LA-8042, Vol. III (April 1980).

30. J. R. Phillips, J. E. Foley, H. O. Menlove, and T. D. Reilly, "Instrumentation Available to IAEA Inspectors," Appendix $N$ in "Materials Management in an Internationally Safeguarded Fuels Reprocessing Plant," Los Alamos Scientific Laboratory report LA-8042, Vol. III (April 1980). 
31. H. M. Jones and R. Y. Lyon, "Use of In-Line Monitors for Process Control of the Hanford Purex Plant," Proc. 20th Conf. Remote Syst. Technol., Idaho Falls, Idaho, September 19-21, 1972 (Atlantic Richfield Hanford Co., Richland, Washington, 1972), CONF-720903, Pp. 61-72.

32. D. T. Bostick, "Acid-Compensated Multiwavelength Determination of Uranium in Process Streams," in Measurement Technology for Safeguards and Materials Control, T. R. Canāa and B. S. Carpenter, Eds., National Bureau of Standards Special Publication 582 (June 1980), pp. 121-128.

33. J. L. Jaech, "Statistical Methods in Nuclear Material Control," Technical Information Center, Oak Ridge, Tennessee, TID-26298 (1973).

34. M. C. Bouzou and A. A. Brutus, "Spectrophotometric Determination of Plutonium in Irradiated Fuels Solutions--Procedures and Shielding Facilities," in Measurement Technology for Safeguards and Materials Control, T. R. Canada and B. S. Carpenter, Eds., National Bureau of Standards Special Publication 582 (June 1980), pp. 497-508.

35. D. B. Smith, "A Critical Review of Volume Measurement Technology," Appendix C in "Coordinated Safeguards for Materials Management in a Fuel Reprocessing Plant," Los Alamos Scientific Laboratory report LA-6881, Vol. II (September 1977).

36. S. C. Suda, "Instruments and Data Analysis Methods for Volume Measurements," in Safeguarding Nuclear Materials, Proc. Symp., Vienna, October 20-24, $\overline{1975}$ (International Atomic Energy Agency, Vienna, 1976), STI/PUB/408, Paper IAEA-SM-201/25, Vol. II, pp. 187-196.

37. L. E. Shuler, L. W. Doher, and L. H. Morrow, "A Displacement Technique for Calibration of Special Nuclear Material Tankage Volumes," Nucl. Mater. Manage. VI(III), 472-479 (1977).

38. F. E. Jones, A. M. Schoonover, and J. F. Houser, "In-Tank Measurement of Solution Density," in Measurement Technology for Safequards and Materials Control, T. R. Canada and B. S. Carpenter, Eds., National Bureau of Standards Special Publication 582 (June 1980), pp. 534-537.

39. J. Watson and T. L. Jones, "An Acoustic Technique for the Determination of Liquor Levels in Tanks," presented at First Meeting Coordinated Research Program, the Use of Installed Instrumentation in Irradiated Fuel Reprocessing Facilities for Safeguards Purposes, Vienna, Austria, March $12-16,1979$.

40. C. K. Mathews, H. C. Jain, V. D. Kavimandarı, and S. K. Aggarwal, "Tracer Techniques for the Input Accountability of Plutonium in Reprocessing Plants: Magtrap and Leadtrap," Nucl. Technol. 42, 297-303 (1979).

41. F. B. Stephens, R. G. Gutmacher, and K. Ernst, "Methods for the Accountability of Reprocessing Plant Dissolver and Waste Solution," Lawrence Livermore Laboratory report NUREG/CR-0515 (December 1978). 
42. W. E. Foster and E. R. Rosal, "Specific Gravity Instruments for a Nuclear Reprocessing Plant," Westinghouse Electric Corporation report WCAP-6033 (December 1, 1959).

43. K. J. Hofstetter, G. M. Tucker, R. P. Kemmerlin, J. H. Gray, and G. A. Huff, "Application of On-Line Alpha Monitors to Process Streams in a Nuclear Fuel Reprocessing Plant," in Nuclear Safeguards Analysis, Nondestructive and Analytical Chemical Techniques, E. A. Hakkila, Ed. (American Chemical Society, Washington, DC, 1978), pp. 124-143.

44. J. Chabert, "In-Line Alpha Counters," Nucl. Appl. 6, 56-62 (1969).

45. D. C. Camp, W. D. Ruhter, and S. Benjamin, "Nondestructive, EnergyDispersive X-Ray Fluorescence Analysis of Product-Stream Concentrations from Processed LWR Fuels," Lawrence Livermore Laboratory report UCRL-52616 (January 1979).

46. C. R. Hudgens and B. D. Craft, "Feasibility Study of the Proposed Use of Automated $X$-Ray Fluorescence Analysis for Measurement of $U$ and $P U$ in Dissolver Tanks," Monsanto Research Corporation report MLM-2533 (September 1978).

47. M. C. Bouzou and A. A. Brutus, "Spectrophotometric Determination of Plutonium in Irradiated Fuel Solutions--Procedures and Shielding Facilities," in Measurement Technology for Safeguards and Materials Control, T. R. Canada and B. S. Carpenter, Eds., National Bureau of Standards Special Publication 582 (June 1980), pp. 497-508.

48. C. T. Roche, R. B. Perry, R. N. Lewis, E. A. Jung, and J. R. Haumann, "A Portable Calorimeter System for Nondestructive Assay of Mixed-Oxide Fuels," in Nuclear Safeguards Analysis, Nondestructive and Analytical Chemical Techniques, E. A. Hakkila, Ed. (American Chemical Society, Washinaton, DC, 1978), pp. 158-178.

49. J. F. Lemming, J. H. Birden, and R. A. Neff, "An In-Line Automated Plutonium Assay System," Nucl. Mater. Manage. V(3), 156-163 (1976).

50. C. L. Fellers and P. W. Seabaugh, "Real-Time Prediction of Calorimeter Equilibrium," Nucl. Instrum. Methods 163, 499-505 (July 15, 1979).

51. J. L. Parker, "A Plutonium Solution Assay System Based on High Resolution Gamma Ray Spectrometry," presented at the American Society for Metals, Salt Lake City, Utah, February 1978.

52. J. L. Parker and T. D. Reilly, "Transmission Measurement Correction for Self Atteruation in Gamma-Ray Assay of Special Nuclear Materials," Nucl. Mater. Manage. 5, 58-67 (1976).

53. J. L. Parker, "Plutonium Solution Assay System Based on High-Resolution Gamma-Ray Spectroscopy," Los Alamos Scientific Laboratory report LA-8 146-MS (January 1978). 
54. R. S. Marshall and B. H. Erkkila, "The Measurement of Plutonium Oxalate in Thermal Neutron Coincidence Counters," in Radioelement Analysis: Progress and Problems, W. S. Lyon, Ed., Proc. Anal. Chem. Nucl. Fuel Reprocess., Proc. ORNL Conf. 23rd, October 9-11, 1979, Gat linburg, Tennessee (Ann Arbor Science Publishers, Inc., Ann Arbor, Michigan, 1980), pp. 301-310.

55. J. E. Foley, "Neutron Coincidence Counters for Nuclear Safeguards Applications," IEEE Trans. Nucl. Sci. NS-19, No. 3, 453 (1972).

56. 3. E. Foley, "Analytical Study on Design of Neutron Coincidence Counters," in "Nuclear Safeguards Research and Development Program Status Report, September-December 1970," Los Alamos Scientific Laboratory report LA-460̄5-MS (January 1971).

57. T. W. Crane, "Prototype 252Cf Shuffler for Neutron Interrogation of 55-gal Barrels," in "Nuclear Safequards Research and Development Program Status Report January-April 1977," Los Alamos Scientific Laboratory report LA-6849-PR (August 1977), pp. 20-21.

58. T. W. Crane, D. A. Close, M. 5. Krick, and H. O. Menlove, "Neutron Methods for Assay of Fissionable Material in the Presence of Fission Products," in Analytical Chemistry in Nuclear Fuel Reprocessing, W. S. Lyon, Ed. (Science Press, Princeton, New Jersey, 1978) pp. 285-291.

59. T.W. Crane, J. L. Parker, and C. A. Spirio, "Comparison of Gamma and Neutron NDA Techniques for 30-gal Waste Barrels," in "Nuclear Safeguards Research and Development Program Status Report SeptemberDecember 1977," Los Alamos Scientific Laboratory report LA-7211-PR (July 1978), pp. 52-54.

60. G. L. Ragan, M. M. Chiles, C. W. Ricker, D. T. Ingersoll, and G. G. Slaughter, "Nondestructive Assay of Subassemblies of Various Spent or Fresh Fuels by Active Neutron Interrogation," Nucl. Mater. Manage. VIII, 334-343 (1979).

61. T. D. Reilly, "The Measurement of Leached Hulls," Los Alamos Scientific Laboratory report LA-7784-MS (ISPO-63) (July 1979).

62. K. J. Hofstetter, B. C. Henderson, J. H. Gray, and G. A. Huff, "Non-Destructive Assay of Leached Hulls in a Nuclear Fuel Reprocessing Plant," in Analytical Methods for Safeguards and Accountability Measurements of Special Nuclear Material, H. T. Yolken and J. E. Bullard, Eds., National Bureau of Standards Special Publication 528 (November 1978), pp. $71-77$.

63. C. A. Ostenak, W. J. Whitty, and R. J. Dietz, "Preliminary Concepts: Materials Management in an Internationally Safeguarded Nuclear-Waste Geologic Repository," Los Alamos Scientific Laboratory report LA-8049-MS (November 1979).

64. S-T. Hsue, F. Hsue, and D. F. Bowersox, "Assay of Low-Level Plutonium Effluents," Nucl. Mater. Manage. X (Proceedings Issue), 453-460 (1981). 
65. T. I. McSweeney, J. W. Johnston, R. A. Schneider, and D. P. Granquist, "Improved Material Accounting for Plutonium Processing Facilities and a 235-U-HTGR Fuel Fabrication Facility," Battelle-Pacific Northwest Laboratories report BNWL-2098 (October 1975).

66. H. A. Dayem, D. D. Cobb, R. J. Dietz, E. A. Hakkila, J. P. Shipley, and D. B. Smith, "Dynamic Materials Accounting in the Back End of the LWR Fuel Cycle," Nucl. Technol. 43, 222-243 (1979).

67. R. Avenhaus, Material Accountability: Theory Verification and Applications (John Wiley and Sons, Inc., New York, 1977).

68. J. E. Lovett, Nuclear Materials: Accountability, Management, Safeguards (American Nuclear Society, 1974).

69. D. B. Smith, "Physical Standards and Valid Calibration," Safeguarding Nucl. Mater., Proc. Symp., Vienna, October 20-24, 1975 (International Atomic Energy Agency, Vienna, 1976), STI/PUB/408, Paper IAEA-SM-201/19, pp. 63-70.

70. "Consolidated Fuel Reprocessing Program Progress Report for Period January I to March 31, 1981," Oak Ridge National Laboratory report ORNL/TM-7773 (June 1981).

71. D. R. Johnson and J. A. Stone, "Light Water Reactor Fuel Reprocessing: Dissolution Studies of Voloxidized and Nonvoloxidized Fuel," E. I. du Pont de Nemours and Co., Savannah River Laboratory report DP-1520 (April 1980).

72. J. H. Goode and R. G. Stacy, "Comparative Studies of Head-End Processing using Iradiated, Mechanically Blended and Coprecipitated $(U, \mathrm{Pu}) \mathrm{O}_{2}$ Reactor Fuels," Oak Ridge National Laboratory report ORNL/TM-6370 (September 1978).

73. R. E. Lerch, "Dissolution of Mixed Oxide Fuel as a Function of Fabrication Variables," Hanford Engineering Development Laboratory report HEDLSA-1935 (August 1979).

74. F. Baumgaertner and W. Ochsenfeld, "Development and Status of LMFBR Fuel Reprocessing in the Federal Republic of Germany," Kernforschungszentrum Karlsruhe report KFK 230 I (May 1976).

75. K. H. Ebert, "Die Wiederaufarbeitung von Schnellbrueter-Brennelementen," Atomkernergie 36, 259-263 (1980).

76. J. Sauteron, M. Bourgeois, J. Couture, and P. Roblin, "Technologie du Retraitement des Combustibles des Reacteurs Rapides," Nucl. Power Its Fuel Cycle, Proc. Int. Conf., Salzburg, Austria, May 2-13, 1977 (International Atomic Energy Agency, Vienna, 1977) STI/PUB/465, Vol. 3, pp. 633-646. 
77. M. H. Ehinger, "Near-Real-Time Accounting in a Reprocessing Facility Using In-Process Inventory Estimation," Proc. Third Ann. Symp. Safeguards Nucl. Mater. Manage., Karlsruhe, Federal Republic of Germany, May 6-8, 1981 (European Safeguards Research and Development Association, 1981), ESARDA 13, pp. 319-322.

78. D. D. Cobb, H. A. Dayem, and A. L. Baker, "Demonstration of Near-Real-Time Accounting at the AGNS Barnwell Plant," Proc. Third Ann. Symp. Safeguards Nucl. Mater. Manage., Karlsruhe, Federal Republic of Germany, May 6-8, 1981 (European Safeguards Research and Development Association, 1981), ESARDA 13, pp. 323-328.

79. J. H. Ellis, "Development and Testing of a Near-Real-Time Accounting System for the Barnwell Reprocessing Facility," Nucl. Mater. Manage. $\underline{x}$ (Proceedings Issue), 402-410 (1981).

80. D. D. Cobb, E. A. Hakkila, H. A. Dayem, J. P. Shipley, and A. L. Baker, "Development and Demonstration of Near-Real-Time Accounting Systems for Reprocessing Plants," Nucl. Mater. Manage. X (Proceedings Issue), $411-421(1981)$.

81. D. D. Cobb and C. A. Ostenak, "Dynamic Materials Accounting for Solvent-Extraction Contactors," in Measurement Technology for Safeguards and Materials Control, T. R. Canada and B. S. Carpenter, Eds., National Bureau of Standards Special Publication 582, $712-717$ (June 1980).

82. D. D. Cobb, L. E. Burkhart, and A. L. Beyerlein, "In-Process Inventory Estimation for Pulsed Columns and Mixer-Settlers," Proc. Second Ann. Symp. Safeguards Nucl. Mater. Manage., Edinburgh, Scotland, March 26-28, 1980 (European Safeguards Research and Development Association, 1980), ESARDA 11, pp. 145-151.

83. "CFRP-HEF Conceptual Design, Process Flow Diagrams, Revision A," Bechtel National, Inc., San Francisco, California (April 21 , 1980).

84. "Consolidated Fuel Reprocessing Program Progress Report for Period January I to March 3l, 1980," W. E. Unger, Comp., Oak Ridge National Laboratory report ORNL/TM-7317 (June 1980).

85. T. Naylor, J. L. Baiintfy, D. S. Burdick, and K. Chu, Computer Simulation Techniques (John Wiley and Sons, Inc. New York, 1966).

86. J. Kleijnen, Statistical Techniques in Simulation (Marcel Dekker, Inc., New York, 1974).

87. A. L. Uriarte and R. H. Rainey, "Dissolution of High-Density $\mathrm{UO}_{2}, \mathrm{PuO}_{2}$, and $\mathrm{UO}_{2}-\mathrm{PuO}_{2}$ Pellets in Inorganic Acids," Oak Ridge National Laboratory report ORNL/3695 (April 1965).

88. W. E. Unger, J. C. Mailen, A. R. Irvine, and C. D. Watson, "Aqueous Fuel Reprocessing Quarterly Report for Period Ending December 31, 1973," Oak Ridge National Laboratory report ORNL/TM-4488 (June 1974). 
89. W. D. Burch, W. E. Unger, B. F. Bottomfield, J. M. Chandler, S. D. Clinton, B. C. Duggins, W. S. Groenier, A. R. Irvine, J. C. Mailen, V. C. A. Vaughen, C. D. Watson, and O. O. Yarbro, "LMFBR Fuel Recycle Program Progress Refort for Period April I to December 31, 1974," Oak Ridge National Laboratory report ORNL/TM-4836 (April 1975).

90. O. K. Tallent and J. C. Mailen, "Study of the Dissolution of Refractory $\mathrm{PuO}_{2}$ in Nitric-Hydrofluoric Acid Dissolvents at $100^{\circ} \mathrm{C}$," Oak Ridge National Laboratory report ORNL/TM-5 I81 (March 1976).

91. W. D. Burch, M. J. Feldman, W. E. Unger, and B. L. Vondra, "LMFBR Reprocessing Program Progress Report for Period January 1 to March 31 , 1976," Oak Ridge National Laboratory report ORNL/TM-5463 (June 1976).

92. W. D. Burch, M. J. Feldman, W. E. Unger, B. F. Bottomfield, J. M. Chandler, B. C. Duggins, W. 5. Groenier, W. D. Holland, A. R. Irvine, J. C. Mailen, V. C. A. Vaughen, C. D. Watson, and O. O. Yarbro, "LMFBR Fuel Recycle Program Progress Report for Period July I to December 31, 1975," Oak Ridge National Laboratory report ORNL/TM-5477 (August 1976).

93. W. D. Burch, M. J. Feldman, W. S. Groenier, and B. L. Vondra, "LMFBR Reprocessing Program Progress Report for Period April 1 to June 30, 1976," Oak Ridge National Laboratory report ORNL/TM-5556 (August 1976).

94. W. D. Holland, C. O. Reiser, R. B. Heimdahl, and W. S. Groenier, "Nuclear Fuel Dissolution and Rinsing Studies Using a Continuous Rotary Dissolver," Oak Ridge National Laboratory report ORNL/TM-5566 (March 1977).

95. "Advanced Fuel Recycle Program Progress Report for Period January 1 to March 31, 1978," W. E. Unger, Comp., Oak Ridge National Laboratory report ORNL/TM-6306 (May 1978).

36. "Alternate Fuel Cycle Technologies/ Thorium Fuel Cycle Technology Programs Quarterly Report for Period April 1 to June 30, 1978," A. D. Kelmers, Comp., Oak Ridge National Laboratory report ORNL/TM-6429 (August 1978).

97. "Advanced Fuel Recycle Program Progress Report for Period April 1 to June 30, 1978," W. E. Unger, Comp., Oak Ridge National Laboratory report ORNL/TM-6427 (September 1978).

98. "Advanced Fuel Recycle Program Progress Report for Period July 1 to September 30, 1978," W. E. Unger, Comp., Oak Ridge National Laboratory report ORNL/TM-6577 (December 1978).

99. T. G. Stanford, "Mathematical Modeling of the Voloxidation Process," Department of Energy report DOE/ET/00944-1 (June 1979).

100. "Consolidated Fuel Reprocessing Program Progress Report for Period January I to March 31, 1979," W. E. Unger, Comp., Oak Ridge National Laboratory report ORNL/TM-6836 (June 1979). 
101. R. E. Lerch, "Dissolution of Mixed Oxide Fuel as a Function of Fabrication Variables," Hanford Engineering Development Laboratory report HEDLSA-1935 (August 1979).

102. J. G. Morgan and W. D. Holland, "Iodine Evolution from Nitric Acid Solutions," Oak Ridge National Laboratory report ORNL/TM-7032 (November 1979).

103. R. G. Wilbourn and G. E. Benedict, "Study of the Effects of Thorium, Uranium, and Zirconium on Tributyl Phosphate Hydrolysis Rate," General A tomic report GA-A 15720 (January 1980).

104. R. G. Wilbourn and G. E. Benedict, "Evaluation of Selected Hydrocarbon Diluents for Nuclear Fuel Solvent Extraction Processing," General Atomic report GA-A 15730 (February 1980).

105. "Consolidated Fuel Reprocessing Program Progress Report for Period July J to September 30, 1980," W. E. Unger, Comp., Oak Ridge National Laboratory report ORNL/TM-7557 (December 1980).

106. W. D. Holland and J. Q. Kirkman, "System Design-Development Status Report: The Dissolution of Spent LMFBR Fuels," Oak Ridge National Laboratory report ORNL/CF-76/4 17 (January 1977).

107. J. Aitchison and 3. A. C. Brown, The Lognormal Distribution (Cambridge University Press, 1957).

108. E. A. Hakkila, D. D. Cobb, H. A. Dayem, R. J. Dietz, E. A. Kern, and J. P. Shipley, "Materials Accounting Considerations for International Safeguards in a Light-Water Reactor Fuels Reprocessing Plant," in Measurement Technology for Safeguards and Materials Control, T. R. Canada and B. S. Carpenter, Eds., National Bureau of Standards Special Publication 582 (June 1980), pp. $718-729$.

109. A. F. Cermak, "Liquid-Liquid System Contactors for Nuclear Fuel Reprocessing Plant," Allied General Nuclear Services report AGNS-35900-3.2-64 (July 1980).

1 10. K. Ikawa, H. Ihara, H. Sakuragi, H. Nishimura, and M. Hirata, "Study of the Application of Dynamic Principles to Safeguarding Spent Fuel Reprocessing Plants," in Measurement Technology for Safeguards and Materials Control, T. R. Canada and B. S. Carpenter, Eds., Naional Bureau of Standards Special Publication 582 (June 1980), pp. 730-739.

111. K. Ikawa, H. Ihara, H. Sakuraại, H. Nishimura, and M. Hirata, "Study of the Application of Semidynamic Material Control Concept to Safeguarding Spent Fuel Reprocessing Plants," Japan Atomic Energy Research Institute memo JAERI-memo-824 I (April 1979). 
112. D. D. Cobb, C. A. Ostenak, J. E. Bennett, A. L. Beyerlein, L. E. Burkhart, and A. F. Cermack, "Estimation of In-Process Inventory in Solvent-Extraction Contactors," Appendix $\mathrm{J}$ in "Materials Management in an Internationally Safeguarded Fuels Reprocessing Plant," Los Alamos National Laboratory report LA-8042, Vol. III (April 1980).

113. W. S. Groenier, "Calculation of the Transient Behavior of a Dilute-Purex Solvent Extraction Process Having Application to the Reprocessing of LMFBR Fuels," Oak Ridge National Laboratory report ORNL-4746 (April 1972).

114. S. B. Watson and R. H. Rainey, "Modifications of the SEPHIS Computer Code for Calculating the Purex Solvent Extraction System," Oak Ridge National Laboratory report ORNL/TM-5 123 (December 1975).

115. G. L. Richardson, "Effect of High Solvent Irradiation on TBP Processing of Spent LMFBR Fuels," Hanford Engineering Development Laboratory report HEDL-TME-73-51 (June 1973).

116. A. D. Mitchell, "A Comparison Between SEPHIS-MOD4 and Previous Modeis of the Purex Solvent Extraction System," Oak Ridge National Laboratory report ORNL/TM-6565 (February 1979).

117. M. C. Thompson and R. L. Shankle, "Calculation of Uranium Inventories in Mixer-Settlers During Solvent Extraction with 7.5\% TBP," E. l. du Pont de Nemours and Co., Savannah River Laboratory report DP-1357 (August 1974).

118. J. T. Lowe, "Calculation of the Transient Behavior of Solvent Extraction Processes," Ind. Eng. Chem. 7, 362-366 (1968).

119. W. C. Scotten, "SOLVEX - A Computer Program for Simulation of Solvent Extraction Processes," E. I. du Pont de Nemours and Co., Savannah River Laboratory report DP-1391 (September 1975).

120. A. L. Beyerlein, J. F. Geldard, H. F. Chung, and J. E. Bennett, "Deviations from Mass Transfer Equilibrium and Mathematical Modeling of Mixer-Sett ler Contactors," in Measurement Technology for Safeguards and Materials Control, T. R. Canada and B. S. Carpenter, Eds., National Bureau of Standards Special Publication 582 (June 1980), pp. 702-711.

121. S. M. Yih and L. Burkhart, "State-of-the-Art Simulation of a U-Pu Partitioning Column for Nuclear Fuel Reprocessing," ANS Proc. Winter Nieeting, Trans. Am. Nucl. Soc. 30, 328 (November 1978).

122. L. Burkhart, "A Survey of Simulation Methods for Modeling Pulsed Sieve-Plate Extraction Columns," Lawrence Livermore Laboratory report UCRL-15 101 (March 1979).

123. D. Engler and S. Perone, "Studies of Dispersed Phase Holdup in Pulsed Column Contactors," General Atomic report GA-C 15570 (December 1979). 
124. A. L. Beyerlein and J. F. Geldard, "Improved Mixer-Settler Models and Applications to Nuclear Accounting Systems," Clemson University draft report submitted to Los Alamos National Laboratory, Safeguards Systems Group, under Contract No. 4-L40-0781 (September 30, 1981).

125. J. M. Crawford, M. H. Ehinger, C. Joseph, and M. L. Madeen, "Development of a Computerized Nuclear Materials Control and Accounting System for a Fuel Reprocessing Plant," Nucl. Mater. Manage. VIII, 405-415 (1979).

126. J. V. Candy, R. A. Emmert, and G. K. Patterson, "Process Monitor Design for an Extraction Column: An Application of Estimation/Detection," Lawrence Livermore Laboratory report UCID-18128 (March 1979).

127. E. A. Kern and D. P. Martinez, "User's Manual for a Process Model Code," Los Alamos National Laboratory report LA-B761-M (March 1981).

128. A. Pritsker, The GASP IV Simulation Language (John Wiley and Sons, Inc., New York, 1974).

129. A. Papoulis, Probability, Random Variables, and Stochastic Processes (McGraw-Hill Book Co., New York, 1965).

130. K. Arrow, Studies in Linear and Nonlinear Programming (Stanford University Press, Stanford, California, 1958).

131. G. Hadley, Nonlinear and Dynamic Programming (Addison-Wesley Publishing Co., Reading, Massachusetts, 1964).

132. S. Vajda, Mathematical Programming (Addison-Wesley Publishing Co., Reading, Massachusetts, 1961).

133. G. Hadley, Linear Programming (Addison-Wesley Publishing Co., Reading, Massachusetts, 1962).

134. C. W. Radcliffe and W. J. Comfort, "Constrained Minimization of a Function of Many Variables," Lawrence Livermore Laboratory report UCRL-51517 (January 24, 1974).

135. M. J. D. Powell, "An Efficient Method for Finding the Minimum of a Function or Several Variables Without Calculating Derivatives," Comput. J. 7, $155-162(1964)$.

136. A. V. Fiacco and G. P. McCormick, Nonlinear Program: Sequential Unconstrained Minimization Techniques (John Wiley and Sons, Inc., New York, 1968). 


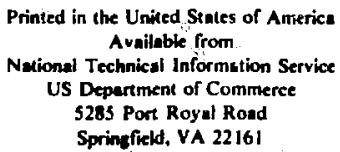

Misroficive (AOI)

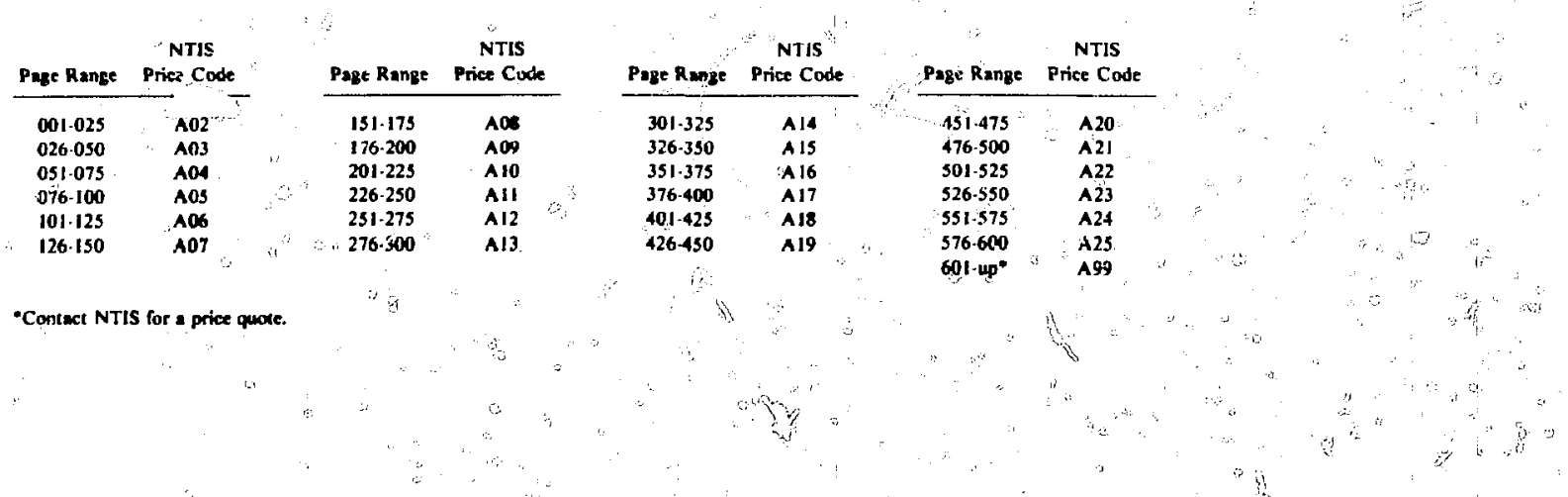






LOS ANDMOS 